Cristiana Villela de Araujo Wanderley

\title{
Variação das Taxas de Sedimentação na Foz do Rio Paraíba do Sul
}

\author{
TESE DE DOUTORADO
}

\author{
DEPARTAMENTO DE QUÍMICA \\ Programa de Pós-Graduação em Química
}

Rio de Janeiro

Agosto de 2013 


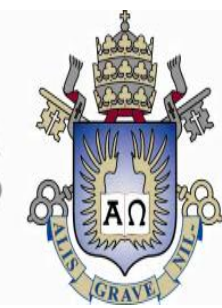

Cristiana Villela de Araujo Wanderley

\author{
Variação das Taxas de Sedimentação \\ na Foz do Rio Paraiba do Sul
}

Tese apresentada como requisito parcial para obtenção do grau de Doutor em Química pelo Programa de Pós-graduação em Química da PUC-Rio.

Orientador: Prof. José Marcus de Oliveira Godoy 
Cristiana Villela de Araujo Wanderley

\section{Variação das Taxas de Sedimentação na Foz do Rio Paraiba do Sul}

Tese apresentada como requisito parcial para obtenção do grau de Doutor pelo Programa de Pós-graduação em Química da PUC-Rio. Aprovada pela Comissão Examinadora abaixo Assinada.

Prof. José Marcus de Oliveira Godoy Orientador Departamento de Química - PUC-Rio

Profa. Isabel Maria Neto da Silva Moreira Departamento de Química - PUC-Rio

Prof. Sambasiva Rao Patchineelam UFF

Profa. Renata Cardia Rebouças

UERJ

Profa. Daniela Silveira Soluri Deparamento de Química - PUC-Rio

Prof. José Eugenio Leal Coordenador Setorial do Centro Técnico Científico - PUC-Rio 
Todos os direitos reservados. É proibida a reprodução total ou parcial do trabalho sem a autorização da universidade, da autora e do orientador.

\section{Cristiana Villela de Araujo Wanderley}

Graduou-se em Química Industrial na PUC-Rio (Pontifícia Universidade Católica do Rio de Janeiro) em 1987. Obteve o título de Mestre em Química Analítica Ambiental em 1995 pelo programa de pós-graduação da PUC-Rio.

Ficha Catalográfica

Wanderley, Cristiana Villela de Araujo

Variação das taxas de sedimentação na foz do Rio Paraiba do Sul / Cristiana Villela de Araujo Wanderley ; orientador: José Marcus de Oliveira Godoy. - 2013.

152 f. : il. (color.) ; $30 \mathrm{~cm}$

Tese (doutorado)-Pontifícia Universidade Católica do Rio de Janeiro, Departamento de Química, 2013. Inclui bibliografia

1. Química - Teses. 2. Datação ${ }^{210} \mathrm{~Pb}$. 3. Velocidades de sedimentação. 4. Sedimentos. 5. Metais pesados. 6. Rio Paraíba do Sul. 7. Brasil. I. Godoy, José Marcus de Oliveira. II. Pontifícia Universidade Católica do Rio de Janeiro. Departamento de Química. III. Título. 


\section{Agradecimentos}

Ao meu orientador, José Marcus de Oliveira Godoy pelo suporte, atenção e pelos conhecimentos transmitidos durante a realização deste trabalho.

À CAPES e à PUC-Rio pelo apoio financeiro.

Ao Zenildo, por todo o apoio prestado durante o trabalho.

Ao IRD por me receber e por todo o suporte com equipamentos, laboratórios e material para as análises.

À UENF pelo suporte nas coletas e à toda a equipe que nos ajudou.

Ao meu filho Marcos que me ajudou muito no laboratório com o peneiramento e trituração das amostras no início do trabalho.

À minha filha Juliana que me ajudou muito na elaboração de figuras e tabelas, formatação do trabalho, preparação de apresentações e apoio durante todo este período.

Ao meu marido Márcio por toda paciência e compreensão.

Aos meus pais por todo o incentivo e carinho.

A todos os amigos do IRD que me receberam tão bem, me ajudaram e me apoiaram muito.

Aos amigos da Pós da PUC, Thaísa, Ricardo, Julianna, Cibele, Cristiane e Carol, por toda sua amizade.

À Fátima, por toda sua boa vontade e sempre pronta a me ajudar.

Aos meus amigos que tantas vezes me compreenderam quando não estive presente em nossos encontros e viagens que costumamos fazer.

A todos que, se não citados aqui, me ajudaram, incentivaram e apoiaram neste período. 


\section{Resumo}

Wanderley, Cristiana Villela de Araujo; Godoy, José Marcus de Oliveira. Variação das taxas de sedimentação na foz do rio Paraíba do Sul. Rio de Janeiro, 2013. 152p. Tese de Doutorado - Departamento de Química, Pontifícia Universidade Católica do Rio de Janeiro.

A cidade de Atafona situada à foz do Rio Paraíba do Sul (RPS) vem sofrendo erosão em sua linha de costa por muitas décadas. Este estudo consiste em uma avaliação das taxas de sedimentação no estuário do Paraíba do Sul e suas correlações com a forte erosão que ocorre em Atafona, Rio de Janeiro. O trabalho foi baseado em quatro transetes ao longo do Estuário do rio Paraíba do Sul contendo 14 pontos de coleta. Cerca de 540 amostras de sedimentos foram obtidas em Janeiro de 2010 e Fevereiro de 2011. As taxas de sedimentação foram determinadas a partir do método da datação com ${ }^{210} \mathrm{~Pb}$ e os inventários de ${ }^{210} \mathrm{~Pb}$ foram determinados para todos os pontos de coleta. Foram aplicados dois modelos para a determinação das taxas de sedimentação: o modelo da Concentração Inicial Constante (modelo CIC) e o modelo da Razão de Suprimento Constante (modelo CRS). Os resultados da datação ${ }^{210} \mathrm{~Pb}$ foram validados com base na variação da concentração elementar ao longo de dois testemunhos. A determinação de elementos foi realizada utilizando a técnica de Espectrometria de Massa com Plasma Indutivamente Acoplado (ICP-MS). A análise multivariada de dados foi aplicada através da análise de fatores principais (AFP) e análise hierárquica de cluster (AHC) a fim de obter informações que traduzam quantitativamente a composição dos sedimentos descrevendo a região. Os inventários de ${ }^{210} \mathrm{~Pb}$ determinados nos pontos de coleta, localizados ao sul do rio Paraíba do Sul (RPS), foram maiores do que os determinados nos pontos de coleta localizados ao centro e ao norte da saída do rio. O valor médio do inventário obtido nos pontos de coleta ao sul da foz do RPS foi de $1,0 \mathrm{~Bq} \mathrm{~cm}{ }^{-2}$, muito superior ao valor médio obtido nos pontos situados ao norte da foz do rio, com valor de $0,16 \mathrm{~Bq} \mathrm{~cm}{ }^{-2}$, indicando que os sedimentos são transportados na direção sul da foz do RPS, ao longo da costa com as correntes de deriva existentes nesta direção. A taxa de acumulação estimada para as camadas mais profundas foi de $0,06 \mathrm{~g} \mathrm{~cm}^{-2} \mathrm{ano}^{-1}$. 
Essa taxa representa um valor base para a taxa de acumulação de sedimentos para o período anterior a 1950. As taxas de acumulação obtidas para o período mais recente variaram de $0,2 \mathrm{~g} \mathrm{~cm}^{-2}$ ano ${ }^{-1}$ nos pontos situados ao norte e ao centro a 0,6 $\mathrm{g} \mathrm{cm}^{-2}$ ano $^{-1}$ nos pontos situados ao sul da foz do RPS. Observou-se que as concentrações de $\mathrm{Cr}, \mathrm{Cu}, \mathrm{Cd}$ e $\mathrm{Zn}$ aumentaram significativamente a partir dos anos oitenta que, coincide com a época do acidente ocorrido com a Cia. de Paraibuna Metais em 1982. Uma das consequências nas mudanças no uso da terra e do represamento de rios é a mudança na natureza dos sedimentos que chegam e se depositam no delta do RPS. A normalização da concentração dos metais pelo alumínio pode ajudar a traçar tais mudanças, principalmente com elementos de origem distinta, como $\mathrm{Ca}$ e $\mathrm{Mg}$. Através da curva obtida entre razão a $\mathrm{Mg} / \mathrm{Al}$ e as idades das camadas sedimentares pode-se observar uma forte mudança no período entre 1962 e 1988. Foram identificados quatro fatores através da AFP traduzindo quatro fases do sedimento: duas representando a matriz, uma representando os carbonatos e a outra representando os sulfetos.

\section{Palavras-chave}

Datação ${ }^{210} \mathrm{~Pb}$; velocidades de sedimentação; sedimentos; metais pesados; Rio Paraíba do Sul; Brasil. 


\section{Abstract}

Wanderley, Cristiana Villela de Araujo; Godoy, José Marcus de Oliveira (Advisor). Sedimentation rates changes at Paraíba do Sul Estuary. Rio de Janeiro, 2013. 152p. Doctor Thesis - Departamento de Química, Pontifícia Universidade Católica do Rio de Janeiro.

The city of Atafona, situated at Paraíba do Sul Estuary, has been suffering erosion in its coastline for decades. This study is an evaluation of sedimentation rates in the Paraíba do Sul estuary and its correlation with the strong erosion that occurs in Atafona city, Rio de Janeiro, Brazil. We performed four transects along Paraíba do Sul Estuary with 14 sampling points. About 540 sediment samples were collected in January 2010 and February 2011. Sedimentation rates were determined by ${ }^{210} \mathrm{~Pb}$ dating method and inventories of ${ }^{210} \mathrm{~Pb}$ were determined for all sampling points. Two models were applied for the sedimentation rates determination: the Constant Initial Concentration model (CIC-model) and the Constant Rate of Supply model (CRS-model). The ${ }^{210} \mathrm{~Pb}$ dating results were validated based on the elemental concentration variation throughout two of the sediment cores. The elements determination was performed using the mass spectrometry with inductively coupled plasma technique (ICP-MS). The multivariate analysis were applied trough the principal factor analysis (PFA) and hierarchical cluster analysis (HAC) in order to obtain factors that may traduce quantitatively the sample composition describing the region. At sampling points located at south of the Paraiba do Sul River (PSR) mouth, ${ }^{210} \mathrm{~Pb}$ inventories were higher than those at the northern and central sampling locations. The inventory average obtained at south was $1.0 \mathrm{~Bq} \mathrm{~cm}^{-2}$, much higher than those located at north of the river mouth, with a mean value $0.16 \mathrm{~Bq} \mathrm{~cm}^{-2}$, indicating that the sediments are transported southward by the alongshore current. The accumulation rate estimated for the deeper layers was $0.06 \mathrm{~g} \mathrm{~cm}^{-2} \mathrm{yr}^{-1}$, which represents a reference value of sediment accumulation rate for the period prior to 1950 . Accumulation rates obtained for the most recent period ranged from $0.2 \mathrm{~g} \mathrm{~cm}^{-2} \mathrm{yr}^{-1}$ in the points situated at north and center to $0.6 \mathrm{~g} \mathrm{~cm}-2 \mathrm{yr}-1$ in points located at south of RPS mouth. It was observed that $\mathrm{Cr}, \mathrm{Cu}, \mathrm{Cd}$ and $\mathrm{Zn}$ 
concentrations increased significantly from the eighties that matches with the $\mathrm{Cia}$ Paraibuna Metals accident occurred in 1982. A consequence of changes in land use and the damming of the river is a change in the nature of the particulates reaching the PSR delta. The normalization of elemental concentrations to aluminum could help trace these changes, particularly for elements with a distinct origin, such as $\mathrm{Ca}$ and $\mathrm{Mg}$. The $\mathrm{Mg} / \mathrm{Al}$ versus ages plot showed a strong change between 1962 and 1988. There were four factors identified that traduce four sediment phases, two of them were related to the matrix, other was related to the carbonate phase and the other representing sulfides phase.

\section{Keywords}

${ }^{210} \mathrm{~Pb}$ dating; sedimentation rates; sediments; heavy metals; Paraíba do Sul River; Brazil. 


\section{Sumário}

1 Introdução 18

1.1. Erosão e Dinâmica Costeira 20

1.2. Hidrodinâmica e Processos relativos aos sedimentos 22

1.3. Histórico de evidências de erosão em foz de rios 22

1.4. Histórico da Região do vale do Paraíba 24

2 Objetivos $\quad 26$

2.1. Objetivo Geral 26

2.2. Objetivos Específicos 26

3 Área de estudo $\quad 27$

3.1. Bacia do Rio Paraíba do Sul 27

3.2. Unidades morfológicas de um Delta 27

3.3. Características do Delta do Rio Paraíba do Sul 28

3.4. Histórico de Atafona 30

3.5. As Barragens no Rio Paraíba do Sul 34

3.6. O Rio Guandu 36

4 Datação de Sedimentos e Taxas de Sedimentação 38

4.1. Radionuclídeos no Ambiente Marinho 38

4.2. $\mathrm{O}^{210} \mathrm{~Pb} \quad 39$

4.3. Fluxo de ${ }^{210} \mathrm{~Pb}$

4.4. Modelos de Datação com ${ }^{210} \mathrm{~Pb} \quad 43$

4.4.1. Modelo CIC 43

4.4.2. Modelo CRS 45

5 Materiais e Métodos $\quad 48$

5.1. Determinação dos pontos de coleta 48

5.1.1. Estudo preliminar e determinação dos pontos de coleta 48

5.1.2. Metodologia de coleta das amostras de sedimento 49

5.1.3. Tratamento das amostras 51

5.2. Análise granulométrica 52 
5.3. Método Analítico utilizado nas amostras para determinação do ${ }^{210} \mathrm{~Pb}$ e cálculo das taxas de sedimentação

5.4. Metodologia de abertura das amostras para determinação de elementos pela técnica de ICP-MS

5.4.1. Análise pela técnica de ICP-MS

5.5. Determinação do teor de carbonatos

5.6. Análise multivariada de dados 59

5.6.1. Análise de fatores principais (AFP) 60

5.6.2. Análise Hierárquica de Cluster

6 Resultados e Discussões

62

6.1. Granulometria

62

6.2. Teor de Carbonatos

65

6.3. Análise dos Inventários de ${ }^{210} \mathrm{~Pb} \quad 65$

6.4. Análise de cada perfil coletado 68

6.4.1. Pontos $1 \mathrm{~N}$ e $3 S \quad 71$

6.4.2. Pontos 1S, 2N e 3SS 71

6.4.3. Pontos 3C, 2SS e 4SS

$\begin{array}{ll}\text { 6.4.4. Ponto } 2 N N & 74\end{array}$

6.4.5. Ponto 4C 75

6.4.6. Pontos 2S, 2C e 4S 76

6.4.7. Resumo das taxas de sedimentação obtidas na região 81

6.5. Validação da datação com ${ }^{210} \mathrm{~Pb} \quad 83$

6.5.1. Análise da amostra de referência de solo NIST 2709

6.5.2. Determinação de metais por ICP-MS 87

6.5.2.1. Determinação dos elementos do perfil 2S 87

6.5.2.2. Determinação dos elementos do perfil 2C 91

6.5.3. Análise de metais normalizados pelo Alumínio 93

6.5.3.1. Cálculo dos fatores de enriquecimento e índices de geoacumulação 95

6.5.4. Fluxo de incorporação de metais 98

6.5.5. Análise estatística dos metais 102

6.5.5.1. Validação da base de dados 102

6.5.5.2. Análise dos fatores principais (AFP) 106

6.5.5.3. Análise por agrupamento 110

7 Conclusões 115 
8 Referências bibliográficas

9 Tabelas auxiliares 


\section{Lista de figuras}

Figura 1 - Vista aérea com linhas de demarcação da área erodida e o esporão arenoso formado no Pontal de Atafona

Figura 2 - Pontal de Atafona - São João da Barra (Ribeiro, 2004)

Figura 3 - Fotos do Pontal de Atafona, 1961 e 2007 (Departamento Nacional de Obras e Saneamento; Gilberto Ribeiro, 2008)

Figura 4 - Fotos da destruição local

Figura 5 - Rio Paraíba do Sul, UEL Santa Cecília,UEL de Vigário e Barragem Santa Branca (Ligth, 2008)

Figura 6- Série de decaimento radioativo do ${ }^{238} \mathrm{U}$ 40

Figura 7- Dinâmica do ${ }^{210} \mathrm{~Pb}$ no meio ambiente (Lima, 1996)

Figura 8- Curva do ${ }^{210} \mathrm{~Pb}$ com a profundidade (tempo) (Projeto SOFIA,1997) 42

Figura 9 - Atividades de ${ }^{210} \mathrm{~Pb}$ ao longo do perfil de sedimento

Figura 10- Localização dos pontos de coleta (1 ${ }^{a}$ campanha em janeiro de 2010 e a segunda em fevereiro 2011)

Figura 11- Corer UWITEC 50

Figura 12- Perfil de sedimento coletado 50

Figura 13-Armazenamento e cortes dos testemunhos 51

Figura 14- Fluxograma do método analítico utilizado

Figura 15- Método analítico. - Solução lixiviada, separação por troca iônica filtração do precipitado de $\mathrm{PbCrO}_{4}$, preparação para contagem $\beta$

Figura 16 - Porcentagem da fração de silte + argila ao longo da profundidade para o prefil 2C.

Figura 17- Porcentagem da fração de silte + argila ao longo da profundidade para o prefil $2 S$

Figura 18 . Imagem da região com os inventários de ${ }^{210} \mathrm{~Pb}_{\mathrm{exc}}$ representados por círculos: os círculos menores representam um valor médio de $0,16 \mathrm{~Bq} \mathrm{~cm}^{-2}$, o círculos médios representam um valor médio de $0,45 \mathrm{~Bq} \mathrm{~cm}^{-2} \mathrm{e}$ os maiores representam os pontos com um valor médio de $1,2 \mathrm{~Bq} \mathrm{~cm}^{-2}$

Figura 19- Perfis de concentração de ${ }^{210} \mathrm{~Pb}_{\text {total }} \mathrm{e}^{210} \mathrm{~Pb}_{\text {excesso }}$ nos perfis de sedimento analisados

Figura 20-Concentração de ${ }^{210} \mathrm{~Pb}$ versus massa acumulada e velocidade de sedimentação calculada pelo modelo CIC para o perfis $3 \mathrm{C}(\mathrm{a})$; 2SS (b) e 4SS (c) 
Figura 21- Concentração de ${ }^{210} \mathrm{~Pb}$ versus massa acumulada e taxa de sedimentação calculada através do modelo CIC para o perfil 2NN (a). Idade versus massa acumulada e taxas de sedimentação calculadas através do modelo CRS para o perfil 2NN (b)_.

Figura 22- Concentração de ${ }^{210} \mathrm{~Pb}$ versus massa acumulada e velocidade de sedimentação calculada pelo modelo CIC para o perfil $4 \mathrm{C}$

Figura 23-Concentração de urânio e de ${ }^{210} \mathrm{~Pb}$ versus massa acumulada para os perfis $2 \mathrm{C}$ e $2 \mathrm{~S}$

Figura 24-Taxas de sedimentação de acordo com a profundidade mássica e idades calculadas pelo modelo CRS nos pontos $2 \mathrm{~S}(\mathrm{a}), 2 \mathrm{C}(\mathrm{b})$ e $4 S(c)$

Figura 25-Variação das taxas de sedimentação anterior aos anos 50 (a) e atual (b) 82

Figura 26-Idade versus concentração de cádmio para o perfil 2S 89

Figura 27-Idade versus concentração de zinco para o perfil 2S 90

Figura 28- Idade versus concentração de cobre para o perfil 2S 90

Figura 29- Idade versus concentração de cromo para o perfil 2S 90

Figura 30-Idade versus concentração de cádmio para o perfil 2C 91

Figura 31- Idade versus concentração de zinco para o perfil 2C 92

Figura 32- Idade versus concentração de cobre para o perfil 2C 92

Figura 33- Idade versus concentração de cromo para o perfil 2C 92

Figura 34-Idade versus relação $\mathrm{Mg} / \mathrm{Al}$ para os pontos 2S e 2C 94

Figura 35-Idade versus relação Sr/Al para os pontos 2S e 2C 94

Figura 36 -Variação dos Igeo para $\mathrm{Cu}, \mathrm{Cr}, \mathrm{Pb}$ e $\mathrm{Zn}$ ao longo do perfil 2S 97

Figura 37 - Variação dos Igeo para Cd ao longo do perfil 2S 98

Figura 38-Variação dos fluxos de Fe, Mn e Ti e do perfil 2C e 2S 100

Figura 39-Variação dos fluxos $\mathrm{Pb}$, Cu e Zn do perfil 2C e 2S 101

Figura 40 - Gráfico do factor scores associados ao fator 1 versus factor $\begin{array}{ll}\text { scores associados ao fator } 2 & 109\end{array}$

Figura 41- Dendograma obtido pela análise por agrupamento de variáveis para o perfil 2S

Figura 42 - Dendograma obtido pela análise por agrupamento de casos para o perfil $2 S$

Figura 43 - Dendograma obtido pela análise por agrupamento de variáveis para o perfil $2 \mathrm{C}$ 
Figura 44 - Dendograma obtido pela análise por agrupamento de casos para o perfil $2 \mathrm{C}$ 


\section{Lista de tabelas}

Tabela 1 - Condições de operação do ICP-MS

ELAN 6000

Tabela 2 - Valores dos Inventários de ${ }^{210} \mathrm{~Pb}_{\text {exc }}$ em cada perfil coletado $\quad 67$

Tabela 3- Análise da Amostra de referência 86

Tabela 4-Análise estatística descritiva para as variáveis do perfil 2S.

Valores em mg kg ${ }^{-1}$ e ${ }^{*}$ ) valores em g kg-1 104

Tabela 5-Estatística descritiva para as variáveis do perfil 2C.

Valores em mg kg $\left.{ }^{-1} \mathrm{e}^{*}\right)$ valores em g kg${ }^{-1} \quad 106$

Tabela 6- Matriz de cargas fatoriais ("factor loadings") obtida através da análise de fatores principais dos sedimentos do perfil 2S. 108

Tabela 7 - Porcentagem da fração de finos $(<63 \mu)$ ao longo de cada perfil 129

Tabela 8 - Concentrações de ${ }^{210} \mathrm{~Pb}$ total e excesso para o perfil $1 \mathrm{~N} \quad 130$

Tabela 9 - Concentrações de ${ }^{210} \mathrm{~Pb}$ total e excesso para o perfil 3S 131

Tabela 10 - Concentrações de ${ }^{210} \mathrm{~Pb}$ total e excesso para o perfil 1S 132

Tabela 11 - Concentrações de ${ }^{210} \mathrm{~Pb}$ total e excesso para o perfil 2N 133

Tabela 12 - Concentrações de ${ }^{210} \mathrm{~Pb}$ total e excesso para o perfil 3SS 134

Tabela 13 - Concentrações de ${ }^{210} \mathrm{~Pb}$ total e excesso para o perfil 3C 135

Tabela 14 - Concentrações de ${ }^{210} \mathrm{~Pb}$ total e excesso para o perfil 2SS 136

Tabela 15 - Concentrações de ${ }^{210} \mathrm{~Pb}$ total e excesso para o perfil 2SS 137

Tabela 16 - Concentrações de ${ }^{210} \mathrm{~Pb}$ total e excesso e taxas de $\begin{array}{ll}\text { sedimentação para o perfil 2NN } & 138\end{array}$

Tabela 17 - Concentrações de ${ }^{210} \mathrm{~Pb}$ total e excesso para o perfil 4C 139

Tabela 18 - Concentrações de ${ }^{210} \mathrm{~Pb}$ total e excesso e taxas de

$\begin{array}{ll}\text { sedimentação para o perfil 2S } & 140\end{array}$

Tabela 19 - Concentrações de ${ }^{210} \mathrm{~Pb}$ total e excesso e taxas de $\begin{array}{ll}\text { sedimentação para o perfil 2C } & 141\end{array}$

Tabela 20 - Concentrações de ${ }^{210} \mathrm{~Pb}$ total e excesso e taxas de sedimentação para o perfil $4 S$

Tabela 21 - Determinação de elementos no perfil 2S.

Valores em $\mathrm{mg} \mathrm{kg}^{-1} \mathrm{e}\left(^{*}\right)$ valores em $\mathrm{g} \mathrm{kg}^{-1}$

Tabela 22 - Determinação de elementos no perfil 2C.

Valores em mg kg-1 e $\left.{ }^{*}\right)$ valores em g kg-1 146

Tabela 23 - Fator de enriquecimento e Igeo do perfil 2S 149 
Tabela 24 - Fator de enriquecimento e Igeo do perfil 2C

Tabela 25 - Fluxo de incorporação de elementos no ponto $2 \mathrm{C}$.

Valores de Massa Acumulada em $\mathrm{g} \mathrm{cm}^{-2}$ e fluxos em $\mu \mathrm{g} \mathrm{cm}^{-2}$ ano $^{-1}$

Tabela 26 - Fluxo de incorporação de elementos no ponto 2S.

Valores de Massa Acumulada em $\mathrm{g} \mathrm{cm}^{-2}$ e fluxos em $\mu \mathrm{g} \mathrm{cm}^{-2} \mathrm{ano}^{-1}$ 


\section{1}

\section{Introdução}

O Brasil vem sofrendo, nos últimos anos, um enorme processo de degradação ambiental, causado pela falta de planejamento na utilização de seus recursos naturais e pela falta da capacidade do meio ambiente em absorver os impactos gerados pelo desenvolvimento.

Atualmente, a preocupação com o meio ambiente não faz parte apenas do interesse da comunidade cientifica, governo e organizações não governamentais, mas também da sociedade como um todo.

Os ambientes aquáticos também têm gerado preocupação, pois são muitas vezes vítimas de exploração desordenada de seus recursos. Os maiores impactos observados nestes ambientes, no país, são devidos aos despejos industriais, agrícolas e domésticos, e aos represamentos em bacias hidrográficas, causando alterações na sedimentação (IBAMA, 2002).

Os lagos e estuários são ambientes deposicionais que apresentam registros dos processos que ocorreram "in situ" em seus sedimentos e em sua bacia de drenagem.

Os sistemas deposicionais da plataforma continental têm elevada importância econômica e ecológica e são considerados os principais depósitos de sedimentos vindos do continente.

Muitos estudos têm mostrado que a composição geoquímica dos sedimentos da plataforma continental interna depende de fatores geológicos, biológicos e climáticos, e podem ser utilizados como traçadores em relação à fonte de origem e mudanças ambientais provocadas por fatores naturais e antropogênicos. (Borrego et al., 2004; Leblanc et al., 2000; Lin et al., 2002; Preda, 2005; Sánchez-García et al., 2010). 
O presente estudo visa avaliar o sistema deposicional e sua composição geoquímica na foz do rio Paraíba do Sul e correlacionar este sistema com as mudanças ocorridas na região. 


\section{1.}

\section{Erosão e Dinâmica Costeira}

A linha de costa é uma das feições mais dinâmicas do planeta. Sua posição no espaço muda constantemente em várias escalas temporais (diárias, sazonais, seculares e milenares). A posição da linha de costa é afetada por muitos fatores, alguns de origem natural e relacionados à dinâmica costeira, como variações do nível relativo do mar e dispersão de sedimentos, e outros relacionados a intervenções humanas na zona costeira como obras de engenharia, represamento de rios, dragagens etc. O resultado da interação entre estes vários fatores, pode ser o avanço da linha de costa mar adentro, o seu recuo em direção ao continente, ou a mesma permanecer em equilíbrio. Quando a linha de costa recua em direção ao continente, está sofrendo erosão (UFBA, 2004).

Alguns autores estimam que cerca de $70 \%$ das linhas de costa do mundo estejam sofrendo erosão. Isto tem despertado a atenção de cientistas em todo o mundo para este fenômeno, para a compreensão de suas causas e do que fazer para minimizar os prejuízos materiais decorrentes. É importante chamar atenção para um dos aspectos fundamentais quando se analisa o fenômeno da erosão costeira: a praia recreativa, onde os efeitos da erosão se expressam de maneira mais visível, é apenas uma pequena porção de uma feição natural maior chamada de antepraia, que também é afetada por processos atuantes na plataforma interna. Portanto, para a compreensão do fenômeno da erosão costeira é necessária a compreensão dos processos dinâmicos que ocorrem na antepraia (UFBA, 2004).

A dinâmica natural das praias está relacionada ao conjunto de processos e a morfologia da linha da costa continental, representando um fluxo aberto de energia e matéria. Esta dinâmica consiste basicamente na entrada de sedimentos procedentes do continente, no transporte e deposição destes sedimentos ao longo da linha da costa e na saída de matéria até o oceano e a plataforma continental, onde se deposita este material.

A natureza dos sedimentos costeiros está relacionada ao tipo do material transportado pelos cursos de água e pelo material transportado pelas ondas, marés, correntes e ventos, como areias, argilas e organismos decompostos ou vivos. Os processos estão vinculados ainda, com a disponibilidade de transporte 
de sedimentos para a praia, tamanho e forma das partículas e profundidade em que se encontra esse material. Neste processo, encontra-se também, a direção predominante da corrente marítima, o impacto das ondas e marés, os sedimentos transportados pelos cursos de água, que abastecem o sistema e, finalmente, os sedimentos carreados pela deriva costeira na plataforma continental e as correntes que transportam estes sedimentos até águas profundas, onde se depositam, formando o leito submarino (Dias, 1984).

A sedimentação nos ambientes costeiros é muito importante como fator decisivo no reconhecimento de áreas e condicionante para a ocorrência das formas de construção, provocando a ampliação de praias, barramento de desembocaduras, chamados de esporões, e criação de depósitos submersos, favorecendo o movimento positivo do continente. Na costa brasileira, o material com que são construídas essas formas serve para distinção das áreas costeiras. Os processos gerais que regulam a dinâmica costeira estão vinculados às relações entre o continente e o oceano e pela ação de agentes dominantes, como correntes, ventos, ondas, marés e cursos de água. Estes processos variam com o tempo na superfície da área ocupada e na uniformidade ou variabilidade de suas condições ambientais (Cavalcanti e Viadana, 2007).

Um litoral arenoso atinge um perfil de equilíbrio que é uma função da dinâmica e da granulometria dos sedimentos. A dinâmica costeira, ditada principalmente pela amplitude das marés e pela altura das ondas, promove a contínua construção e destruição deste perfil de equilíbrio. Ao se considerar um tempo suficientemente longo, pode-se admitir que exista um perfil médio de equilíbrio. O abaixamento ou a elevação do nível relativo do mar irão romper este perfil de equilíbrio médio, quando então serão acionados os mecanismos que levarão ao restabelecimento do equilíbrio rompido. Quando ocorre a elevação do nível relativo do mar, o perfil de equilíbrio será restabelecido pela erosão da pós-praia e do continente e pela acumulação dos sedimentos erodidos na antepraia (Martin, et al., 1984). 


\section{2.}

\section{Hidrodinâmica e Processos relativos aos sedimentos}

A maior parte da erosão ao longo da costa oceânica é produzida pelas ondas. A energia trazida pelas ondas é dissipada não só contra as rochas, mas também na turbulência causada no fundo e no movimento de sedimentos que são colocados em suspensão. Os sedimentos quer sejam produzidos pelas ondas batendo contra as rochas, ou levados pelos rios para o mar, são redistribuídos pelas correntes marítimas que constroem diferentes tipos de praia.

A maioria das ondas atinge a praia num ângulo oblíquo. O curso da onda pode ser decomposto em duas componentes direcionais: uma, com orientação perpendicular, e outra, com orientação paralela à praia. A primeira produz erosão de impacto e a segunda produz uma corrente de transporte de sedimentos ao longo da costa. Quanto maior for o ângulo de incidência da onda, em relação à linha perpendicular à costa, maior será o transporte de sedimentos ao longo da costa; daí a designação de deriva da praia para este fenômeno. O resultado final da interação entre forças erosiva e forças deposicionais é uma grande variedade de linhas de costa e formas costeiras (Maia, 2002).

Em um ambiente aquático, as partículas de silte e argila tendem a se acumular em condições de menor energia, enquanto que a acumulação de areias reflete um ambiente mais dinâmico e energético. As variações granulométricas em diferentes seções do perfil refletem, particularmente, mudanças sazonais no regime hidrodinâmico (Pereira e Soares-Gomes, 2002).

Perfis anômalos de ${ }^{210} \mathrm{~Pb}$ em testemunhos, como camadas caracterizadas pela ausência ou excesso de ${ }^{210} \mathrm{~Pb}$ não suportado, podem estar relacionados à diminuição da taxa de sedimentação ou entrada repentina de sedimento por eventos catastróficos, como desmoronamentos, atividades antrópicas, como dragagens, construção de portos e estradas (Smith e Walton, 1980; Barnes et al., 1978).

\section{3.}

\section{Histórico de evidências de erosão em foz de rios}

Antigamente, dizia-se que o rio invadia o mar. Agora, com a visível morte lenta do rio é o mar que invade o rio. $O$ processo erosivo nas áreas adjacentes 
às desembocaduras fluviais tem sido muito observado e, provavelmente, estão relacionados com as transformações ocorrentes na bacia de drenagem.

As linhas de costa em diferentes partes do mundo vêm sofrendo processos de erosão marinha, que, em geral, são resultados de ações naturais e atividades antrópicas. A erosão costeira é, atualmente, considerada um fenômeno global. Os estudos realizados pela União Geográfica Internacional (UGI) demonstram que $70 \%$ das costas sedimentares do mundo estão passando por erosão, enquanto $10 \%$ estão em progradação e $20 \%$ estão estáveis (Muehe, 2006).

Alguns estudos de processos erosivos na costa do estado do Ceará apresentaram velocidades bem diferentes, com taxas médias de erosão variando de $0,05 \mathrm{~m} a^{-1}$ a $5 \mathrm{~m} \mathrm{ano}^{-1}$ (Morais et al., 2006). As principais causas da erosão foram observadas como: a) elevação do nível relativo do mar; b) ocupação e urbanização das áreas caracterizadas como fonte de sedimentos, c) obras portuárias, e repercussões no litoral vindas das transformações sócio espaciais no interior da bacia de drenagem (Dias, 1990; Morais, 2006 e Morais et al., 2002).

Inúmeros trabalhos sobre a morfodinâmica de desembocaduras fluviais vêm sendo desenvolvidos no Brasil e no mundo. Trabalhos realizados por Siegle (1999) no Rio Camboriú, por Oliveira et al. (2002) no Rio Mondego, por Ferreira (2004) no Rio Tejo e por Uda et al. (2005) no Rio Shinkaua podem ser tomados como exemplos. Morais e Pinheiro (2000) e Morais et al. (2002) observaram o problema da erosão marinha na praia do Pontal de Maceió na foz do rio Jaguaribe, no Ceará, e relacionaram esse fenômeno com a dinâmica fluvial e com as transformações da paisagem nos últimos 40 anos.

Outro local de grande interesse é a foz do rio São Francisco, onde tais evidências também foram observadas. Em 1988, um pequeno povoado com cem famílias, chamado Vila do Cabeço no município de Brejo Grande ao norte da capital, foi tragado pelas ondas do mar. O caso é considerado como uma das erosões mais severas de toda a costa do país. A construção de hidrelétricas represa a água e sedimentos que naturalmente seriam jogados na zona costeira (Nicolodi, 2008). Os principais reservatórios do rio São Francisco, são Sobradinho, Itaparica, Paulo Afonso e Xingó, que produzem energia hidrelétrica. Atualmente, em $21 \%$ da costa sergipana o mar vem avançando num processo de erosão severa. Atalaia Nova é um dos pontos mais críticos de erosão no 
Estado, depois da Vila do Cabeço, onde pescadores e moradores de casas ao longo dos 150 quilômetros do litoral sergipano estão passando por uma batalha contra o mar, que vem avançando pela areia e derrubando o que encontra pela frente.

O avanço do mar, que também provocou graves danos ambientais na zona costeira de Olinda, pode ter sido causado pela combinação de vários eventos, particularmente, a redução do fornecimento de sedimentos às praias, a presença de linhas de recifes paralelos à costa que dificultam o transporte de areia da plataforma interna para a praia e, finalmente, as numerosas intervenções realizadas para o melhoramento do Porto do Recife. A posição da linha de costa de Olinda, entre 1915 e 1950, recuou em aproximadamente 80 metros, o que resultou em um intenso processo erosivo, que se instalou, principalmente nas praias dos Milagres, do Carmo e de São Francisco (CPRH, 2000).

\section{4. \\ Histórico da Região do vale do Paraíba}

Com a chegada dos colonizadores, e o início do ciclo do ouro em Minas Gerais (1600), o vale do Paraíba, adquire uma importância estratégica como corredor comercial, aproximando o interior de Minas à costa paulista. O vale assistiu assim à construção das primeiras estradas e à formação de pequenos povoados que serviram de suporte aos comerciantes.

Esta dinâmica comercial, nos finais do século XVIII, é substituída pelas culturas do café e da cana-de-açúcar, que se expandiram por todo o vale. $\mathrm{O}$ cultivo do café deu início ao processo de desmatamento e à ocupação extensiva da bacia, determinando um processo de alteração drástica da paisagem regional. Rapidamente, a bacia do Paraíba do Sul tornou-se responsável pela quase totalidade da produção cafeeira do país. Em meados do século XIX houve a expansão da criação de gado leiteiro e a migração da população rural para áreas urbanas. A agricultura representa uma das mais importantes fontes de poluição dos solos e das águas pelo uso descontrolado de fertilizantes e agrotóxicos, onde a cana-de-açúcar mantém-se como principal cultura na bacia.

A estagnação econômica e social resultante da crise do café e da cana-deaçúcar foi gradualmente superada através de um lento processo de industrialização. Com o início do século $X X$, a atividade industrial tornou-se o 
eixo de desenvolvimento da bacia. O processo de industrialização de São Paulo e a implantação, em 1946, da Companhia Siderúrgica Nacional (CSN), na cidade de Volta Redonda/RJ, permitiram a integração econômica dos estados do Rio de Janeiro e São Paulo, transformando a bacia num dos eixos de comunicação e desenvolvimento cruciais para a região e para o país, graças às condições excepcionais que oferecia - suprimento de água, energia suficiente, mercado consumidor e fácil escoamento da produção. A expansão e intensificação do desenvolvimento industrial exigiram a construção de novas rodovias, acelerada pela implantação da indústria automobilística, complementando assim o sistema viário já existente (CEIVAP, 2007).

Em termos gerais, o uso da água reflete as atividades humanas em seu conjunto. Os principais usos da água na bacia são: abastecimento, diluição de esgotos, irrigação (agricultura), geração de energia hidrelétrica, processos industriais e, em menor escala, pesca, aquicultura, recreação e navegação (CEIVAP, 2007). 


\section{2}

\section{Objetivos}

2.1.

\section{Objetivo Geral}

Avaliar se a variação das taxas de sedimentação dos testemunhos coletados da região do delta e pro-delta do Rio Paraíba do Sul está associada às intervenções na Bacia.

\section{2.}

\section{Objetivos Específicos}

- Coletar dados históricos das intervenções ocorridas no RPS;

- Coletar dados históricos sobre a erosão costeira que ocorre em Atafona, no município de São João da Barra, RJ, onde se localiza a foz do RPS;

- Coletar testemunhos lamosos no delta e pro-delta do RPS, que possam representar material vindo do rio;

- Datar os sedimentos destes testemunhos e calcular as taxas de sedimentação;

- Determinar a concentração de metais pesados e avaliar a contaminação do local;

- Avaliar os resultados e estudar das correlações com os dados históricos. 


\section{3 Área de estudo}

\section{1. Bacia do Rio Paraíba do Sul}

O Rio Paraíba do Sul (RPS) e seus afluentes correspondem à maior bacia hidrográfica da região sudeste, com aproximadamente $55.000 \mathrm{~km}^{2}$ distribuída por três estados (São Paulo, Minas Gerais e Rio de Janeiro). Situado entre as latitudes $20^{\circ} 26^{\prime} \mathrm{S}$ e $23^{\circ} 38^{\prime} \mathrm{S}$ e as longitudes $41^{\circ} 00^{\prime} \mathrm{W}$ e $46^{\circ} 30^{\prime} \mathrm{W}$, o RPS origina-se na serra da Bocaina (SP). Ele nasce na confluência dos rios Paraitinga e Paraibuna, e percorre cerca de 1.137 km até sua foz no município de São João da Barra (RJ). Seus principais afluentes são o Jaguari, o Buquira, o Paraibuna, o Preto, o Pomba e o Muriaé. Esses dois últimos são os maiores e deságuam, respectivamente, a 140 e a $50 \mathrm{~km}$ da foz. O sistema serve ainda como fonte de abastecimento para cerca de 14 milhões de pessoas no estado do Rio de Janeiro, incluindo $85 \%$ dos habitantes da Região Metropolitana, através da transposição de um grande volume de água do Rio Paraíba do Sul para a bacia do Rio Guandu (Carvalho, 2002; Souza, 2009).

A situação atual do rio é preocupante, pois, durante o seu curso, ele tem sido impactado por várias formas de exploração como desmatamentos e urbanização nas margens, uso indevido de agrotóxicos, lançamento de efluentes domésticos, industriais e resíduos sólidos, além da existência de inúmeras barragens e represas, principalmente devido ao desvio para o Rio Guandu. Como consequência das formas de exploração e poluição a região vem sofrendo erosão e assoreamento.

\section{2.}

\section{Unidades morfológicas de um Delta}

Os rios são os receptores finais das alterações que ocorrem em sua bacia de drenagem, pois são coletores naturais da paisagem, refletindo o uso e ocupação do solo de sua bacia, onde se observa processos de degradação, 
assoreamento e homogeneização do leito, diminuição da diversidade de habitats e microhabitats, e a eutrofização artificial (Goulart e Callisto, 2003). De acordo com Christofoletti (1980), todos os acontecimentos que ocorrem na bacia de drenagem repercutem direta ou indiretamente nos rios.

Os deltas são formados em frente às desembocaduras fluviais pela deposição de sedimentos alóctones (sedimentos de outras áreas). Em geral a acumulação de sedimentos é mais rápida do que a remoção pelos processos costeiros. Os deltas, em geral, são representados morfologicamente por três partes: a planície deltaica, a frente deltaica e o prodelta.

A Planície deltaica é formada por canais dependendo do gradiente da plataforma e capacidade de transporte das correntes. Diferenças morfológicas entre a parte superior (mais fluvial) e inferior (mais estuarina) da planície. É uma zona dominada por processos fluviais.

A Frente deltaica é o local de intensa deposição onde a morfologia deltaica é estabelecida. Sedimentos grossos depositados em frente aos canais, cuja morfologia depende do fluxo de energia, das diferenças de densidade entre os meios (fluvial e marinho) e da declividade da plataforma.

O Prodelta é a região com predomínio de sedimentação fina (silte e argila) e localizada além do nível de base das ondas. É caracteristicamente plana e mais horizontalizada.

\section{3. \\ Características do Delta do Rio Paraíba do Sul}

Extensos trechos da costa atlântica da América do Sul são caracterizados por grandes depósitos lamosos regionais, especialmente onde um ou mais rios aportam significativas quantidades de sedimento fino em suspensão (Kjerfve et al., 2003). Os processos dinâmicos de transporte e deposição de lama na plataforma interna dependem da interação entre as ondas geradas pelo vento, da disponibilidade de sedimentos finos, da amplitude das marés e das correntes costeiras.

O Rio Paraíba do Sul vem sofrendo, ao longo dos últimos anos, intenso processo de modificação de sua foz caracterizado pelo avanço do mar e pela erosão acentuada da praia de Atafona (Figura 1). Em períodos de enchentes, o 
jato de água junto à desembocadura de um rio irá constituir um obstáculo que tenderá a bloquear o transporte de areias. Isto ocasionará uma acumulação de areia do lado à montante (acima) da corrente de deriva litorânea (corrente gerada pelas ondas, e responsável pelo transporte dos sedimentos ao longo de uma praia arenosa) e uma possível erosão do lado à jusante (abaixo) da corrente. Entretanto, a erosão da parte à jusante (abaixo) da corrente é frequentemente compensada pelo aporte de sedimentos supridos pelo próprio rio. Em períodos de estiagem o obstáculo representado pelo fluxo fluvial irá praticamente desaparecer e a deriva litorânea provocará a construção de um esporão arenoso que tenderá a fechar a desembocadura. Do mesmo modo, ocorrerá uma erosão parcial do depósito formado no período precedente, que se encontrava saliente em relação ao alinhamento da praia (Fig. 2).

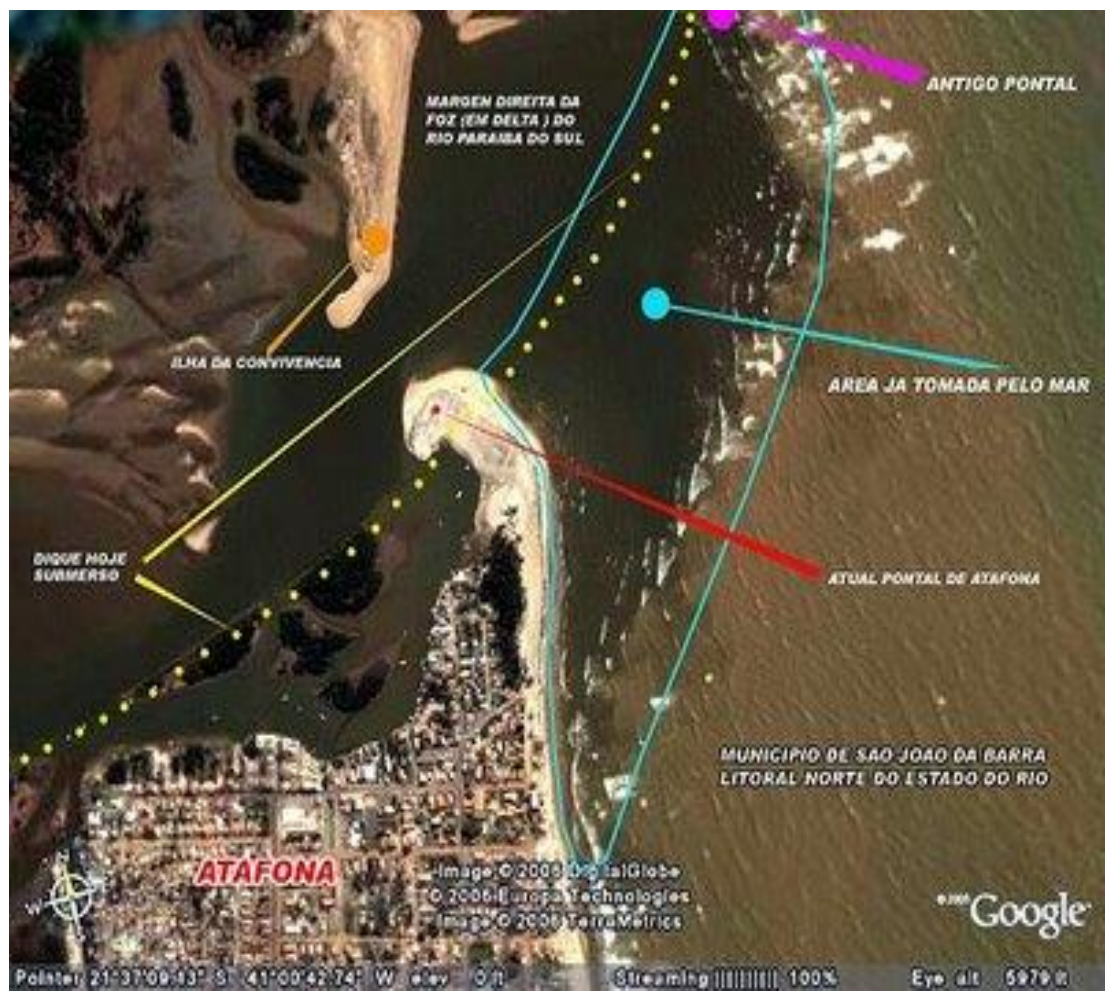

Figura 1 - Vista aérea com linhas de demarcação da área erodida e o esporão arenoso formado no Pontal de Atafona 

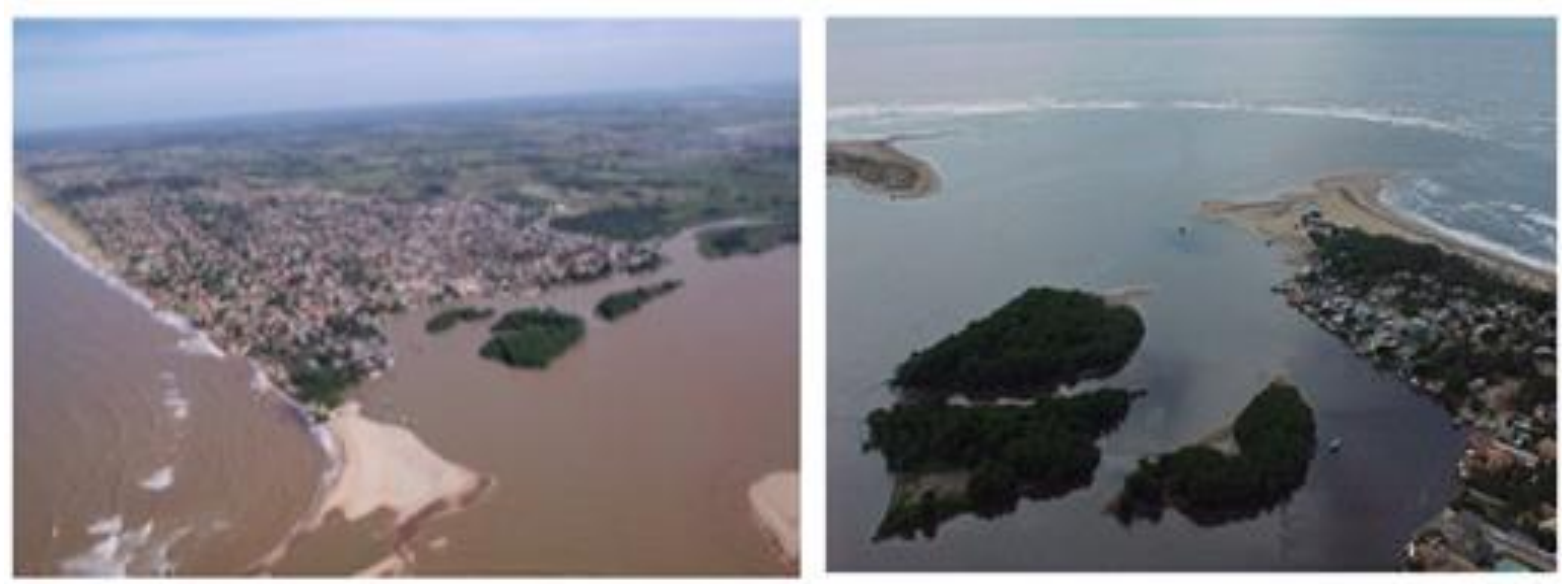

Figura 2 - Pontal de Atafona - São João da Barra (Ribeiro, 2004).

A planície costeira em frente ao delta do Rio Paraíba do Sul tem duas assimetrias morfologicamente diferentes. Ao norte, apresenta características de progradação em torno de $6 \mathrm{~m}^{2}$ ano $^{-1}$ nos últimos 5000 anos. Ao sul, apresenta enormes processos de erosão observados nos últimos 20 anos no Pontal de Atafona, onde as taxas de erosão são da ordem de $7 \mathrm{~m} \mathrm{ano}^{-1}$ (Bastos e Silva, 2000 e 2003).

A distribuição superficial de sedimentos no delta do RPS indica que praticamente toda a faixa litorânea é recoberta por lama, aproximadamente $4 \mathrm{~km}$ mar a dentro, tanto ao norte quanto ao sul da desembocadura do rio. Há dois depósitos de lama vinda do RPS no prodelta. Ao norte com $3 \mathrm{~m}$ de profundidade e ao sul com 2,5 m de profundidade (Murillo et al., 2009).

\section{4 . \\ Histórico de Atafona}

O pontal de Atafona, situado no município de São João da Barra (RJ) no norte-fluminense, localizado bem na foz do RPS, tem sofrido com a seca do rio e a erosão causada pelo avanço do mar. Atafona está realmente perdendo a briga contra o mar. A praia vem sendo invadida pelas ondas que estão destruindo casas e expulsando moradores que vivem na orla. Os ventos e as ondas são tão fortes que 180 construções próximas à praia já desapareceram. A cidade que até os anos 50 atraía vários moradores para a costa, hoje tem um número bastante reduzido de casas ainda de pé perto da areia. A figura 3 apresenta fotos da praia de Atafona em 1961 (à esquerda) e em 2007 (à direita), quando o mar já havia avançado sobre boa parte da faixa costeira. 

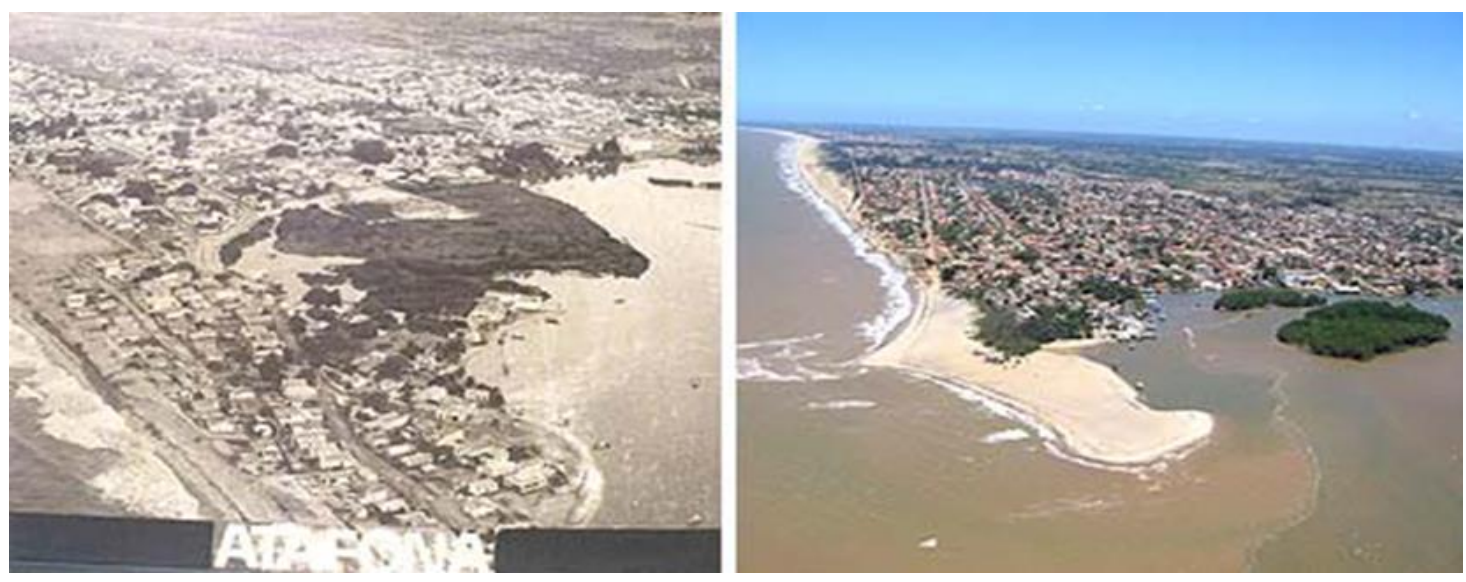

Figura 3 - Fotos do Pontal de Atafona, 1961 e 2007 (Departamento Nacional de Obras e Saneamento; Gilberto Ribeiro, 2008)

O processo erosivo observado nos últimos anos em Atafona tem sido objeto de investigação e pesquisa por muitas universidades e institutos de pesquisa. Identificar os fatores que contribuem para a existência deste processo requer criterioso estudo sobre suas causas naturais no processo geológico de construção da planície do delta do RPS e as causas antrópicas, principalmente vinculadas ao RPS.

Segundo Ribeiro (Departamento de Engenharia Cartográfica da UERJ), que estuda o avanço do mar em Atafona desde 2004, a causa mais provável do fenômeno é a combinação de fatores naturais, como o vento, as ondas e o movimento das marés. A força dos ventos amplia a capacidade destrutiva das ondas sobre a praia e faz com que o mar avance cada vez mais rápido. Além disso, a ação humana é um agravante. "A construção de barragens no rio Paraíba do Sul diminuiu a quantidade de sedimentos e água que chegam à praia", explica. "Dessa forma diminui-se a faixa de areia e aumenta-se a intensidade da erosão." Os sedimentos acumulados nas margens do rio acabam sendo levados pelo vento e formam dunas que invadem a cidade.

O Laboratório de Geologia Marinha (LAGEMAR) da Universidade Federal Fluminense (UFF), em parceria com o Departamento de Engenharia Cartográfica da Universidade do Estado do Rio de Janeiro (UERJ), executou o mapeamento digital da linha de costa e faixa de praia de Atafona à Grussaí objetivando configurar e quantificar a perda devido à erosão costeira em andamento, principalmente em Atafona, que, até o presente momento, já provocou a destruição de 183 construções em 14 quadras (Figueiredo et al., 2004). 
Do ponto de vista histórico, pode-se observar que os seguintes fatos ocorreram e foram publicados em jornais locais (Ribeiro, 2004):

- 1975: destruição de algumas casas na llha da Convivência

- 1976: desabamentos de casas no pontal de Atafona

- 1977: destruição de 2 casas

- 1978: foi observado recuo do mar

- 1981: o mar recua aproximadamente $600 \mathrm{~m}$

- 1990: registro de mais destruições imobiliárias

- 1991: Capela Nossa Senhora dos Navegantes destruída pelo mar.

Relatos de pessoas no local comprovam a ocorrência de tais eventos relacionados acima (Vieira, 2004; Noronha (a), 2004), (Ribeiro, 2004).

Relatos na imprensa escrita (Jornal Folha da Manhã, 2003; Jornal O Globo, 2004) despertam a curiosidade da população local em geral e, ao mesmo tempo, afligem os proprietários das construções. A população, em função de perdas imobiliárias, tem sido diretamente afetada com o fenômeno de forma dramática. A Figura 4 mostra alguns registros da destruição local.

Vários estudos em relação ao fenômeno da erosão nesta área têm sido realizados. A taxa de retrogradação associada à erosão foi estimada como $7,5 \mathrm{~m}$ ano $^{-1}$, tendo como referências dados de 1976 (fotografia aérea) e 1996 (linha de frente de erosão determinada com GPS), compreendendo um período de 20 anos. O mapeamento cartográfico para o monitoramento espaço-temporal do fenômeno apontou uma taxa estimada de $7,8 \mathrm{~m}^{2}$ ano $^{-1}$ nesta região para o período de 1954-2004. Em um período de 10 anos, entre 1954 e 1964, a área erodida aumentou $311.128,48 \mathrm{~m}^{2}$ (Ribeiro et al., 2004). 

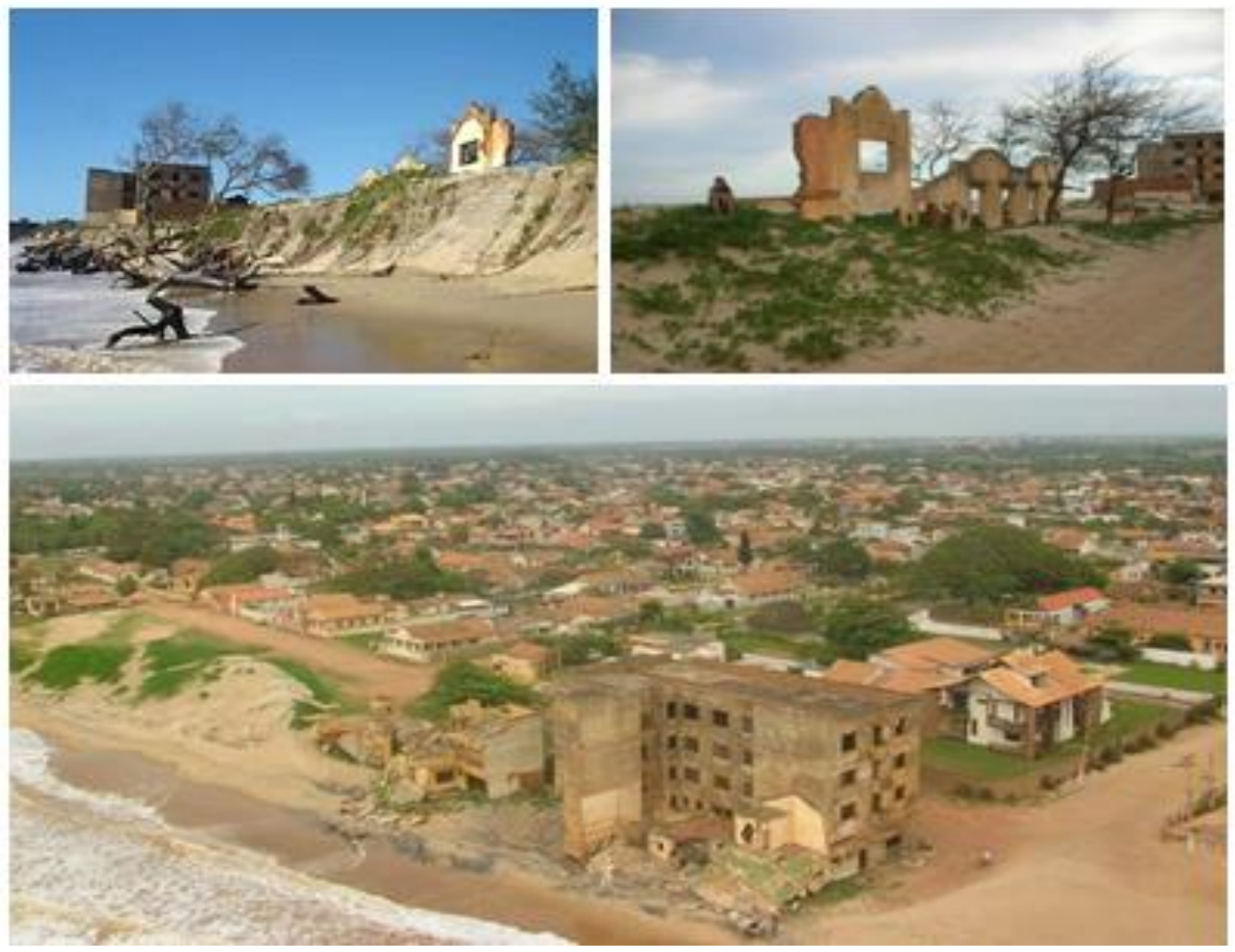

Figura 4 - Fotos da destruição local

뭉

再

ণ্ণ్

త్ర

章

음

ปุ 


\section{5.}

\section{As Barragens no Rio Paraíba do Sul}

O Brasil é o 23ํㅜ país com mais água disponível por pessoa no mundo, com $48.314 \mathrm{~m}^{3}$ por pessoa. Ao mesmo tempo em que o Brasil apresenta um dos maiores potenciais hídricos mundiais, em contraste ocorre também um grande problema de assoreamento de rios, córregos, lagos e barragens.

O impacto ambiental gerado pela construção de uma barragem deve ser amenizado com medidas de preservação. As possibilidades devem ser estudadas antes do início da implementação da barragem, mas isso só é possível graças às novas geotecnologias que geram informações fundamentais, normalmente armazenadas em banco de dados georreferenciados por meio de Sistemas de Informações Geográficas (SIG). Com o SIG pode-se estudar diversos aspectos que envolvem a implementação da barragem e avaliar o impacto ambiental de sua implantação, permitindo antecipar eventuais problemas que possam vir ocorrer (IPABHi, 2007).

O Rio Paraíba do Sul é um dos mais importantes rios da bacia hidrográfica da região sudeste. Ele tem vazões variadas, principalmente devido às barragens construídas ao longo de seu percurso. A captação de água para abastecimento corresponde a $64 \mathrm{~m}^{3} \mathrm{~s}^{-1}\left(17 \mathrm{~m}^{3} \mathrm{~s}^{-1}\right.$ para abastecimento domiciliar da população residente na bacia, mais $47 \mathrm{~m}^{3} \mathrm{~s}^{-1}$ para o abastecimento da Região Metropolitana do Rio de Janeiro), mais, aproximadamente, $14 \mathrm{~m}^{3} \mathrm{~s}^{-1}$ para uso industrial e, 30 $\mathrm{m}^{3} \mathrm{~s}^{-1}$ para uso agrícola.

A Usina Hidrelétrica de Fontes, no Ribeirão das Lajes, associada à Barragem e ao Reservatório de Lajes, foi a 1a unidade geradora de energia e entrou em operação em 1908. Em 1913 entrou em operação o Desvio TócosLajes e duas novas unidades geradoras de 12,5 MW na Usina de Fontes, garantindo o suprimento de energia elétrica para o Rio de Janeiro até a entrada em operação da $1^{\underline{a}}$ unidade da UHE Ilha dos Pombos, ocorrida em 1924.

Como no entorno da Região Metropolitana do Rio de Janeiro já não existiam mananciais de água significativos, no início da década de 40 foram construídas duas adutoras para fins de abastecimento público com capacidade total de $5,5 \mathrm{~m}^{3} \mathrm{~s}^{-1}$, utilizando-se águas provenientes do Reservatório de Lajes após serem turbinadas pela Usina de Fontes. Com o aumento da demanda, a alternativa para o aumento da capacidade de geração de energia era a 
ampliação da Usina de Fontes com a utilização de água desviada do Rio Piraí. A partir daí, se pode acompanhar o histórico das construções de desvios e barragens do RPS. A seguir, a Figura 5 mostra algumas destas barragens e elevatórias.

1945 - A Light foi autorizada pelo Governo Federal a implantar novas usinas hidrelétricas no entorno das usinas de Fontes com base no aumento da disponibilidade hídrica obtida por força da derivação das águas dos rios Paraíba do Sul e Piraí. Esse desvio, denominado Paraíba-Piraí, transfere as águas do Rio Piraí remanescentes do desvio Tócos-Lajes e do Rio Paraíba do Sul para o Ribeirão das Lajes.

1952 - Entrada em operação do Desvio Paraíba-Piraí, constituído pelas seguintes instalações:

- Usina Elevatória de Santa Cecília, localizada no Rio Paraíba do Sul em Barra do Piraí, contando com quatro unidades de bombeamento, $160 \mathrm{~m}^{3} / \mathrm{s}$ de capacidade, túnel e canal para encaminhamento das águas para o reservatório de Santana.

- Barragem e Reservatório de Santana, no Rio Piraí, propiciando o encaminhamento das vazões bombeadas do Rio Paraíba do Sul para a Usina Elevatória de Vigário.

- Usina Elevatória de Vigário, localizada em Piraí, contando com quatro unidades de bombeamento, $190 \mathrm{~m}^{3} \mathrm{~s}^{-1}$ de capacidade, destinada a transpor as águas provenientes dos rios Paraíba do Sul e Piraí para o Reservatório de Vigário.

- Reservatório e Canal de Vigário, que encaminham as águas para a tomada d'água que alimenta as usinas Nilo Peçanha e Fontes Nova.

1955 - Construção da Estação de Captação e Tratamento do Guandu, que entrou em operação em 1955.

1959 - Construção da Barragem de Santa Branca no trecho superior do Rio Paraíba do Sul, no Estado de São Paulo. O reservatório entrou em operação em dezembro e vem sendo operado para regularização das vazões do Rio Paraíba do Sul de modo a permitir o bombeamento em Santa Cecília. 

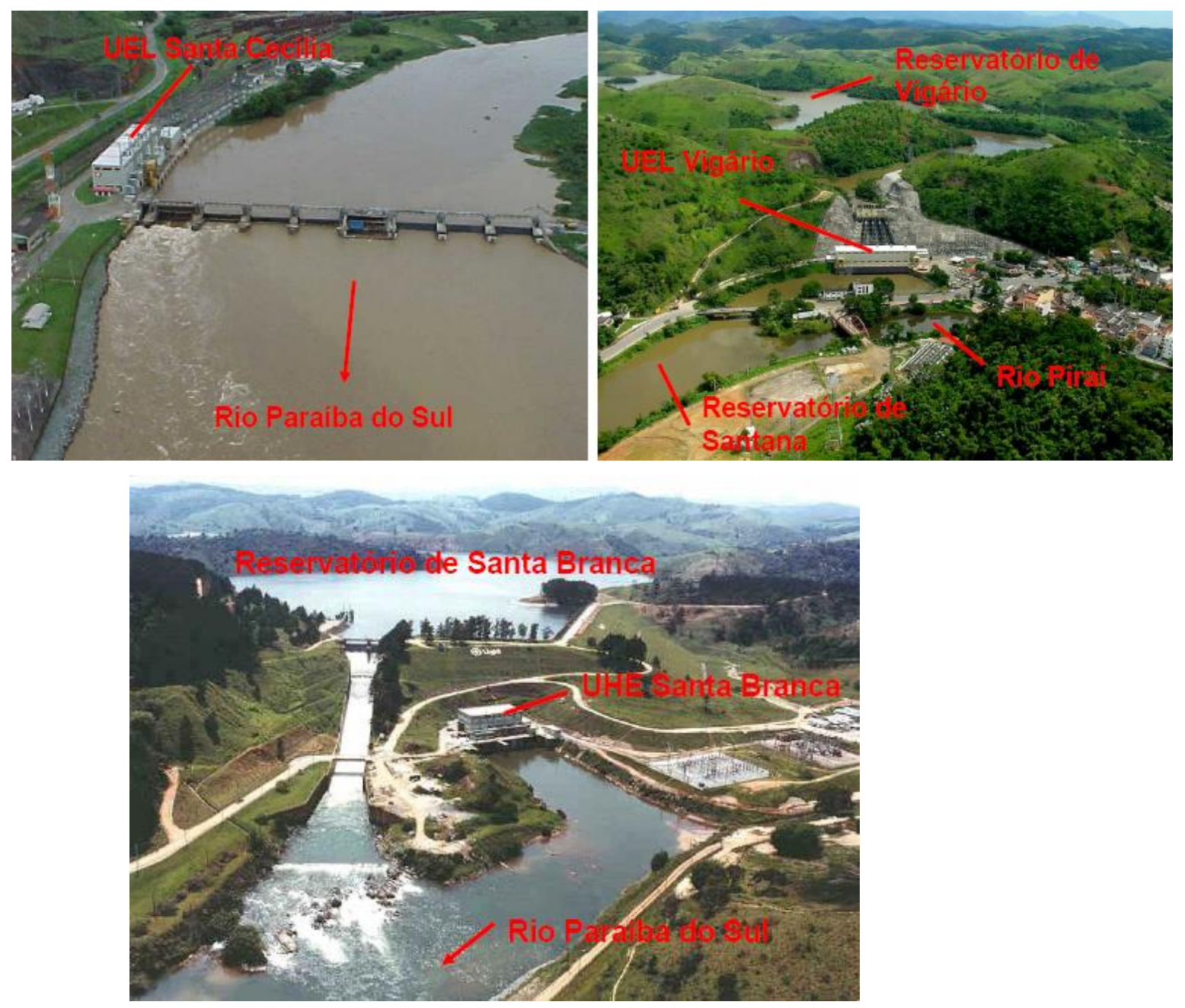

Figura 5 - Rio Paraíba do Sul, UEL Santa Cecília,UEL de Vigário e Barragem Santa Branca (Ligth, 2008).

\section{6. \\ O Rio Guandu}

O Rio Guandu era um rio de pequeno porte há alguns anos. Mas se tornou um rio bastante caudaloso depois da transposição da águas do rio Paraíba do Sul, sendo primeiramente usado para a produção de energia elétrica pela empresa Light Serviços de Eletricidade e para uso industrial, e hoje é voltado, principalmente, para o abastecimento de água da RMRJ. Sua água abastece cerca de $80 \%$ da população do Grande Rio.

Suas nascentes localizam-se na Serra do Mar, em diversos municípios. Alguns riachos se unem na represa de Ribeirão das Lajes, um dos formadores do rio Guandu, que é importante para a regulação da vazão e do nível da água do rio e tem papel importante na economia local. Depois de passar pela represa, 
- Ribeirão das Lajes, recebe as águas do Rio Paraíba do Sul através de transposição em Barra do Piraí pela estação elevatória de Santa Cecília e, depois de receber as águas do Rio Santana, passa finalmente a denominar-se Rio Guandu. 


\section{Datação de Sedimentos e Taxas de Sedimentação}

\section{1. Radionuclídeos no Ambiente Marinho}

O ambiente marinho, além de ocupar praticamente $71 \%$ da superfície da crosta terrestre, é considerado um vazadouro natural dos continentes, onde muitos elementos provenientes de fontes antropogênicas lançados nos oceanos, têm se aproximado ou excedido os níveis naturais.

Muitos elementos são reciclados, acumulados e posteriormente liberados pelos oceanos, existindo uma grande interação entre os ecossistemas. O vulcanismo submarino, a lixiviação dos continentes e o transporte pelos aerossóis provavelmente, são as principais rotas de entrada de elementos, incluindo os radionuclídeos, nos oceanos (Yu et al., 1994).

Os radionuclídeos, uma vez introduzidos no meio ambiente, são dispersos, diluídos e redistribuídos, podendo permanecer em solução, serem ingeridos pelos organismos vivos ou adsorvidos em partículas dispersas no meio, dependendo das características ambientais, das suas diferentes propriedades químicas e do comportamento destes elementos que são afetados por leis de adsorção, formação de colóides e outros processos. Os elementos radioativos podem ser retirados da água do mar por adsorção em superfícies sólidas, num processo denominado "scavenging".

O comportamento químico de ${ }^{210} \mathrm{~Pb},{ }^{226} \mathrm{Ra}$ e ${ }^{137} \mathrm{Cs}$ é típico dos isótopos estáveis das famílias nas quais pertencem. Devido à alta afinidade de retenção em partículas, $\mathrm{o}^{210} \mathrm{~Pb}$ é retirado da coluna d'água pelo material particulado em suspensão e se deposita no sedimento, enquanto a maioria do ${ }^{226} \mathrm{Ra}$ e ${ }^{222} \mathrm{Rn}$, precursores de ${ }^{210} \mathrm{~Pb}$, se dissolvem rapidamente na água. Chanton et al. (1983) observaram que $\mathrm{o}^{210} \mathrm{~Pb}$ associa-se preferencialmente ao material orgânico, silte e argila do sedimento, enquanto que a sua concentração é baixa nas areias. Segundo Carvalho (1995), a concentração de ${ }^{210} \mathrm{~Pb}$ em sedimentos de estuários aumenta inversamente com 0 tamanho dos grãos do sedimento. Assim, 
sedimentos com grande porcentagem de areia apresentam menor quantidade deste radionuclídeo. Entretanto, a concentração de ${ }^{210} \mathrm{~Pb}$ aumenta diretamente com a porcentagem de matéria orgânica.

O ${ }^{210} \mathrm{~Pb}$ e seus produtos de decaimento têm sido utilizados para estudos sobre a dinâmica de ecossistemas aquáticos, sendo importantes traçadores naturais para estudos de processos costeiros.

4.2.

$$
\mathrm{O}^{210} \mathrm{~Pb}
$$

O método de datação $c o m{ }^{210} \mathrm{~Pb}$ tem sido muito usado para a datação de sedimentos depositados em ambientes aquáticos em torno de 100 a 150 anos (Koide et al., 1973; Matsumoto, 1975; Appleby e Oldfield, 1978).

O ${ }^{210} \mathrm{~Pb}$, com tempo de meia-vida de 22,26 anos, ocorre naturalmente como um dos radioisótopos da série de decaimento do ${ }^{238} \mathrm{U}$ (Figura 6). $\mathrm{O}$ desequilíbrio entre o ${ }^{210} \mathrm{~Pb}$ e o ${ }^{226} \mathrm{Ra}$, com tempo de meia-vida de 1.602 anos, ocorre através da difusão do ${ }^{222} \mathrm{Rn}$ (com tempo de meia-vida de 3,82 dias) do solo para a atmosfera. Uma fração do ${ }^{222} \mathrm{Rn}$ formada pelo ${ }^{226} \mathrm{Ra}$ no solo, se libera e se difunde para a atmosfera, onde, decai para formar uma seqüência de vários nuclídeos de meia-vida curta, até a formação do ${ }^{210} \mathrm{~Pb}$ de meia-vida relativamente longa, que é chamado de ${ }^{210} \mathrm{~Pb}_{\text {exc }}$, ou seja, em excesso (Figura 7). 


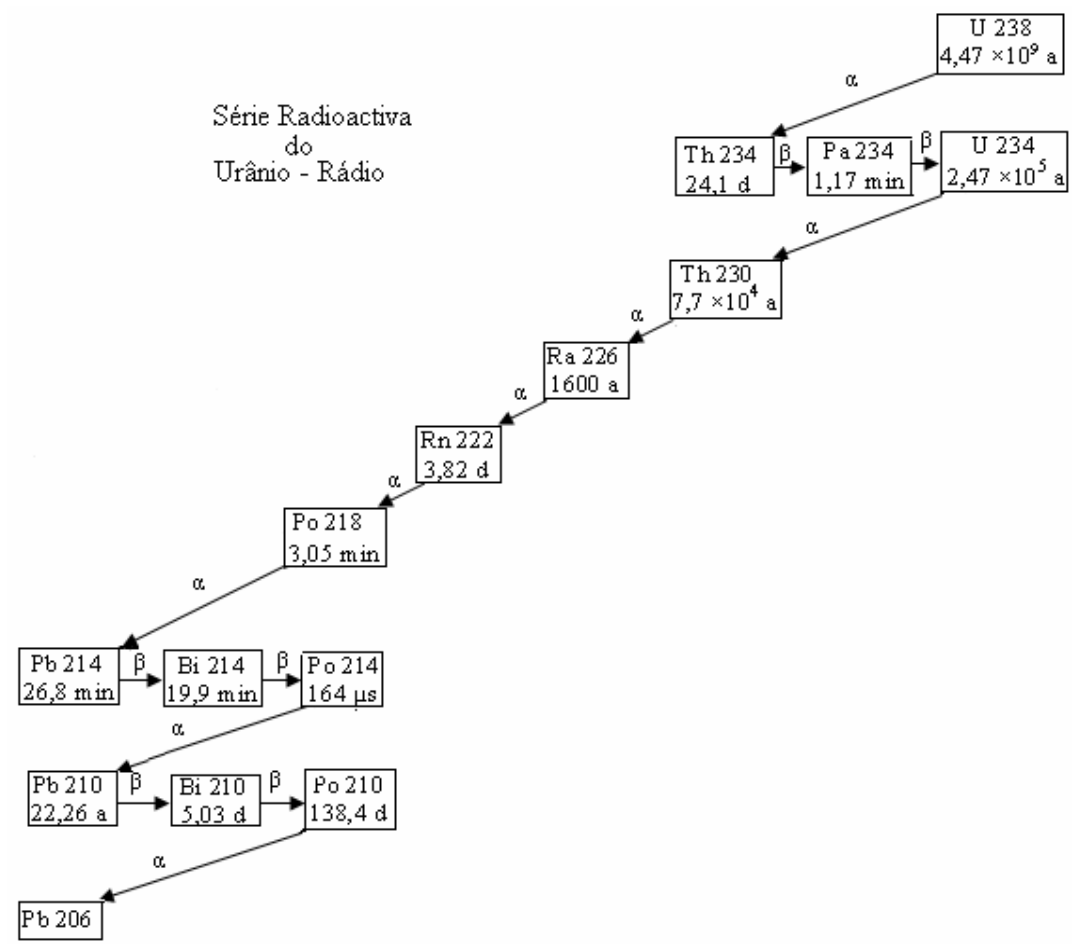

Figura 6- Série de decaimento radioativo do ${ }^{238} \mathrm{U}$.

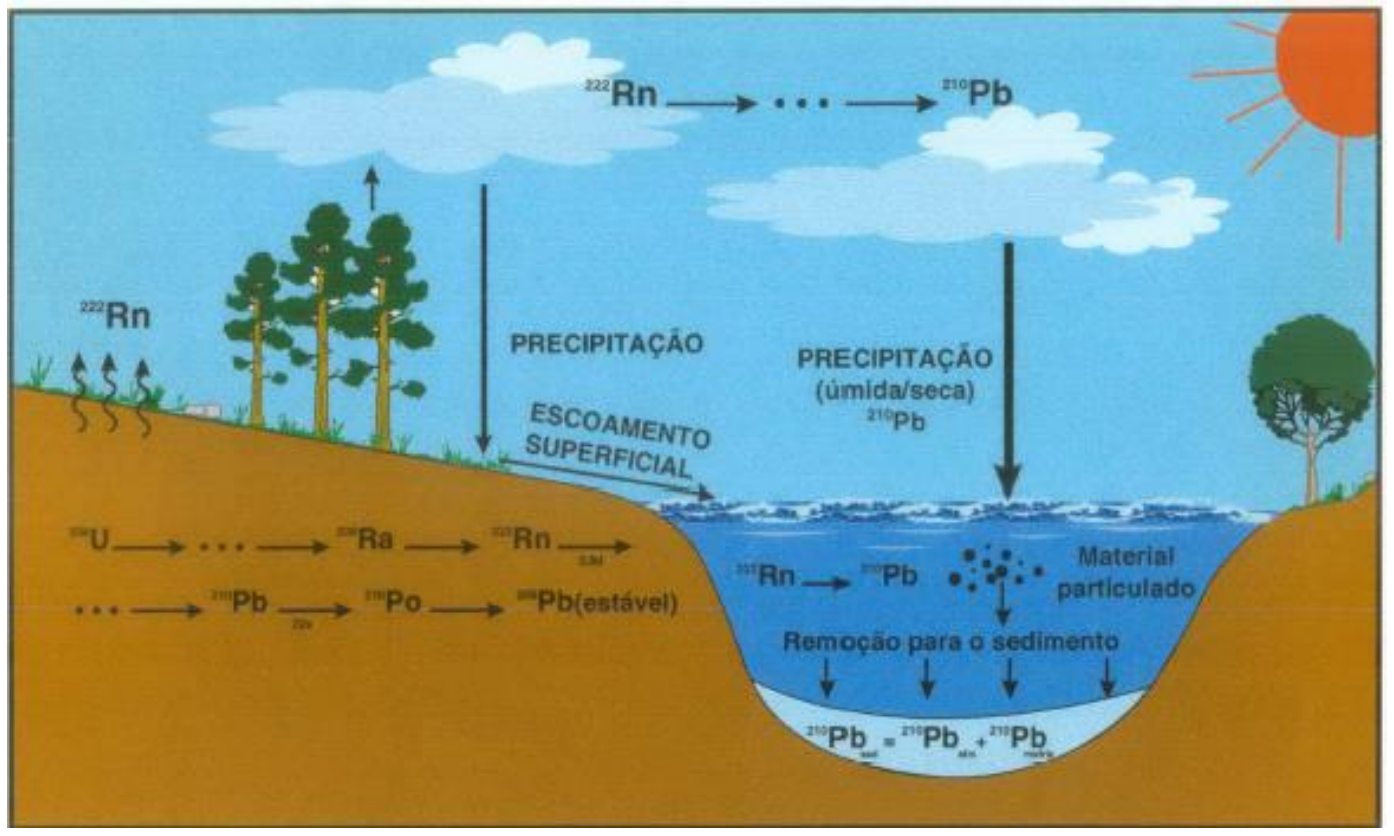

Figura 7- Dinâmica do ${ }^{210} \mathrm{~Pb}$ no meio ambiente (Lima, 1996) 
O ${ }^{210} \mathrm{~Pb}_{\text {exc }}$ é removido da atmosfera por precipitação (chuva ou neve) ou deposição seca. Esta precipitação é considerada constante por unidade de área para uma mesma região e depende de uma serie de fatores relacionados às características do solo, ventilação e índice pluviométrico. $\mathrm{O}{ }^{210} \mathrm{~Pb}_{\text {exc }}$ que se deposita nas superfícies de lagos, estuários e oceanos, é absorvido nos sedimentos, ou capturado pelo solo. (Appleby e Oldfield, 1983).

A fração de ${ }^{210} \mathrm{~Pb}_{\text {sup }}$, denominada "suportada radiologicamente", é aquela que se manteve no solo, em equilíbrio com $0{ }^{222} \mathrm{Rn}$, que não emanou para a atmosfera e está em equilíbrio com o ${ }^{226} \mathrm{Ra}$.

$\mathrm{O} \mathrm{Pb}$ total presente no sedimento tem dois componentes: é uma soma das frações de ${ }^{210} \mathrm{~Pb}$ em excesso ou não suportado radiologicamente $\left({ }^{210} \mathrm{~Pb}_{\text {exc }}\right)$ que deriva do fallout atmosférico e do ${ }^{210} \mathrm{~Pb}$ suportado radiologicamente $\left({ }^{210} \mathrm{~Pb}_{\text {sup }}\right)$ que está em equilíbrio com o ${ }^{226} \mathrm{Ra}$. Portanto,

$$
{ }^{210} \mathrm{P} b_{\text {total }}={ }^{210} \mathrm{P} b_{\text {suportado }}+{ }^{210} \mathrm{P} b_{\text {excesso }} \quad \text { Eq.(1) }
$$

A medida da atividade do ${ }^{226} \mathrm{Ra}$ representa a atividade do ${ }^{210} \mathrm{~Pb}$ radiologicamente suportado $\left({ }^{210} \mathrm{~Pb}_{\text {sup }}\right)$ pois, de acordo com o decaimento radioativo, eles estão em equilíbrio radiológico tendo portanto, a mesma atividade radioativa por unidade de massa.

Sabe-se que, com o aumento da profundidade, a concentração de ${ }^{210} \mathrm{~Pb}_{\mathrm{exc}}$ tende a zero (Smith e Walton, 1980; Joshi e Fox, 1985) (Figura 8). Quando o valor da concentração de ${ }^{210} \mathrm{~Pb}_{\text {total }}$ se torna constante com o aumento da profundidade (representa $0{ }^{210} \mathrm{~Pb}_{\text {sup }}$ ), este valor é subtraído da concentração de ${ }^{210} \mathrm{~Pb}_{\text {total }}$ das camadas acima deste ponto. Isso corrige a concentração de ${ }^{210} \mathrm{~Pb}_{\text {exc }}$, e então esse valor é usado para o cálculo da taxa de sedimentação. 


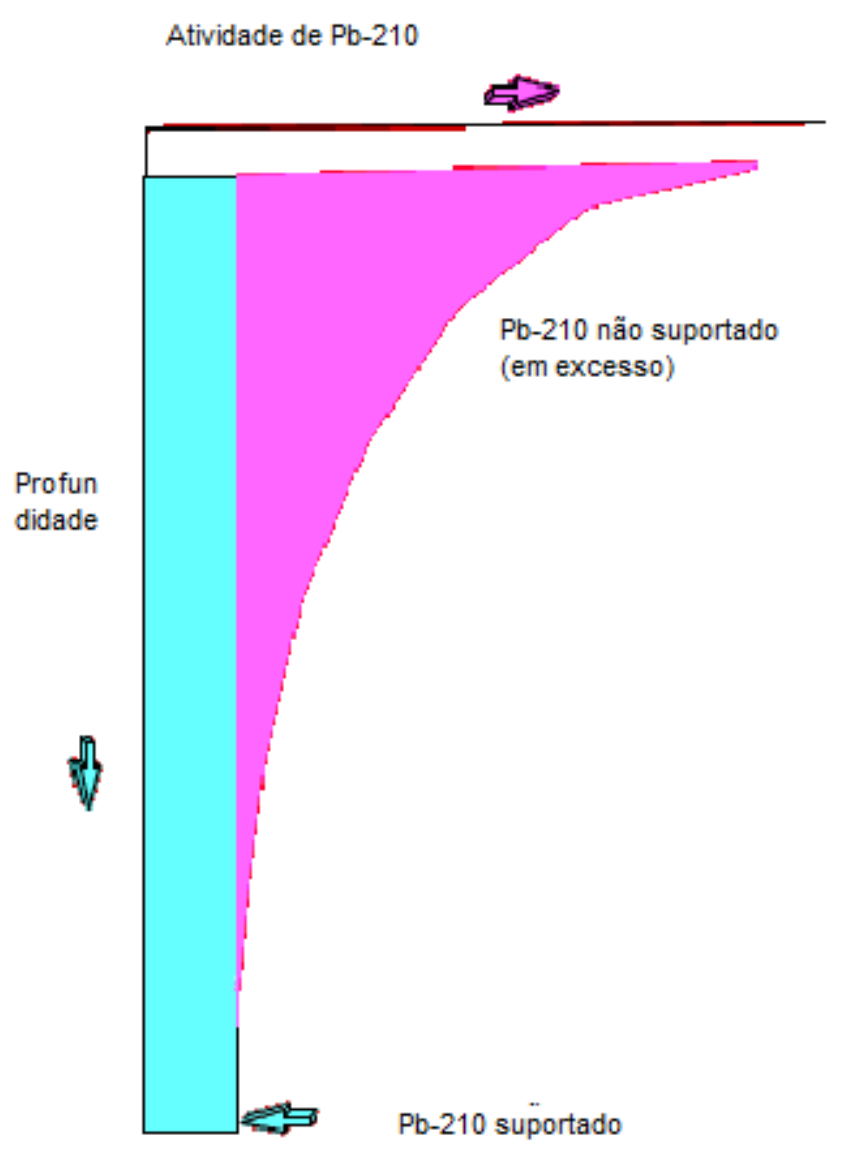

Figura 8- Curva do ${ }^{210} \mathrm{~Pb}$ com a profundidade (tempo) (Projeto SOFIA, 1997).

\section{3.}

Fluxo de ${ }^{210} \mathrm{~Pb}$

O fluxo de ${ }^{210} \mathrm{~Pb}$ em uma determinada região vai depender de uma série de fatores geográficos e metereológicos. Em um estuário as duas principais fontes de ${ }^{210} \mathrm{~Pb}$ em excesso são o fallout atmosférico resultante da emanação do ${ }^{222} \mathrm{Rn}$ e o input dos rios, trazendo material sedimentar terrígeno (de origem continental) e antropogênico. Apesar de existirem algumas pequenas variações no fallout atmosférico de ${ }^{210} \mathrm{~Pb}$, assumindo-se condições climáticas estáveis, o fluxo deposicional de ${ }^{210} \mathrm{~Pb}$ tem sido considerado constante ao longo dos anos em determinadas regiões (Appleby e Oldfield, 1992). 
O fluxo anual de ${ }^{210} \mathrm{~Pb}_{\text {exc }}(\Phi)$ no perfil é obtido através da equação:

$$
\phi=\left[\lambda_{210} \cdot \mathrm{A}(\infty)\right] \quad\left(\mathrm{mBq} \mathrm{cm} \mathrm{ano}^{-1}\right) \quad \text { Eq. }(2)
$$

Onde,

$\mathrm{A}(\infty)=$ atividade integrada total de ${ }^{210} \mathrm{~Pb}_{\mathrm{exc}}$ do perfil $\left(\mathrm{mBq} \mathrm{cm}{ }^{-2}\right)$

$\lambda_{210}=$ constante de decaimento do ${ }^{210} \mathrm{~Pb}\left(0,03114 \mathrm{ano}^{-1}\right)$

\section{4.}

\section{Modelos de Datação com ${ }^{210} \mathrm{~Pb}$}

Existem essencialmente dois modelos principais para a datação de sedimentos pela técnica com ${ }^{210} \mathrm{~Pb}$. Estes modelos são conhecidos como $\mathrm{CIC}$ (Concentração inicial constante) e CRS (Razão de suprimento constante).

\subsection{1. Modelo CIC}

No modelo denominado CIC, supõe-se que a área estudada é estável sem mudanças na taxa de sedimentação e a incorporação do ${ }^{210} \mathrm{~Pb}_{\text {exc }}$ ou não suportado aos sedimentos ocorre a um fluxo constante, portanto, a concentração inicial de ${ }^{210} \mathrm{~Pb}_{\text {exc }}\left(\mathrm{C}_{\mathrm{o}}\right)$ é constante. A concentração de ${ }^{210} \mathrm{~Pb}_{\text {exc }}(\mathrm{C})$ vai apresentar um decaimento exponencial em relação profundidade representada pela massa acumulada de sedimento. Quando se constrói o gráfico da concentração de ${ }^{210} \mathrm{~Pb}_{\text {exc }}$ em escala logarítima versus a massa acumulada, o perfil do ${ }^{210} \mathrm{~Pb}_{\text {exc }}$ vai parecer linear e a taxa de sedimentação será determinada graficamente através do coeficiente da reta observada. Nestas condições, segundo o modelo proposto por Krishnaswamy et al., (1971), a concentração de atividade do ${ }^{210} \mathrm{~Pb}_{\text {exc }}$ vai variar ao longo do perfil de acordo com a equação da lei do decaimento radioativo: 


$$
\begin{array}{ll}
C(x)=C_{0} \cdot e^{-\lambda \cdot t} & \text { Eq. (3) } \\
\text { ou } & \\
C(x)=C_{0} \cdot e^{-\lambda \cdot \frac{x}{w}} & \text { Eq. (4) }
\end{array}
$$

Onde:

$C(x)=$ concentração de atividade a uma profundidade $x$

$C_{o}=$ concentração de atividade inicial do ${ }^{210} \mathrm{~Pb}_{\text {exc }}\left(\mathrm{mBq} \mathrm{g}^{-1}\right)$

$\lambda=$ constante de decaimento do ${ }^{210} \mathrm{~Pb}\left(0,03114 \mathrm{ano}^{-1}\right)$

$X=$ profundidade expressa pela massa acumulada $\left(\mathrm{g} \mathrm{cm}^{-2}\right)$

$\mathrm{t}=$ idade da camada de sedimento a uma profundidade $\mathrm{x}$ (anos)

$W=$ taxa de sedimentação $\left(\mathrm{g} \mathrm{cm}^{-2} \mathrm{ano}^{-1}\right)$

A curva para determinação da taxa de sedimentação é obtida a partir do gráfico do logaritmo da concentração de atividade de ${ }^{210} \mathrm{~Pb}_{\text {exc }}$ versus a profundidade da camada de sedimento. A inclinação $(a)$ da reta obtida corresponde a:

$$
a=-\frac{\lambda}{w} \quad \text { Eq. }(5)
$$

Onde $w$ é a taxa de sedimentação que se deseja determinar.

A idade do sedimento pode ser calculada utilizando-se a equação (3) de modo que,

$$
t=\frac{1}{\lambda} \cdot \ln \left[\frac{C_{0}}{C(x)}\right] \quad \text { Eq. }(6)
$$




\subsection{2.}

\section{Modelo CRS}

O outro modelo utilizado para datação é o CRS. Este modelo também se baseia nas diferenças entre as atividades do ${ }^{210} \mathrm{~Pb}_{\text {total }}$ e aquela em equilíbrio secular com $\mathrm{O}^{226} \mathrm{Ra}$. O modelo CRS assume que o fallout atmosférico de ${ }^{210} \mathrm{~Pb}$ na superfície aquática é constante resultando em uma razão de suprimento ou incorporação nos sedimentos constante independente das possíveis variações nas taxas de sedimentação ao longo do tempo (Goldberg, 1963; Oldfield et al., 1978; Robbins e Edgington, 1978; Appleby e Oldfield, 1983). Normalmente o modelo CRS é aplicável em perfis não lineares e não monotônicos ao longo da profundidade onde se podem observar grandes variações nas taxas de sedimentação e erosão nos últimos 150 anos.

A atividade do ${ }^{210} \mathrm{~Pb}_{\text {exc }}$ acumulada abaixo dos sedimentos de idade $t$ vai variar ao longo do perfil de acordo com a equação:

$$
A(x)=A(\infty) \cdot e^{-\lambda \cdot t} \quad \text { Eq. }(7)
$$

Onde:

$A(\infty)=$ atividade integrada total de ${ }^{210} \mathrm{~Pb}_{\text {exc }}$ do perfil $\left(\mathrm{mBq} \mathrm{cm}^{-2}\right)$ (da superfície até a profundidade máxima a ser datada);

$A(x)=$ atividade integrada de ${ }^{210} \mathrm{~Pb}_{\mathrm{exc}}\left(\mathrm{mBq} \mathrm{cm}{ }^{-2}\right)$ abaixo da profundidade $\mathrm{x}$ $\mathrm{cm}$;

$\lambda=$ constante de decaimento do ${ }^{210} \mathrm{~Pb}\left(0,03114 \mathrm{ano}^{-1}\right)$

$\mathrm{t}$ = idade (em anos) de uma determinada camada de sedimento;

A idade de uma determinada seção para uma profundidade qualquer $(x)$ será determinada pela equação:

$$
t=\frac{1}{\lambda} \cdot \ln \left[\frac{A(\infty)}{A(x)}\right] \quad \text { Eq. }(8)
$$

A figura 9 ilustra como calcular de $A(x)$, onde $A(x)$ de cada camada (mBq $\mathrm{cm}^{-2}$ ) é estimada através da relação:

$$
A(x)=\sum m_{x} \cdot C_{210}^{2 b e x c}(x) \quad \text { Eq. }(9)
$$


Sendo,

$m_{x}=$ massa seca da camada $\mathrm{x}$, dividida pela área da seção. $\left(\mathrm{g} \mathrm{cm}^{-2}\right)$.

$C_{210 \text { Pbexc }}(\mathrm{x})=$ concentração de atividade do ${ }^{210} \mathrm{~Pb}_{\text {exc }}$ na camada $\mathrm{x}\left(\mathrm{mBq} \mathrm{g}^{-1}\right)$

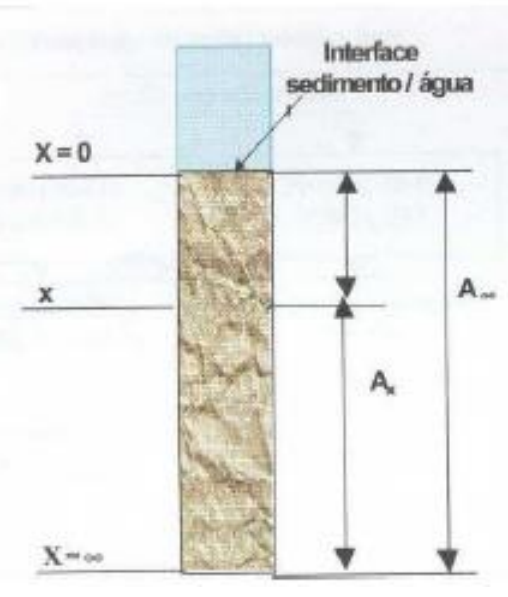

Figura 9 - Atividades de ${ }^{210} \mathrm{~Pb}$ ao longo do perfil de sedimento.

Uma vez calculadas as idades de cada camada, pode-se obter o valor da velocidade de sedimentação de cada camada (ou camada/camada) do perfil através da relação a seguir (Appleby e Oldfield, 1978):

$$
w_{x}=\lambda_{210} \cdot \frac{A(x)}{C(x)}
$$

Onde:

$W_{X}=$ velocidade ou taxa de sedimentação da camada $\times\left(\mathrm{g} \mathrm{cm}^{-2} \mathrm{ano}^{-1}\right)$, também conhecida como velocidade mássica .

Finalmente, para o cálculo da velocidade de sedimentação média de um dado perfil, faz-se uma regressão linear da idade calculada de cada camada contra a respectiva profundidade ou seção deste perfil, onde o coeficiente angular da reta obtida representa a taxa de sedimentação média $\left(\mathrm{g} \mathrm{cm}^{-2} \mathrm{ano}^{-1}\right)$ (Joshi; Shukla, 1991). A regressão linear obtida através do método dos mínimos quadrados nos dá a seguinte equação: 


$$
P=v I+b
$$

Onde:

$$
\begin{aligned}
& P=\text { profundidade da camada }\left(\mathrm{g} \mathrm{cm}^{-2} \mathrm{ano}^{-1}\right) \\
& V=\text { velocidade de sedimentação média }\left(\mathrm{g} \mathrm{cm}^{-2} \mathrm{ano}^{-1}\right) \\
& \mathrm{I}=\text { idade da camada (anos) } \\
& \mathrm{b}=\text { termo independente }
\end{aligned}
$$




\section{5 \\ Materiais e Métodos}

\section{1. Determinação dos pontos de coleta}

\subsection{1. Estudo preliminar e determinação dos pontos de coleta}

Inicialmente, foi realizado o reconhecimento da área de estudo e batimetria local, utilizando a Carta Náutica 1403 do Ministério da Marinha do Brasil.

Para complementação das informações a serem levantadas em campo foram feitas coletas de dados preliminares analógicos e digitais em fontes disponibilizadas em órgãos da administração pública como BNDO (Banco Nacional de Dados Oceanográficos), CHN (Centro de Hidrografia da Marinha), MMA (Ministério do Meio Ambiente) e CEIVAP (Comitê da Bacia Hidrográfica do Paraíba do Sul).

Alguns resultados de análise sedimentológica entre as coordenadas $21^{\circ}$ $35^{\prime} \mathrm{S}$ e $40^{\circ} 55^{\prime} \mathrm{W}$ e $21^{\circ} 40^{\circ} \mathrm{S}$ e $41^{\circ} 05^{\prime} \mathrm{W}$ foram adquiridos no Banco Nacional de Dados Oceanográficos (BNDO).

A partir destes resultados foram estudados os pontos mais prováveis de se encontrar sedimentos compostos por lama. Dentro desta área demarcada, foram encontradas 116 amostras de sedimentos. Selecionou-se, como referência, as coordenadas das amostras que tinham lama e silte em sua composição, para posterior orientação dos pontos de coleta. Apesar de observar alguns pontos com esta composição, a maioria das amostras obtidas no BNDO encontrava-se muito afastadas dos locais de interesse para o estudo. Sendo assim, surgiu uma nova alternativa utilizando as imagens do Google Earth, onde se pode visualizar por satélite, a costa e o delta do RPS permitindo observar os pontos mais adequados para a coleta do material a ser estudado.

Pelas imagens através do Google Earth e os estudos preliminares para a coleta, foi decidido marcar quatro transetes a partir do ponto central da 
desembocadura do RPS, sendo o primeiro na direção da saída do rio, um ao norte e outros dois ao sul. Foram marcados quatro pontos com intervalos de 1 $\mathrm{km}$ em cada transete, o que significa que as amostras encontram-se entre a frente deltaica e o prodelta.

Foram feitas duas campanhas de coleta. A primeira foi realizada em 19/01/2010 e a segunda campanha em 14/02/2011 (Figura 10).

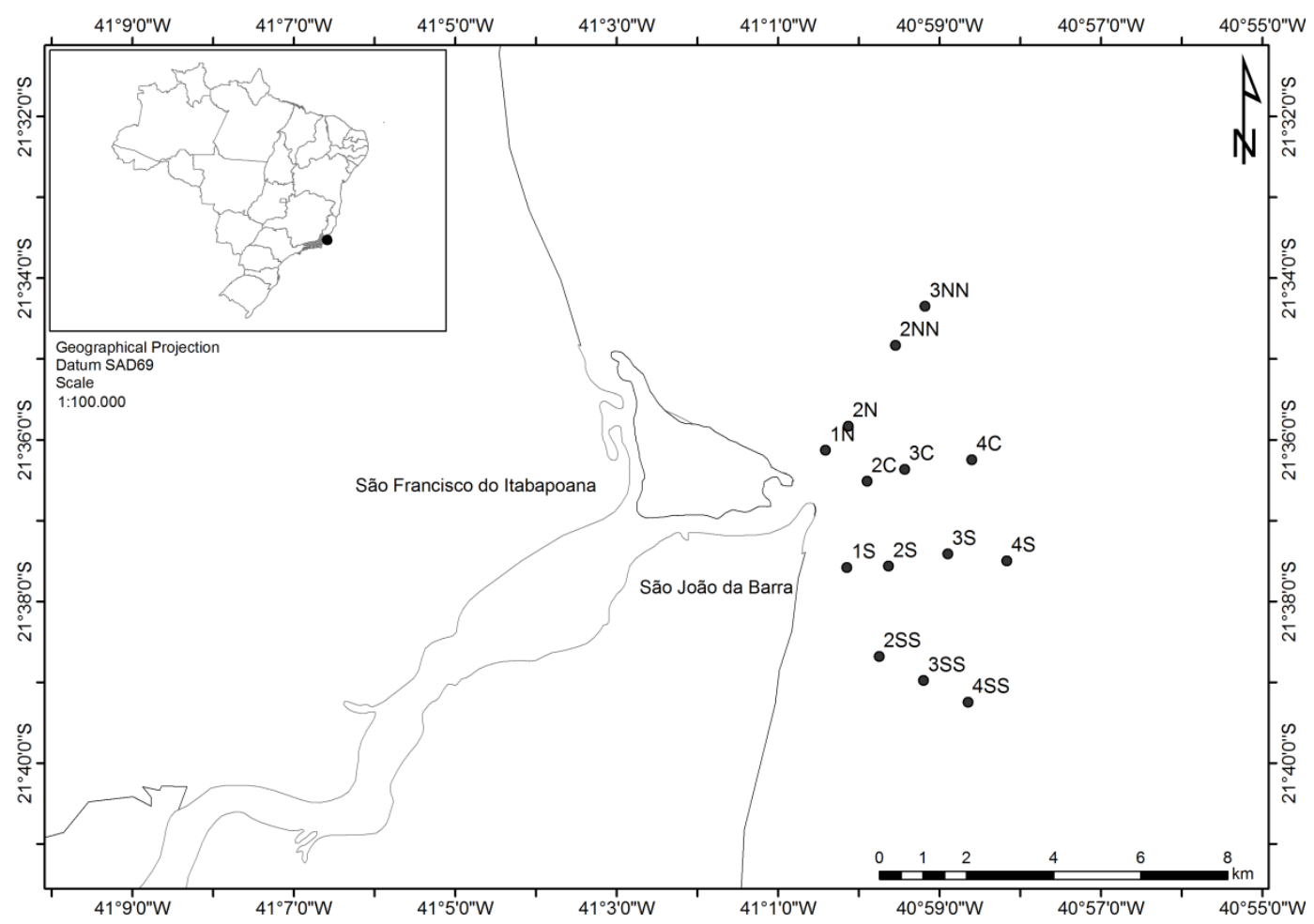

Figura 10- Localização dos pontos de coleta (1 $1^{\mathrm{a}}$ campanha em janeiro de 2010 e a segunda em fevereiro 2011).

\subsection{2.}

\section{Metodologia de coleta das amostras de sedimento}

A definição de técnicas e equipamentos depende muito conhecimento das características gerais do ambiente a ser investigado, tais como a dimensão, profundidade, tipo de sedimento, entre outras. É necessário, também, avaliar as embarcações e a infraestrutura disponível a bordo, tais como local para estocagem das amostras, disponibilidade e tipo de guincho.

Uma vez determinados os locais apropriados para melhor aproveitamento do estudo, a coleta dos sedimentos foi feita usando um corer UWITEC, ideal para coluna sedimentar de até 3 metros de profundidade. O corer UWITEC 
permite a coleta simultânea de três perfis de sedimento. Esse equipamento tem ainda, um dispositivo próprio para seccionar a coluna de sedimento em intervalos de centímetro em centímetro (Figuras 11 e 12).
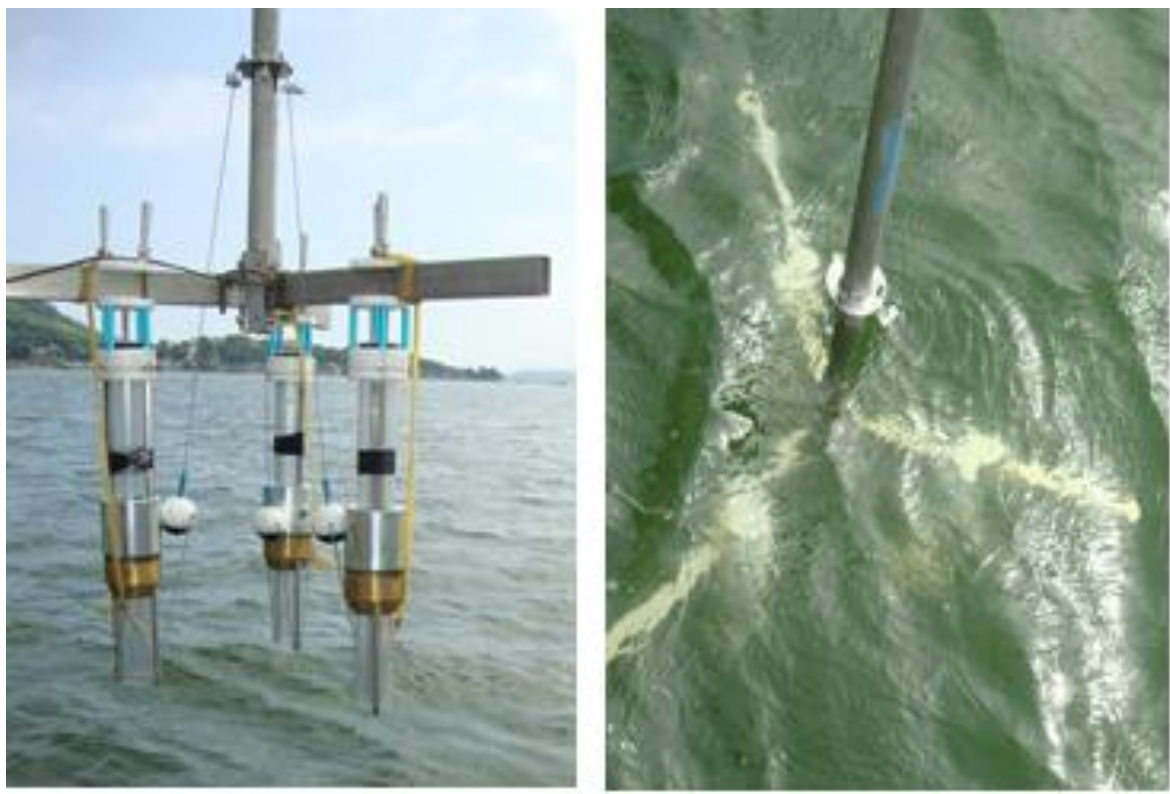

Figura 11- Corer UWITEC
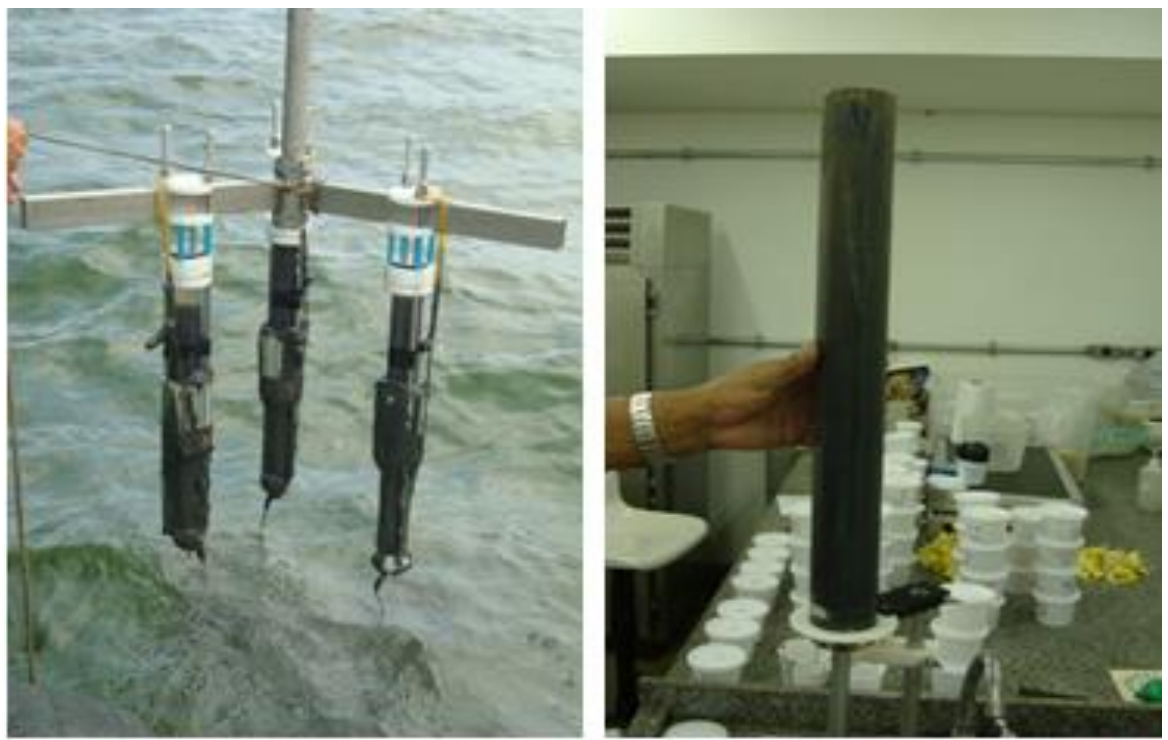

Figura 12- Perfil de sedimento coletado 


\subsection{3.}

\section{Tratamento das amostras}

Cada testemunho coletado foi armazenado no barco de coleta, em caixas com grades de apoio vertical para que as camadas não se misturassem. Quando em terra, foram levados imediatamente para o laboratório da UENF, em Campos. No laboratório, cada perfil foi seccionado em amostras de $1 \mathrm{~cm}$ e estas, armazenadas em potes plásticos pré-pesados para serem levadas para análise nos laboratórios do IRD, no Rio de Janeiro (Figura 13). Ainda no laboratório da UENF, foi retirada uma alíquota de cada amostra de aproximadamente $2 \mathrm{~g}$ para a análise granulométrica.

Tendo chegado ao laboratório do IRD, cada amostra foi seca a $70^{\circ} \mathrm{C}$ em estufa com ar circulante até massa constante, para posterior cálculo do teor de umidade.

Após a secagem, todas as amostras de cada testemunho foram homogeneizadas pelo processo de trituração em moinho e posterior peneiramento.
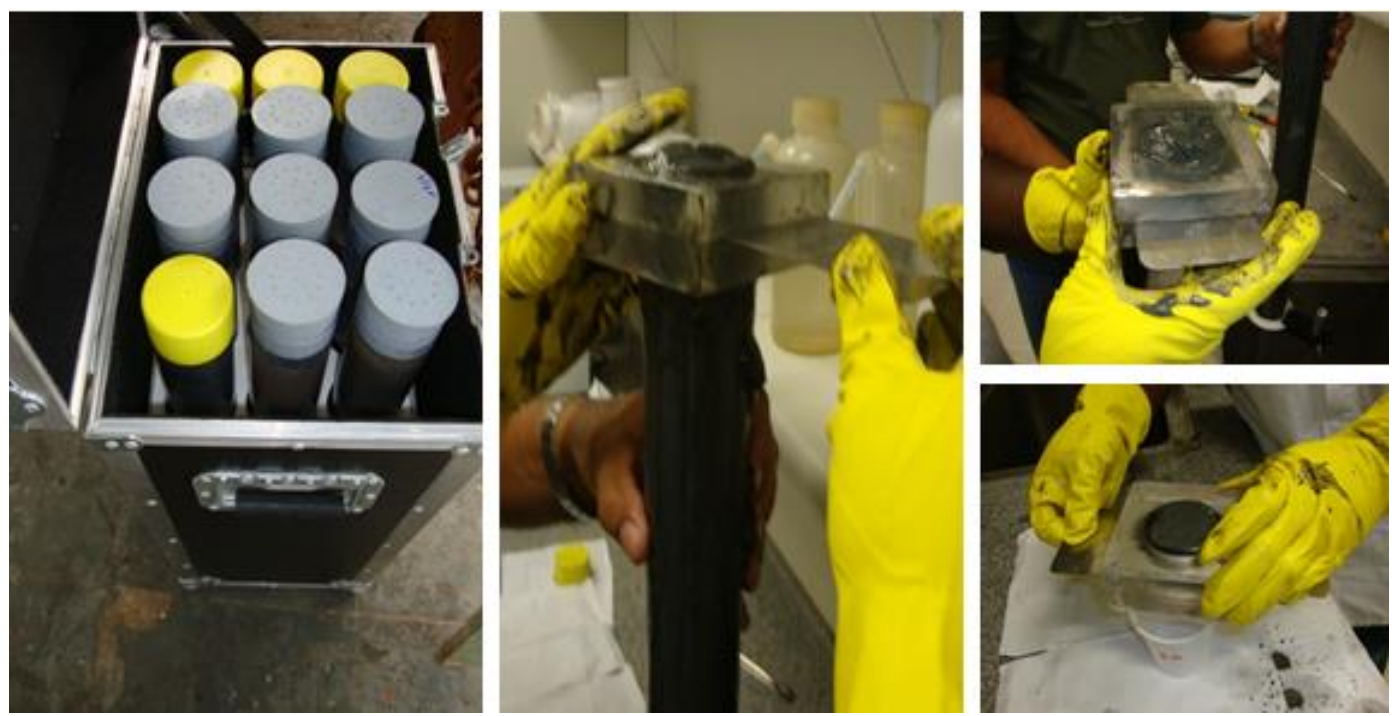

Figura 13-Armazenamento e cortes dos testemunhos. 


\section{2.}

\section{Análise granulométrica}

A granulometria dos sedimentos é importante para compreendermos a hidrodinâmica dos ecossistemas aquáticos, principalmente, quando o transporte do material é fortemente influenciado pelas variações hidrológicas de um rio.

A caracterização do sedimento é muito útil quando se quer conhecer a origem e os processos a que estes ambientes estiveram submetidos em um passado recente, por volta de cem anos, ou mais antigo como milhares de anos (Hedges et al., 1986). O "scavenging" das substâncias na coluna d'água é mais fácil em partículas finas (menores), em geral silte e argilas, pois tem uma área maior de superfície por unidade de massa, em relação às partículas maiores, como as areias. Devido a esta característica, é tão importante o conhecimento da granulometria do material.

A granulometria foi realizada através do analisador de partícula por difração a laser, modelo Shimadzu SALD-3101 nos laboratórios Universidade Estadual Norte Fluminense Darcy Ribeiro, UENF. A técnica foi aplicada após a separação da fração do material maior do que $2 \mathrm{~mm}$ por peneiramento. As frações mais finas foram então determinadas por difração a laser e classificadas segundo a escala Wentworth (Sugio, 1973).

A análise do material de referência (JISS, Licopodium and Glassbeads) foi realizada e o coeficiente de variação observado foi menor do que $10 \%$ para cada fração com erro de aproximadamente $3 \%$.

\section{3. \\ Método Analítico utilizado nas amostras para determinação do ${ }^{210} \mathrm{~Pb}$ e cálculo das taxas de sedimentação}

O método analítico utilizado foi o da lixiviação do ${ }^{210} \mathrm{~Pb}$ com $\mathrm{HBr} 0,5 \mathrm{~mol} \mathrm{~L}^{-1}$ (Wanderley, 1995) representado no fluxograma e na Figura 15.

O uso do $\mathrm{HBr} 0,5 \mathrm{~mol} \mathrm{~L}-1$, torna o $\mathrm{pH}$ adequado a lixiviação do ${ }^{210} \mathrm{~Pb}_{\text {total }} \mathrm{e}$, permite uma separação mais seletiva deste, usando a troca iônica (Wanderley, 1995; Godoy et al. , 1998).

No condicionamento da amostra em meio de $\mathrm{HBr} 0,5 \mathrm{~mol} \mathrm{~L}^{-1}$, considerando o elemento $\mathrm{Pb}$ em sua forma iônica mais comum, $\mathrm{Pb}^{2+}$, há a formação de bromo- 
complexos aniônicos solúveis, do tipo $\mathrm{PbBr}^{3-}$, com o íons $\mathrm{Br}^{-}$. Esta é uma propriedade que poucos íons apresentam, o que faz com que, em meio de brometos, o íon $\mathrm{Pb}^{2+}$ seja retido em resina aniônica forte tipo Dowex $1 \times 8$, separando-o de uma série de elementos, principalmente, Cs, U, Th, Ba, Ra, Po, que são interferentes na analise radiométrica e $\mathrm{Al}$ e $\mathrm{Fe}$, que são macroconstituintes das amostras de sedimentos e, por isso, desejável a sua separação.

A adição de carreadores de $\mathrm{Pb}$ tem objetivo de aumentar e quantificar a recuperação do ${ }^{210} \mathrm{~Pb}$.

A hidroxilamina hidroclorada é adicionada à solução, pois, de acordo com Benoit and Hemond, ${ }^{210} \mathrm{~Pb}$ e ${ }^{210} \mathrm{Po}$ podem estar presentes em sedimentos associados com óxidos de $\mathrm{Mn}$ e $\mathrm{Fe}$, sendo estes, complexados a ela nesta etapa. Os elementos interferentes são, em sua maioria, eliminados na etapa de retenção da resina ( $\mathrm{Fe}, \mathrm{Al}, \mathrm{Ca}, \mathrm{Ba})$, e outros, na etapa de eluição do chumbo, feita com $\mathrm{HNO}_{3}$.

$\mathrm{O} \mathrm{Pb}$ presente no eluente é precipitado como cromato de chumbo e o ${ }^{210} \mathrm{~Pb}_{\text {total }}$ é determinado através de seu produto de decaimento o ${ }^{210} \mathrm{Bi}$, que emite radiação beta com 1,16 MeV de energia e apresenta uma meia-vida de 5,01 dias (Joshi e Ku, 1979; Blais e Marshall, 1988; Pacer, 1983; Amaral et al., 1988; Nevissi, 1991; Hataye et al., 1991; Moreira, 1993; Momoshima et al., 1994). A atividade do ${ }^{210} \mathrm{~Pb}_{\text {exc }}$ ou não suportado radiologicamente, que será usada na datação, é obtida pela diferença entre as concentrações de ${ }^{210} \mathrm{~Pb}_{\text {total }}$ e 0 ${ }^{210} \mathrm{~Pb}_{\text {suportado }}$.

A determinação de ${ }^{226} \mathrm{Ra}$ e ${ }^{210} \mathrm{~Pb}$ em amostras ambientais como sedimentos aquáticos, onde teores destes radionuclídeos são bastante baixos, exigem, principalmente, a utilização de equipamentos de contagem beta muito baixa (inferiores a 0,5 contagens por minuto ou $10 \mathrm{mBq}$ ) (Mozeto,2006). A determinação de chumbo via ${ }^{210} \mathrm{Bi}$ tem a vantagem de ser rápida e a partícula beta facilmente detectada. A desvantagem é que a radiação de fundo para o detector beta é maior do que para o detector alfa, tomando o limite de detecção mais alto (Holtzman, 1987). 


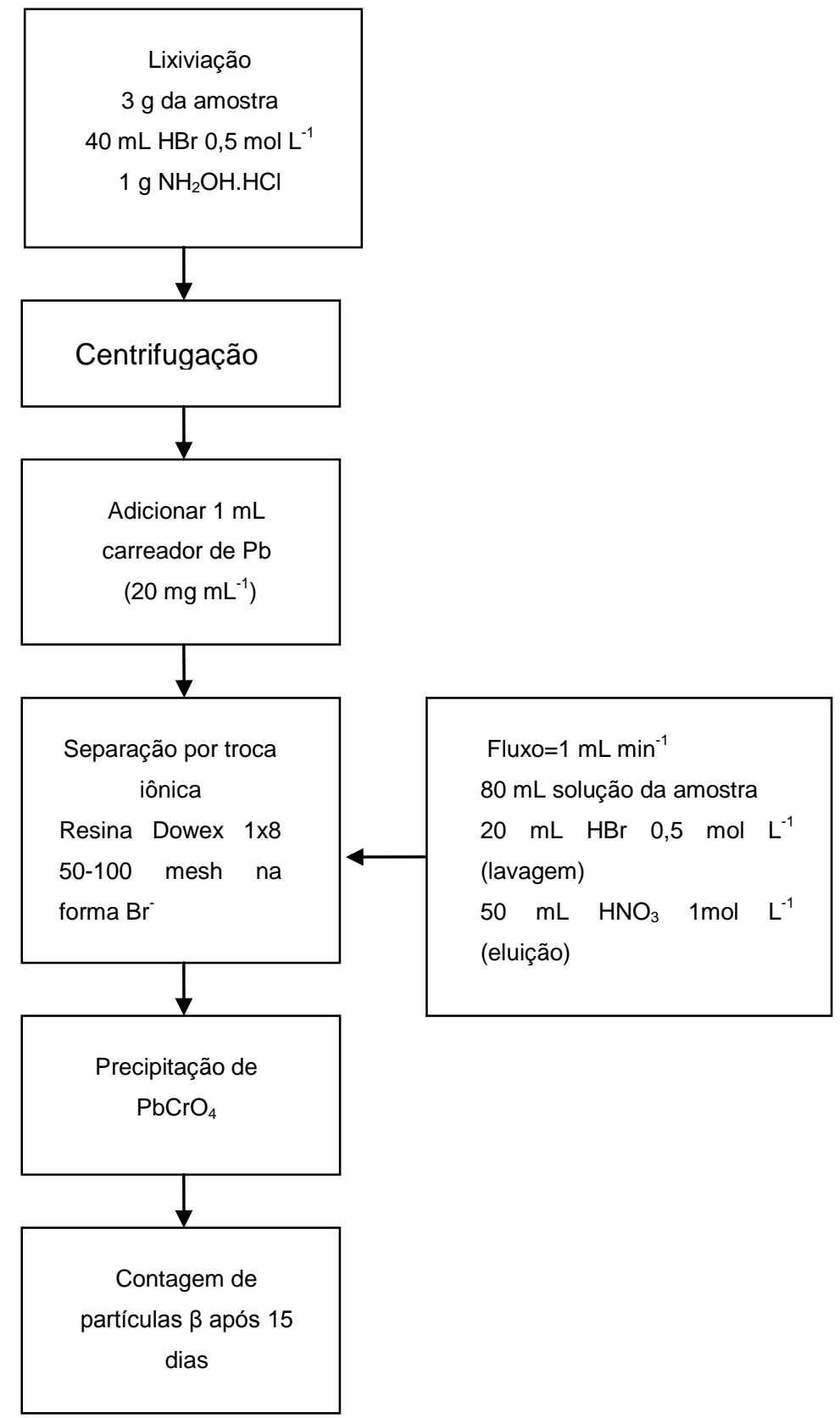

Figura 14- Fluxograma do método analítico utilizado. 


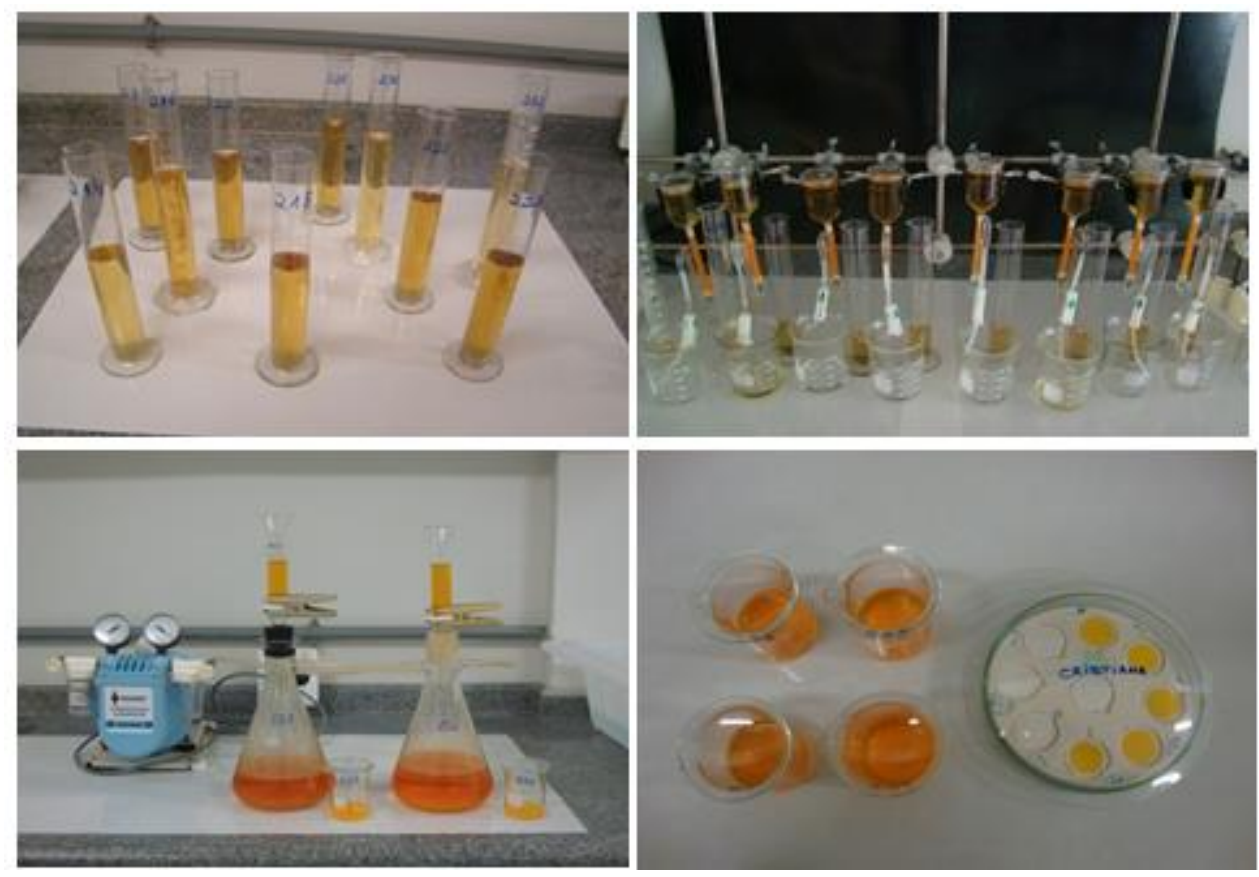

Figura 15- Método analítico. - Solução lixiviada, separação por troca iônica, filtração do precipitado de $\mathrm{PbCrO}_{4}$, preparação para contagem $\beta$.

\section{4 . \\ Metodologia de abertura das amostras para determinação de elementos pela técnica de ICP-MS}

A metodologia para a digestão das amostras de sedimentos foi aplicada de acordo com Godoy et al. (2004). Foi feita uma digestão ácida das amostras a partir de $250 \mathrm{mg}$ de sedimento, com $\mathrm{HNO}_{3}(10 \mathrm{~mL}), \mathrm{HF}(2 \mathrm{~mL})$ e $\mathrm{HClO}_{4}(0,4 \mathrm{~mL})$ em bombona de teflon a quente $\left(250^{\circ} \mathrm{C}\right)$. Após a digestão do material a solução foi levada à secura e então, retomada com $40 \mathrm{~mL}$ de $\mathrm{HNO}_{3} 2 \%$. A solução resultante foi diluída na proporção de 0,5:10 para a determinação dos elementos por ICP-MS no equipamento Perkin-Elmer ELAN 6000.

A amostra de referência de solo NIST SRM 2709 foi analisada a fim de verificar o procedimento analítico.

\subsection{1.}

\section{Análise pela técnica de ICP-MS}

A técnica de espectrometria de massas com plasma indutivamente acoplado, ICP-MS, é muito utilizada para a determinação de elementos em nível de traços e para análises isotópicas. Seu elevado desempenho está relacionado 
à capacidade analítica multielementar associada à sua alta sensibilidade e limites de detecção bem baixos, na ordem de $\mu \mathrm{g} \mathrm{L}^{-1}$.

$\mathrm{Na}$ análise por espectrometria de massa com plasma indutivamente acoplado, as soluções das amostras são introduzidas no plasma de argônio através de um nebulizador e os íons formados no plasma são extraídos através de uma interface.

A interface geralmente consiste em dois cones metálicos, o amostrador e o skimmer. Cada cone possui um pequeno orifício (aproximadamente $1 \mathrm{~mm}$ ) para a passagem dos íons para o analisador de massas (quadrupolo).

Uma vez introduzidos no analisador de massas, são selecionados de acordo com sua razão massa/carga $(\mathrm{m} / \mathrm{z})$ e detectados por um multiplicador de elétrons (Skoog et al., 2006).

O equipamento utilizado para as análises foi o espectrômetro de massa com plasma indutivamente acoplado ICP-MS SCIEX ELAN 6000, da PerkinElmer, equipado com um nebulizador "cross flow" e uma câmara de spray padrão de Ryton. A Tabela 1 descreve as condições de operação do equipamento para a realização das análises.

O modo de análise semi-quantitativa é uma aplicação da análise por ICPMS que possibilita a determinação simultânea de aproximadamente 80 elementos em uma amostra desconhecida. Este método tem sido aplicado em amostras de diferentes naturezas como biológicas, ambientais, industriais, alimentícias e outras.

Os softwares de análise de ICP-MS semi-quantitativa permitem a rápida aquisição de dados analíticos, corrigindo automaticamente interferências isobáricas, moleculares e poliatômicas. Este tipo de análise está baseado numa curva de sensibilidade para todos os elementos (definida como íons por segundo por unidade de concentração). O número de íons por segundo é convertido em concentração do elemento na amostra através de uma curva de calibração obtida analisando-se padrões de concentrações conhecidas.

A curva de calibração foi obtida através de uma solução padrão multielemntar, contendo elementos distribuídos através do intervalo de variação de massa a ser analisada, a fim de se obter maior exatidão da análise. 
A solução multielementar de $20 \mu \mathrm{g} \mathrm{L}^{-1}$ foi preparada a partir dos padrões de calibração 2, 3 e 5 (10 mg L'-1 e $\mathrm{HNO}_{3}$ 2\%) da Perkin-Elmer e para $\mathrm{Na}, \mathrm{Mg}, \mathrm{Al}$, $\mathrm{K}, \mathrm{Ca}$, Ti e Fe , $100 \mu \mathrm{g} \mathrm{L}^{-1}$ foram utilizados e padrões mono-elementares (10 mg $\mathrm{L}^{-1}$ e $\mathrm{HNO}_{3} 2 \%$ ) também da Perkin-Elmer, totalizando 50 elementos.

A técnica do padrão interno é utilizada a fim de corrigir interferências devido à instabilidade eletrônica do instrumento, mudanças nas taxas de aspiração e nebulização e efeitos de matriz, melhorando a repetitividade e exatidão das análises. Os elementos In e TI foram utilizados como padrões internos, de modo que suas concentrações finais nos padrões, nas amostras e nos brancos fossem de $20 \mu \mathrm{L} \mathrm{L}^{-1}$ (Godoy, 2001).

Tabela 1 - Condições de operação do ICP-MS ELAN 6000

\begin{tabular}{lc}
\hline \multicolumn{2}{c}{ Condições do Plasma } \\
\hline Potência da radiofrequência & $1050 \mathrm{~W}$ \\
Vazão de argônio para o plasma & $17 \mathrm{~L} \mathrm{~min}^{-1}$ \\
Vazão de argônio auxiliar & $1,2 \mathrm{~L} \mathrm{~min}^{-1}$ \\
Vazão de argônio para o nebulizador & $0,9-1,2 \mathrm{~L} \mathrm{~min}^{-1}$ \\
Taxa de aspiração da amostra & $1,0 \mathrm{~mL} \mathrm{~min}^{-1}$ \\
\hline \multicolumn{2}{c}{ Parâmetros de Medida } \\
\hline Modo de varredura & "Peak hopping" \\
Varredura da lente & Habilitada \\
Modo de detecção & Pulso e Analógico \\
Tempo de permanência & 50 ms \\
Número de varreduras por leitura & 6 \\
Número de leituras por réplica & 1 \\
Número de réplicas & 1 \\
\hline
\end{tabular}




\section{5. \\ Determinação do teor de carbonatos}

O carbonato de cálcio $\left(\mathrm{CaCO}_{3}\right)$ em geral, ocorre na natureza como calcita, sendo a forma mais comum, e como aragonita. Estas duas formas diferem, entre si, por seus arranjos cristalinos.

A calcita ocorre, mais freqüentemente, como calcário, dolomita (carbonato misto de cálcio e magnésio [ $\left.\mathrm{Ca} \mathrm{Mg}\left(\mathrm{CO}_{3}\right)_{2}\right]$ ) e mármore (toda rocha constituída de carbonato de cálcio e possível de ser polida é denominada de mármore). Tanto o mármore, como o calcário, caracterizam-se por apresentar baixa dureza e por reagirem, efervescendo, com ácidos.

$\mathrm{O}$ carbonato em presença do íon $\mathrm{H}^{+}$se decompõe, formando $0 \mathrm{CO}_{2}$, produzindo a reação de efervescência. $O$ carbonato de cálcio em presença de um ácido reage segundo a equação abaixo:

$$
\mathrm{Ca} \mathrm{CO}_{3}(\mathrm{~s})+2 \mathrm{H}^{+}(\mathrm{aq}) \rightarrow \mathrm{Ca}^{2+}(\mathrm{aq})+\mathrm{H}_{2} \mathrm{O}(\mathrm{l})+\mathrm{CO}_{2}(\mathrm{~g})
$$

A relação entre a deposição de sedimentos terrígenos e carbonáticos controla a distribuição dos sedimentos em uma determinada área de estudo. Quanto maior o aporte fluvial, menor a concentração de carbonatos nestes sedimentos. A contribuição terrígena, caracterizada por sedimentos ricos em silte e argila e pobres em carbonatos, é observada, em geral, na plataforma interna onde o input dos rios é dominante. Particularmente, no RPS, os sedimentos atingem a plataforma continental externa com fluxo médio de entrada de sedimentos no mar entre 1,0 a 2,0 x $10^{6} \mathrm{t} \mathrm{ano}^{-1}$ (Lacerda et al., 2004).

A determinação de carbonatos foi feita através de adições sucessivas de $1 \mathrm{ml}$ de ácido nítrico $1 \mathrm{~mol}$ L-1 a $1 \mathrm{~g}$ de sedimento previamente seco. Após cada adição, a amostra foi seca em estufa com ar circulante a $60 \circ \mathrm{C}$ e repesada a temperatura ambiente. $\mathrm{O}$ procedimento foi repetido até a obtenção de peso constante da amostra, onde supostamente todo o carbonato teria sido eliminado.

O teor de carbonato foi estimado através da diferença entre o peso inicial e o peso final da amostra segundo a relação:

$$
\% \text { carbonatos }=\frac{M_{1}-M_{2}}{M_{1}} \times 100 \quad \text { Eq.(12) }
$$


Onde:

$M_{1}=$ massa inicial da amostra,

$M_{2}=$ massa da amostra após a eliminação dos carbonatos.

\section{6.}

\section{Análise multivariada de dados}

A análise multivariada de dados é uma ferramenta estatística que apresenta uma visão mais global do fenômeno do que a abordagem univariada. A denominação "Análise Multivariada" corresponde a um grande número de métodos e técnicas que utilizam simultaneamente várias variáveis na interpretação teórica do conjunto de dados obtidos.

Existem vários métodos de análise multivariada com finalidades bem diversas entre si. Quando o interesse é verificar como as amostras se relacionam, ou seja, o quanto estas são semelhantes segundo as variáveis utilizadas no trabalho, dois métodos podem ser utilizados: a análise por agrupamento hierárquico e a análise de fatores principais.

A análise de fatores principais é uma técnica estatística poderosa que pode ser utilizada para redução do número de variáveis e para fornecer uma visão estatisticamente privilegiada do conjunto de dados. Este tipo de análise fornece as ferramentas adequadas para identificar as variáveis mais importantes no espaço dos componentes principais.

A utilização da análise multivariada de dados através da análise de fatores principais permite a identificação da composição dos sedimentos determinando as fases minerais presentes na amostra possibilitando um entendimento da situação real na região em estudo.

Todas as análises de fatores principais foram realizadas com auxílio do programa SPSS versão 17.0 e as análises hierárquicas de agrupamentos (cluster) foram realizadas através do programa Statistica e do SPSS 17.0.. 


\subsection{1.}

\section{Análise de fatores principais (AFP)}

A análise fatorial aborda a estrutura das correlações entre um grande número de variáveis, definindo um conjunto de dimensões comuns, chamadas de fatores. Com a análise fatorial, se pode identificar as dimensões separadas da estrutura e então determinar o grau em que cada variável é explicada por cada dimensão.

Uma vez que essas dimensões e a explicação de cada variável estejam determinadas, os dois principais usos da análise fatorial - resumo e redução de dados - podem ser conseguidos.

Ao resumir os dados, a análise fatorial obtém dimensões (fatores) que quando interpretadas e compreendidas, descrevem os dados em um número muito menor de conceitos do que as variáveis individuais originais (Hair, 2009; Godoy, 2001).

Os fatores principais são, então, as novas variáveis que foram constituídas a partir da correlação entre as variáveis originais. Cada fator principal agrupa variáveis que possuem maior correlação. As variáveis que possuem a mesma variabilidade no tempo indicam que são provenientes da mesma fase, mesmo processo de formação ou transporte.

$\mathrm{Na}$ análise de fatores principais a identificação dos fatores indica qualitativamente a composição das fases que contribuem na composição da amostra descrevendo a região.

O planejamento de uma análise fatorial envolve três decisões importantes:

1- cálculo dos dados de entrada (no caso uma matriz de correlação) para atender os objetivos especificados de agrupamento de variáveis a partir da validação da base de dados;

2- o planejamento de estudo em termos do número de variáveis;

3- o tamanho necessário para a amostra em termos absolutos e como função do número de variáveis envolvidas na análise.

No que se refere ao tamanho da amostra, uma análise fatorial é dificilmente realizada com uma amostra com menos de 50 observações e, de 
preferência, o tamanho da amostra deve ser maior ou igual a 100. Ainda segundo Hair (2009), como regra geral, o mínimo é ter pelo menos cinco vezes mais observações (casos) do que o número de variáveis a serem analisadas. É importante que haja um numero mínimo de amostras baseado nos graus de liberdade da base de dados a fim de se obter resultados confiáveis. Esse número pode ser calculado segundo Henry et al. (1984), pela equação:

$$
N>30+\left[\left(\frac{P+3}{2}\right)\right]
$$

Onde,

$\mathrm{N}=$ número de amostras,

$\mathrm{P}=$ numero de variáveis

\subsection{2.}

\section{Análise Hierárquica de Cluster}

A análise hierárquica de cluster $(\mathrm{AHC})$ é utilizada a fim de identificar grupos de objetos com propriedades semelhantes dentro de um grande conjunto de dados. Sendo assim, a AHC classifica as variáveis (elementos químicos) e as amostras de sedimentos de acordo com a similaridade da composição química (distância entre elas).

$\mathrm{Na} \mathrm{AHC}$, inicialmente cada amostra é tratada individualmente e, então, a matriz de similaridade é analisada; em cada passo se diminui uma dimensão da matriz e as amostras são reunidas em grupos. O processo é repetido até que todas as amostras se reúnam em um único grupo de acordo com o grau de similaridade.

O resultado dessa análise é expresso na forma de dendogramas, que são gráficos de fácil visualização e interpretação de resultados.

O método de agrupamento utilizado foi o método Ward (método da variância mínima). O método Ward incorpora um objeto a um grupo se essa união proporcionar a menor variância no sistema. 


\section{6 \\ Resultados e Discussões}

\section{1.}

\section{Granulometria}

A análise granulométrica consiste na determinação das dimensões das partículas que constituem as amostras. A composição do sedimento em termos granulométricos pode ser divida em cascalhos, areia, silte e argila (argilominerais).

Cascalhos, areias e silte são constituídos de minerais resistentes ao intemperismo (como o quartzo, a turmalina e a ilmenita), minerais parcialmente intemperizados (como feldspatos $(K)$, micas e ferrosos como a hematita) e fragmentos de rocha.

A fração da argila é formada praticamente de argilominerais, mas é importante notar que todo argilo-mineral é uma argila, mas nem toda a argila é um argilo-mineral. Os argilo-minerais são os principais constituintes do solo e são formados basicamente por camadas de sílica $\left(\mathrm{SiO}_{2}\right)$, hidróxido de alumínio $\left(\mathrm{Al}_{2}(\mathrm{OH})_{3}\right)$ e silicatos hidratados de alumínio $\left(\mathrm{Al}_{4}\left[\mathrm{Si}_{4} \mathrm{O}_{10}\right](\mathrm{OH})_{8}\right)$.

Segundo a escala de Wentworth, argilas são as partículas cuja dimensão é inferior a 1/256 $\mathrm{mm}(0,0039 \mathrm{~mm})$, silte corresponde ao conjunto de partículas cujas dimensões se encontram entre esta dimensão e 1/16 mm (0,0625 mm), as partículas de areia têm entre $1 / 16 \mathrm{~mm}$ e $1 \mathrm{~mm}$, os grânulos variam entre 1 e 4 $\mathrm{mm}$, os seixos entre 4 e $64 \mathrm{~mm}$, e os blocos têm mais de $64 \mathrm{~mm}$.

O domínio de partículas finas (silte e argila) está associado a uma maior área superficial do sedimento, permitindo um acúmulo de matéria orgânica. Percentagens mais altas de partículas finas no sedimento são comumente encontradas em sedimentos com altas concentrações de carbono orgânico e que pode ser associado ao acúmulo de detritos advindos de fontes antrópicas (Porto Filho, 1996). 
Sedimentos predominantemente arenosos caracterizam-se por apresentarem reduzida concentração de carbono orgânico, ao contrário de partículas finas compostas por argila e silte, que apresentam maior teor de carbono orgânico e, consequentemente, maior a tendência de adsorção de compostos orgânicos hidrofóbicos e de metais (Muniz, 2003).

Como exemplificado através dos perfis $2 \mathrm{C}$ e 2S, figuras 16 e 17, respectivamente, a percentagem de finos (silte + argila) é bastante constante ao longo do perfil, situando-se na faixa de $90 \%$. Pode se observar que apenas nas camadas da base dos perfis este percentual decresce para algo na faixa de $75 \%$.

A tabela 7 encontrada no capítulo 9 descreve a porcentagem da fração de finos $(<63 \mu)$ encontrada ao longo de cada perfil coletado.

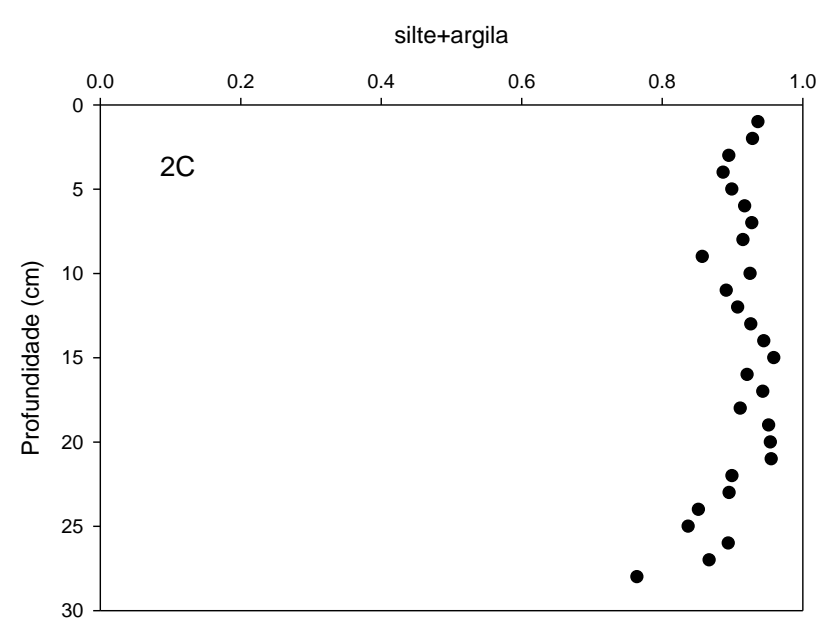

Figura 16 - Porcentagem da fração de silte + argila ao longo da profundidade para o prefil 2C. 


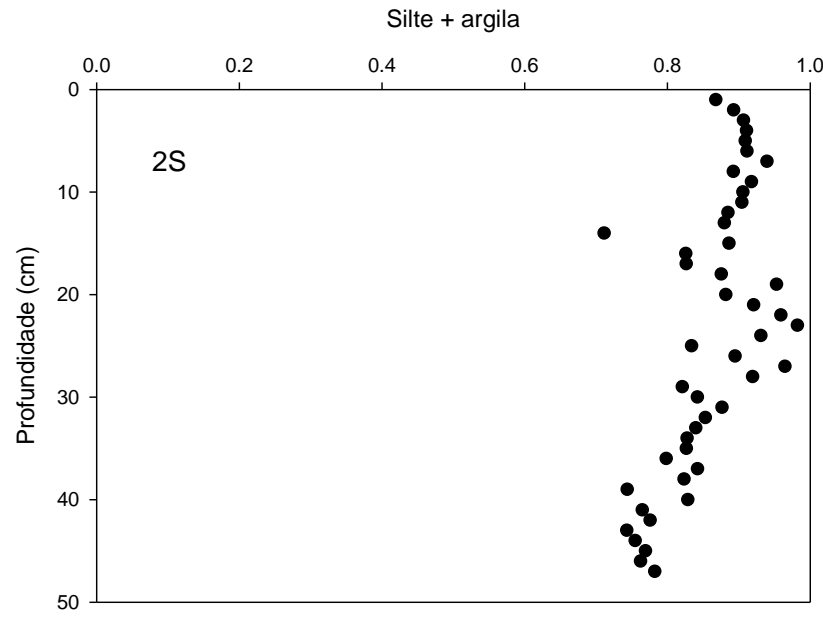

Figura 17- Porcentagem da fração de silte + argila ao longo da profundidade para o prefil 2S. 


\section{2.}

\section{Teor de Carbonatos}

A determinação de carbonatos é de grande importância na avaliação da mudança da natureza dos sedimentos podendo indicar um maior ou menor caráter marinho em relação ao caráter terrígeno nos sedimentos depositados.

O percentual de carbonatos foi estimado em três amostras do ponto $2 \mathrm{~S}$, uma vez que neste ponto, foram observadas três inclinações, ou seja, três taxas de sedimentação.

Cada amostra pertencia a uma destas taxas de sedimentação observadas, representando assim a composição do perfil coletado.

Os percentuais de carbonatos estimados foram de $4 \%$ para a amostra representando os sedimentos superficiais (em torno de $7,5 \mathrm{~g} \mathrm{~cm}^{-2}$ ), $13 \%$ para a amostra representativa dos sedimentos na profundidade média (por volta de 13,1 $\mathrm{g} \mathrm{cm}^{-2}$ ), e 22\% para a amostra do fundo (aproximadamente $20,8 \mathrm{~g} \mathrm{~cm}^{-2}$ ). Observa-se que estes valores são bem inferiores aos percentuais de silte+argila obtidos através da granulometria, $83 \%, 92 \%$ e $84 \%$ respectivamente.

$\mathrm{Na}$ verdade, pode-se dizer que as mudanças ocorridas na região do estuário (em relação às taxas de sedimentação) controlam a natureza do sedimento depositado.

\section{3.}

\section{Análise dos Inventários de ${ }^{210} \mathrm{~Pb}$}

A fim de identificar as áreas de maior deposição na região da foz do RPS, foi calculado o inventário total de ${ }^{210} \mathrm{~Pb}_{\text {exc }}$ com o proposto por Appleby e Oldfield, (1992).

Os inventários de ${ }^{210} \mathrm{~Pb}_{\text {exc }}$ foram calculados em cada ponto de amostragem. A Tabela 2 apresenta os resultados para cada ponto com as devidas coordenadas e o comprimento de cada perfil coletado.

Em alguns pontos de coleta o perfil coletado não apresentou uma concentração de ${ }^{210} \mathrm{~Pb}_{\text {exc }}$ constante nas camadas mais profundas, significando que havia falta de ${ }^{210} \mathrm{~Pb}_{\text {exc }}$ correspondente ao sedimento existente abaixo da ultima seção do perfil. Nestes casos, para obter o inventário total de ${ }^{210} \mathrm{~Pb}_{\text {exc }}$, a 
concentração de ${ }^{210} \mathrm{~Pb}_{\text {exc }}$ correspondente ao sedimento abaixo da seção de fundo foi estimada com base no modelo CIC.

As estimativas dos inventários de ${ }^{210} \mathrm{~Pb}_{\text {exc }}$ nos pontos $1 \mathrm{~S}$ e $4 \mathrm{~S}$ foram 1,25 $\mathrm{Bq} \mathrm{cm}^{-2}$ e 1,66 $\mathrm{Bq} \mathrm{cm}^{-2}$ respectivamente. Estes valores estão acima do valor encontrado para a região, $1 \mathrm{~Bq} \mathrm{~cm}^{-2}$ na Lagoa de Cima, em Campos (Silva, 1999) reforçando teoria de que existe entrada de sedimentos e que o direcionamento destes está na direção ao sul da foz.

A partir da Figura 18, é possível visualizar melhor o direcionamento dos sedimentos na direção sul em relação a foz do RPS. Foi calculada uma média para os valores dos inventários obtidos de ${ }^{210} \mathrm{~Pb}$ mais baixos, no valor de 0,16 $\mathrm{Bq} \mathrm{cm}^{-2}$; uma média para os valores intermediários, com $0,45 \mathrm{~Bq} \mathrm{~cm}^{-2}$ e outra para os valores mais altos, estimada em $1,2 \mathrm{~Bq} \mathrm{~cm}^{-2}$.

Os círculos foram feitos em três tamanhos, um para cada valor médio calculado. Observou-se um aumento na frequência dos pontos com os círculos maiores em direção ao sul da foz do RPS.

Uma vez que os valores obtidos para os pontos ao norte da desembocadura do RPS foram muito menores do que os valores obtidos ao sul, pode se concluir que o transporte de sedimentos ocorre em direção ao sul da foz, de acordo com a corrente de deriva. 
Tabela 2 - Valores dos Inventários de ${ }^{210} \mathrm{~Pb}_{\mathrm{exc}}$ em cada perfil coletado

\begin{tabular}{|c|c|c|c|}
\hline Ponto de coleta & $\begin{array}{l}\text { Comprimento total do } \\
\text { perfil }\left(\mathrm{cm} / \mathrm{g} \mathrm{cm}^{-2}\right)\end{array}$ & Localização & $\begin{array}{l}\text { Inventário } \\
{ }^{210} \mathrm{~Pb}_{\mathrm{exc}} \\
\left(\mathrm{Bq} \mathrm{cm}{ }^{-2}\right)\end{array}$ \\
\hline $1 \mathrm{~N}$ & $52 / 24$ & $21^{\circ} 36^{\prime} 08^{\prime \prime} \mathrm{S} \quad 41^{\circ} 00^{\prime} 25.3^{\prime \prime} \mathrm{W}$ & 0,17 \\
\hline $2 \mathrm{~N}$ & $34 / 14$ & $21^{\circ} 35^{\prime} 49.7^{\prime \prime S} \quad 41^{\circ} 00^{\prime} 08^{\prime \prime} \mathrm{W}$ & 0,40 \\
\hline $2 \mathrm{C}$ & $32 / 19$ & $21^{\circ} 36^{\prime} 30.5^{\prime \prime S} \quad 40^{\circ} 59^{\prime} 53.6^{\prime \prime} \mathrm{W}$ & 0,53 \\
\hline $3 \mathrm{C}$ & $29 / 17$ & $21^{\circ} 36^{\prime} 22,1^{\prime \prime S} \quad 40^{\circ} 59^{\prime} 26.4^{\prime \prime} \mathrm{W}$ & 0,36 \\
\hline $4 C$ & $26 / 14$ & $21^{\circ} 36^{\prime} 15^{\prime \prime} \mathrm{S} \quad 40^{\circ} 58^{\prime} 36^{\prime \prime} \mathrm{W}$ & 0,15 \\
\hline $1 S$ & $51 / 29$ & $21^{\circ} 37^{\prime \prime} 35.2^{\prime \prime} \mathrm{S} \quad 1^{\circ} 00^{\prime} 9.2^{\prime \prime} \mathrm{W}$ & 1,25 \\
\hline $2 S$ & $51 / 29$ & $21^{\circ} 37^{\prime} 33.5^{\prime \prime} \mathrm{S} 40^{\circ} 59^{\prime} 38.2^{\prime \prime} \mathrm{W}$ & 1,09 \\
\hline $3 S$ & $34 / 18$ & $21^{\circ} 37^{\prime} 25^{\prime \prime} \mathrm{S} \quad 40^{\circ} 58^{\prime} 54^{\prime \prime W}$ & 0,47 \\
\hline $4 S$ & $35 / 28$ & $21^{\circ} 38^{\prime} 09^{\prime \prime} \mathrm{S} \quad 40^{\circ} 59^{\prime} 53^{\prime \prime} \mathrm{W}$ & 1,66 \\
\hline 2SS & 42 / 24 & $21^{\circ} 38^{\prime} 40.8^{\prime \prime} \mathrm{S} 40^{\circ} 59^{\prime} 45.1^{\prime \prime} \mathrm{W}$ & 0,85 \\
\hline $3 s s$ & $55 / 27$ & $21^{\circ} 38^{\prime} 58.9^{\prime \prime S} \quad 40^{\circ} 59^{\prime} 12.3^{\prime \prime} \mathrm{W}$ & 0,98 \\
\hline $4 S S$ & $51 / 26$ & $21^{\circ} 39^{\prime} 14.7^{\prime \prime S} \quad 40^{\circ} 58^{\prime} 39.2^{\prime \prime} \mathrm{W}$ & 1,34 \\
\hline $2 N N$ & $43 / 26$ & $21^{\circ} 34^{\prime} 49.9^{\prime \prime} \mathrm{S} \quad 40^{\circ} 59^{\prime} 33.3^{\prime \prime} \mathrm{W}$ & 0,48 \\
\hline $3 N N$ & $11 / 4,4$ & $21^{\circ} 34^{\prime} 21.4^{\prime \prime S} 40^{\circ} 59^{\prime} 10.8^{\prime \prime} \mathrm{W}$ & - \\
\hline
\end{tabular}




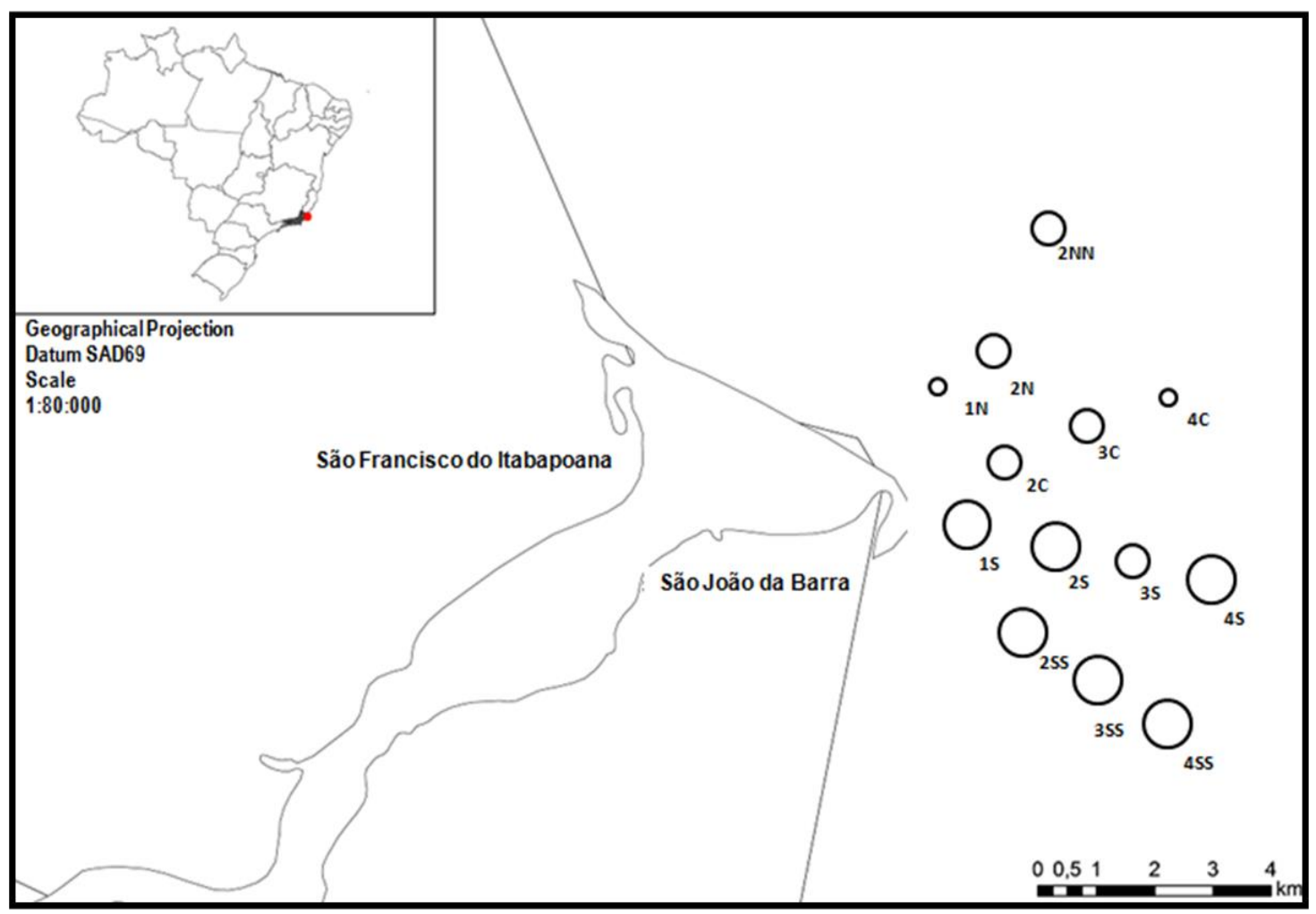

Figura 18. Imagem da região com os inventários de ${ }^{210} \mathrm{~Pb}_{\mathrm{exc}}$ representados por círculos: os círculos menores representam um valor médio de $0,16 \mathrm{~Bq} \mathrm{~cm}^{-2}$, o círculos médios representam um valor médio de $0,45 \mathrm{~Bq} \mathrm{~cm}^{-2}$ e os maiores representam os pontos com um valor médio de $1,2 \mathrm{~Bq} \mathrm{~cm}^{-2}$.

\section{4 .}

\section{Análise de cada perfil coletado}

A fim de apresentar os resultados de cada perfil analisado, a Figura 19 reúne, para cada ponto estudado, as concentrações de ${ }^{210} \mathrm{~Pb}$ ao longo do perfil versus a massa acumulada.

A apresentação dos resultados será dividida de acordo com os comportamentos de cada perfil, agrupando os pontos estudados com comportamentos similares em cada subitem.

O ponto de coleta $3 \mathrm{NN}$, localizado aproximadamente a três quilômetros da costa, não foi analisado devido a grande quantidade de conchas e pedras presentes nas amostras, e, também pelo comprimento do perfil com apenas 11 centímetros $\left(4,4 \mathrm{~g} \mathrm{~cm}^{-2}\right)$. 


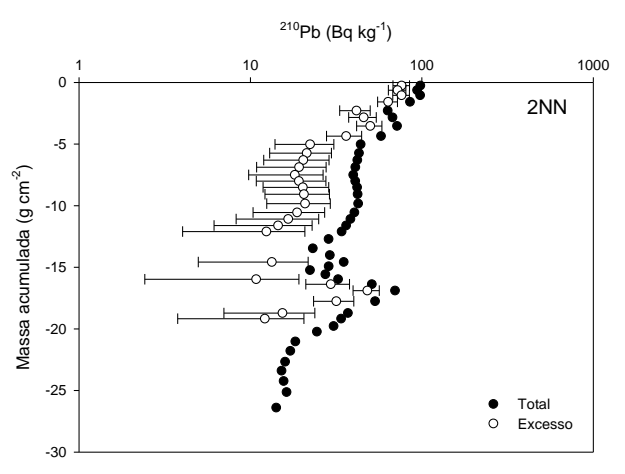

(a)

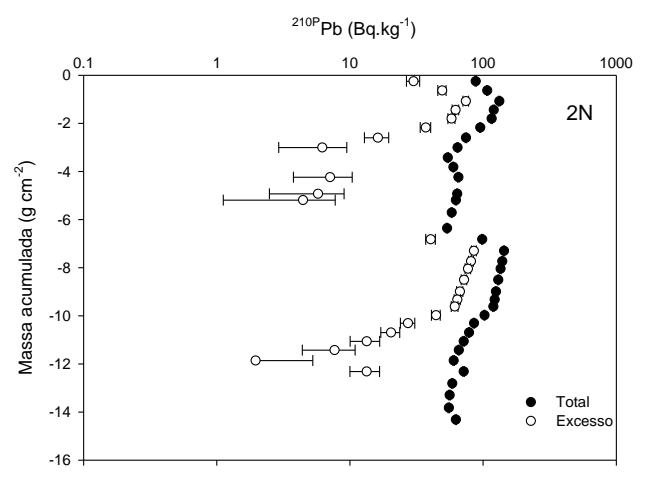

(c)

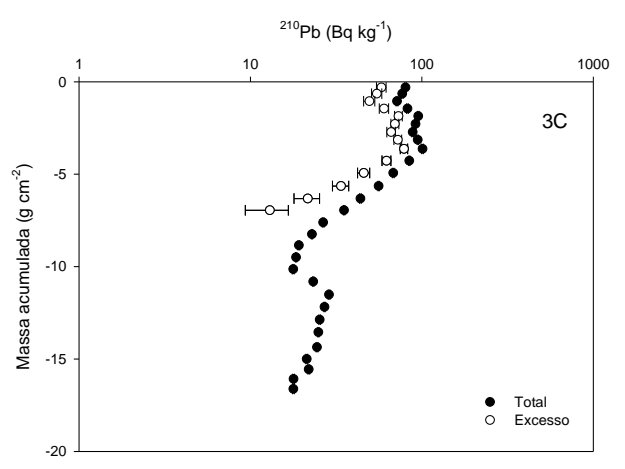

(e)

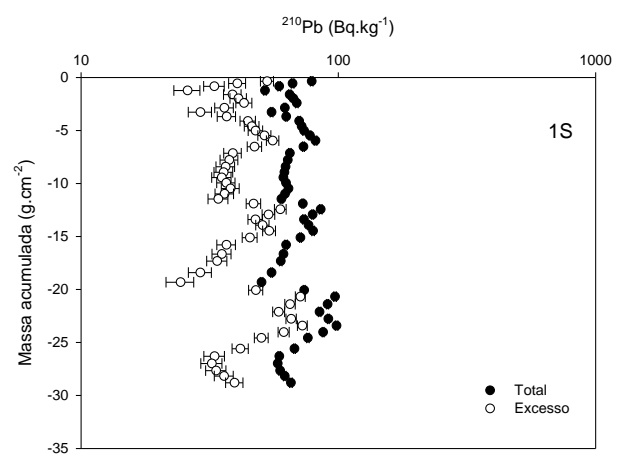

(g)

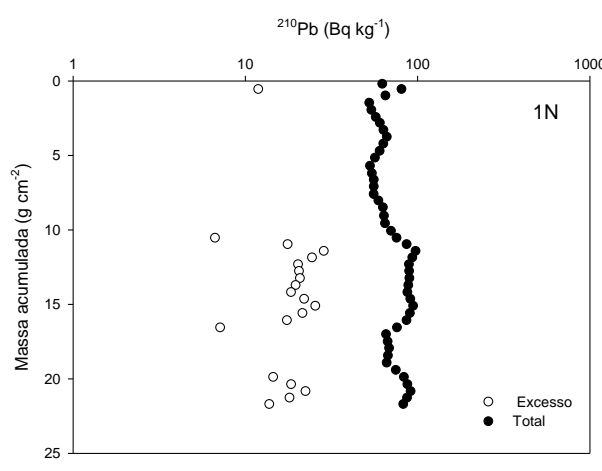

(b)

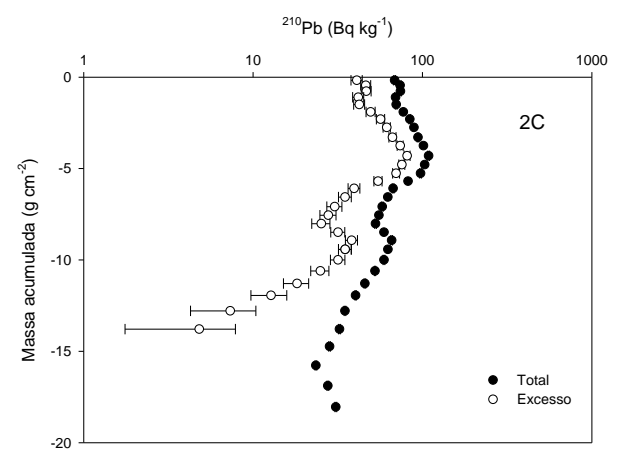

(d)

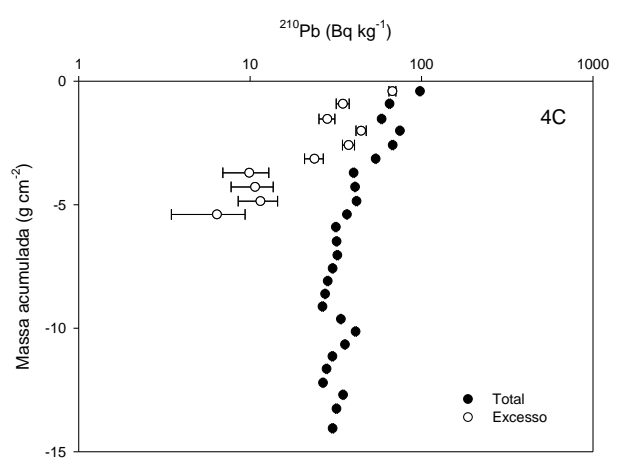

(f)

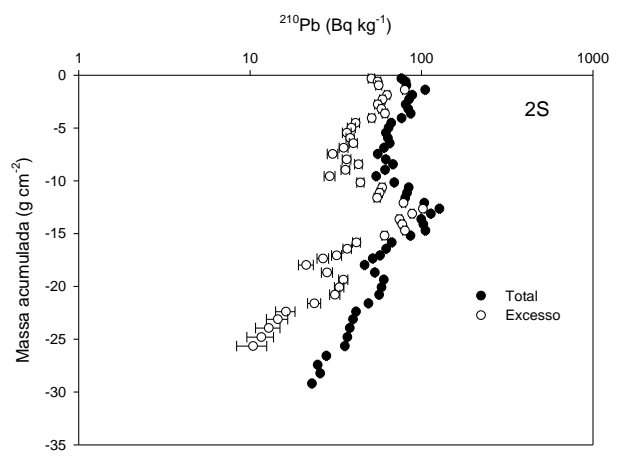

(h) 


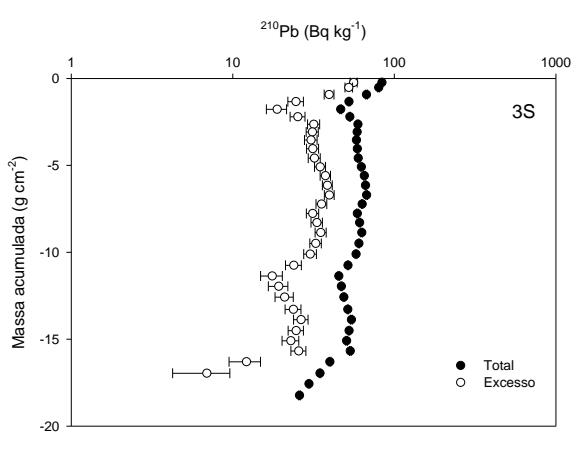

(i)

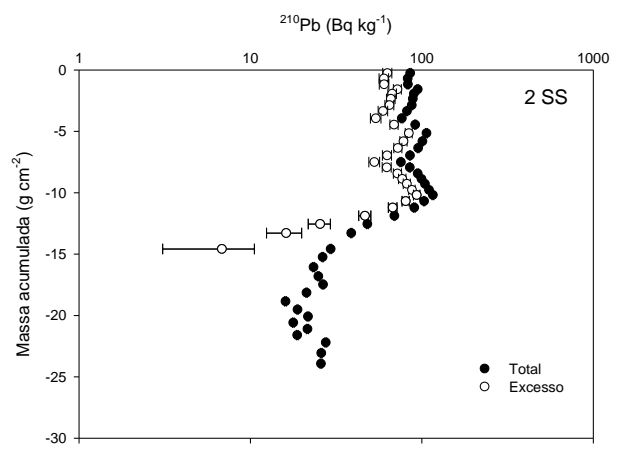

(k)

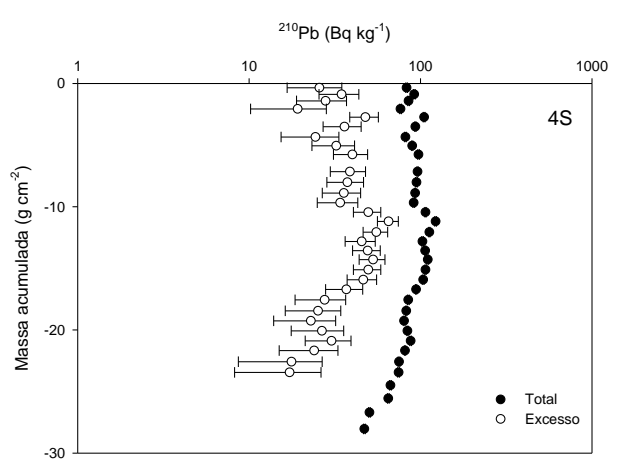

(j)

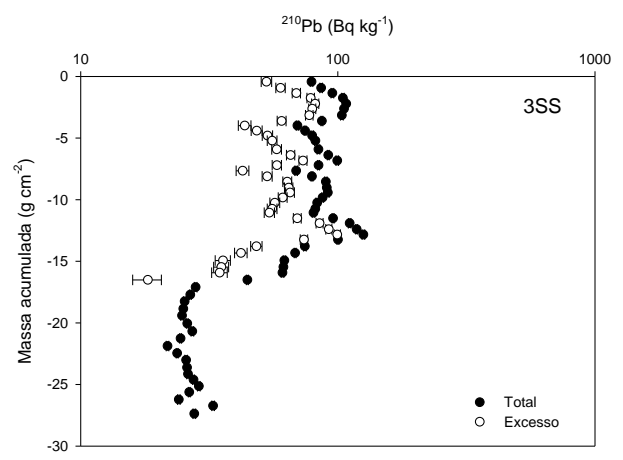

(l)

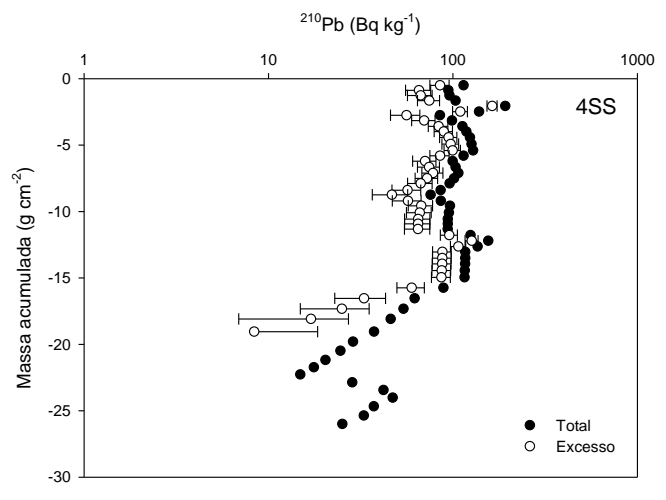

(m)

Figura 19- Perfis de concentração de ${ }^{210} \mathrm{~Pb}_{\text {total }} \mathrm{e}^{210} \mathrm{~Pb}_{\text {excesso }}$ nos perfis de sedimento analisados. 


\subsection{1. \\ Pontos $1 \mathrm{~N}$ e $3 \mathrm{~S}$}

Nos perfis $1 \mathrm{~N}$ e $3 \mathrm{~S}$ as concentrações de ${ }^{210} \mathrm{~Pb}_{\text {exc }}$ obtidas não apresentaram um decaimento exponencial em função da profundidade.

O perfil $1 \mathrm{~N}$, com profundidade mássica de $24,1 \mathrm{~g} \mathrm{~cm}^{-2}$, e o perfil $3 \mathrm{~S}$, com $18,4 \mathrm{~g} \mathrm{~cm}^{-2}$, apresentaram valores de ${ }^{210} \mathrm{~Pb}_{\text {exc }}$ bastante homogêneos ao longo da profundidade, praticamente constantes de onde se pode concluir que cada perfil se apresentou todo como uma zona de mistura ao longo da profundidade (Figura 19 (b) e (i) e Tabelas 8 e 9 encontradas no capítulo 9). Este comportamento pode estar associado às atividades antropogênicas, como a pesca de arrasto que é muito praticada na região, ou ao processo de bioturbação devido à presença de muitas poliquetas encontradas nas amostras, ou também, associado ao processo erosivo.

Baseada nas limitações destes perfis, não foi possível fazer a datação nem estimar as taxas de sedimentação nestes pontos. A única informação obtida a partir destes pontos de coleta foi o valor do inventário de ${ }^{210} \mathrm{~Pb}_{\text {exc }}$ em cada ponto.

\subsection{2. Pontos 1S, 2N e 3SS}

Nos perfis, $1 \mathrm{~S}, 2 \mathrm{~N}$ e $3 \mathrm{SS}$, as concentrações de ${ }^{210} \mathrm{~Pb}_{\text {exc }}$ obtidas não apresentaram decaimento exponencial em função da profundidade e os valores para concentrações de ${ }^{210} \mathrm{~Pb}_{\text {exc }}$ estão nas tabelas 10,11 e 12 do capítulo 9.

As curvas de concentração de ${ }^{210} \mathrm{~Pb}_{\text {exc }}$ versus massa acumulada ao longo da profundidade apresentaram alguns segmentos paralelos. As curvas obtidas e o comportamento das concentrações de ${ }^{210} \mathrm{~Pb}$ ao longo da profundidade nos pontos 1S, 2N e em parte do 3SS sugerem que houve períodos de deposição de material com diferentes composições químicas. Este resultado foi observado a partir da repetição de curvas paralelas de ${ }^{210} \mathrm{~Pb}_{\text {exc }}$ versus a massa acumulada existentes nestes perfis (Figura 19 (c), (g) e (I)).

\subsection{3.}

\section{Pontos 3C, 2SS e 4SS}

Alguns autores afirmam que os perfis que apresentam camada de mistura não devem ser usados para fins de datação, estes devem ser usados apenas 
para estimar as taxas de sedimentação (Sanchez-Cabeza e Ruiz-Fernandes, 2012). Apesar de ter sido mostrado que é possível usar tais perfis para fins de datação, se as correções necessárias forem aplicadas a cada modelo (Carrol e Lerche, 2003; Joshi et al., 1988), estes perfis foram utilizados apenas para determinação das taxas de sedimentação.

O ponto de coleta $3 \mathrm{C}$ está na linha central distante aproximadamente $3 \mathrm{~km}$ da costa. O perfil 3C apresentou uma camada de mistura superficial até $3,1 \mathrm{~g}$ $\mathrm{cm}^{-2}$. Abaixo desta, foi observado uma variação exponencial da concentração de ${ }^{210} \mathrm{~Pb}$ em excesso com a profundidade possibilitando, assim, a aplicação do modelo CIC e a determinação da taxa de sedimentação nesta região. A taxa de sedimentação observada nesta área foi de $0,058( \pm 0,005) \mathrm{g} \mathrm{cm}^{-2}$ ano $^{-1}$ (Figura 20 (a)).

O ponto de coleta $2 \mathrm{SS}$ está situado aproximadamente a $2 \mathrm{~km}$ da costa na direção sul. O perfil apresentou uma variação exponencial da concentração de ${ }^{210} \mathrm{~Pb}_{\text {exc }}$ com a profundidade nas camadas mais profundas, a partir de $10,2 \mathrm{~g} \mathrm{~cm}$ ${ }^{2}$, onde foi observada uma provável zona de mistura até esta profundidade. $\mathrm{O}$ modelo CIC foi aplicado na região abaixo da camada de mistura (abaixo de 10,2 $\left.\mathrm{g} \mathrm{cm}^{-2}\right)$ onde foi estimada uma taxa de sedimentação no valor de 0,057 $( \pm 0,005)$ $\mathrm{g} \mathrm{cm}^{-2}$ ano $^{-1}$ (Figura 20 (b)).

O ponto $4 S S$ está situado aproximadamente a $4 \mathrm{~km}$ da costa. Neste perfil, também foi observada uma provável camada de mistura até a profundidade de $11,4 \mathrm{~g} \mathrm{~cm}^{-2}$. O modelo CIC foi aplicado nas camadas inferiores, abaixo de $11,4 \mathrm{~g}$ $\mathrm{cm}^{-2}$, uma vez que foi observada linearidade a partir desta profundidade. A velocidade de sedimentação estimada através do modelo $\mathrm{CIC}$ para esta região foi de $0,060( \pm 0,005) \mathrm{g} \mathrm{cm}^{-2}$ ano $^{-1}$ (Figura 20 (c)).

As concentrações de ${ }^{210} \mathrm{~Pb}$ total e excesso para o perfis 3C, 2SS e 4SS estão nas tabelas 13,14 e 15 do capítulo 9. 


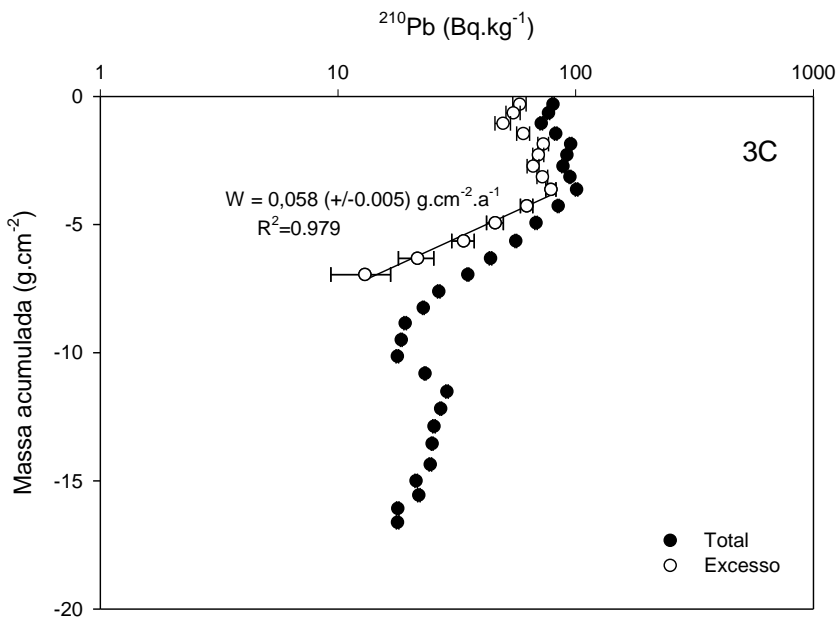

(a)

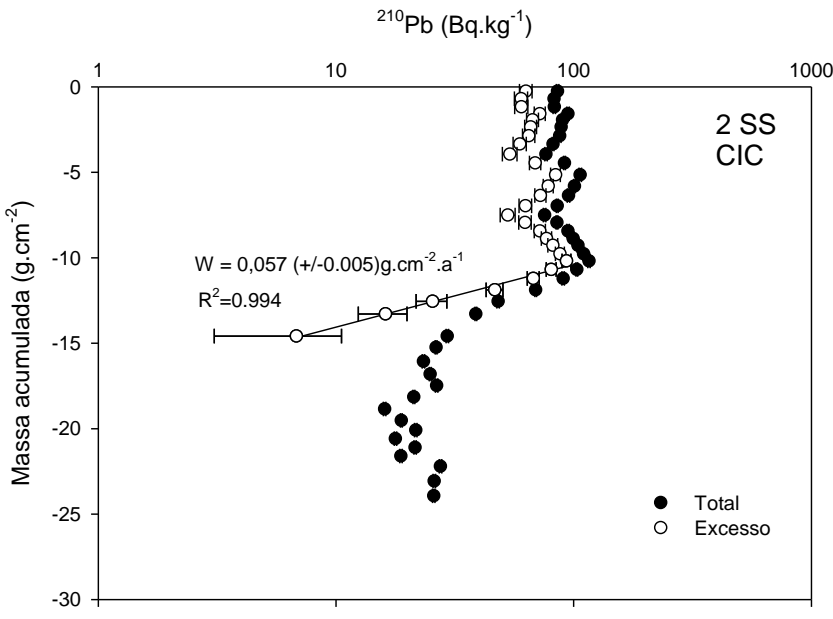

(b)

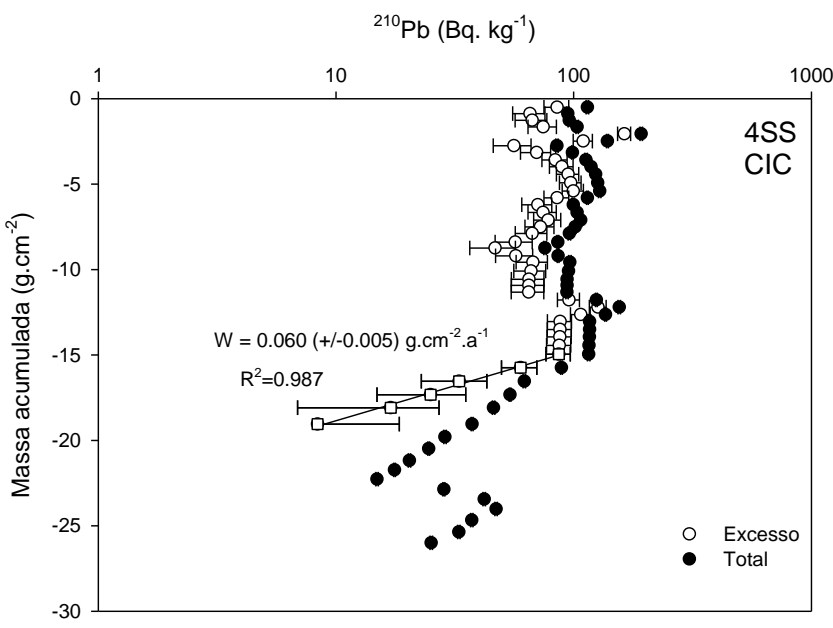

(c)

Figura 20-Concentração de ${ }^{210} \mathrm{~Pb}$ versus massa acumulada e velocidade de sedimentação calculada pelo modelo CIC para o perfis 3C (a); 2SS (b) e 4SS (c). 


\subsection{4. \\ Ponto 2NN}

Segundo Carrol e Lerche, 2003, uma forma de expandir a utilização dos modelos mais simples em perfis de sedimento com características diferentes é aplicar vários modelos a porções diferentes de um mesmo perfil de sedimento.

O ponto $2 \mathrm{NN}$, distante aproximadamente $2 \mathrm{~km}$ da costa, apresentou uma variação exponencial da concentração de ${ }^{210} \mathrm{~Pb}$ em excesso com a profundidade somente nas camadas bem mais profundas, abaixo de $16,4 \mathrm{~g} \mathrm{~cm}^{-2}$. A taxa de sedimentação nesta região foi estimada no valor de $0,054( \pm 0,008) \mathrm{g} \mathrm{cm}^{-2}$ ano-1 através do modelo CIC (Figura 21 (a)).

O modelo CRS foi aplicado nas camadas superiores do perfil onde foi obtida uma taxa de sedimentação no valor de $0,248( \pm 0,003) \mathrm{g} \mathrm{cm}^{-2} a^{-1}$ para sedimentos recentes até o ano de 1960. Foi estimada a taxa de sedimentação para o período anterior aos anos 60 no valor de $0,054( \pm 0,008) \mathrm{g} \mathrm{cm}^{-2}$ ano ${ }^{-1}$, de acordo com o valor encontrado pelo modelo CIC para as camadas de fundo. (Figura 21 (b)).

As concentrações de ${ }^{210} \mathrm{~Pb}$ total e excesso e as taxas de sedimentação observadas para o perfil 2NN estão na tabela 16 do capítulo 9 . 

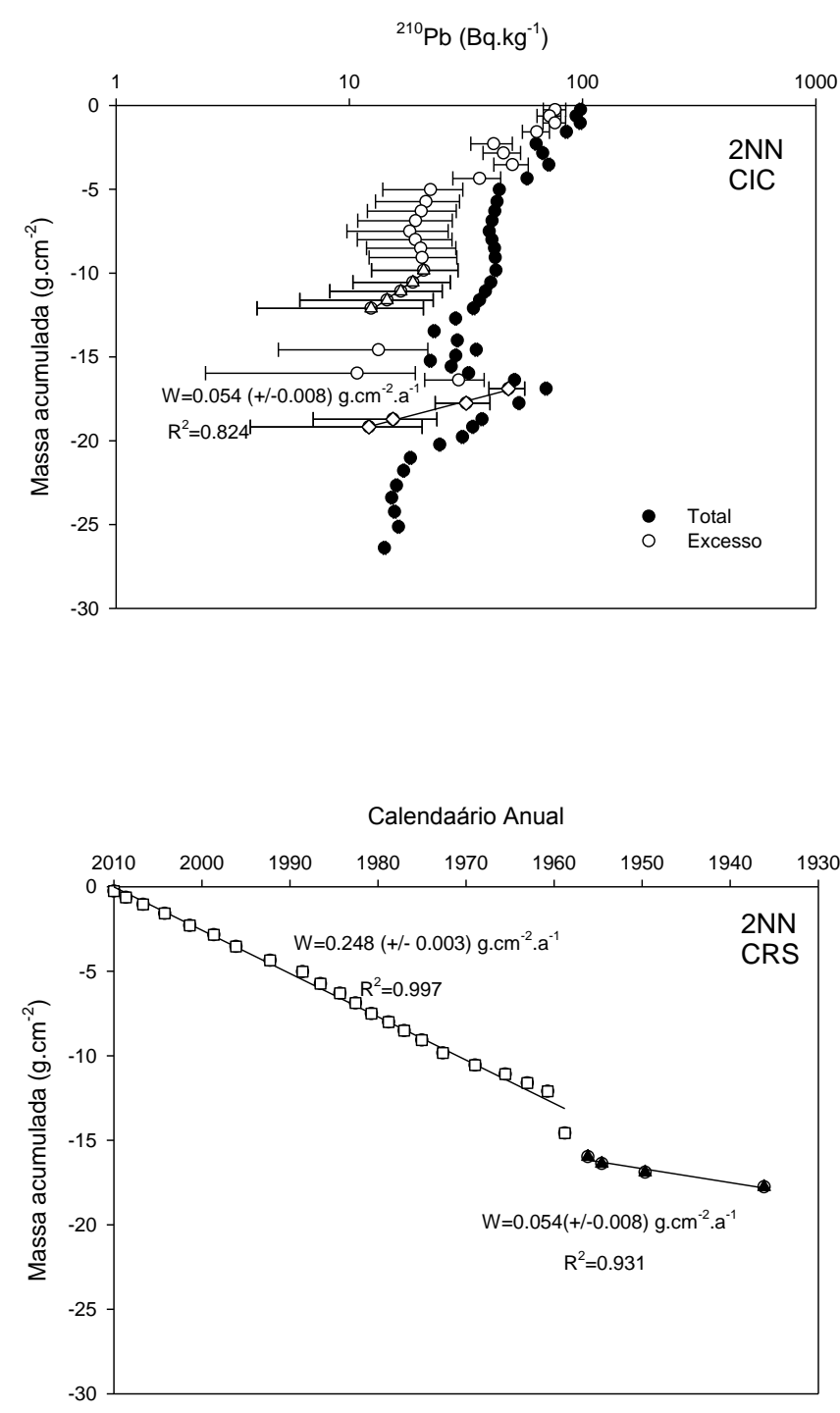

Figura 21- Concentração de ${ }^{210} \mathrm{~Pb}$ versus massa acumulada e taxa de sedimentação calculada através do modelo CIC para o perfil 2NN (a). Idade versus massa acumulada e taxas de sedimentação calculadas através do modelo CRS para o perfil 2NN (b).

\subsection{5.}

Ponto 4C

O ponto $4 \mathrm{C}$ se encontra a $4 \mathrm{~km}$ na direção da desembocadura do RPS. O modelo CIC foi aplicado nas camadas superiores, até $5,4 \mathrm{~g} \mathrm{~cm}^{-2}$, onde foi observada certa variação exponencial até essa profundidade. Abaixo desta, não foram observados valores de ${ }^{210} \mathrm{~Pb}_{\text {exc }}$. A taxa de sedimentação estimada com valor de $0,063( \pm 0,002) \mathrm{g} \mathrm{cm}^{-2}$ ano-1 se manteve constante nos últimos 70 anos (Figura 22). Neste local o inventário de ${ }^{210} \mathrm{~Pb}$ observado foi o mais baixo em relação aos outros pontos de coleta, $0,16 \mathrm{~Bq} \mathrm{~cm}^{-2}$, reforçando que essa região 
não é muito afetada pela pluma do rio, uma vez que essa flui em direção ao sul com a corrente de deriva.

As concentrações de ${ }^{210} \mathrm{~Pb}$ total e excesso para o perfil $4 \mathrm{C}$ estão na tabela 17 do capítulo 9.

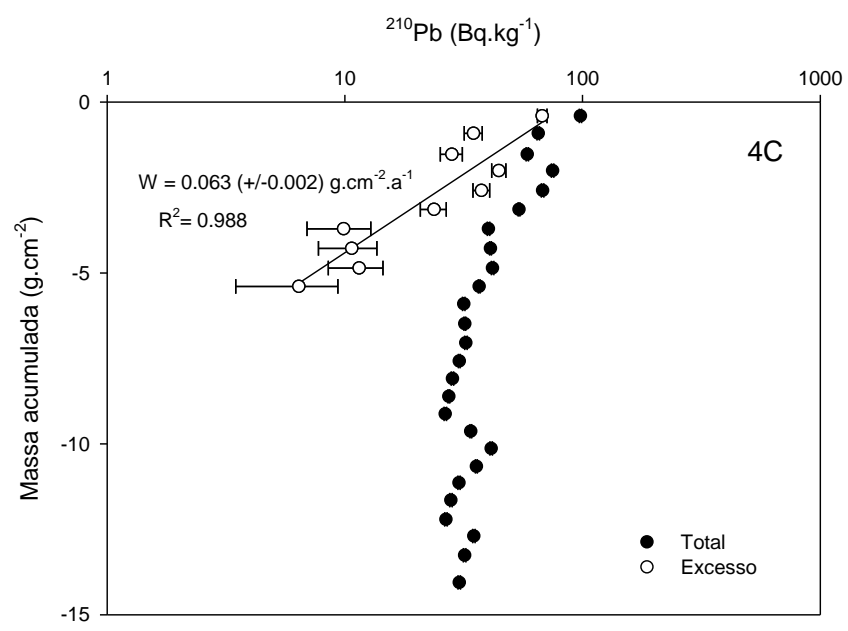

Figura 22- Concentração de ${ }^{210} \mathrm{~Pb}$ versus massa acumulada e velocidade de sedimentação calculada pelo modelo CIC para o perfil 4C.

\subsection{6. \\ Pontos 2S, 2C e 4S}

O perfil $2 S$ está localizado a $1 \mathrm{~km}$ na direção sul em relação à foz do RPS, distante aproximadamente dois quilômetros da costa, o perfil 4S, também localizado na direção sul, situado aproximadamente a quatro quilômetros da costa,e, o ponto $2 \mathrm{C}$ está localizado a dois $\mathrm{km}$ da costa, em frente à saída do rio.

Em alguns pontos foi observado que as concentrações de ${ }^{210} \mathrm{~Pb}$ apresentaram alguns picos em vez de atingir uma concentração constante nas camadas mais profundas (Figura $19 \mathrm{~d}, \mathrm{f}, \mathrm{h}, \mathrm{I}$ e $\mathrm{m}$ ). Estes picos poderiam indicar uma variação na concentração de ${ }^{226} \mathrm{Ra}$ ao longo perfil, invalidando a subtração do valor de ${ }^{210} \mathrm{~Pb}$ que representaria $0{ }^{210} \mathrm{~Pb}$ suportado. Esta hipótese foi testada com base na concentração de urânio ao longo dos perfis $2 \mathrm{~S}$ e $2 \mathrm{C}$. No ponto $2 \mathrm{C}$ foi observado que as duas últimas camadas apresentaram um aumento nas concentrações de ${ }^{210} \mathrm{~Pb}$, mas no ponto $2 S$ esses aumentos não foram observados. O teor de urânio ao longo do ponto $2 \mathrm{~S}$ é constante, ao contrário do ponto $2 \mathrm{C}$ que apresentou um aumento a partir de $12 \mathrm{~g} \mathrm{~cm}^{-2}$ (Figura 23). A região do perfil $2 \mathrm{C}$ onde ocorreu o pico da concentração de urânio não corresponde à 
mesma região onde houve um aumento na concentração de ${ }^{210} \mathrm{~Pb}$. Pelo contrário, na região onde aparece este pico da concentração de urânio no ponto $2 \mathrm{C}$, corresponde a uma diminuição exponencial da concentração de ${ }^{210} \mathrm{~Pb}$ com a profundidade indicando que o urânio e o chumbo presentes não são de mesma origem.

Nesta região do Rio de Janeiro, U e Th são associados com minerais como a monazita e zirconita, que são minerais refratários onde sua dissolução requer procedimentos que envolvem temperaturas muito elevadas e ácido não-volátil concentrado, ou mesmo fusão (Godoy, 2007). Estes procedimentos de dissolução são diferentes do processo de lixiviação, envolvendo $0,5 \mathrm{~mol} \mathrm{~L}^{-1}$ de ácido a $80^{\circ} \mathrm{C}$, indicando que os picos na concentração ${ }^{210} \mathrm{~Pb}$ não estão associados com os picos de concentração de urânio. No entanto, essa suposição de que os picos de ${ }^{210} \mathrm{~Pb}$ e $U$ não estão associados reforça a importância de validar os resultados da datação que serão discutidos mais a frente.
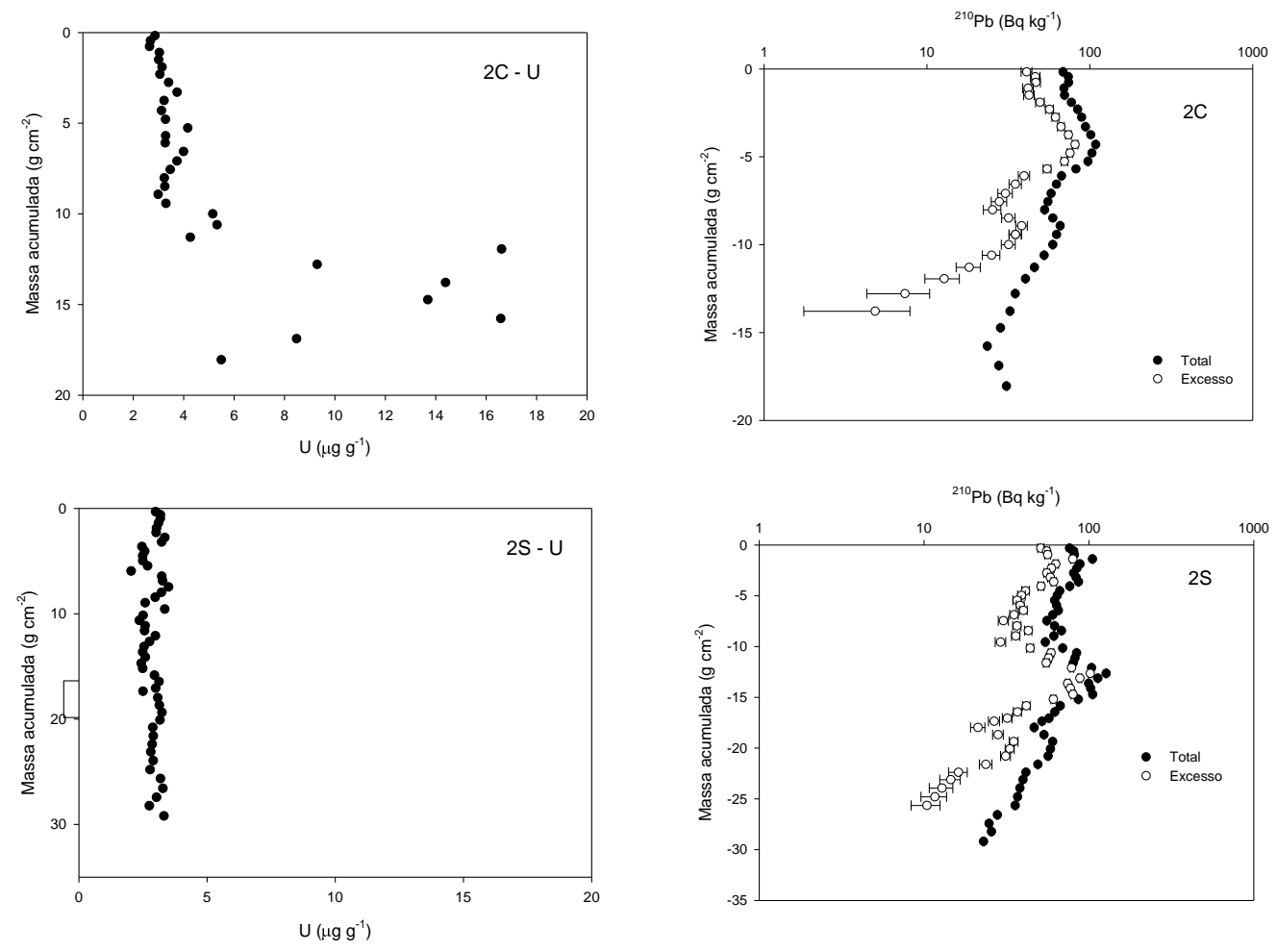

Figura 23-Concentração de urânio e de ${ }^{210} \mathrm{~Pb}$ versus massa acumulada para os perfis $2 \mathrm{C}$ e 2S. 
A aplicação dos modelos de mistura deve ser abordada quando se observa a atividade de ${ }^{210} \mathrm{~Pb}$ bastante uniforme nas camadas superficiais do perfil e, para que esta seja considerada uma evidência de zona de mistura, é muito importante que o todo o material destas camadas esteja bastante homogêneo (Robbins et al. 1978; Benninger et al., 1979).

Inicialmente os perfis $2 \mathrm{~S}$ e $2 \mathrm{C}$ sugeriam uma pequena camada de mistura superficial. Baseada na determinação elementar, não foi evidente a existência da camada de mistura, pois, em ambos os pontos, foram observadas variações nas concentrações superficiais de alguns elementos como, por exemplo, o estrôncio (Tabelas 21 e 22 do capítulo 9). Sendo assim o modelo CRS foi aplicado sem correção para a camada de mistura proposta por Appleby e Oldfield.

No ponto $2 S$ foram observadas três taxas de sedimentação: uma representada por uma taxa de deposição mais recente, até 1992, estimada em $0,579( \pm 0,007) \mathrm{g} \mathrm{cm}^{-2} \mathrm{ano}^{-1}$, a segunda entre o período de 1987 a 1952, estimada em $0,150( \pm 0,003) \mathrm{g} \mathrm{cm}^{-2} \mathrm{ano}^{-1}$ e a terceira nas camadas de fundo estimada em $0,083( \pm 0,003) \mathrm{g} \mathrm{cm}^{-2}$ ano $^{-1}$ para o período anterior a 1945 (Figura 24 (a)). Na figura 24 ainda é possível observar alguns períodos de transição entre as três zonas definidas pelas taxas de sedimentação.

Os resultados observados no ponto $2 \mathrm{C}$ foram similares aos observados no ponto $2 S$ sendo que, os valores das velocidades de sedimentação estimadas ficaram um pouco abaixo dos valores estimados para o ponto 2S. Três taxas de sedimentação foram estimadas: a primeira para os sedimentos recentes até 2006, no valor de $0,400( \pm 0,013) \mathrm{g} \mathrm{cm}^{-2}$ ano ${ }^{-1}$; a segunda para o período entre 2000 e 1960 no valor de $0,131( \pm 0,004) \mathrm{g} \mathrm{cm}^{-2}$ ano $^{-1}$; e a terceira para os sedimentos de fundo para o período anterior a 1950 no valor de $0,047( \pm 0,002) \mathrm{g}$ $\mathrm{cm}^{-2}$ ano $^{-1}$ (Figura $24(\mathrm{~b})$ ).

No ponto de coleta $4 \mathrm{~S}$, situado aproximadamente a $4 \mathrm{~km}$ da costa, a concentração de ${ }^{210} \mathrm{~Pb}_{\text {exc }}$ não alcançou um valor constante nas camadas de fundo, que representaria $0{ }^{210} \mathrm{~Pb}$ suportado radiologicamente, necessário para a aplicação do modelo de datação indicando que o perfil coletado não era longo o suficiente para alcançar tal concentração.

As concentrações de ${ }^{210} \mathrm{~Pb}_{\text {exc }}$ correspondentes aos sedimentos abaixo da ultima camada do perfil coletado foram estimadas com base no modelo CIC. Foi feita uma média dos valores de ${ }^{210} \mathrm{~Pb}$ suportado entre os pontos de coleta 
adjacentes ao ponto $4 \mathrm{~S}$, no valor de $28 \mathrm{~Bq} \mathrm{~kg}$. Com este valor, foram recalculados os valores de ${ }^{210} \mathrm{~Pb}$ em excesso até que suas concentrações tendessem a zero. A partir daí o valor do ${ }^{210} \mathrm{~Pb}$ suportado foi estimado para os fins da datação e cálculos das taxas de sedimentação utilizando o modelo CRS.

Os resultados obtidos neste local foram três taxas de sedimentação: a mais alta para deposição de sedimentos recentes até 1990 no valor de 0,626 ( \pm $0,025) \mathrm{g} \mathrm{cm}^{-2}$ ano $^{-1}$; uma intermediária para o período entre 1990 e $1950 \mathrm{com}$ valor estimado de $0,241( \pm 0,007) \mathrm{g} \mathrm{cm}^{-2}$ ano $^{-1}$; e a terceira com o valor mais baixo, $0,067( \pm 0,009) \mathrm{g} \mathrm{cm}^{-2}$ ano-1 , para o período anterior aos anos 50 (Figura $24(c))$.

As concentrações de ${ }^{210} \mathrm{~Pb}$ total e excesso e as taxas de sedimentação observadas para o perfis $2 \mathrm{~S}, 2 \mathrm{C}$ e 4 S estão, respectivamente, nas tabelas 18,19 e 20 do capítulo 9. 


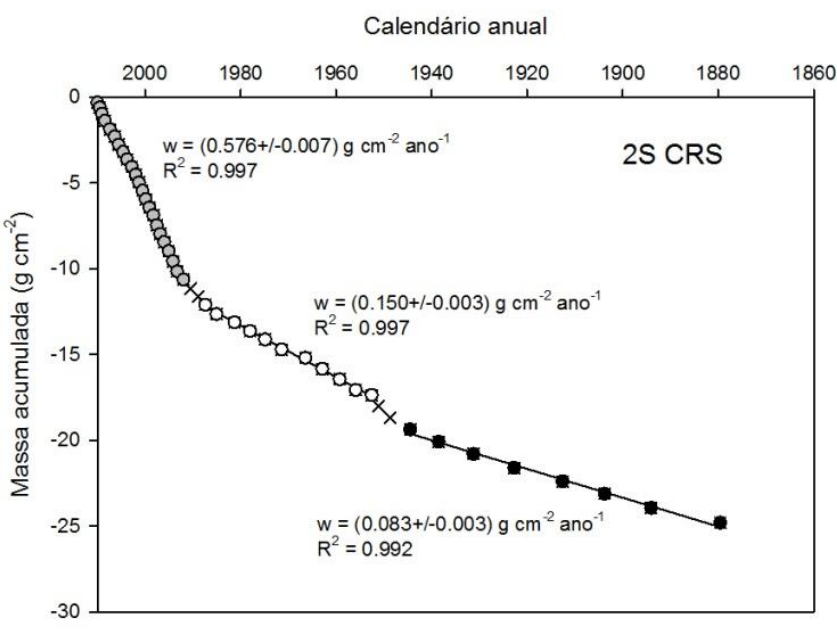

(a)

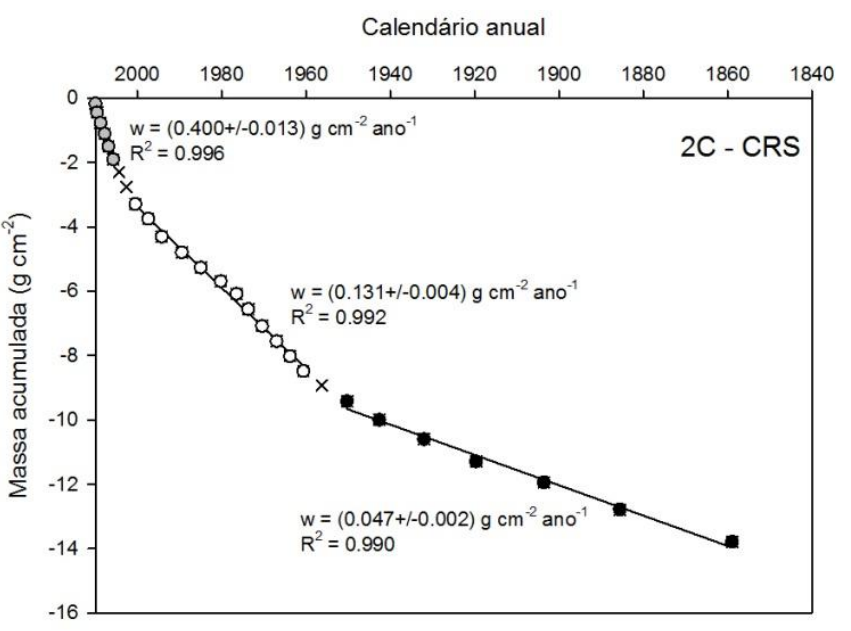

(b)

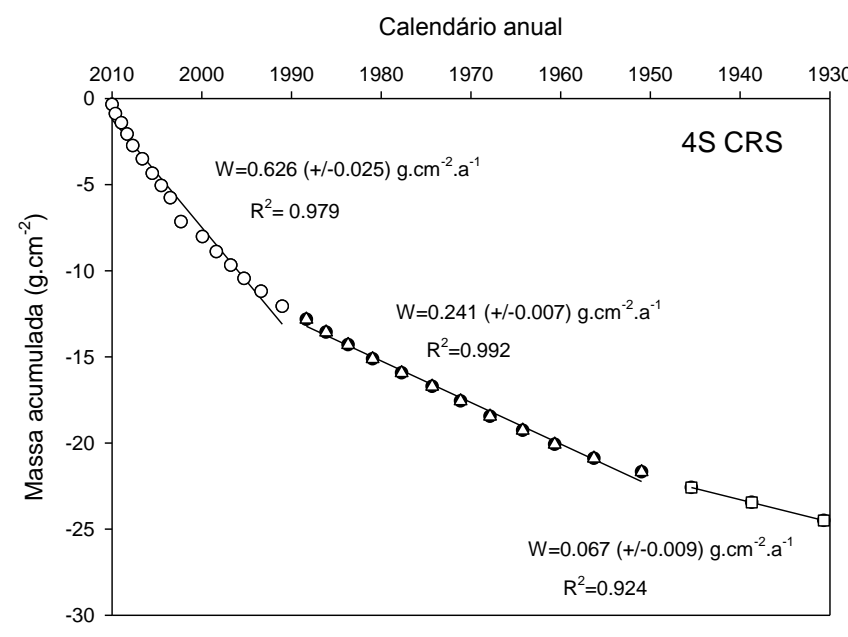

(c)

Figura 24-Taxas de sedimentação de acordo com a profundidade mássica e idades calculadas pelo modelo CRS nos pontos $2 \mathrm{~S}$ (a), 2C (b) e 4S (c). 


\subsection{7. \\ Resumo das taxas de sedimentação obtidas na região}

A figura 25 traduz a situação das taxas de sedimentação encontradas na região do estuário do RPS para o período anterior aos anos 50 (figura 25 (a)) e para o período mais recente (Figura 25 (b)).

A partir da figura 25 (a) observa-se que as taxas de sedimentação para o período anterior aos anos 50 foram todas muito baixas variando entre 0,05 e 0,1 $\mathrm{g} \mathrm{cm}^{-2}$ ano $^{-1}$.

A figura 25 (b) indica que atualmente as taxas de sedimentação estão bem mais altas na direção ao sul da foz do RPS.

A variação nas taxas de sedimentação aumenta do norte para o sul, apresentando valores de $0,2 \mathrm{~g} \mathrm{~cm}^{-2}$ ano ${ }^{-1}$ ao norte da foz, $0,4 \mathrm{~g} \mathrm{~cm}^{-1}$ ano ${ }^{-1}$ na parte central e chegando a valores entre 0,6 e $0,7 \mathrm{~g} \mathrm{~cm}^{-2}$ ano-1 ao sul da sua foz.

Nota-se ainda, que os pontos ao norte da foz não são de grande deposição, uma vez que possuem baixa taxa de sedimentação enquanto os pontos ao sul apresentam uma zona de maior deposição, provavelmente influenciados pela corrente de deriva que vai para a direção sul (Kumar et al.,2003; Hamilton, 2001).

Outro fator que pode contribuir para o aumento das taxas de sedimentação ao sul da foz do RPS seria o aporte de sedimentos vindos da própria erosão costeira existente nesse local. Os sedimentos de origem antropogênica e continental provenientes da erosão podem estar sendo depositados nesta região contribuindo para o aumento das taxas de sedimentação observadas. 


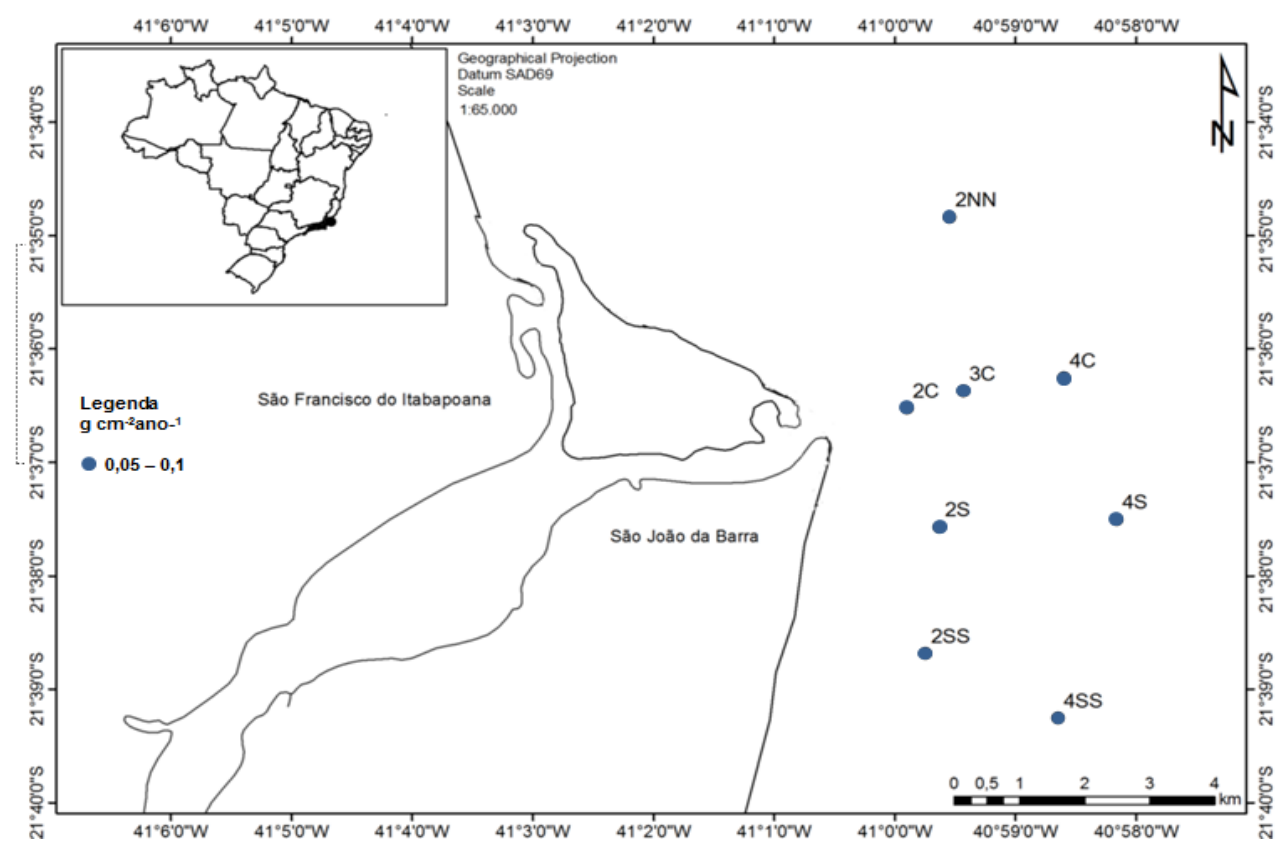

(a) Taxas de sedimentação anteriores aos anos 50.

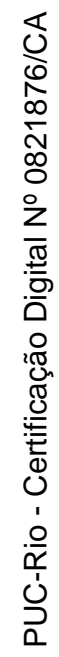

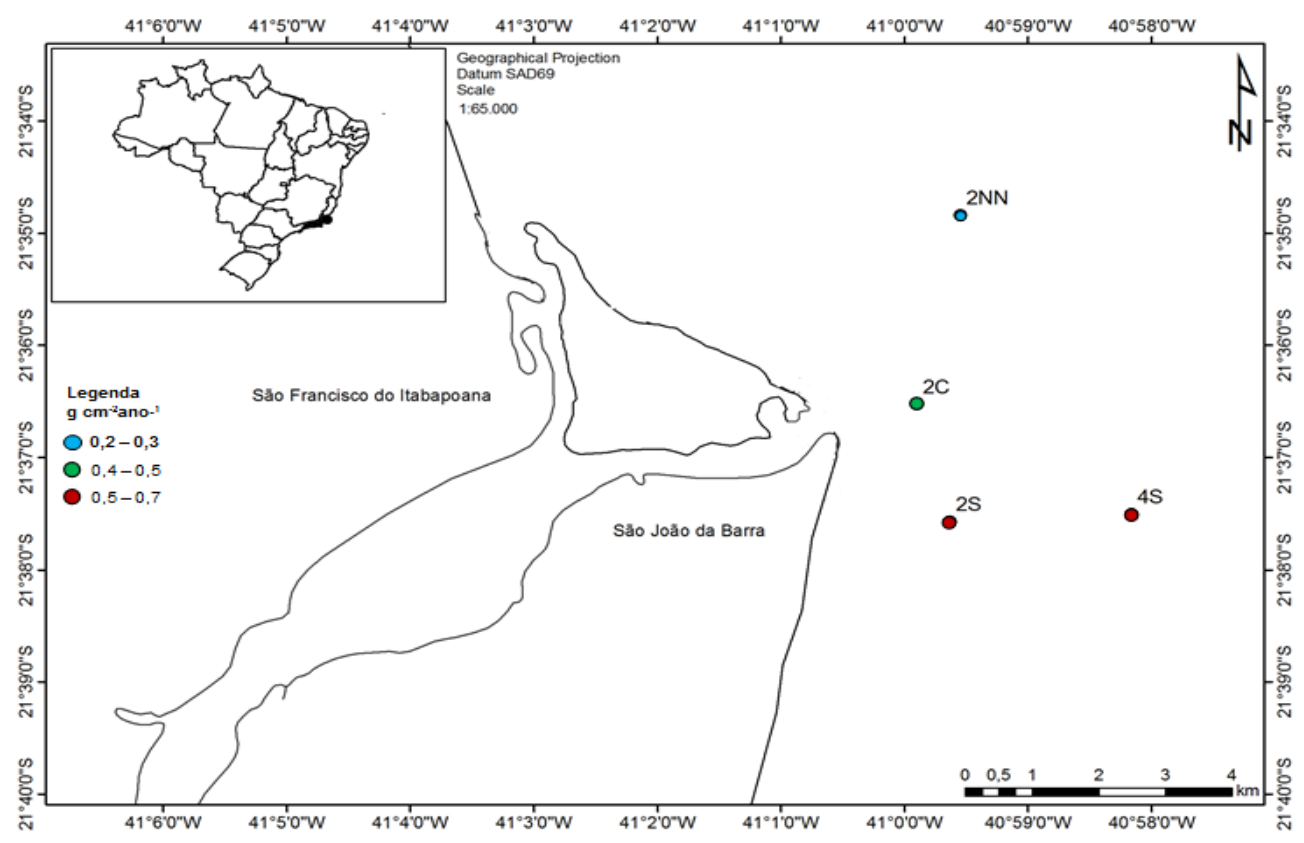

(b) Taxas de sedimentação recentes.

Figura 25-Variação das taxas de sedimentação anterior aos anos 50 (a) e atual (b).. 


\section{5 . \\ Validação da datação com ${ }^{210} \mathrm{~Pb}$}

A determinação de alguns metais em conjunto com a reconstrução histórica de uma certa região é uma das ferramentas para a validação da datação obtida através do ${ }^{210} \mathrm{~Pb}$ presente nos sedimentos desta região.

Outras ferramentas disponíveis para este fim são a determinação e comparação dos fluxos e inventários de ${ }^{210} \mathrm{~Pb}$ entre perfis de uma mesma região desde que esta não sofra grande aporte de rios e também as concentrações de ${ }^{137} \mathrm{Cs}$ em sedimentos marinhos uma vez que ele é fortemente adsorvido nas partículas mais finas do sedimento (Sanchez-Cabeza et al., 1999; Appleby e Oldfield, 1992).

A contaminação de metais-traço em ambientes costeiros está relacionada com as fontes de poluição existentes em rios e estuários. Os metais são transportados para o oceano principalmente pelos rios através de estuários e as principais fontes de metais antropogênicos em áreas costeiras são terrestres tais como, mineração, agricultura, pecuária, indústrias, desenvolvimento urbano e outras possíveis atividades humanas desenvolvidas perto dos rios e estuários (Morton e Blackmore, 2001).

O RPS é um dos rios mais importantes no fornecimento de água para a região sudeste do Brasil. Ele também drena uma área industrial muito importante e a segunda maior área de produção de cana-de-açúcar do país, podendo introduzir metais poluentes ao longo do rio As duas maiores fontes contaminantes na parte mais baixa da bacia do RPS são a agricultura e a mineração de ouro no começo dos anos 80 (Lacerda et al., 1993). Outros problemas ambientais descritos a seguir, também estão relacionados a vários acidentes e derramamentos segundo Relatório de visita e avaliação do acidente ambiental no RPS, trecho entre São Fidélis e São João da Barra (Fiperj):

1982 : Vazamento da Cia. Paraibuna de Metais, com o rompimento de um dique de contenção de rejeitos no Rio Paraibuna, que carreou resíduos de metais pesados (principalmente cromo cádmio e zinco) e outras substâncias tóxicas, contaminando o RPS desde a confluência com o Paraibuna até a foz;

1984: Acidente rodoviário em que um caminhão despejou $3 \times 10^{4} \mathrm{~L}$ de ácido sulfúrico no Rio Piabanha; 
1986: vazamento de $4 \times 10^{4} \mathrm{~L}$ de PCB;

1987: Uma máquina de terraplanagem bateu no "vent" do oleoduto do Sistema Guararema - REVAP (Refinaria do Vale do Paraíba), da Petrobras, causando o rompimento do duto e o vazamento de $2 \times 10^{5} \mathrm{~L}$ do produto (óleo combustível) para o Rio Paraíba do Sul (CETESB).

1988: Vazamento de óleo ascarel (que contém PCB utilizado como isolante em equipamentos elétricos, sobretudo transformadores) contido em $3 \times 10^{3} \mathrm{~L}$ de água utilizada para apagar 0 incêndio de transformadores na Thyssen Fundições;

1989: vazamento de um tanque de metanol com aproximadamente $3 \mathrm{x}$ $10^{4} \mathrm{~L}$

2002, 2004 e 2007: bloom de cianobacteria e interrupção do fornecimento de água por aproximadamente 6 dias;

2003: $2 \times 10^{7} \mathrm{~L}$ de rejeitos de uma indústria de papel (Indústria Cataguazes de Papel) contendo material basicamente alcalino, orgânico e enriquecido em $\mathrm{Pb}, \mathrm{Hg}$ e outros metais, interrompendo o fornecimento de água por 8 dias;

2006 e 2007: vazamento de $4 \times 10^{8} \mathrm{~L}$ e $2 \times 10^{9} \mathrm{~L}$, respectivamente, de bauxita enriquecida em sulfato de alumínio, também originados da contaminação de uma indústria de papel;

2008: rompimento de um dique de contenção da empresa Servatis, causando um vazamento de cerca de $8 \times 10^{3} \mathrm{~L}$ de um produto chamado Endosulfan,um composto organoclorado, usado na produção de pesticidas e inseticidas.

Devido ao histórico desta região, com tantos despejos e vazamentos de material contaminante, a validação da datação com ${ }^{210} \mathrm{~Pb}$ foi abordada através dos metais analisados e a possível relação com os dados históricos.

\subsection{1.}

\section{Análise da amostra de referência de solo NIST 2709}

A determinação dos elementos foi realizada através da análise por ICP-MS usando o método semiquantitativo ou TotalQuant ${ }^{\circledR}$. A amostra de referência de 
solo NIST SRM 2709 foi empregada como controle a fim de garantir o procedimento analítico utilizado, incluindo a dissolução da amostra e a análise por ICP-MS. Na tabela 3 são apresentados os resultados obtidos para a amostra de referência NIST SRM 2709.

Considerando o critério de aceitação empregado pelo Departamento de Energia Norte Americano (DOE) para determinação de elementos-traço em exercícios interlaboratoriais envolvendo amostras ambientais, $20 \%$ de erro, tais resultados, com exceção do elemento $\mathrm{Ga}$, estão em concordância com os valores certificados (Godoy, 2001). 
Tabela 3- Análise da Amostra de referência

\begin{tabular}{|c|c|c|c|}
\hline \multicolumn{4}{|c|}{ Nist SRM 2709 (solo) } \\
\hline Elemento & Valor certificado & Valor obtido & Erro relativo(\%) \\
\hline $\mathrm{Na}$ & 11600 & 13013 & 12 \\
\hline $\mathrm{Mg}$ & 15100 & 15814 & 5 \\
\hline $\mathrm{Al}$ & 75000 & 74651 & 0 \\
\hline $\mathrm{K}$ & 20300 & 20545 & 1 \\
\hline $\mathrm{Ca}$ & 18900 & 19477 & 3 \\
\hline $\mathrm{Sc}$ & 12 & 12 & 0 \\
\hline $\mathrm{Ti}$ & 3420 & 3635 & 6 \\
\hline $\mathrm{V}$ & 112 & 117 & 4,5 \\
\hline $\mathrm{Cr}$ & 130 & 130 & 0 \\
\hline $\mathrm{Mn}$ & 538 & 563,7 & 4,8 \\
\hline $\mathrm{Fe}$ & 35000 & 36293 & 4 \\
\hline Co & 13,4 & 12,6 & -6 \\
\hline $\mathrm{Ni}$ & 88 & 78 & -11 \\
\hline $\mathrm{Cu}$ & 34,6 & 38 & 9 \\
\hline $\mathrm{Zn}$ & 106 & 109 & 3 \\
\hline $\mathrm{Ga}$ & 14 & 17 & 22 \\
\hline As & 17,7 & 20,0 & 13 \\
\hline $\mathrm{Rb}$ & 96 & 97 & 1 \\
\hline $\mathrm{Sr}$ & 231 & 239 & 3 \\
\hline $\mathrm{Y}$ & 18 & 17 & -8 \\
\hline Mo & 2 & 2,1 & 5 \\
\hline $\mathrm{Cd}$ & 0,38 & 0,45 & 19 \\
\hline $\mathrm{Sb}$ & 7,9 & 8,2 & 3 \\
\hline Cs & 5,3 & 5,4 & 3 \\
\hline $\mathrm{Ba}$ & 968 & 948 & -2 \\
\hline La & 23 & 22 & -3 \\
\hline $\mathrm{Ce}$ & 42 & 43 & 2 \\
\hline $\mathrm{Nd}$ & 19 & 19 & -2 \\
\hline $\mathrm{Sm}$ & 3,8 & 4,0 & 5 \\
\hline $\mathrm{Eu}$ & 0,9 & 1,0 & 14 \\
\hline Dy & 3,5 & 3,0 & -14 \\
\hline Ho & 0,54 & 0,62 & 15 \\
\hline $\mathrm{Yb}$ & 1,6 & 1,9 & 16 \\
\hline W & 2 & 2,2 & 12 \\
\hline $\mathrm{Pb}$ & 18,9 & 18,4 & -3 \\
\hline Th & 11 & 10,2 & -7 \\
\hline U & 3 & 3,3 & 9 \\
\hline
\end{tabular}




\subsection{2. \\ Determinação de metais por ICP-MS}

Muitos estudos em ecossistemas aquáticos têm utilizado os sedimentos de fundo como uma fonte de acumulação de poluentes a partir da coluna d'água e, portanto, propício aos monitoramentos ambientais, possibilitando o conhecimento das principais fontes de poluição dentro do sistema aquático.

A abertura total de cada camada de sedimento e a posterior determinação de metais foram feitas em dois pontos de coleta, ou seja, em dois perfis. Os perfis de amostras escolhidos foram o $2 \mathrm{C}$ e o $2 \mathrm{~S}$ porque a datação foi calculada através do modelo CRS nos dois pontos e, também, pela localização de cada um: o 2S, mais ao sul em uma região de maior deposição e, o $2 \mathrm{C}$ em frente à foz do rio em uma região de maior energia e menor deposição em relação ao $2 S$. Desta forma acreditou-se poder avaliar e estudar melhor o impacto na região como descrito anteriormente.

Foram determinados 50 elementos para cada perfil. As tabelas 21 e 22 com as concentrações determinadas para cada perfil encontram-se no capítulo 9.

\subsubsection{1. Determinação dos elementos do perfil $2 S$}

A partir da determinação das concentrações dos elementos do perfil $2 S$ observou-se alterações no comportamento de alguns metais dentre eles o cobre, o zinco, cádmio e cromo (Tabela 21, capítulo 9).

O cobre é encontrado em sistemas aquáticos sob a forma solúvel, particulada e coloidal, porém as duas últimas são as mais comuns. Geralmente seu transporte acontece na forma adsorvida e tem a propriedade de se fixar rapidamente aos sedimentos. As principais contribuições de cobre, além das contribuições naturais como, por exemplo, vegetação, partículas vulcânicas e organismos aquáticos, podem estar relacionadas a esgotos domésticos, origem industrial e agricultura uma vez que o elemento é muito utilizado em indústrias como as de mineração, químicas, aço e de fertilizantes (Gusmão, 2004).

O zinco é considerado um elemento essencial, importante para o "desenvolvimento e função de todas as células vivas" (Cavalcanti, 2003, p. 
1546). O zinco geralmente está associado aos argilominerais sob a forma de óxidos e hidróxidos de ferro e manganês, e também encontrado na matéria orgânica na maioria dos ambientes aquáticos (Forstner, 1983). As contribuições de zinco estão ligadas às ligas metálicas como o latão e o bronze, além de ser utilizado na produção de telhas e calhas residenciais, usado na produção de pilhas e também como pigmento em tintas de cor branca.

As fontes naturais de cádmio são devido às atividades vulcânicas, erosão de rochas sedimentares e fosfáticas e incêndios florestais enquanto as maiores contribuições antropogênicas estão relacionadas às atividades de mineração, produção e consumo de baterias (níquel-cádmio), pigmentos, componentes eletrônicos. Existem ainda, as fontes onde o cádmio pode estar em ligas de zinco, chumbo e cobre, em emissões de indústrias de ferro e aço, combustíveis fósseis (carvão, óleo, gás, turfa e madeira), cimento e fertilizantes fosfatados. Em ambientes aquáticos, as formas de cádmio não solúveis ou adsorvidas ao sedimento apresentam pouca mobilidade enquanto determinados sais e complexos são solúveis e com alta mobilidade na água (FIT, CETESB, 2011).

Nos ambientes aquáticos o cromo III, em geral, é rapidamente precipitado e adsorvido a partículas suspensas e sedimentos de fundo enquanto o cromo $\mathrm{VI}$ está presente, predominantemente, na forma solúvel (Cotta, 2003). As contribuições naturais são devido aos incêndios florestais e às erupções vulcânicas. O cromo VI, que é considerado cancerígeno, presente no meio ambiente é quase todo proveniente das atividades humanas sendo originado nas emissões das indústrias de cimento, galvânicas, fundições, soldagem, mineração, lixos urbanos e industriais, incineração, fertilizantes e especialmente a sua utilização em curtumes (Schnitzler, 2005).

De acordo com Coelho (2012), o monitoramento de elementos traço na bacia do RPS foi implementado nos anos setenta e, somente no final desta década, o programa de monitoramento ambiental no RPS foi estabelecido como base de rotina, ou seja, só existem registros de contaminações após este período. Coelho também afirma que a Cia Paraibuna de Metais desde sua abertura em 02/1980, despejou no RPS uma grande quantidade de metais pesados, principalmente $\mathrm{Zn}$ e Cd. Depois do acidente ocorrido em 1982, foi reportado que as concentrações de $\mathrm{Zn}$ ficaram acima de $500 \mathrm{mg} \mathrm{kg}{ }^{-1} \mathrm{em}$ Itaocara, que fica $150 \mathrm{~km}$ abaixo da confluência do Rio Paraibuna com o RPS e $150 \mathrm{~km}$ acima da sua foz. 
As concentrações de cádmio e zinco no perfil 2S (Figuras 26 e 27) mostram um comportamento bastante parecido com o descrito por Coelho, com um aumento significante nas concentrações após 1980, coincidindo com o início da operação da Cia Paraibuna de Metais. Para os dois metais, ao final dos anos 80 , parece que foi alcançada uma nova média de concentração com valores maiores.

As figuras 28 e 29 descrevem o comportamento das concentrações de cobre e cromo que também seguiram o padrão de zinco e cádmio, com o aumento das concentrações a partir dos anos oitenta e mantendo uma concentração mais alta até os dias de hoje. Este fato também está associado à Cia Paraibuna de Metais, uma vez que esta despejava rejeitos ricos em Zn e Cd e outros metais pesados desde sua implantação. As maiores concentrações de Cu podem, também, estar associadas a fungicidas usados na plantação de cana de açúcar, praticada na região e contaminação de lixo urbano.

Os valores máximos observados para o cromo, o cobre e o zinco foram de $102 \mathrm{mg} \mathrm{kg}^{-1}, 48 \mathrm{mg} \mathrm{kg}^{-1}$ e $139 \mathrm{mg} \mathrm{kg}^{-1}$, respectivamente em torno de 1990. A concentração de cádmio apresentou um valor máximo por volta de 1994, com o valor de $0,5 \mathrm{mg} \mathrm{kg}^{-1}$. As concentrações destes metais estimadas neste trabalho estão próximas às concentrações de alguns metais determinadas por Molisani et al. (1999) na região: $52 \mathrm{mg} \mathrm{kg}^{-1}$ para Cu, $115 \mathrm{mg} \mathrm{kg}^{-1}$ para Cr e $162 \mathrm{mg} \mathrm{kg}^{-1}$ para o zinco.

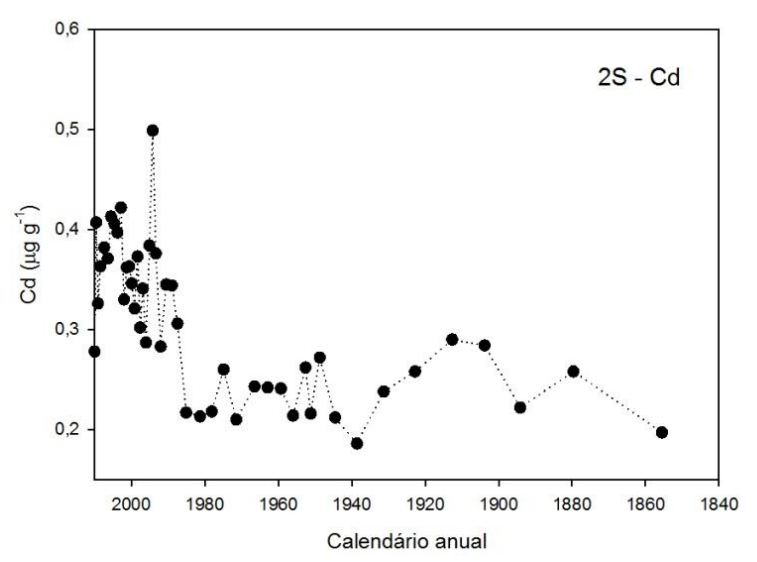

Figura 26-Idade versus concentração de cádmio para o perfil 2S 


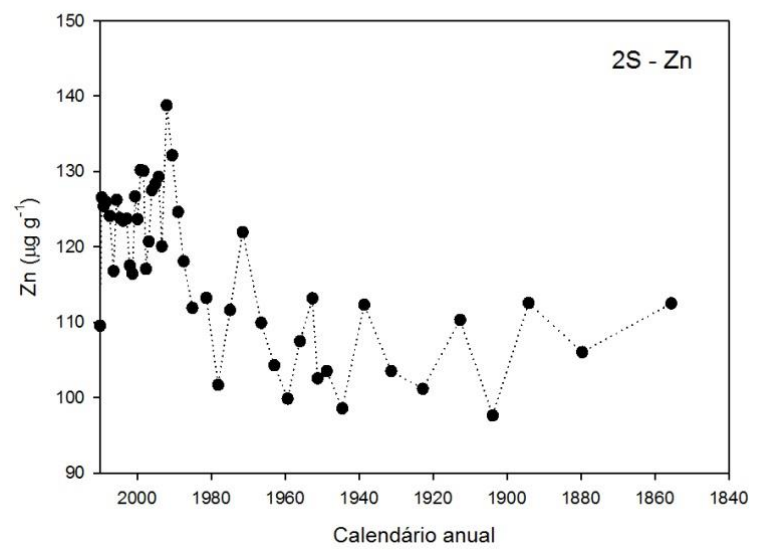

Figura 27-Idade versus concentração de zinco para o perfil 2S.

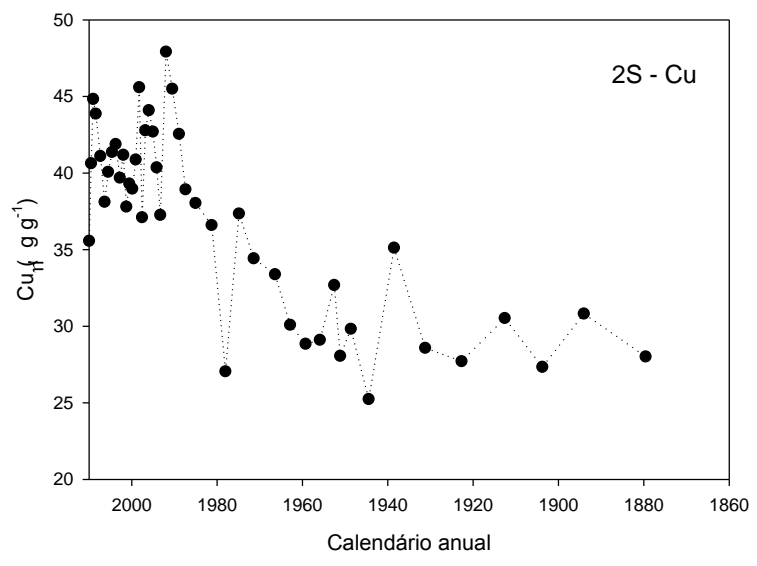

Figura 28- Idade versus concentração de cobre para o perfil 2S.

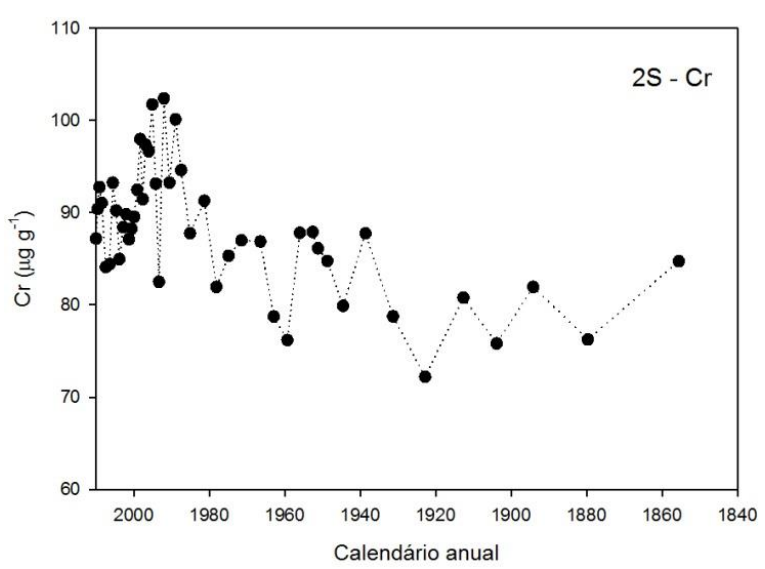

Figura 29- Idade versus concentração de cromo para o perfil 2S. 


\subsubsection{2.}

\section{Determinação dos elementos do perfil 2C}

Do mesmo modo que no perfil 2S, no perfil $2 \mathrm{C}$ observou-se que o zinco e o cádmio apresentaram um comportamento semelhante com o aumento de suas concentrações a partir de 1940 e indicando um pico de concentração no início dos anos setenta (Figuras 30 e 31 e Tabela 22 do capítulo 9). Além destes metais, foi observado que o cobre e o cromo também seguiram este mesmo padrão de comportamento (Figuras 32 e 33). No entanto, como mencionado por Coelho anteriormente, não existem dados referentes à poluição de metais no sistema do RPS anteriores à segunda metade dos anos 70. Neste caso a validação das datas calculadas para o perfil 2C não foi possível.

Os valores máximos estimados das concentrações foram de $42 \mathrm{mg} \mathrm{kg}^{-1}$ para Cu e Ni, $89 \mathrm{mg} \mathrm{kg}^{-1}$ para o $\mathrm{Cr}, 69 \mathrm{~g} \mathrm{~kg}^{-1}$ para Fe e $191 \mathrm{~g} \mathrm{~kg}^{-1}$ para o Al.

Os valores estimados das concentrações de $\mathrm{Cu}, \mathrm{Cr}$ e $\mathrm{Zn}$ no ponto $2 \mathrm{C}$ estão um pouco abaixo das concentrações determinadas por Molisani et al. (1999), sendo justificado pelo ponto 2C ser de menor deposição e maior energia em relação ao $2 \mathrm{~S}$, como já foi dito anteriormente.

Existe uma mesma variação dos metais apontados do que a observada para alumínio e a mudança pode ser devido a uma mudança na natureza do sedimento. Tal mudança pode ser observada através da normalização de alguns elementos pelo alumínio como será discutida no item 6.5.3.

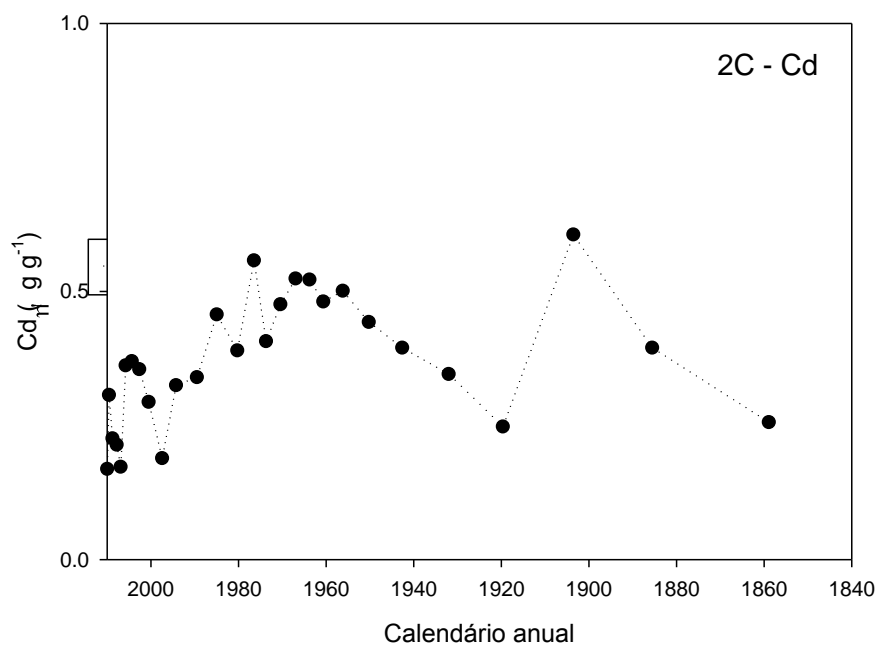

Figura 30-Idade versus concentração de cádmio para o perfil 2C. 


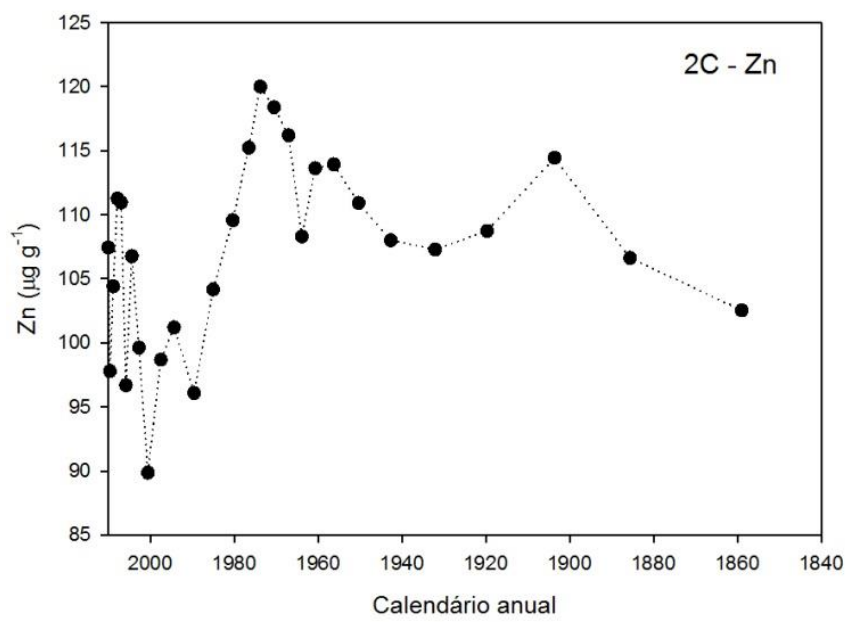

Figura 31- Idade versus concentração de zinco para o perfil 2C.

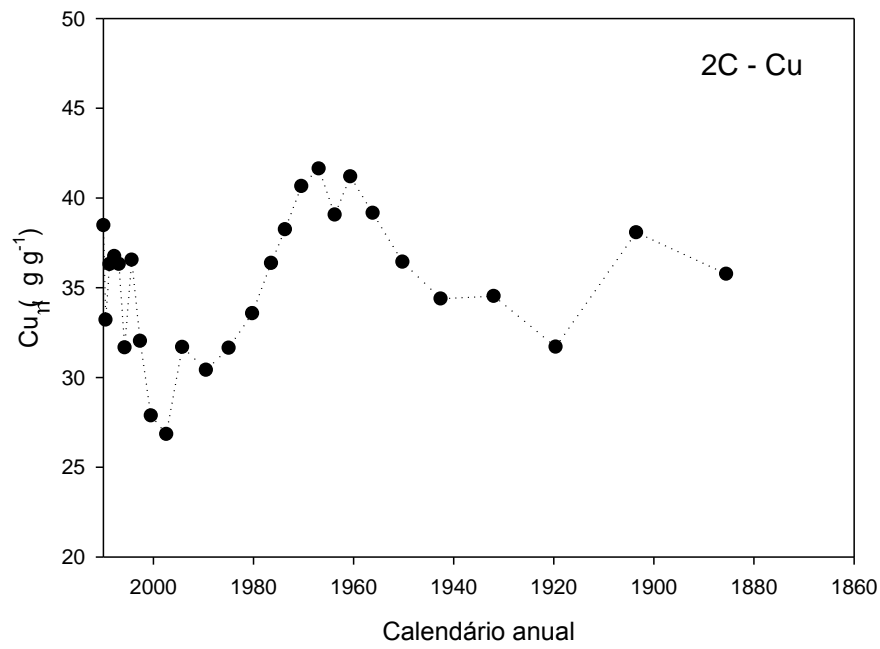

Figura 32- Idade versus concentração de cobre para o perfil 2C.

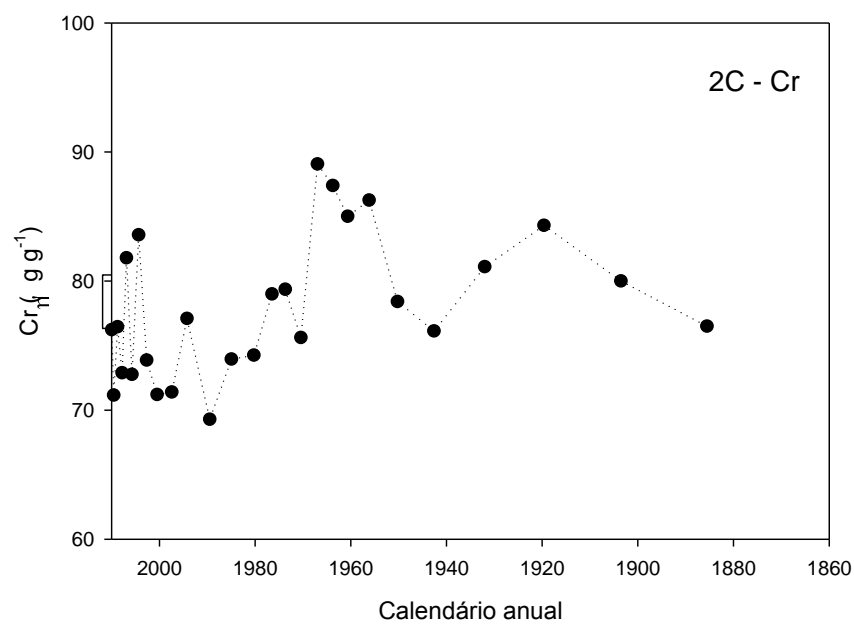

Figura 33- Idade versus concentração de cromo para o perfil 2C. 


\subsection{3. \\ Análise de metais normalizados pelo Alumínio}

As mudanças do uso da terra e represamento dos rios têm como consequência a mudança na natureza do material particulado que chega e se deposita no delta dos rios. Nestes casos, a normalização da concentração dos elementos com o alumínio pode ajudar a traçar tais mudanças, principalmente através de alguns elementos que tenham origem diferente deste, como o caso do $\mathrm{Ca}$, do $\mathrm{Mg}$ e do Sr.

O magnésio é utilizado como um traçador natural para fins de documentar e identificar a mistura de sedimentos marinhos e fluviais em estuários. Ele ocorre em três formas diferentes: uma pequena parte trocável, uma parte incorporada aos carbonatos e outra associada aos silicatos (minerais argilosos). O conteúdo de dolomita (carbonato de $\mathrm{Ca}$ e $\mathrm{Mg}$ ) em sedimentos também pode indicar a influência marinha.

Através da figura 34 se pode observar a relação $\mathrm{Mg} / \mathrm{Al}$ para os pontos $2 \mathrm{~S}$ e 2C. Observa-se que houve uma variação significante na razão $\mathrm{Mg} / \mathrm{Al}$ ocorrida entre 1962 e 1988 no ponto 2S. Esta variação indica uma mudança na natureza dos sedimentos que coincide com o período em que ocorreram as maiores intervenções no sistema do RPS através de construções de usinas hidrelétricas, início da transposição do RPS para o Rio Guandu a fim de abastecimento da cidade do Rio de Janeiro e as construções de várias barragens.

Cada curva apresenta praticamente dois patamares em relação às concentrações. A distância entre os patamares é maior na curva do ponto $2 \mathrm{~S}$, provavelmente, porque esta é uma zona de maior deposição do que o ponto $2 \mathrm{C}$. A redução progressiva da razão $\mathrm{Mg} / \mathrm{Al}$ é evidente com o aumento da deposição de material terrígeno na região ao sul da foz do RPS (2S) que pode ser resultante da própria erosão na costa dessa região. Para a curva no ponto $2 S$ observa-se um patamar mais alto na região entre 1962 e 1930 com razões médias no valor de 0,10 , indicando um caráter marinho dos sedimentos; e um patamar mais baixo com razões médias no valor de 0,06 para o período a partir de 1988 até a atualidade indicando um caráter terrígeno aos sedimentos. A maior variação na caracterização dos sedimentos ocorre entre 1962 e 1988 com a distância observada entre os dois patamares. A curva $2 \mathrm{C}$ também apresenta dois patamares distintos, mas a partir dela, não se pode tirar conclusões em 
relação às datas e fatos históricos. Através da relação $\mathrm{Mg} / \mathrm{Al}$ observada no ponto $2 S$, pode-se sugerir que há um efeito de diluição devido ao aumento da deposição de material terrígeno rico em metais que são misturados a sedimentos marinhos mais pobres em metais.

O efeito de diluição dos sedimentos marinhos pela influência de material terrígeno pode ser observado também através da razão entre estrôncio e alumínio uma vez que esse elemento também pode ser utilizado como um traçador bastante sensível da fração carbonática ( $90 \%$ é de origem marinha) (Salomons, 1977). A evidência é maior principalmente para o perfil 2S. A figura 35 indica que, em concordância com a relação $\mathrm{Mg} / \mathrm{Al}$, houve uma mudança significativa na natureza dos sedimentos a partir da década de sessenta se estendendo até o final da década de oitenta.

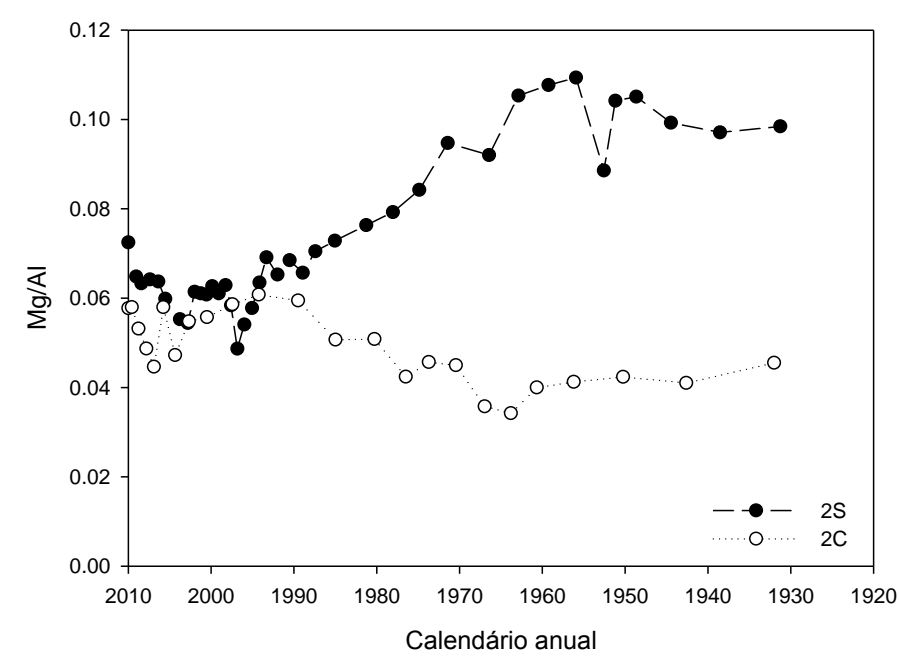

Figura 34-Idade versus relação $\mathrm{Mg} / \mathrm{Al}$ para os pontos $2 \mathrm{~S}$ e $2 \mathrm{C}$.

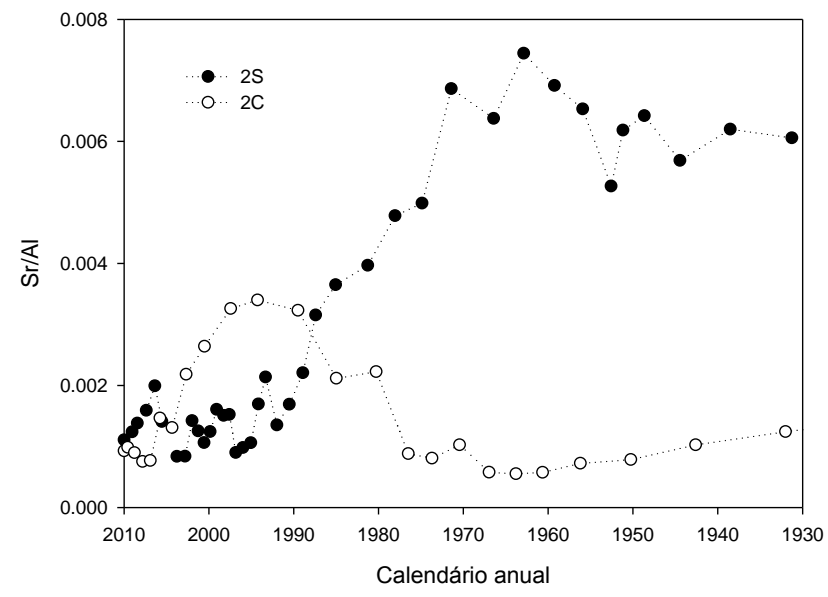

Figura 35-Idade versus relação Sr/Al para os pontos 2S e 2C. 


\subsubsection{1. \\ Cálculo dos fatores de enriquecimento e índices de geoacumulação}

O desenvolvimento industrial e a agricultura são grandes responsáveis pelo aporte de metais pesados nos ambientes aquáticos que atingem a costa através do transporte dos resíduos pelos rios. O outro contribuinte no aporte de metais pesados é a deposição atmosférica. $O$ fator de enriquecimento é muito utilizado para avaliar a contribuição antrópica em sedimentos contaminados ou modificados.

A razão entre a concentração do metal normalizado no sedimento e sua concentração natural normalizada na área é definida como fator de enriquecimento (FE). Este fator indica quantas vezes as concentrações dos metais variaram em relação às concentrações do background do local estudado. As intensidades das possíveis anomalias de metais e possíveis mudanças na natureza dos sedimentos foram observadas utilizando o fator de enriquecimento (FE) definido por Gresens (1967), tendo o Al como elemento normalizador, de acordo com a equação:

$$
F E=\frac{\left(\frac{M}{A l}\right) \text { amostra }}{\left(\frac{M}{A l}\right) \text { referência }} \quad \text { Eq.(14) }
$$

Onde:

$(\mathrm{M} / \mathrm{Al})_{\text {amostra }}$ representa a razão entre a concentração do metal pesado de interesse normalizado pelo alumínio na amostra, ou seja, em cada camada de sedimento.

$(\mathrm{M} / \mathrm{Al})_{\text {referência }}$ representa a mesma razão em relação ao fundo geoquímico natural de referência (background).

A caracterização do fundo geoquímico natural do estuário do RPS foi realizada a partir da média das concentrações dos metais pesados presentes nos sedimentos de fundo normalizados pela média das concentrações de alumínio na mesma região, neste caso, sedimentos das camadas entre 29 e 32 $\mathrm{cm}$ para o perfil $2 \mathrm{C}$ e entre 48 e $51 \mathrm{~cm}$ para o prefil $2 \mathrm{~S}$.

O índice de geoacumulação (Igeo), introduzido por Müller (1979), também é muito utilizado na avaliação geoquímica de ambientes impactados, onde se classifica as classes de poluição dos metais pesados nos sedimentos. $\mathrm{O}$ 
índice apresenta sete classes de poluição em função dos graus de 0 (ausência de poluição) a 6 (poluição muito forte). Uma vez que os índices observados foram bem baixos, os mesmos foram utilizados neste trabalho para avaliar as mudanças ocorridas na região. O Igeo estabelece a relação entre as concentrações de metais de interesse encontrados na região em estudo e um valor referencial deste metal relativo ao fundo geoquímico natural da mesma (Mortatti et al., 2010). O cálculo do Igeo é obtido através da relação:

$$
\text { Igeo }=\log _{2} \frac{M e_{\text {amostra }}}{1,5 . M e_{\text {referência }}}
$$

Onde:

$[\mathrm{Me}]_{\mathrm{amostra}}$ representa a concentração do metal pesado no sedimento,

$[\mathrm{Me}]_{\text {referência }}$ representa a concentração do metal pesado relativo ao fundo geoquímico natural de referência,

O fator 1,5 é usado para compensar possíveis variações dos dados de "background" devido a efeitos litogênicos.

A concentração do metal relativo ao fundo geoquímico natural de referência foi calculada pela média das concentrações dos sedimentos de fundo, para os dois perfis, 2C e 2S, do mesmo modo que para o cálculo do FE.

As tabelas que reúnem os valores calculados para o FE e para o lgeo dos elementos selecionados em cada perfil para a avaliação do impacto ambiental através dos sedimentos se encontram no capítulo 9 (Tabelas 23 e 24).

Uma vez que a datação foi validada no ponto $2 S$ e suas taxas de sedimentação são mais altas, as mudanças podem ser observadas com mais nitidez e segurança neste ponto. Os índices lgeo e FE apresentaram praticamente a mesma variação, portanto, os resultados para os metais foram apresentados em função dos índices de geoacumulação para o perfil 2S. Neste caso, observa-se que o Igeo para cobre, cromo, chumbo e zinco, apesar de serem negativos vêm num crescente desde os anos 80 e atingindo um máximo em meados dos anos 90 (Figura 36).

O cádmio apresentou dois patamares na representação do Igeo ao longo do perfil 2S. O gráfico da variação do Igeo mostra uma mudança significativa em meados dos anos 60 com o valor de $-0,5$ aumentando para 0 entre os anos 
oitenta e meados de mil novecentos e noventa a partir daí formando um novo patamar no valor médio de $+0,2$ até os dias de hoje (Figura 37). Há ainda um pico positivo no Igeo do $\mathrm{Cd}$ em 1994 indicando uma fraca poluição na região enquanto os outros Igeos calculados indicam ausência de poluição nesta região do delta do RPS.

Tais mudanças coincidem com as afirmações feitas por Coelho, 2012, quando diz que a Cia Paraibuna de Metais vem despejando uma grande quantidade de metais pesados no RPS desde sua abertura em 02/1980, principalmente $\mathrm{Zn}$ e Cd.

Uma vez que os índices de geoacumulação são determinados a partir das concentrações dos elementos nas camadas superiores em relação ao fundo geoquímico de referência da região, estes fatos também podem ser abordados e avaliados a partir dos valores de fluxo de incorporação dos metais, como será discutido no item a seguir.

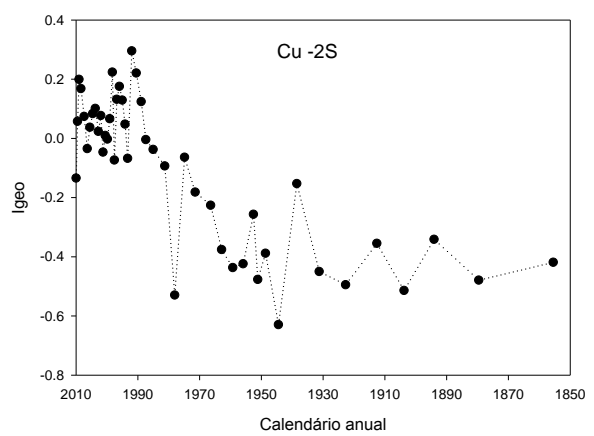

(a)

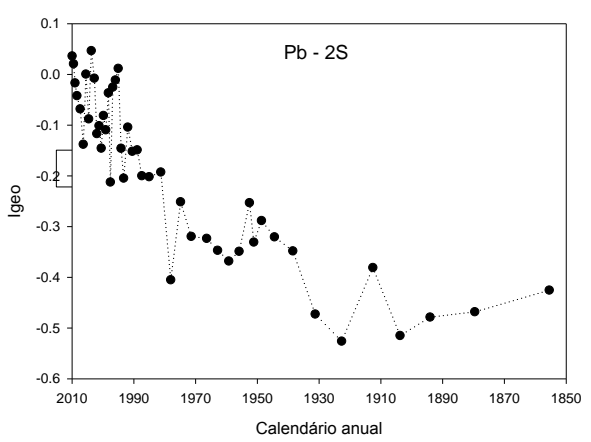

(c)

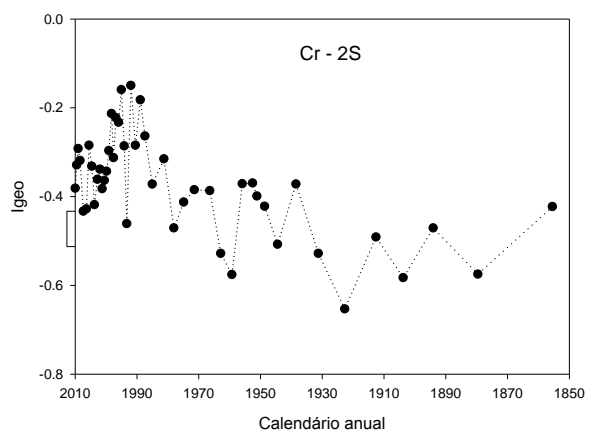

(b)

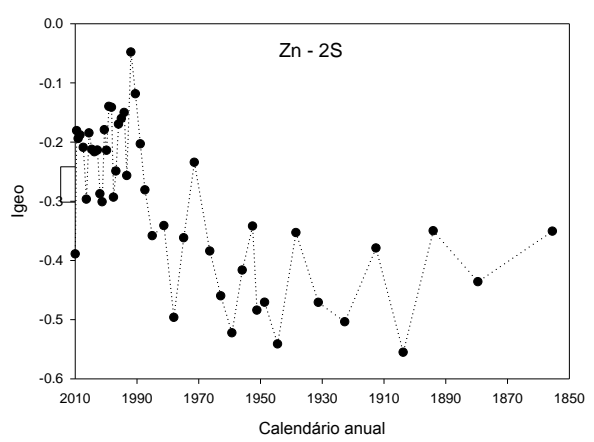

(d)

Figura 36 -Variação dos Igeo para $\mathrm{Cu}, \mathrm{Cr}, \mathrm{Pb}$ e $\mathrm{Zn}$ ao longo do perfil $2 \mathrm{~S}$. 


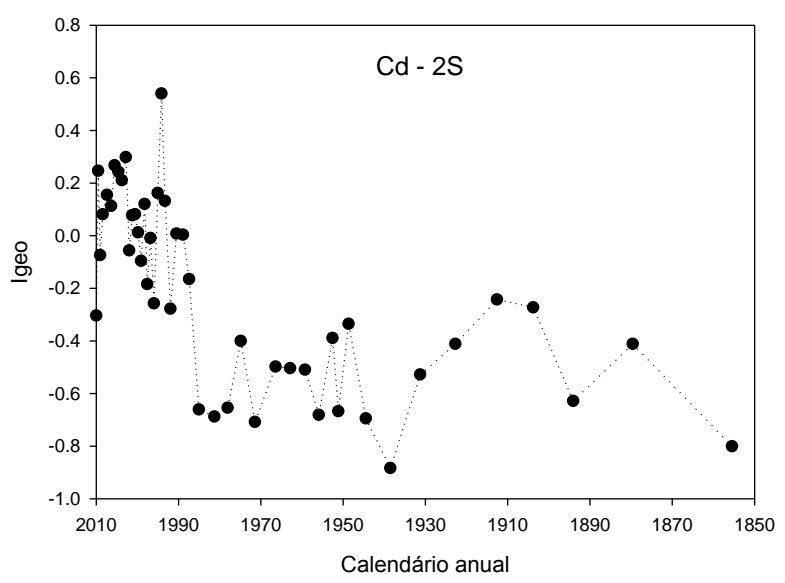

Figura 37 - Variação dos Igeo para Cd ao longo do perfil 2S

\subsection{4.}

\section{Fluxo de incorporação de metais}

O transporte de material particulado da coluna d'água para os sedimentos pose ser estimado a partir das taxas de sedimentação e das concentrações dos elementos. Deste modo, é possível calcular o fluxo de deposição de cada elemento em cada área estudada.

As curvas dos fluxos foram plotadas em função do calendário anual para o ponto $2 \mathrm{~S}$ e da profundidade mássica para o ponto $2 \mathrm{C}$. As tabelas que descrevem os valores dos fluxos dos elementos nos pontos $2 \mathrm{C}$ e $2 \mathrm{~S}$ se encontram no capítulo 9 (Tabelas 25 e 26, respectivamente).

Uma vez que $\mathrm{Fe}$, Mn e Ti são elementos de origem terrígena, o aporte de sedimentos continentais pode ser avaliado através dos gráficos dos fluxos de incorporação destes metais.

Ao observar a curva do fluxo de incorporação do ferro no ponto 2S nota-se que o fluxo vinha aumentando levemente até a década de 50 , onde apresenta um pico, e, volta a aumentar em meados dos anos 80 atingindo valores muito superiores aos observados anteriormente. No período entre meados dos anos 50 e meados dos anos 80 , o fluxo se manteve praticamente constante, tendo atingido um valor mínimo em torno de 1970. 
No ponto $2 \mathrm{C}$, apesar de não se comparar com as datas, o fluxo de ferro nas camadas mais recentes também é muito mais alto em relação ao fluxo das camadas mais profundas.

Observa-se, também, que houve um aumento do fluxo nas camadas mais antigas até certa profundidade em concordância com perfil $2 \mathrm{~S}$.

As curvas dos fluxos de titânio e manganês acompanham os perfis das curvas do fluxo de ferro (Figura 38).

Através das curvas de fluxo versus o calendário anual dos elementos chumbo, cobre e zinco no ponto $2 \mathrm{~S}$ observa-se, também, um aumento dos fluxos a partir da década de 80 (Figura 39). Tais aumentos podem estar relacionados, com a erosão existente na região, onde os sedimentos erodidos contribuem com o aumento de aporte terrígeno e, consequentemente, provocam tanto um aumento nas taxas de sedimentação quando no fluxo de incorporação de metais. 

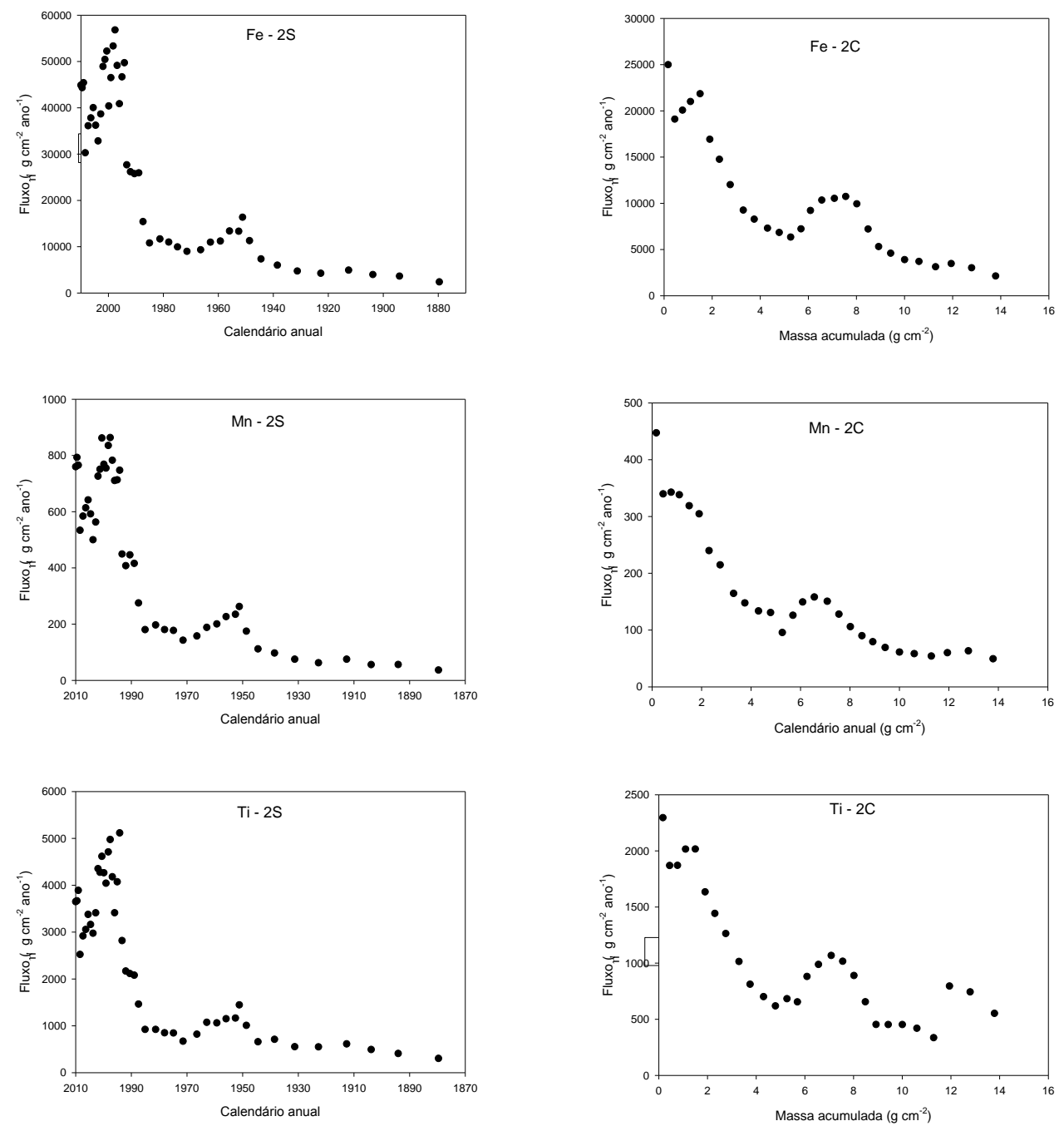

Figura 38-Variação dos fluxos de Fe, Mn e Ti e do perfil 2C e 2S. 

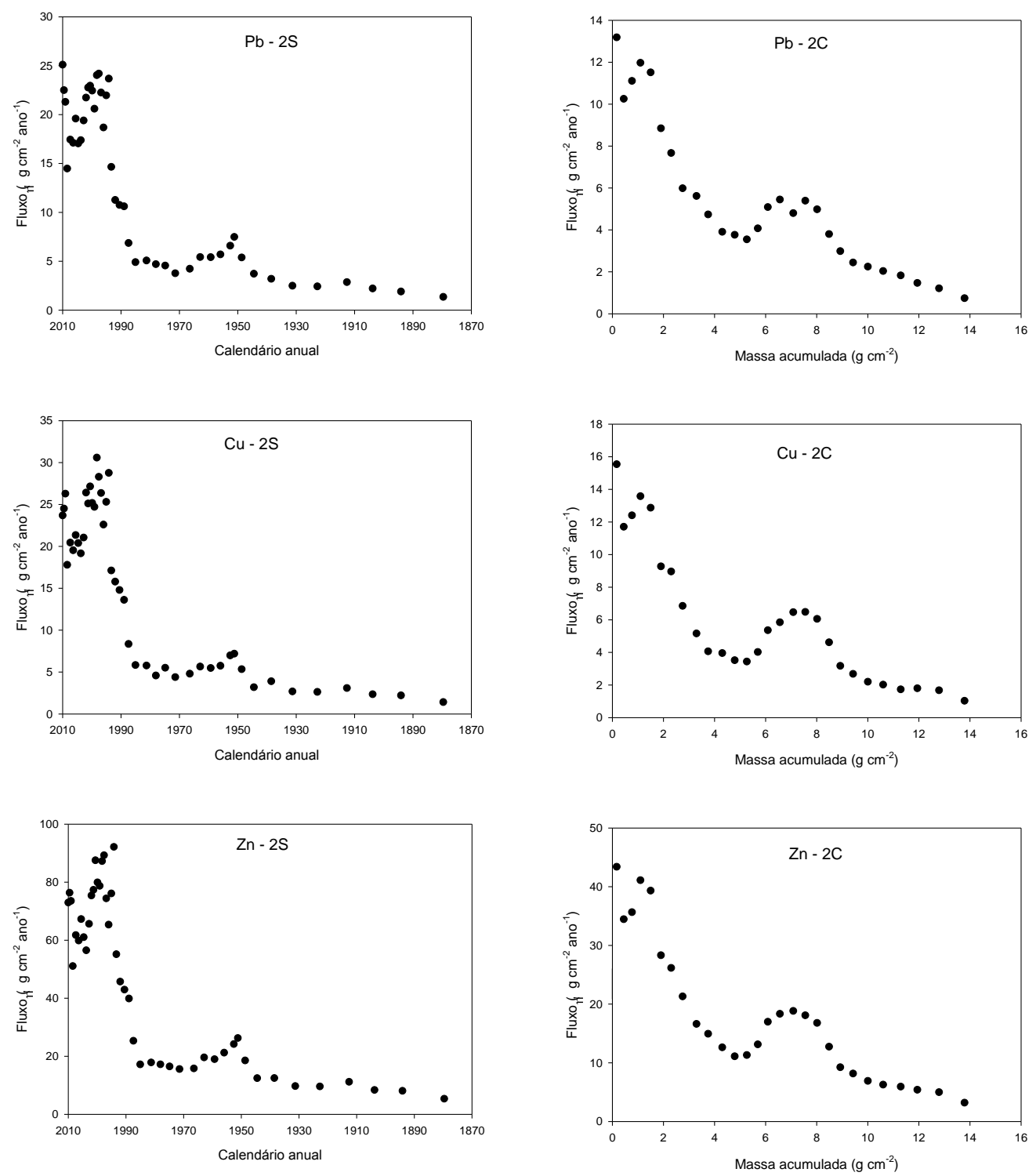

Figura 39-Variação dos fluxos $\mathrm{Pb}$, Cu e Zn do perfil 2C e 2S. 


\subsection{5.}

\section{Análise estatística dos metais}

A análise multivariada de dados foi abordada através da análise de fatores principais (AFP) e análise hierárquica de cluster (AHC).

\subsubsection{1.}

\section{Validação da base de dados}

Para uma utilização segura da base de dados foi feita uma avaliação detalhada do conjunto de dados obtida a partir dos seguintes passos:

- Identificação das variáveis que apresentam problemas na determinação com a técnica de ICP-MS;

- Identificação das variáveis com valores abaixo do limite de detecção;

- Identificação das variáveis apresentadas com valores faltantes;

- Identificação de outliers através da regressão linear múltipla entre as variáveis;

- Aplicação de histogramas, gráficos de dispersão entre as variáveis e testes de distribuição normal e lognormal;

As Tabelas 4 e 5 apresentam a estatística descritiva dos elementos determinados para cada perfil, $2 \mathrm{~S}$ e $2 \mathrm{C}$ respectivamente, antes de serem feitos os cortes das variáveis para a análise dos fatores principais. No perfil $2 \mathrm{C}$ foram determinados 51 elementos enquanto no perfil $2 S$ foram determinados 50 elementos. Essa diferença se dá devido aos valores de Ca, que apresentaram desvios muito altos no perfil 2S.

O Se é um elemento que possui uma sensibilidade considerada baixa na técnica de ICP-MS (Godoy, 2001). Ele apresenta problemas na determinação com a técnica de ICP-MS causado por interferências poliatômicas que possuem a mesma razão massa/carga, no caso ${ }^{40} \mathrm{Ar}^{40} \mathrm{Ar}^{+}$. Sendo assim, essa variável foi cortada do conjunto de variáveis.

Seguindo os passos descritos acima, os valores de cada variável foram observados em relação aos limites de detecção. A variável que apresentasse muitos valores menores ou perto do limite de detecção era descartada do conjunto de variáveis, como foi o caso do B com muitos valores faltantes. As variáveis que contivessem poucos valores faltantes foram mantidas e estes 
valores foram estimados através da regressão linear como foi o caso do Al e do Sc.

Considera-se outliers os valores anômalos que podem representar uma contaminação na medida. Os outliers podem influenciar na análise multivariada de dados, pois não estão representando verdadeiramente a variabilidade média da base de dados. A identificação de outliers foi realizada através da regressão linear múltipla entre as variáveis, onde se algum valor fosse muito diferente do padrão de correlação, era eliminado da base de dados. Nenhuma variável foi considerada como outlier dentro da base de dados estudada.

As variáveis que apresentaram baixa correlação com o conjunto das outras variáveis (ou seja, não eram bem explicadas pelo conjunto de variáveis), foram cortadas do conjunto de dados, como por exemplo, $\mathrm{Ag}, \mathrm{Li}, \mathrm{Be}, \mathrm{Ge}$ e $\mathrm{Nb}$. O Ca também foi cortado do conjunto de variáveis do perfil $2 \mathrm{C}$, pois este não estava presente no conjunto analisado no perfil 2S. Após a validação dos dados, a nova base de dados era constituída de 43 variáveis. 
Tabela 4-Análise estatística descritiva para as variáveis do perfil 2S. Valores em $\mathrm{mg} \mathrm{kg}^{-1}$ $\mathrm{e}\left(^{*}\right)$ valores em $\mathrm{g} \mathrm{kg}^{-1}$.

\begin{tabular}{|c|c|c|c|c|c|}
\hline Elementos & $\mathbf{N}$ & Mínimo & Máximo & Média & Desvio padrão \\
\hline $\begin{array}{l}\mathrm{Li} \\
\mathrm{Be}\end{array}$ & $\begin{array}{l}51 \\
51\end{array}$ & $\begin{array}{l}33 \\
1.6\end{array}$ & $\begin{array}{l}55 \\
3.2\end{array}$ & $\begin{array}{l}44.6 \\
2.45\end{array}$ & $\begin{array}{l}4.5 \\
0.39\end{array}$ \\
\hline B & 44 & 35 & 65 & 48.9 & 7.7 \\
\hline $\mathrm{Na}^{*}$ & 51 & 12 & 41 & 21.4 & 6.1 \\
\hline$M g^{*}$ & 51 & 6.2 & 13 & 8.95 & 1.5 \\
\hline $\mathrm{Al}^{*}$ & 49 & 65 & 152 & 116 & 21 \\
\hline $\mathrm{K}^{*}$ & 51 & 7.3 & 19 & 11.5 & 3.2 \\
\hline $\mathrm{Sc}$ & 50 & 9.0 & 18 & 14.1 & 2.2 \\
\hline $\mathrm{Ti}^{*}$ & 51 & 5.0 & 7.2 & 6.11 & 0.51 \\
\hline $\mathrm{V}^{*}$ & 51 & 0.09 & 0.15 & 0.12 & 0.02 \\
\hline $\mathrm{Cr}^{*}$ & 51 & 0.07 & 0.10 & 0.09 & 0.01 \\
\hline$M n^{*}$ & 51 & 0.62 & 1.4 & 1.06 & 0.22 \\
\hline $\mathrm{Fe}^{*}$ & 51 & 43 & 81 & 65.7 & 12 \\
\hline Co & 51 & 12 & 18 & 14.8 & 1.3 \\
\hline $\mathrm{Ni}$ & 51 & 30 & 43 & 35.8 & 3.3 \\
\hline $\mathrm{Cu}$ & 51 & 25 & 48 & 35.7 & 6.5 \\
\hline $\mathrm{Zn}^{*}$ & 51 & 0.09 & 0.14 & 0.12 & 0.01 \\
\hline Ga & 51 & 23 & 37 & 30.6 & 4.4 \\
\hline $\mathrm{Ge}$ & 51 & 4.3 & 6.9 & 5.59 & 0.72 \\
\hline As & 51 & 12 & 26 & 18.1 & 3.8 \\
\hline $\mathrm{Se}$ & 51 & 1.5 & 8.0 & 4.46 & 1.2 \\
\hline $\mathrm{Rb}$ & 51 & 24 & 105 & 70.3 & 21 \\
\hline $\mathrm{Sr}$ & 51 & 0.10 & 0.81 & 0.38 & 0.22 \\
\hline Y & 51 & 9.3 & 22 & 16.8 & 2.9 \\
\hline $\mathrm{Nb}$ & 51 & 18 & 26 & 21.7 & 2.0 \\
\hline Mo & 51 & 0.84 & 1.7 & 1.30 & 0.26 \\
\hline $\mathrm{Ag}$ & 51 & 0.33 & 1.2 & 0.62 & 0.20 \\
\hline $\mathrm{Cd}$ & 51 & 0.14 & 0.50 & 0.30 & 0.08 \\
\hline $\mathrm{Sb}$ & 51 & 0.10 & 0.31 & 0.22 & 0.04 \\
\hline Cs & 51 & 2.5 & 4.6 & 3.81 & 0.52 \\
\hline $\mathrm{Ba}^{*}$ & 51 & 0.20 & 0.51 & 0.32 & 0.09 \\
\hline La & 51 & 23 & 60 & 43.0 & 9.2 \\
\hline $\mathrm{Ce}$ & 51 & 46 & 125 & 90.3 & 19 \\
\hline $\operatorname{Pr}$ & 51 & 4.9 & 13 & 9.71 & 2.0 \\
\hline $\mathrm{Nd}$ & 51 & 19 & 46 & 35.0 & 6.5 \\
\hline $\mathrm{Sm}$ & 51 & 3.4 & 7.8 & 6.05 & 0.98 \\
\hline $\mathrm{Eu}$ & 51 & 0.91 & 1.9 & 1.44 & 0.22 \\
\hline $\mathrm{Gd}$ & 51 & 3.2 & 8.7 & 6.38 & 1.3 \\
\hline $\mathrm{Tb}$ & 51 & 0.40 & 0.97 & 0.76 & 0.14 \\
\hline Dy & 51 & 2.1 & 5.1 & 3.92 & 0.67 \\
\hline Ho & 51 & 0.37 & 1.0 & 0.73 & 0.13 \\
\hline $\mathrm{Er}$ & 51 & 1.1 & 2.8 & 2.08 & 0.36 \\
\hline $\mathrm{Tm}$ & 51 & 0.16 & 0.34 & 0.28 & 0.04 \\
\hline $\mathrm{Yb}$ & 51 & 1.0 & 2.4 & 1.91 & 0.29 \\
\hline Lu & 51 & 0.14 & 0.33 & 0.26 & 0.04 \\
\hline W & 51 & 1.1 & 1.8 & 1.32 & 0.19 \\
\hline $\mathrm{Pb}$ & 51 & 23 & 38 & 31.5 & 4.0 \\
\hline $\mathrm{Bi}$ & 51 & 0.1 & 0.4 & 0.25 & 0.06 \\
\hline Th & 51 & 7.9 & 19 & 14.5 & 2.7 \\
\hline U & 51 & 2.0 & 3.5 & 2.89 & 0.33 \\
\hline
\end{tabular}


Tabela 5-Estatística descritiva para as variáveis do perfil $2 \mathrm{C}$. Valores em $\mathrm{mg} \mathrm{kg}^{-1} \mathrm{e}\left({ }^{*}\right)$ valores em $\mathrm{g} \mathrm{kg}^{-1}$.

\begin{tabular}{|c|c|c|c|c|c|}
\hline Elementos & $\mathbf{N}$ & Mínimo & Máximo & Média & Desvio padrão \\
\hline $\begin{array}{l}\mathrm{Li} \\
\mathrm{Be}\end{array}$ & $\begin{array}{l}32 \\
32\end{array}$ & $\begin{array}{l}38.1 \\
1.9\end{array}$ & $\begin{array}{l}60.0 \\
3.2\end{array}$ & $\begin{array}{l}49.2 \\
2.51\end{array}$ & $\begin{array}{l}4.3 \\
0.36\end{array}$ \\
\hline$B$ & 32 & 2.9 & 104 & 51.0 & 21 \\
\hline $\mathrm{Na}^{*}$ & 32 & 8.4 & 36 & 21.4 & 7.2 \\
\hline$M g^{*}$ & 32 & 5.7 & 9.1 & 7.72 & 0.80 \\
\hline $\mathrm{Al}^{*}$ & 32 & 111 & 191 & 150 & 22 \\
\hline $\mathrm{K}^{*}$ & 32 & 7.7 & 17 & 10.4 & 2.4 \\
\hline $\mathrm{Ca}^{*}$ & 32 & 8.0 & 64 & 26.5 & 15 \\
\hline Sc & 32 & 11 & 17 & 14.2 & 1.7 \\
\hline $\mathrm{Ti}^{*}$ & 32 & 5.3 & 17.8 & 8.30 & 4.6 \\
\hline $\mathrm{V}$ & 32 & 103 & 139 & 119.5 & 9.1 \\
\hline $\mathrm{Cr}$ & 32 & 68 & 89 & 77.5 & 5.3 \\
\hline $\mathrm{Mn}^{*}$ & 32 & 0.68 & 1.6 & 1.03 & 0.17 \\
\hline $\mathrm{Fe}^{*}$ & 32 & 50 & 74 & 61.7 & 5.0 \\
\hline Co & 32 & 12 & 15 & 13.4 & 0.84 \\
\hline $\mathrm{Ni}$ & 32 & 25 & 42 & 33.5 & 4.1 \\
\hline $\mathrm{Cu}$ & 32 & 27 & 42 & 34.7 & 3.9 \\
\hline $\mathrm{Zn}$ & 32 & 90 & 121 & 108 & 7 \\
\hline $\mathrm{Ga}$ & 32 & 20 & 33 & 27.5 & 3.4 \\
\hline $\mathrm{Ge}$ & 32 & 4.4 & 6.7 & 5.54 & 0.64 \\
\hline As & 32 & 9.6 & 25 & 15.4 & 3.9 \\
\hline $\mathrm{Rb}$ & 32 & 54 & 86 & 66.2 & 8.1 \\
\hline $\mathrm{Sr}$ & 32 & 97 & 491 & 216 & 110 \\
\hline$Y$ & 32 & 16 & 24 & 19.0 & 1.9 \\
\hline $\mathrm{Nb}$ & 32 & 18 & 42 & 23.7 & 7.4 \\
\hline Mo & 32 & 0.95 & 1.7 & 1.38 & 0.20 \\
\hline $\mathrm{Cd}$ & 32 & 0.17 & 0.61 & 0.36 & 0.12 \\
\hline $\mathrm{Sb}$ & 32 & 0.09 & 0.47 & 0.22 & 0.07 \\
\hline Cs & 32 & 2.8 & 4.1 & 3.33 & 0.37 \\
\hline $\mathrm{Ba}$ & 32 & 190 & 404 & 260 & 57 \\
\hline $\mathrm{La}$ & 32 & 36 & 94 & 53.9 & 10 \\
\hline $\mathrm{Ce}$ & 32 & 71 & 184 & 115 & 20 \\
\hline $\operatorname{Pr}$ & 32 & 8.3 & 21 & 12.3 & 2.3 \\
\hline $\mathrm{Nd}$ & 32 & 30 & 69 & 41.3 & 7.1 \\
\hline $\mathrm{Sm}$ & 32 & 4.9 & 11 & 6.82 & 1.1 \\
\hline $\mathrm{Eu}$ & 32 & 1.2 & 1.8 & 1.53 & 0.17 \\
\hline $\mathrm{Gd}$ & 32 & 5.1 & 12 & 7.28 & 1.2 \\
\hline $\mathrm{Tb}$ & 32 & 0.66 & 1.3 & 0.90 & 0.11 \\
\hline Dy & 32 & 3.3 & 6.0 & 4.35 & 0.48 \\
\hline $\mathrm{Ho}$ & 32 & 0.66 & 0.99 & 0.82 & 0.07 \\
\hline $\mathrm{Er}$ & 32 & 1.8 & 2.7 & 2.27 & 0.21 \\
\hline $\mathrm{Tm}$ & 32 & 0.26 & 0.37 & 0.31 & 0.03 \\
\hline $\mathrm{Yb}$ & 32 & 1.8 & 2.6 & 2.09 & 0.21 \\
\hline $\mathrm{Lu}$ & 32 & 0.24 & 0.39 & 0.30 & 0.03 \\
\hline W & 32 & 1.0 & 1.5 & 1.25 & 0.11 \\
\hline $\mathrm{Pb}$ & 32 & 24 & 37 & 31.2 & 3.4 \\
\hline $\mathrm{Bi}$ & 32 & 0.15 & 0.28 & 0.22 & 0.04 \\
\hline Th & 32 & 13 & 51 & 18.9 & 7.0 \\
\hline$U$ & 32 & 2.6 & 17 & 5.35 & 4.1 \\
\hline
\end{tabular}




\subsubsection{2.}

\section{Análise dos fatores principais (AFP)}

Em análises multivariadas, principalmente Análise de Fatores Principais (AFP) e Análise de Componentes Principais (ACP), é importante que haja um número mínimo de amostras baseado nos graus de liberdade da base de dados a fim de se obter resultados confiáveis (Godoy, 2001).

No caso do perfil 2S com 51 amostras, o maior número possível de variáveis a ser utilizado é 38 segundo a equação (13). A partir da definição do número de variáveis que deveriam estar envolvidas no novo conjunto validado, foram adotados os seguintes critérios para a redução deste número:

- Os testes preliminares mostraram que o grupo das terras raras apresentou uma forte correlação entre os elementos praticamente formando um grupo separado entre eles. Neste caso, somente La e Ce foram incluídos no conjunto das variáveis como representantes do grupo dos lantanídeos;

- O elemento $Y$ também foi cortado. Devido à sua posição na tabela periódica, grupo 3B, ele apresenta uma alta correlação com o grupo dos lantanídeos;

- O elemento $\mathrm{Na}$ foi cortado do conjunto das variáveis por estar presente na água do mar em grandes concentrações;

- Os elementos que estão presentes em amostras de sedimentos em concentrações muito baixas, como $\mathrm{Bi}, \mathrm{W}, \mathrm{Ga}, \mathrm{Rb}, \mathrm{Nd}, \mathrm{Sb}, \mathrm{Ba}$ e Cs e, portanto considerados menos importantes para a análise multivariada de dados, também foram cortados.

Ao final da aplicação de todos os critérios para validação e redução da base de dados $2 \mathrm{~S}$, a nova base ficou com 22 variáveis e 51 amostras para aplicação da análise de fatores principais.

A Tabela 6 mostra os quatro fatores principais obtidos a partir da AFP com a variância responsável por cada um deles. Observa-se também, que os quatro fatores obtidos são responsáveis por $91,1 \%$ da variabilidade total dos dados. A tabela apresenta os resultados obtidos para este conjunto de dados no ponto $2 S$ através da matriz das cargas fatoriais (factors loadings) com rotação varimax. A tabela mostra ainda, os elementos retidos em cada um dos quatro fatores com a 
sua comunalidade. A carga fatorial significa a correlação de cada variável com o fator, ou seja, indicam o grau de correspondência entre a variável e o fator. As variáveis com maiores cargas fatoriais fazem com que esta variável seja representativa do fator. $O$ ponto de corte para fins de interpertação é $\pm 0,4$ embora todas as cargas fatoriais maiores que $+0,1$ e menores que $-0,1$ tenham contribuído no cálculo da comunalidade. A comunalidade, que representa a fração de cada variável que é explicada pelos fatores obtidos, pode ser observada sendo maior do que $79 \%$ para cada variável.

O fator 1 está relacionado com a fase argilo-mineral devido a presença de $\mathrm{Fe}, \mathrm{Mn}$ e Al, a esta fase estão associados também os metais $\mathrm{Pb}, \mathrm{Mo}$, Cu e $\mathrm{Cr}$.

O fator 2 parece estar relacionado aos sulfetos formados com metais de transição como $\mathrm{Co}, \mathrm{Ni}, \mathrm{Cr}$ e $\mathrm{Zn}$. Esses metais, provavelmente, são introduzidos no ambiente aquático por fontes antropogênicas e são adsorvidos pelos sedimentos formando sulfetos em camadas mais profundas onde existem ambientes mais anóxicos.

O fator 3, com Mg, Sr e As, parece estar relacionado à fase carbonática presente em grandes quantidades em ambientes marinhos. O Cd aparece anticorrelacionado com os outros elementos nesta fase.

O fator 4 está relacionado à fase mineral mais pesada, como a monazita, devido à presença dos elementos radioativos Th e $U$, elementos que estão representando as terras raras, La e Ce e também Al e Sc.

Observa-se ainda, que os fatores 1 e 4 parecem estar relacionados com a matriz do sedimento. 
Tabela 6- Matriz de cargas fatoriais ("factor loadings") obtida através da análise de fatores principais dos sedimentos do perfil $2 \mathrm{~S}$.

\begin{tabular}{|c|c|c|c|c|c|}
\hline Elementos & $\begin{array}{c}\text { Fator } 1 \\
\text { Minerais argilosos }\end{array}$ & $\begin{array}{c}\text { Fator } 2 \\
\text { Sulfetos }\end{array}$ & $\begin{array}{c}\text { Fator } 3 \\
\text { Carbonatos }\end{array}$ & $\begin{array}{c}\text { Fator } 4 \\
\text { Matriz } \\
\text { sedimento }\end{array}$ & Comunalidade \\
\hline $\mathrm{K}$ & $-0,92$ & - & - & - & 0,94 \\
\hline $\mathrm{Mn}$ & 0,81 & 0,50 & - & - & 0,95 \\
\hline $\mathrm{Pb}$ & 0,81 & - & - & - & 0,93 \\
\hline Mo & 0,80 & 0,43 & - & - & 0,87 \\
\hline $\mathrm{Fe}$ & 0,79 & 0,53 & - & - & 0,94 \\
\hline $\mathrm{Al}$ & 0,76 & - & - & 0,47 & 0,96 \\
\hline $\mathrm{v}$ & 0,72 & 0,63 & - & - & 0.98 \\
\hline $\mathrm{Cu}$ & 0,65 & 0,63 & - & - & 0,95 \\
\hline Sc & 0,59 & 0,49 & - & 0,45 & 0,83 \\
\hline Co & - & 0,90 & - & - & 0,92 \\
\hline $\mathrm{Ni}$ & - & 0,88 & - & - & 0,95 \\
\hline $\mathrm{Cr}$ & 0,51 & 0,78 & - & - & 0,90 \\
\hline $\mathrm{Zn}$ & 0,53 & 0,68 & - & - & 0,88 \\
\hline $\mathrm{Ti}$ & - & 0,67 & 0,59 & - & 0,86 \\
\hline $\mathrm{Mg}$ & - & - & $-0,87$ & - & 0,88 \\
\hline As & - & - & $-0,83$ & - & 0,82 \\
\hline $\mathrm{Sr}$ & $-0,49$ & - & $-0,77$ & - & 0,93 \\
\hline $\mathrm{Cd}$ & 0,48 & - & 0,71 & - & 0,79 \\
\hline$u$ & - & - & - & 0,90 & 0,91 \\
\hline $\mathrm{La}$ & 0,45 & - & - & 0,81 & 0,94 \\
\hline $\mathrm{Ce}$ & 0,56 & - & - & 0,74 & 0,96 \\
\hline Th & 0,63 & - & - & 0,71 & 0,96 \\
\hline Autovalor & 13,60 & 3,50 & 1,80 & 1,10 & Varância Total \\
\hline Variância (\%) & 62,00 & 16,10 & 8,10 & 4,80 & 91,10 \\
\hline
\end{tabular}


A Figura 40 apresenta os escores ("factor scores") associados ao fator 1 plotados contra aqueles associados ao fator 2. Cada ponto neste gráfico representa uma camada do perfil 2S. Foram identificados dois grupos principais de acordo com as profundidades mássicas e as características dos sedimentos.

O primeiro fator, a fase argilomineral, diferencia os grupos de acordo com o aporte continental. Em particular, a diferenciação é observada entre as camadas situadas antes e depois de $17 \mathrm{~g} \mathrm{~cm}^{-2}$, aproximadamente em 1960, quando ocorre a inflexão da razão $\mathrm{Mg} / \mathrm{Al}$. A presença de uma fase anóxica, representada pelo fator 2 , parece um fator determinante só para as camadas mais profundas, particularmente onde não se encontra mais $0{ }^{210} \mathrm{~Pb}$ não suportado.

Não foi possível a aplicação da AFP para o perfil $2 \mathrm{C}$ uma vez que o número de casos tem que ser bem maior do que o número das variáveis como descrito por Henry et al. (1984), e este só possui 32 amostras.

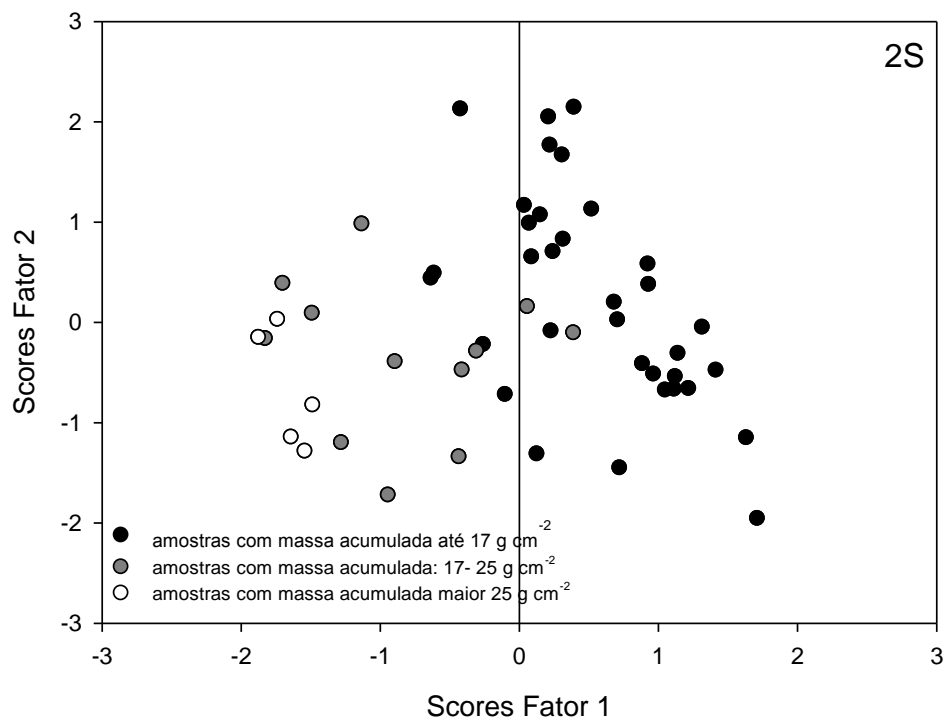

Figura 40 - Gráfico do factor scores associados ao fator 1 versus factor scores associados ao fator 2 


\subsubsection{3. \\ Análise por agrupamento}

A fim de verificar os resultados e a ortogonalidade dos quatro fatores principais obtidos para o perfil 2S, a AHC foi aplicada ao conjunto das 22 variáveis junto aos factors scores que foram adicionados à matriz de dados como novas variáveis.

Quando a AHC foi aplicada às variáveis, foram identificados cinco grupos através do dendograma obtido (Figura 41). A distribuição dos grupos no dendograma não é exatamente igual à distribuição pela AFP, onde as maiores diferenças aparecem em relação à distribuição dos elementos contidos no fator 3. Neste caso, ao invés de um único grupo contendo os elementos do fator três ( $\mathrm{Mg}$, Sr, As e Cd), a AHC separou os elementos contidos neste fator em dois grupos: um com $\mathrm{Mg}$, As, $\mathrm{Sr}$ que estavam associados negativamente ao $\mathrm{Cd}$ no fator 3 na AFP e adicionando o $\mathrm{K}$ que estava associado negativamente ao fator 1, e outro grupo só com o Cd.

O comportamento do cádmio pode ser explicado pela existência de fontes antropogênicas, como a Cia. Paraibuna de Metais.

A distribuição dos outros grupos apresentou a mesma distribuição das variáveis contidas nos fatores principais (calculados pela AFP) com cada fator associado, mostrando a distribuição dos elementos de acordo com aquela obtida através da AFP.

Quando a AHC foi aplicada aos casos, foram identificados quatro grupos que podem ser classificados em dois grandes grupos: o grupo de sedimentos das camadas superficiais e o grupo de sedimentos das camadas de fundo (Figura 42) como observado na Figura 40.

Ao comparar estes resultados com os resultados da AFP na figura 40 podemos dizer que é possível identificar os mesmos grupos através dos dois métodos de análise multivariada mostrando que os métodos aplicados estão de acordo entre si.

Considerando o mesmo grupo de 22 variáveis aplicado aos AFP e AHC ao perfil 2S, foi realizada a $\mathrm{AHC}$ para o perfil $2 \mathrm{C}$ apenas para fins de comparação dos resultados obtidos para o ponto $2 \mathrm{~S}$. 
A Figura 43 mostra os resultados obtidos através da AHC aplicada às variáveis. Através do dendograma obtido foi possível identificar cinco grupos: o primeiro grupo está relacionado à fase mineral devido à presença de La, Ce e Th. O cádmio aparece relacionado nesta fase, mas essa associação pode ser uma conseqüência da existência de pelo menos duas fontes de cádmio, uma natural e outra antropogênica (Cia. Paraibuna de Metais). O segundo grupo pode ser identificado como a fase de sulfetos, contendo ferro, zinco e vanádio. O terceiro grupo parece se relacionar à fase argilomineral, com Al e Sc associados a alguns elementos traço. O quarto grupo representa a fase carbonática associada ao arsênio, estrôncio e magnésio. Apenas o quinto grupo mostrou uma fase diferente das observadas no perfil 2S. Nesta fase manganês, potássio e cobalto apareceram associados.

A Figura 44 mostra os resultados obtidos através da AHC aplicada aos casos para o perfil 2C. Quando aplicado às amostras, foram obtidos dois clusters: um grupo relacionado com as camadas mais profundas, onde praticamente não se encontra ${ }^{210} \mathrm{~Pb}_{\text {exc }}$; e outro grupo composto por todas as outras camadas. Pode-se dizer que estes resultados concordaram com os resultados do perfil $2 \mathrm{~S}$, com dois grandes grupos envolvendo as camadas de sedimento superficiais e as de fundo. A diferença dos resultados observada entre os dois perfis se dá, provavelmente devido ao reduzido número de amostras existentes no perfil $2 \mathrm{C}$. 


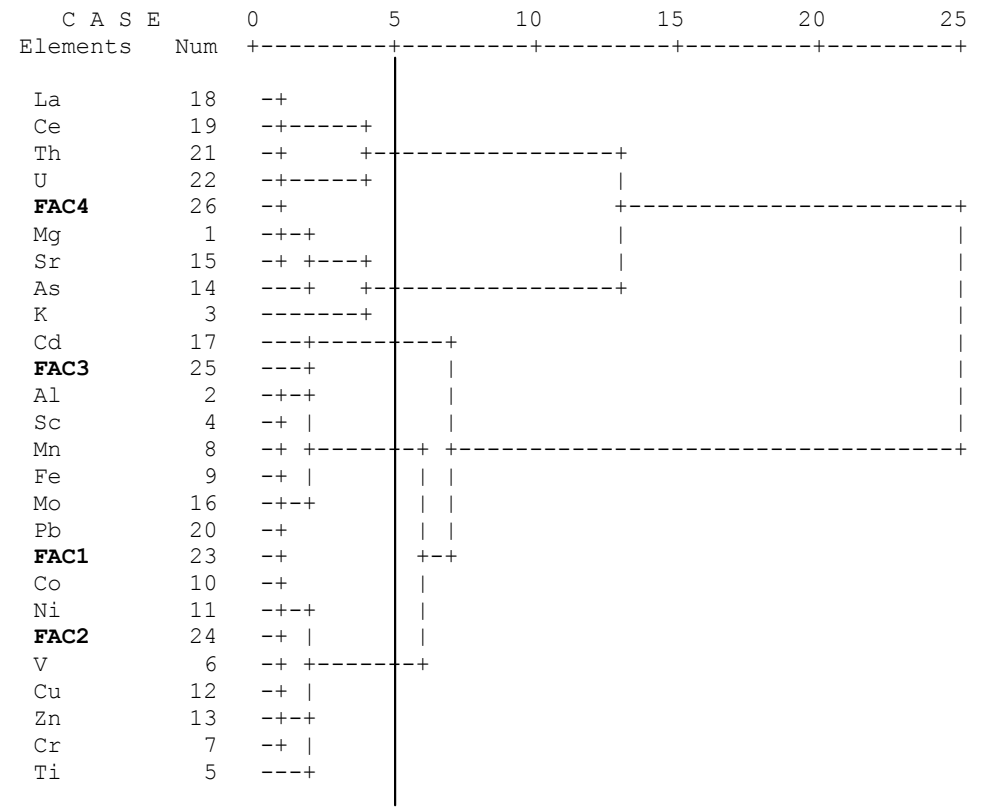

Figura 41- Dendograma obtido pela análise por agrupamento de variáveis para o perfil $2 S$. 


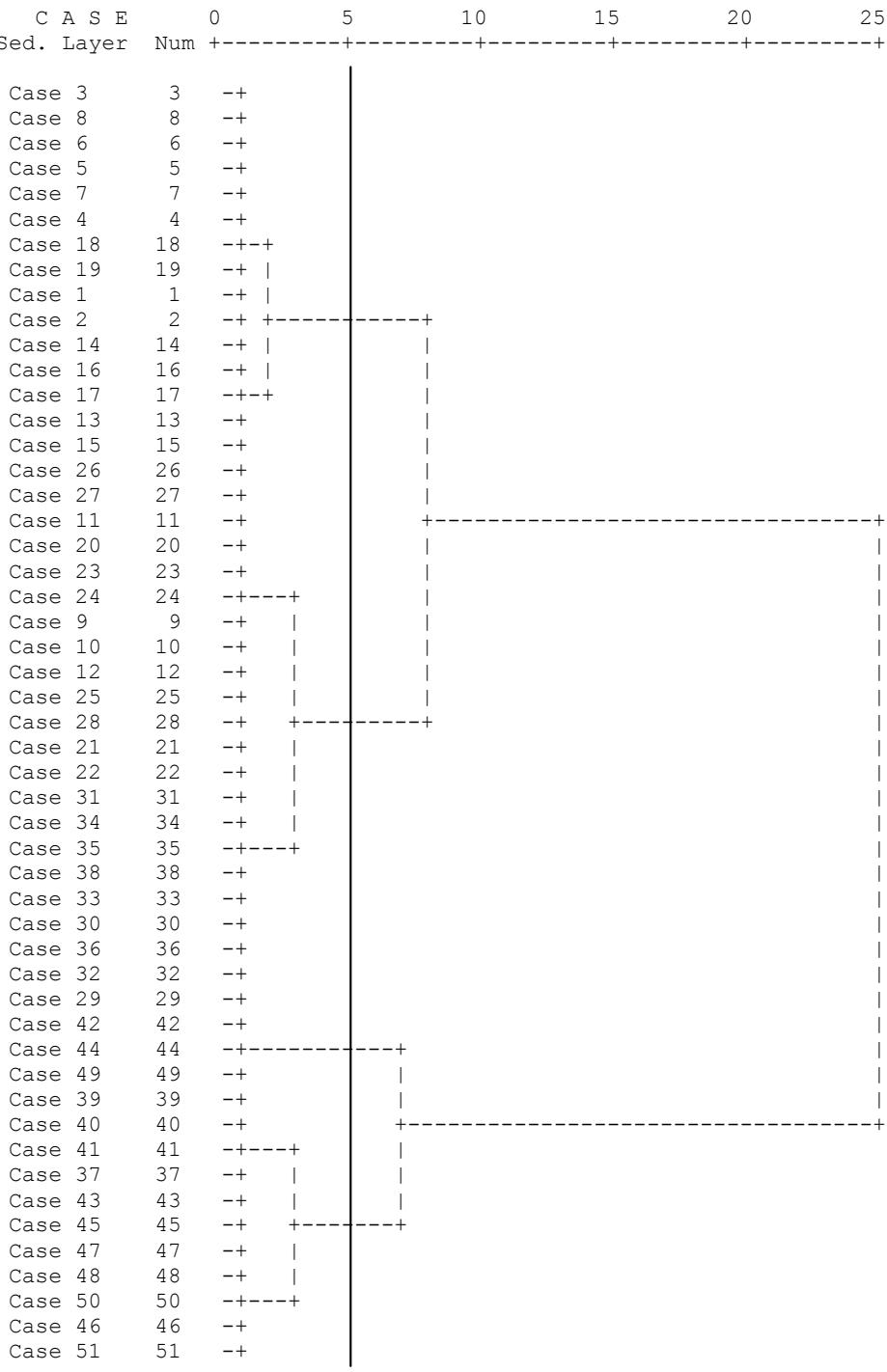

Figura 42 - Dendograma obtido pela análise por agrupamento de casos para o perfil 2S. 


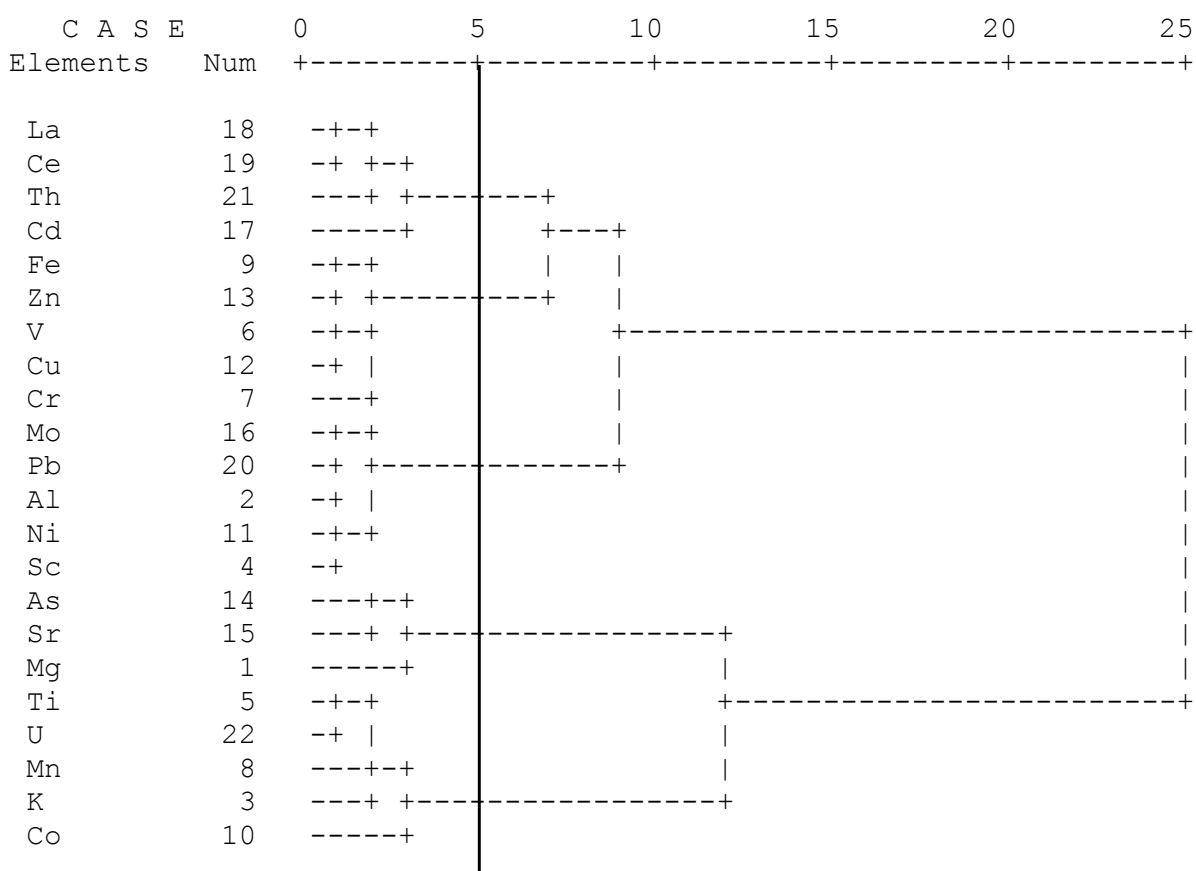

Figura 43 - Dendograma obtido pela análise por agrupamento de variáveis para o perfil 2C.

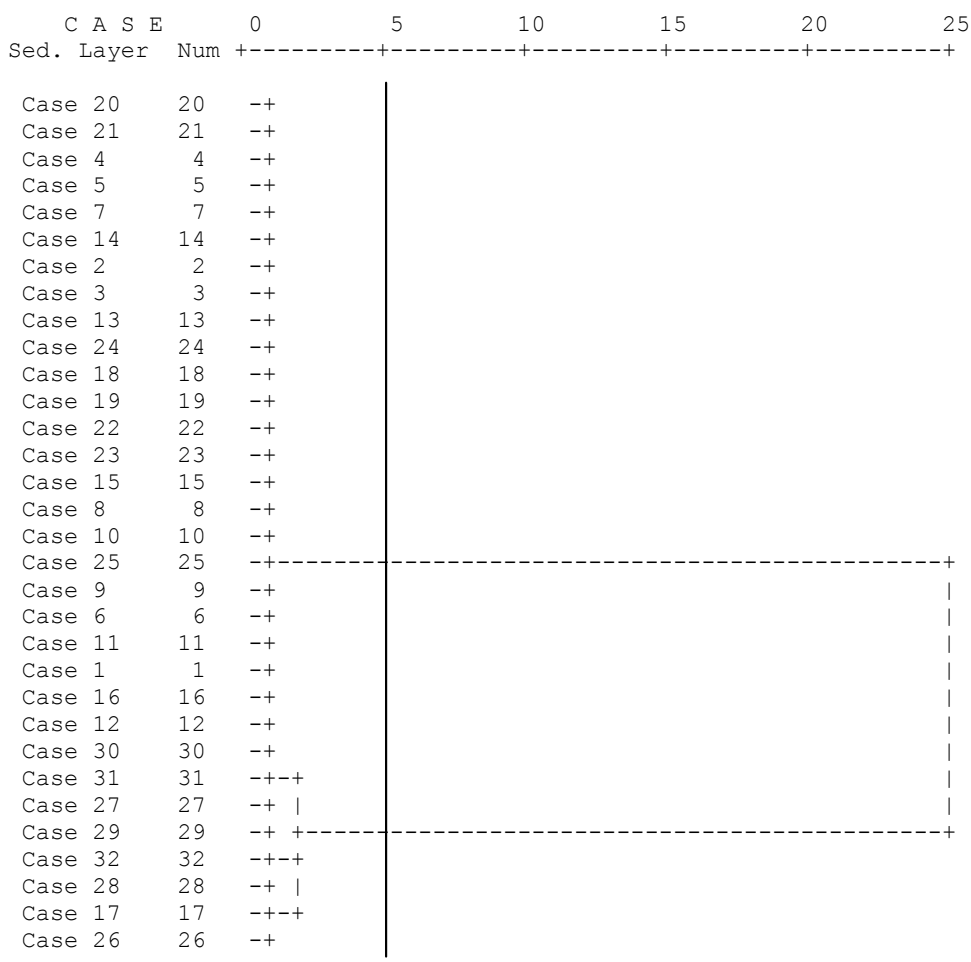

Figura 44 - Dendograma obtido pela análise por agrupamento de casos para o perfil 2C. 


\section{7 \\ Conclusões}

Com base nos valores dos inventários de ${ }^{210} \mathrm{~Pb}$ foi possível identificar o transporte de sedimentos para a direção sul do continente de acordo com a corrente de deriva. Tal fato foi observado através da comparação entre os valores obtidos para os pontos ao norte e ao sul da foz do RPS, $0,16 \mathrm{~Bq} \mathrm{~cm} \mathrm{~cm}^{-2} \mathrm{e}$ $1,0 \mathrm{~Bq} \mathrm{~cm}{ }^{-2}$, respectivamente. A confirmação da direção do transporte dos sedimentos foi obtida através das taxas de sedimentação encontradas, onde as taxas observadas ao sul também foram bem mais altas do que as taxas observadas ao norte da foz do RPS.

Os estudos desenvolvidos neste trabalho indicaram um valor de base para as taxas de sedimentação encontradas na região do estuário do RPS para o período anterior aos anos 50-60 de 0,06 $\mathrm{g} \mathrm{cm}^{-2}$ ano-1 e um valor médio de 0,6 g $\mathrm{cm}^{-2}$ ano $^{-1}$ para o período mais recente nos pontos de coleta ao sul da foz do RPS.

A análise de alguns elementos no ponto $2 S$ foi determinante na validação da datação como, por exemplo, o $\mathrm{Cr}$, $\mathrm{Cd}$, Cu e $\mathrm{Zn}$, onde os valores encontrados neste perfil podem estar relacionados com o rompimento de uma barragem de rejeitos da indústria Cia Paraibuna de Metais, em 1982, contaminando o RPS com metais pesados, principalmente $\mathrm{Cr}$, Cd e $\mathrm{Zn}$.

A mudança na natureza do material particulado ou sedimento que chega e se deposita no delta do RPS foi fortemente observada através da relação $\mathrm{Mg} / \mathrm{Al}$. A partir da curva da relação $\mathrm{Mg} / \mathrm{Al}$ versus o tempo é possível notar dois patamares bem distintos: um anterior aos anos 60 com caráter marinho predominante, e um posterior aos anos 80 com caráter de sedimentos terrígenos predominante, indicando uma possível diluição dos sedimentos marinhos com o aporte de sedimento terrígeno.

Vários indicadores foram estudados a fim de verificar as mudanças na região ocorridas entre 1960 e 1980: o fluxo de metais, o fator de enriquecimento e o índice de geoacumulação. 
Durante o período entre 1960 e meados de 1980 o aporte de sedimentos foi baixo em relação aos dias atuais. Fato observado, também, através das taxas de sedimentação. Isso pode estar relacionado com as barragens e desvios praticados no curso do RPS nesta época, diminuindo o aporte de sedimentos terrigenos, porém, nota-se que atualmente houve um aumento nas taxas de sedimentação recentes, explicada pelos próprios sedimentos erodidos da costa e depositados no estuário do RPS.

A análise de fatores principais (AFP) e a análise por agrupamento possibilitaram a identificação da composição química do sedimento da região. A AFP identificou 4 fatores, cada um representando uma fase do sedimento. Os fatores 1 e 4, relacionados à matriz do sedimento onde o fator 1 representa a fase argilo-mineral devido a presença de $\mathrm{Fe}, \mathrm{Mn}$ e $\mathrm{Al}$ associados aos metais $\mathrm{Pb}$, Mo, $\mathrm{Cu}$ e $\mathrm{Cr}$ e o fator 4 representa a fase mineral mais pesada, como a monazita, devido à presença dos elementos radioativos Th e $\mathrm{U}$ e as terras raras, La e Ce. O fator 2 está relacionado aos sulfetos formados com metais de transição como $\mathrm{Co}, \mathrm{Ni}, \mathrm{Cr}$ e $\mathrm{Zn}$ introduzidos no ambiente aquático por fontes antropogênicas e o fator 3 , com $\mathrm{Mg}$, $\mathrm{Sr}$ e As, representa a fase carbonática presente em grandes quantidades em ambientes marinhos.

As concentrações de alguns metais podem ser comparadas com os resultados obtidos nas Baías da Ribeira e de Sepetiba, que também estão localizadas no estado do Rio de Janeiro.

Sob o ponto de vista ambiental, a Baía da Ribeira é considerada bem preservada enquanto a Baía de Sepetiba é fortemente contaminada principalmente por metais como $\mathrm{Zn}$ e $\mathrm{Cd}$ provenientes de antigas indústrias metalúrgicas existentes na região (Gomes, 2009).

Os valores das concentrações médias dos elementos $\mathrm{V}, \mathrm{Cr}, \mathrm{Ni}, \mathrm{Pb}$ e $\mathrm{Zn}$ nos pontos $2 \mathrm{~S}$ e $2 \mathrm{C}$ são equivalentes aos encontrados na Baía da Ribeira. Em contraste, a concentração média de $\mathrm{Cd}\left(0,4 \mathrm{mg} \mathrm{kg}^{-1}\right)$ é superior à Baía da Ribeira $\left(0,2 \mathrm{mg} \mathrm{kg}^{-1}\right)$, mas inferior à da Baía de Sepetiba $\left(3,2 \mathrm{mg} \mathrm{kg}^{-1}\right)$.

As concentrações médias de cobre, nos pontos $2 \mathrm{~S}\left(36 \mathrm{mg} \mathrm{kg}^{-1}\right)$ e $2 \mathrm{C}$ (35 $\mathrm{mg} \mathrm{kg}^{-1}$ ) são mais elevadas do que na Baía da Ribeira $\left(24,6 \mathrm{mg} \mathrm{kg}^{-1}\right)$, mas equivalente à observada em Sepetiba $\left(32 \mathrm{mg} \mathrm{kg}^{-1}\right)$. 
Carvalho (1992) determinou a concentração de metais pesados na área da plataforma continental do RPS, onde os valores médios relatados para $\mathrm{Cu}, \mathrm{Cr}$ e $\mathrm{Zn}$, são bastante semelhantes aos observados neste estudo. Isto indica a ausência da contaminação por estes metais nesta região provavelmente devido ao efeito de diluição causado pela entrada de material particulado não contaminado no estuário do RPS (Carvalho et al. 2002). 
8

\section{Referências bibliográficas}

AMARAL. E.C.S.; CARVALHO, Z.L.; GODOY.J.M. Transfer of ${ }^{226} \mathrm{Ra}$ and ${ }^{210} \mathrm{~Pb}$ to forage and milk in a Brazilian high natural radioactivity region. Radiat. Prot. Dosimetry, v. 24, n. 1/4. p.119-121, 1988.

APPLEBY , P.G., OLDFIELD, F. The calculation of lead-210 dates assuming a constant rate of supply of unsupported $210 \mathrm{~Pb}$ to the sediment. Catena 5:1-8, 1978.

APPLEBY, P. G.; OLDFIELD, F. in Uranium series Disequilibrium: Application to Earth, Marine and Environmental Sciences, Ivanovich, M., Harmon, R.S. eds; Oxford Sciences Publications, Claredon Press, Oxford, 1992, ch. 21

APPLEBY, P.G. AND OLDFIELD, F. The assessment of ${ }^{210} \mathrm{~Pb}$ data from sites with varying sediment accumulation rates. Hydrobiologia 103, pp 29-35, 1983.

AZEVEDO, M. V. H. Entrevista concedida a Gilberto Ribeiro. 18 janeiro 2004. (RIBEIRO, et al., 2004)

BARNES, R. S.; BIRCH, P. B.; SPYRIDAKIS, D. E.; SCHELL, W. R. Changes In the sedimentation histories of lakes using Lead-210 as a tracer of sinking particulate matter. In: PROCEEDINGS OF AN INTERNATIONAL SYMPOSIUM ON ISOTOPE HYDROLOGY, p. 875898, 19-23 June 1978.

BASTOS, A.C. e SILVA, C.G. Caracterização morfodinâmica do litoral Norte Fluminense, RJ, Brasil. Revista Brasileira de Oceanografia., v.48, n. 1 , p. $41-60.2000$

BASTOS, A. C. e SILVA, C.G.. Coastal morphological compartments along the northeast littoral of Rio de Janeiro state, Brazil. Journal of Coastal Research, v.35, p.309-317. 2003.

BENNINGER, L.K.et al.. ${ }^{210} \mathrm{~Pb}$ balance in Long Island Sound. Geochimica et Cosmochimica Acta v. 42, p. 1165-1174,1979.

BORREGO, J., LÓPEZ-GONZÁLEZ, N., CARRO, B. Geochemical signature as paleoenvironmental markers in Holocene sediments of the 
Tinto river estuary (SW Spain). Estuarine, Coastal and Shelf Science, 61, 631-641, 2004.

CARROLL, J.; LERCHE, I.; in Sedimentary Processes - Quantification Using Radionuclides, Radioactivity in the Environment Series V. 5, Elsevier, 272 p., Amsterdam, 2003.

CARVALHO,F. P. (b) ${ }^{210} \mathrm{~Pb}$ and ${ }^{210} \mathrm{Po}$ in sediments and suspended matter in the Tagus estuary, Portugal. Local enhancement of natural levels by wastes from phosphate ore processing industry. Science of the Total Environment, v. 159, p. 201-214, 1995.

CARVALHO, C.E.V. Distribuição de metais pesados na plataforma continental Nordeste e Sudeste do Brasil. 1992.Dissertação (Mestrado). 91 p. Departamento de Geoquímica, Universidade Federal Fluminense.

CARVALHO,C.E.V. et al. Contribution of a medium-sized tropical river to the particulate heavy-metal load for the South Atlantic Ocean. Science of the Total Environment, v. 284, p. 85-93, 2002.

CAVALCANTI, A. D., VIADANA. Caracterização e Processos da Dinâmica Natural Costeira. 2007, Natal. Simpósio Brasileiro de Geografia Física Aplicada, 12. (XII SBGFA).

CAVALCANTI, A.D. Monitoramento da Contaminação por elementos traço em ostras comercializadas em Recife, Pernambuco, Brasil. Caderno de Saúde Pública, Rio de Janeiro, v.19, p.1545-1551, set/out 2003.

CHANTON, J.P.; MARTENS, C.S.; KIPPHUT, G.W. Lead-210 sediment geochronology in a changing coastal environment. Geochimica Et Cosmochimica Acta, v. 47, p. 1791-1804, 1983.

CHRISTOFOLETTI, A. Geomorfologia 2.ed. São Paulo: Edgard Blücher, 1980, $313 \mathrm{p}$.

CEIVAP. Comitê da Bacia Hidrográfica do Paraíba do Sul. Plano de Recursos Hídricos da Baciado Rio Paraíba do Sul- Resumo Plano de Recursos Hídricos Consolidado. R-10, 2007.

CPRH. Agencia Estadual de Meio Ambiente e Recursos Hídricos, 2000.

COELHO, V.; Paraiba do Sul, um rio estratégico. Rio de Janeiro: Casa da Palavra. 2012. 336 p. 
COTTA, J. A.O. Diagnóstico ambiental do solo e sedimento do parque estadual turístico do Alta Ribeira (PETAR), 2003. 130 f. Dissertação (Mestrado em Ciências), Universidade de São Paulo, São Carlos, SP.

DIAS, G. T. M. A frente deltaica do Rio Paraíba do Sul; fisiografia submarina e distribuição sedimentar. 1984. In: CONGRESSO BRASILEIRO DE GEOLOGIA, 33. Rio de Janeiro, 1984. Anais... Resumos expandidos, Rio de Janeiro, v1, p.83-84.

DIAS, J. A. A Evolução Actual do Litoral Português. Protecção Civil, v. III, n .10,p.2-15, Lisboa, Portugal, 1990.

FERREIRA, J. C. Coastal Zone Vulnerability and Risk Evaluation. A Tool For Decision-Making (An Example In The Caparica Littoral - Portugal). Journal of Coastal Research, Special Issue 39: 1590- 1593, 2004.

FIGUEIREDO et al. Atafona: Avaliação preliminar do processo de erosão costeira. 2004. In: II Simpósio Brasileiro de Oceanografia. Vitória, 2004.

FIT, CETESB. Ficha de Informações Toxicológicas, Companhia Ambiental do Estado de São Paulo, 2011.. Disponível em: http://www.cetesb.sp.gov.br/tecnologia-ambiental/laboratorios/109informacoes-toxicologicas\#.

FORSTNER, U.; WITTMANN,G.T. Metal pollution in the aquatic environment. Berlin: Springer-Verlag, 1983, 486p.

GODOY et al. An Alternative Method for the Determination of Excess ${ }^{210} \mathrm{~Pb}$ in Sediments. Radiation Protection Dosimetry, v.75, n.1, p.111115, 1998.

GODOY, M.L.D.P. Avaliação do impacto ambiental causado pela emissão atmosférica de elementos traço pelo Complexo Termoelétrico Jorge Lacerda, Capivari de Baixo, SC. Rio de Janeiro, 2001. 169 p., Tese (Doutorado)- Departamento de Química, Pontifícia Universidade Católica do Rio de Janeiro.

GODOY, M.L. et al.,.Application of multivariate statistical analysis to superficial soils around a coal burning power plant. Journal of the Brazilian Chemical Society v.15, p. 122-130, 2004

GODOY, J. M.; GODOY, M. L. D. P.; ARONNE, C.C.; Journal of Brazilian Chemical Society, v. 18, 969, 2007.

GOLDBERG, E. D. - Geochronology with ${ }^{210} \mathrm{~Pb}$. In: Radioactive dating Int. Atom. Energy Ag. Viena; 121-131, 1963. 
GOMES, F. C. et al. Metal Concentrations, fluxes, inventories and chronologies in sediments from Sepetiba and Ribeira Bays: A comparative Study. Marine Pollutlon Bulletin.,v. 59, p. 123. 2009

GOULART, M.D; CALLISTO, M. Bioindicadores de Qualidade de Água como ferramenta em estudos de impacto ambiental. FAPAM. Ano II (Número II): 153-163, 2003.

GRESENS, R. L. Composition-volume relationships of metasomatism. Chemical Geology, v. 2, p. 47-55, 1967.

GUSMÃO, L. F. M. Efeitos do cobre e do cromo na comunidade zooplanctônica: um estudo experimental em mesocosmos. 2004. 288 f. Dissertação de Mestrado em Ciências da Engenharia Ambiental, Escola de Engenharia de São Carlos, Universidade de São Paulo, São Carlos.

HAIR, J. F. J. et al. Análise multivariada de dados. 6a. ed. Porto Alegre: Bookman, 2009, $688 \mathrm{p}$.

HAMILTON, D. G.; EBERSOLE B.A. Establishing uniform longshore currents in a large-scale sediment transport facility. Coastal Engineering, v. 42 , p. 199-218, 2001.

HATAYE. I.; SUGANUMA, H.: SHIMIZU. 1. Mutual separation of ${ }^{210} \mathrm{Po}$ ${ }^{210} \mathrm{Bi}$ and ${ }^{210} \mathrm{~Pb}$ with solvent extraction using copper dithizonate-CCL and dithizone-CCl4 solutions. Journal of Radioanalytical Nuclear Chemistry. v. 148, n. 1, p. 101-105, 1991.

HEDGES, J.I.; Clark, W.A; Quay, P.D.; Richey, J.E.; Devol, A.; Santos, U. Composition and fluxes of particulate organic material in the Amazon River. Limnology and Oceanography, 31(4): 717-738, 1986.

HENRY, R. C., LEWIS, C. W., HOPKE, P. K., WILLIAMSON, H. J. Review of Receptor Model. Fundamentals. Atmospheric Environment, v.18, n.8, p.1507-1515, 1984.

HOLTZMAN. R.B. The determination of ${ }^{210} \mathrm{~Pb}$ and ${ }^{210} \mathrm{Po}$ in biological and environmental materials. Journal of Radioanalytical Nuclear Chemistry, v. 115, n. 1, p. 59-70. 1987.

IBAMA. Instituto Brasileiro do Meio Ambiente e dos Recursos Naturais Renováveis. Geo Brasil 2002: Perspectivas do Meio Ambiente no Brasil. Relatório, Brasília, 2002.

IPABHi, Seminário de Recursos Hídricos da Bacia Hidrográfica do Paraíba do Sul (1), 2007, Taubaté. Anais I Seminário de Recursos 
Hídricos da Bacia Hidrográfica do Paraíba do Sul: o Eucalipto e o Ciclo Hidrológico-Análise de impactos ambientais gerados pela construção de uma barragem na Bacia do Médio Una, Taubaté, SP, 07-09 novembro 2007, p. 43-50.

JORNAL FOLHA DA MANHÃ. Erosão marítima em Atafona será estudada, Jornal Folha da Manhã, Campos dos Goytacases, 12 nov. 2003.

JORNAL O GLOBO. Mar de Atafona ameaça prédio da PM e caixa d'água que abastece veranistas, Jornal O GLOBO, Rio de Janeiro, 27 jan. 2004.

JOSHI, S. R.; KU. T. L. Measurements of ${ }^{210} \mathrm{~Pb}$ from a sediment core off the coast of California. Journal of Radioanalytical Chemistry, v. 52, n. 2, p. 329-334, 1979.

JOSHI, S. R.; FOX, M. E. The ${ }^{210} \mathrm{~Pb}$ and ${ }^{137} \mathrm{Cs}$ profiles in sediment cores from Bay of Quinte, Lake Ontario. Journal of Radioanalytical Nuclear Chemistry, v. 90, n. 1, p. 207-215, 1985.

JOSHI, S.R.; SHUKLA, B.S.; MCNEELY, R.; Journal of Radioanalytical Nuclear Chemistry, v. 125, p. 341, 1988.

JOSHI, S. R., SHUKLA, B.S. Ab Initio derivation of formulations for ${ }^{210} \mathrm{~Pb}$ dating of sediments. Journal of Radioanalytical Nuclear Chemistry, v. 148, p. 73-79, 1991.

KJERFVE, B. G. et al. 2003. Morphodynamics of muddy environments along the Atlantic coasts of North and South America, In: Muddy Coasts of the World: Processes, Deposits and Functions. Elsevier Science B. V. Amsterdam: T.Healy, Y. Wang and J.-A. Healy, p. 479-532.

KRISHNASWAMY, S. et al.Geochronology of lake sediments. Earth and Planetary Science Letters. v. 11, p.407-414, 1971.

KOIDE, M; BRULAND, K. W.; GOLDBERG, E. D.; Th-228/Th-232 and Pb210 geochronologies in marine and lake sediments. Geochimica Et Cosmochimica Acta , v. 37, pp. 1171-1187, 1973.

KUMAR, V. S.; ANAND N. M.; CHANDRAMOHAN P.; NAIK G. N. Longshore sediment transport rate-measurement and estimation, central west coast of India. Coastal Engineering v.48, p.95-109, 2003.

LABHID/COPPE/UFRJ - Laboratório de Hidrologia e Estudos de Meio Ambiente da COPPE/UFRJ, Relatório, 1999. 
LACERDA, L.D et al. Mercury in Sediments from the Paraiba do Sul River Continental Shelf, S.E. Brazil. Marine Pollution Bulletin, v. 26, n. 4, p. 220-222, 1993.

LACERDA, L.D et al. Mercury distributions in continental shelf sediments from two offshore oil fields in southeastern Brazil. Bull. Environ. Contam. Toxicol., v.72, p. 178-185, 2004.

LEBLANC, M. et al. 4,500-years-old mining pollution in southwestern Spain: long-term implications for modern mining pollution. Economic Geology, v. 95, p. 655-662, 2000.

LIGTH, Energia: A Relação entre o Abastecimento de Água da Região Metropolitana do Rio de Janeiro e a Geração de Energia Elétrica, 2008.

LIMA, A.L.C. Geocronologia de Hidrocarbonetos Poliaromáticos (PAHs). Estudo de Caso: Baía de Guanabara. Rio de Janeiro, 1996, 117 p. Dissertação (Mestrado). Departamento de Química, Pontifícia Universidade Católica do Rio de Janeiro.

LIN, S. et al. Influence of the Yangtze River and grain size on the spatial variations of heavy metals and organic carbon in the East China Sea continental shelf sediments. Chemical Geology, v. 182, p. 377-394, 2002.

MAIA, V. Dinâmica Costeira. O Ambientalista - Boletim Ambiental, 2002, $n^{\circ} 6$.

MARTIN, L. et al. Significado geológico das variações dos graus de arredondamento das areias holocênicas da Planície Costeira do Rio Paraíba do Sul, (RJ). In: CONGRESSO BRASILEIRO DE GEOLOGIA, 33. 1984, Rio de janeiro. Anais... 1984.

MATSUMOTO, E. - “210 Pb Geochronology of sediments from Lake Shinji”. Geochemical Journal, v.9, p. 167-172, 1975.

MOLISANI , M.M. et al.Heavy Metals in Sediments of the Lower Paraíba do Sul River and Estuary, R.J., Brazil. Bull. Environ. Contam. Toxicol. v. 63 , p. 682-690, 1999.

MOMOSHIMA, N.et al. Simultaneous determination of ${ }^{210} \mathrm{Bi}$ and ${ }^{210} \mathrm{Po}$ on pine needles by solvent extraction and liquid scintillation counting. Journal of Radioanalytical Nuclear Chemistry, v. 177, n. 2, p. 219-228, 1994.

MORAIS, J. O. ; PINHEIRO, L. S. Evolução a curto e médio prazo da zona costeira adjacente à foz do Rio Jaguaribe-Ceará. Revista de Ciências e 
Tecnologia da UECE, v. 2, n.2, p. 69-77. Fortaleza, CE, Brasil (ISSN:1516-9758), 2000.

MORAIS, J. O., PINHEIRO, L. S.; CAVALCANTE, A. A.- Dinâmica Costeira. In: O Novo Espaço da Produção Globalizada: O Baixo Jaguaribe - CE, FUNECE, Fortaleza, CE, 2002. v. 1, p.119-159 (ISBN: 8587203142).

MORAIS, J. O., PAULA, D. P.; PINHEIRO, L. S. (2006) - Influência dos Processos Estuarinos do Rio Jaguaribe na Variação da Linha de Costa da Praia de Pontal de Maceió - Ceará - Brasil, In: Simpósio Nacional de Geomorfologia, 6. 2006, Goiânia. Anais..., 2006, p. 10.

MORTATTI, J., HISSLER, C., PROBST, J.L. Heavy Metal Distribution in the Bottom Sediments Along Tietê River Basin, Geol. USP, Sér. cient., São Paulo, v. 10, n. 2, p. 3-11, 2010.

MORTON, B.; BLACKMORE, G. Marine Pollution Bulletin, v. 42, p.1236, 2001

MOREIRA, S. R. D. Determinação de ${ }^{210} \mathrm{~Pb}$ em águas minerais da cidade de Águas da Prata. 1993. Dissertação (Mestrado) - IPEN Instituto de Pesquisas Energéticas e Nucleares. São Paulo.

MOZETO, A. A.; UMBUZEIRO, G.A.; JARDIM, W. F. Métodos de coleta, Análises Físico-químicas e Ensaios Biológicos e Ecotoxicológicos de Sedimentos de Água Doce. Projeto Qualised. São Paulo, 2006.

MUEHE, D. Erosion in the Brazilian coastal zone: an overview. Journal of Coastal Research, SI 39 (Proceedings of the 8th International Coastal Symposium), p. 43 - 48. Itajaí, SC, Brasil, 2006.(disponível em http://siaiacad09.univali.br/ics2004/ arquivos/07_dieter.pdf).

MÜLLER, G. - Schwermetalle in den sediment des rheins-veränderungen seit. Umschav, v. 79, p. 133-149, 1979.

MUNIZ, P.et al. Environ. Int.v.1, p.1096, 2003.

MURILLO, V. C.; SILVA, C. G.; FERNANDEZ, G. Nearshore Sediments and Coastal Evolution of Paraíba do Sul River Delta, Rio de Janeiro, Brazil. Journal of Coastal Research, SI 56 (Proceedings of the 10th International Coastal Symposium), p. 650-654. Lisbon, Portugal, ISSN 0749-0258, 2009. 
NEVISSI, A. E. Measurement of Lead-210, Bismudi-210, and Polonium210 in environmental samples. Journal of Radioanalytical Nuclear Chemistry, v. 148, n. 1, p.21-131, 1991.

NICOLODI, J. L. Ministério do Meio Ambiente Secretaria de Mudanças Climáticas e Qualidade Ambiental. Departamento de Qualidade Ambiental na Indústria Gerência de Qualidade Costeira e do Ar. Documento síntese do SIMPÓSIO NACIONAL SOBRE EROSÃO COSTEIRA, 1. 2008.

NORONHA, J. (a). Entrevista concedida a Noronha. Atafona, 15 fev. 2004.

NORONHA, J. (b). Uma Dama Chamada Atafona, Cultura Goitacá, 2004.

OLDFIELD, F.; APPLEBY, P.G. ; BATTARBEE, R. W. Alternative ${ }^{210} \mathrm{~Pb}$ dating: results from the New Guinea Highlands and Lough Erne. Nature, v. 271 , p. $339-342,1978$.

OLIVEIRA, F.S.B.F.; FREIRE, P.M.S., LARANGEIRO, S.H.C.D. Characterization of the dynamics of Figueira da foz beach, Portugal. Journal of Coastal Research, v. 36, p. 552-563, 2002.

PACER, R. A. The role of Cherenkov and liquid scintillation counting in evaluating the anion-exchange separation of ${ }^{210} \mathrm{~Pb}-{ }^{210} \mathrm{Bi}-{ }^{210} \mathrm{Po}$. Journal of Radioanalytical Chemistry, v. 77, n. 1, p. 19-28, 1983.

PETHICK, J. An Introduction to Coastal Geomorphology. London: Edward Arnold, 1984.

PEREIRA, R. C.; SOARES-GOMES, A. Biologia Marinha. Rio de janeiro. Interciência, 2002. 382p.

PORTO FILHO, E. A geomorfologia e o manejo do ecossistema, Florianópolis. Geosul, 1996.

PREDA, M., COX, M.E. Chemical and mineralogical composition of marine sediments, and relation to their source and transport, Gulf of Carpentaria, Northern Australia. Journal of Marine Systems, v. 53, p. 169-186, 2005.

RIBEIRO, G.P. et al. Análise espaço-temporal no suporte à avaliação do processo de erosão costeira em Atafona, São João da Barra (RJ). Revista Brasileira de Cartografia, No 56/02, 2004.

RIBEIRO, G.P, Pereira, C.Q., Silva, A.E. In: Simpósio Brasileiro de Ciências Geodésicas e Tecnológicas da Geoinformação, 2: Mapeamento Digital da Dinâmica do Pontal Arenoso e do Campo de Dunas de Atafona, São João da Barra (RJ), Recife, 8-11 setembro, 2008. 
ROBBINS, J. A. AND EDGINGTON, D. N. Determination of recent sedimentation rates in Lake Michigan, using ${ }^{210} \mathrm{~Pb}$ and ${ }^{137} \mathrm{Cs}$. Geochimica Et Cosmochimica Acta, v.39, p. 285-304, 1978.

SALOMONS, W; MOOK, W.G. Trace metal concentrations in estuarine sediments: mobilization, mixing or precipitation. Netherlands Journal of Sea Research, v.11, n. 2, p. 119-129, 1977.

SANCHEZ-CABEZA, J. A. et al. Progress Ocean., v. 44, p. 313, 1999.

SANCHEZ-CABEZA, J.A.; RUIZ-FERNANDES, A.C. In: Radiocronologia de Sedimentos Costeros Utilizando ${ }^{210} \mathrm{~Pb}$ : Modelos, Validacion y Aplicaciones, Viena: International Atomic Energy Agency, 2012, páginas 47-61.

SÁNCHEZ-GARCÍA, L., ANDRÉS, J.R., MARTÍN-RUBÍ, J.A. Geochemical signature in offshore sediments from the Gulf of Cádiz inner shelf: Sources and spatial variability of major and trace elements. Journal of Marine Systems, v. 80, p.191-202, 2010.

SCHNITZLER, D. C. Avaliação integrada da qualidade dos sedimentos da bacia do Iraí: Determinação e estudo da dinâmica de metais pesados. 2005. 68 p. Monografia (Conclusão de Curso), Universidade Federal do Paraná, UFPR, PR.

SIEGLE, E. Morfodinâmica da Desembocadura do Rio Camboriú, Balneário Camboriú. 1999 . 137 p. Dissertação (Mestrado), Universidade Federal do Rio Grande do Sul, UFGRS. Porto Alegre, RS, Brasil.

SILVA, M.A.L. Estoque e Taxa de Sedimentação de Metais Pesados e Carbono em Perfis Sedimentares de um Ecossistema Fluvial: A Lagoa de Cima. 1999. 125 p. Dissertação (Mestrado em Biociências e Biotecnologia). Universidade Estadual do Norte Fluminense Darcy Ribeiro, Fundação Estadual do Norte Fluminense.

SKOOG, D. A. Fundamentos de Química Analítica, $8{ }^{a}$ Edição. São Paulo: Editora Thomson. 2006.p

SMITH, J.N., WALTON, A. Sediment accumulation rates and geochronologies measured in the Saguenay Fjord using the $\mathrm{Pb}-210$ dating method. Geochimica Et Cosmochimica Acta, v. 44, p. 225-240, 1980.

SOFIA Project. Geochronology in the South Florida Ecosystem and Associated Ecosystem Programs. Disponível em: < 
http://www.sofia.usgs.gov/publications/posters/geochron/ > Acesso em março 2011 .

SOUZA, T. A. et al. Use of multitracers for the study of water mixing in the Paraíba do Sul River estuary. Journal of Environmental Radioactivity, v.XXX, p. 1-7, 2009.

SUGIO, K. Introdução a sedimentologia. São Paulo: Edgard Blucher, 1973. 317p.

WANDERLEY, C.V.A.,.Estudo comparativo de métodos de determinação de ${ }^{210} \mathrm{~Pb}$ atmosférico, visando avaliação da velocidade de sedimentação. Rio de Janeiro, 1995, 70 p. Dissertação (Mestrado) Departamento de Química, Pontifícia Universidade Católica do Rio de Janeiro.

UDA, T. et al. Beach erosion in Japan as a Structural Problem. In: Biennial Coastal Zone Conference, 14. 2005. New Orleans, Louisiana, USA. Proceedings of the 14th Biennial Coastal Zone Conference, New Orleans, 2005.

UFBA, CPGG. Universidade Federal da Bahia, Centro de Peaquisa em Geofísica e Geologia, disponível em: www.cpgg.ufba.br/lec/BEeros.htm, atualizado em 21/12/2004. Acesso em abril, 2011.

VIEIRA, J. Entrevista concedida a Vieira. Atafona, 15 fev. 2004.

$\mathrm{YU}, \mathrm{K}$. N. et al. A preliminary study on the Radon concentrations in water in Hong Kong and the associated health effects. Appl. Radiat. Isot., v. 45, n. 7, p. 809-810, 1994. 
9

Tabelas auxiliares

Este capítulo destina-se à consulta de dados que geraram as análises utilizadas neste trabalho. 
Tabela 7 - Porcentagem da fração de finos $(<63 \mu)$ ao longo de cada

perfil

\begin{tabular}{|c|c|c|c|c|c|c|c|c|c|c|c|c|c|c|}
\hline \multirow{2}{*}{$\begin{array}{c}\text { Profundidade } \\
\text { (cm) }\end{array}$} & \multicolumn{14}{|c|}{ SILTE + ARGILA $(<63 \mu)$} \\
\hline & $1 \mathrm{~N}$ & $1 S$ & $2 S$ & 2C & $2 \mathrm{~N}$ & 2NN & 2SS & $3 C$ & $3 \mathbf{S}$ & 3NN & 3SS & $4 C$ & $4 S$ & 4SS \\
\hline 1 & 0,85 & 0,96 & 0,87 & 0,94 & 0,91 & 0,92 & 0,91 & 0,91 & 0,89 & 0,04 & 0,90 & 0,64 & 0,96 & 0,96 \\
\hline 2 & 0,89 & 0,90 & 0,89 & 0,93 & 0,92 & 0,92 & 0,89 & 0,97 & 0,88 & 0,88 & 0,88 & 0,80 & 0,94 & 0,95 \\
\hline 3 & 0,93 & 0,86 & 0,91 & 0,89 & 0,93 & 0,90 & 0,88 & 0,95 & 0,90 & 0,34 & 0,90 & 0,85 & 0,91 & 0,97 \\
\hline 4 & 0,83 & 0,92 & 0,91 & 0,89 & 0,91 & 0,92 & 0,91 & 0,91 & 0,90 & 0,88 & 0,91 & 0,80 & 0,94 & 0,98 \\
\hline 5 & 0,89 & 0,92 & 0,91 & 0,90 & 0,92 & 0,72 & 0,93 & 0,94 & 0,90 & 0,94 & 0,92 & 0,86 & 0,84 & 0,99 \\
\hline 6 & 0,96 & 0,96 & 0,91 & 0,92 & 0,87 & 0,85 & 0,87 & 0,90 & 0,90 & 0,97 & 0,91 & 0,84 & 0,88 & 0,98 \\
\hline 7 & 0,93 & 0,99 & 0,94 & 0,93 & 0,92 & 0,97 & 0,81 & 0,95 & 0,91 & 0,78 & 0,87 & 0,91 & 0,83 & 0,90 \\
\hline 8 & 0,91 & 0,95 & 0,89 & 0,91 & 0,92 & 0,84 & 0,81 & 0,92 & 0,91 & 0,94 & 0,88 & 0,92 & 0,89 & 0,92 \\
\hline 9 & 0,95 & 0,86 & 0,92 & 0,86 & 0,92 & 0,78 & 0,80 & 0,92 & 0,94 & 0,87 & 0,89 & 0,94 & 0,89 & 0,97 \\
\hline 10 & 0,92 & 0,93 & 0,91 & 0,93 & 0,90 & 0,69 & 0,84 & 0,83 & 0,99 & 0,82 & 0,91 & 0,88 & 0,91 & 0,98 \\
\hline 11 & 0,94 & 0,95 & 0,90 & 0,89 & 0,93 & 0,84 & 0,81 & 0,86 & 0,89 & 0,88 & 0,87 & 0,92 & 0,90 & 0,97 \\
\hline 12 & 0,95 & 0,95 & 0,88 & 0,91 & 0,93 & 0,80 & 0,86 & 0,84 & 0,90 & & 0,91 & 0,92 & 0,91 & 0,97 \\
\hline 13 & 0,93 & 0,95 & 0,88 & 0,93 & 0,80 & 0,84 & 0,87 & 0,88 & 0,86 & & 0,94 & 0,92 & 0,90 & 0,96 \\
\hline 14 & 0,93 & 0,92 & 0,71 & 0,94 & 0,89 & 0,74 & 0,88 & 0,85 & 0,89 & & 0,91 & 0,94 & 0,91 & 0,97 \\
\hline 15 & 0,95 & 0,90 & 0,89 & 0,96 & 0,77 & 0,94 & 0,87 & 0,86 & 0,91 & & 0,82 & 0,92 & 0,91 & 0,96 \\
\hline 16 & 0,93 & 0,92 & 0,83 & 0,92 & 0,99 & 0,96 & 0,88 & 0,87 & 0,89 & & 0,85 & 0,92 & 0,88 & 0,97 \\
\hline 17 & 0,92 & 0,83 & 0,83 & 0,94 & 0,90 & 0,83 & 0,90 & 0,92 & 0,73 & & 0,96 & 0,94 & 0,93 & 0,97 \\
\hline 18 & 0,93 & 0,83 & 0,88 & 0,91 & 0,92 & 0,88 & 0,90 & 0,81 & 0,88 & & 0,94 & 0,94 & 0,92 & 0,97 \\
\hline 19 & 0,91 & 0,77 & 0,95 & 0,95 & 0,95 & 0,86 & 0,90 & 0,76 & 0,83 & & 0,90 & 0,91 & 0,90 & 0,97 \\
\hline 20 & 0,90 & 0,96 & 0,88 & 0,95 & 0,97 & 0,94 & 0,90 & 0,81 & 0,81 & & 0,93 & 0,86 & 0,86 & 0,98 \\
\hline 21 & 0,92 & 0,96 & 0,92 & 0,96 & 0,96 & 0,98 & 0,91 & 0,84 & 0,83 & & 0,91 & 0,96 & 0,91 & 0,81 \\
\hline 22 & 0,84 & 0,98 & 0,96 & 0,90 & 0,97 & 0,98 & 0,91 & 0,86 & 0,89 & & 0,96 & 0,93 & 0,90 & 0,99 \\
\hline 23 & 0,93 & 0,97 & 0,98 & 0,90 & 0,95 & 0,84 & 0,91 & 0,82 & 0,76 & & 0,94 & 0,94 & 0,87 & 0,90 \\
\hline 24 & 0,94 & 0,97 & 0,93 & 0,85 & 0,93 & 0,95 & 0,87 & 0,79 & 0,90 & & 0,95 & 0,96 & 0,83 & 0,97 \\
\hline 25 & 0,88 & 0,95 & 0,83 & 0,84 & 0,89 & 0,95 & 0,84 & 0,83 & 0,81 & & 0,95 & 0,92 & 0,81 & 0,99 \\
\hline 26 & 0,89 & 0,96 & 0,89 & 0,89 & 0,96 & 0,96 & 0,79 & 0,83 & 0,84 & & 0,94 & 0,94 & 0,85 & 1,00 \\
\hline 27 & 0,92 & 0,92 & 0,96 & 0,87 & 0,98 & 0,97 & 0,79 & 0,86 & 0,79 & & 0,81 & & 0,89 & 0,88 \\
\hline 28 & 0,86 & 0,95 & 0,92 & 0,76 & 0,94 & 0,96 & 0,79 & 0,87 & 0,83 & & 0,85 & & 0,78 & 0,96 \\
\hline 29 & 0,93 & 0,92 & 0,82 & 0,75 & 0,97 & 0,98 & 0,79 & 0,85 & 0,77 & & 0,84 & & 0,81 & 0,90 \\
\hline 30 & 0,86 & 0,93 & 0,84 & 0,78 & 0,87 & 0,96 & 0,79 & & 0,80 & & 0,89 & & 0,85 & 0,94 \\
\hline 31 & 0,93 & 0,85 & 0,88 & 0,74 & 0,79 & 0,85 & 0,76 & & 0,76 & & 0,87 & & 0,83 & 0,95 \\
\hline 32 & 0,96 & 0,85 & 0,85 & 0,75 & 0,91 & 0,71 & 0,79 & & 0,78 & & 0,90 & & 0,83 & 0,98 \\
\hline 33 & 0,91 & 0,73 & 0,84 & & 0,95 & 0,92 & 0,77 & & 0,80 & & 0,90 & & 0,83 & 0,96 \\
\hline 34 & 0,91 & 0,60 & 0,83 & & 0,85 & 0,97 & 0,77 & & 0,81 & & 0,84 & & 0,78 & 0,97 \\
\hline 35 & 0,88 & 0,72 & 0,83 & & & 0,96 & 0,90 & & 0,83 & & 0,84 & & & 0,96 \\
\hline 36 & 0,96 & 0,53 & 0,80 & & & 0,96 & 0,90 & & & & 0,84 & & & 0,97 \\
\hline 37 & 0,95 & 0,67 & 0,84 & & & 0,92 & 0,86 & & & & 0,84 & & & 0,95 \\
\hline 38 & 0,93 & 0,80 & 0,82 & & & 0,81 & 0,84 & & & & 0,74 & & & 0,91 \\
\hline 39 & 0,53 & 0,84 & 0,74 & & & 0,93 & 0,79 & & & & 0,81 & & & 0,94 \\
\hline 40 & 0,91 & 0,82 & 0,83 & & & 0,87 & 0,80 & & & & 0,84 & & & 0,97 \\
\hline 41 & 0,95 & 0,82 & 0,76 & & & 0,92 & 0,81 & & & & 0,85 & & & 0,65 \\
\hline 42 & 0,94 & 0,81 & 0,78 & & & 0,94 & & & & & 0,88 & & & 0,88 \\
\hline 43 & 0,91 & 0,87 & 0,74 & & & 0,98 & & & & & 0,84 & & & 0,98 \\
\hline 44 & 0,83 & 0,82 & 0,75 & & & & & & & & 0,82 & & & 0,98 \\
\hline 45 & 0,93 & 0,88 & 0,77 & & & & & & & & 0,81 & & & 0,98 \\
\hline 46 & 0,97 & 0,81 & 0,76 & & & & & & & & 0,82 & & & 0,97 \\
\hline 47 & 0,97 & 0,85 & 0,78 & & & & & & & & 0,83 & & & 0,99 \\
\hline 48 & 0,93 & 0,81 & 0,82 & & & & & & & & 0,85 & & & 0,96 \\
\hline 49 & 0,92 & 0,84 & 0,73 & & & & & & & & 0,86 & & & 0,95 \\
\hline 50 & 0,93 & 0,85 & 0,74 & & & & & & & & 0,84 & & & 0,89 \\
\hline 51 & 0,91 & 0,88 & 0,79 & & & & & & & & 0,85 & & & \\
\hline 52 & 0,86 & & & & & & & & & & 0,87 & & & \\
\hline 53 & & & & & & & & & & & 0,86 & & & \\
\hline 54 & & & & & & & & & & & 0,88 & & & \\
\hline 55 & & & & & & & & & & & 0,87 & & & \\
\hline
\end{tabular}


Tabela 8 - Concentrações de ${ }^{210} \mathrm{~Pb}$ total e excesso para o perfil $1 \mathrm{~N}$

\begin{tabular}{|c|c|c|c|c|c|c|c|}
\hline $\begin{array}{l}\text { Profundidade } \\
\text { (cm) }\end{array}$ & $\begin{array}{c}\text { Massa } \\
\text { acumulada } \\
\left(\mathrm{g} \mathrm{cm}^{-2}\right)\end{array}$ & $\begin{array}{c}{ }^{210} \mathrm{~Pb} \text { total } \\
\left(\mathrm{Bq} \mathrm{kg}{ }^{-1}\right)\end{array}$ & Erro & $\begin{array}{c}{ }^{210} \mathrm{~Pb} \mathrm{exc} \\
\left(\mathrm{Bq} \mathrm{kg}^{-1}\right)\end{array}$ & Erro & $\begin{array}{c}{ }^{210} \mathrm{~Pb} \text { exc } \\
(\mathrm{mBq} \mathrm{cm})\end{array}$ & Erro \\
\hline 1 & 0,19 & 62,4 & 0,74 & - & 6,09 & - & 0,14 \\
\hline 2 & 0,55 & 80,7 & 1,0 & 11,9 & 6,12 & 4,21 & 0,34 \\
\hline 3 & 0,98 & 65,0 & 0,77 & - & & - & \\
\hline 4 & 1,47 & 52,4 & 0,62 & - & & - & \\
\hline 5 & 1,95 & 53,9 & 0,64 & - & & - & \\
\hline 6 & 2,43 & 57,2 & 0,48 & - & & - & \\
\hline 7 & 2,81 & 60,4 & 0,72 & - & & - & \\
\hline 8 & 3,29 & 63,3 & 0,53 & - & & - & \\
\hline 9 & 3,75 & 66,3 & 0,79 & - & & - & \\
\hline 10 & 4,21 & 63,3 & 0,53 & - & & - & \\
\hline 11 & 4,70 & 60,3 & 0,72 & - & & - & \\
\hline 12 & 5,16 & 56,6 & 0,48 & - & & - & \\
\hline 13 & 5,70 & 52,9 & 0,63 & - & & - & \\
\hline 14 & 6,20 & 54,3 & 0,46 & - & & - & \\
\hline 15 & 6,63 & 55,7 & 0,66 & - & & - & \\
\hline 16 & 7,08 & 55,7 & 0,47 & - & & - & \\
\hline 17 & 7,59 & 55,6 & 0,66 & - & & - & \\
\hline 18 & 8,03 & 59,3 & 0,50 & - & & - & \\
\hline 19 & 8,49 & 62,9 & 0,75 & - & & - & \\
\hline 20 & 9,05 & 63,8 & 0,54 & - & & - & \\
\hline 21 & 9,56 & 64,7 & 0,77 & - & & - & \\
\hline 22 & 10,1 & 70,1 & 0,59 & 1,28 & & - & \\
\hline 23 & 10,5 & 75,5 & 0,90 & 6,67 & 6,11 & 3,10 & 0,42 \\
\hline 24 & 11,0 & 86,4 & 0,73 & 17,6 & 6,08 & 7,69 & 0,32 \\
\hline 25 & 11,4 & 97,4 & 1,16 & 28,6 & 6,15 & 12,75 & 0,52 \\
\hline 26 & 11,8 & 93,2 & 0,78 & 24,4 & 6,09 & 10,69 & 0,34 \\
\hline 27 & 12,3 & 89,1 & 1,06 & 20,2 & 6,13 & 9,31 & 0,49 \\
\hline 28 & 12,8 & 89,3 & 0,75 & 20,5 & 6,09 & 9,32 & 0,34 \\
\hline 29 & 13,2 & 89,6 & 1,06 & 20,8 & 6,13 & 9,95 & 0,51 \\
\hline 30 & 13,7 & 88,4 & 0,74 & 19,6 & 6,09 & 9,02 & 0,34 \\
\hline 31 & 14,2 & 87,2 & 1,04 & 18,4 & 6,13 & 8,78 & 0,49 \\
\hline 32 & 14,6 & 90,8 & 0,76 & 21,9 & 6,09 & 9,86 & 0,34 \\
\hline 33 & 15,1 & 94,3 & 1,12 & 25,5 & 6,14 & 11,97 & 0,53 \\
\hline 34 & 15,6 & 90,3 & 0,76 & 21,5 & 6,09 & 10,44 & 0,37 \\
\hline 35 & 16,1 & 86,3 & 1,03 & 17,4 & 6,13 & 8,31 & 0,49 \\
\hline 36 & 16,5 & 76,0 & 0,64 & 7,14 & 6,07 & - & \\
\hline 37 & 17,0 & 65,7 & 0,78 & - & & - & \\
\hline 38 & 17,5 & 67,0 & 0,56 & - & & - & \\
\hline 39 & 17,9 & 68,4 & 0,81 & - & & - & \\
\hline 40 & 18,4 & 67,3 & 0,57 & - & & - & \\
\hline 41 & 18,9 & 66,2 & 0,79 & - & & - & \\
\hline 42 & 19,4 & 74,8 & 0,63 & - & & - & \\
\hline 43 & 19,9 & 83,3 & 0,99 & 14,51 & 6,12 & 6,83 & 0,47 \\
\hline 44 & 20,4 & 87,3 & 0,73 & 18,44 & 6,08 & 8,95 & 0,36 \\
\hline 45 & 20,8 & 91,2 & 1,08 & 22,37 & 6,14 & 10,45 & 0,51 \\
\hline 46 & 21,3 & 86,9 & 0,73 & 18,07 & 6,08 & 7,88 & 0,32 \\
\hline 47 & 21,7 & 82,6 & 0,98 & 13,77 & 6,12 & 5,96 & 0,42 \\
\hline 48 & 22,2 & 72,9 & 0,87 & - & & - & \\
\hline 49 & 22,6 & 72,0 & 0,86 & - & & - & \\
\hline 50 & 23,1 & 66,7 & 0,79 & - & & - & \\
\hline 51 & 23,6 & 73,4 & 0,87 & - & & - & \\
\hline 52 & 24,1 & 59,1 & 0,70 & - & & - & \\
\hline
\end{tabular}


Tabela 9 - Concentrações de ${ }^{210} \mathrm{~Pb}$ total e excesso para o perfil $3 S$.

\begin{tabular}{|c|c|c|c|c|c|c|c|}
\hline $\begin{array}{l}\text { Profundidade } \\
\text { (cm) }\end{array}$ & $\begin{array}{c}\text { Massa } \\
\text { acumulada } \\
\left(\mathrm{g} \mathrm{cm}^{-2}\right)\end{array}$ & $\begin{array}{l}{ }^{210} \mathrm{~Pb} \text { total } \\
\left(\mathrm{Bq} \mathrm{kg} \mathbf{~ k g}^{-1}\right)\end{array}$ & Erro & $\begin{array}{c}{ }^{210} \mathrm{~Pb} \text { exc } \\
\left(\mathrm{Bq} \mathrm{kg}^{-1}\right)\end{array}$ & Erro & $\begin{array}{l}{ }^{210} \mathrm{~Pb} \mathrm{exc}^{-2} \\
\left(\mathrm{mBq} \mathrm{cm}{ }^{-2}\right)\end{array}$ & Erro \\
\hline 1 & 0,23 & 83,9 & 1,0 & 56,1 & 2,8 & 13,1 & 0,66 \\
\hline 2 & 0,52 & 80,1 & 0,95 & 52,3 & 2,8 & 15,2 & 0,82 \\
\hline 3 & 0,93 & 67,3 & 0,80 & 39,5 & 2,8 & 15,9 & 1,1 \\
\hline 4 & 1,33 & 52,4 & 0,62 & 24,6 & 2,7 & 10,0 & 1,1 \\
\hline 5 & 1,77 & 46,6 & 0,55 & 18,8 & 2,7 & 8,32 & 1,2 \\
\hline 6 & 2,21 & 53,1 & 0,45 & 25,3 & 2,7 & 10,9 & 1,2 \\
\hline 7 & 2,64 & 59,6 & 0,71 & 31,8 & 2,7 & 13,8 & 1,2 \\
\hline 8 & 3,08 & 58,9 & 0,50 & 31,2 & 2,7 & 13,6 & 1,2 \\
\hline 9 & 3,54 & 58,3 & 0,69 & 30,5 & 2,7 & 14,1 & 1,3 \\
\hline 10 & 4,04 & 59,1 & 0,50 & 31,3 & 2,7 & 15,8 & 1,4 \\
\hline 11 & 4,59 & 59,8 & 0,71 & 32,1 & 2,7 & 17,5 & 1,5 \\
\hline 12 & 5,09 & 62,6 & 0,53 & 34,8 & 2,7 & 17,3 & 1,3 \\
\hline 13 & 5,60 & 65,3 & 0,78 & 37,5 & 2,8 & 19,0 & 1,4 \\
\hline 14 & 6,15 & 66,3 & 0,56 & 38,6 & 2,7 & 21,3 & 1,5 \\
\hline 15 & 6,71 & 67,4 & 0,80 & 39,6 & 2,8 & 22,3 & 1,6 \\
\hline 16 & 7,23 & 63,2 & 0,53 & 35,5 & 2,7 & 18,4 & 1,4 \\
\hline 17 & 7,77 & 59,1 & 0,70 & 31,3 & 2,7 & 16,8 & 1,5 \\
\hline 18 & 8,30 & 61,0 & 0,51 & 33,2 & 2,7 & 17,5 & 1,4 \\
\hline 19 & 8,87 & 62,9 & 0,75 & 35,1 & 2,7 & 20,0 & 1,6 \\
\hline 20 & 9,49 & 60,4 & 0,51 & 32,7 & 2,7 & 20,5 & 1,7 \\
\hline 21 & 10,1 & 58,0 & 0,69 & 30,2 & 2,7 & 18,5 & 1,7 \\
\hline 22 & 10,7 & 51,7 & 0,44 & 23,9 & 2,7 & 15,4 & 1,7 \\
\hline 23 & 11,4 & 45,3 & 0,54 & 17,6 & 2,7 & 10,8 & 1,7 \\
\hline 24 & 12,0 & 47,0 & 0,40 & 19,3 & 2,7 & 11,5 & 1,6 \\
\hline 25 & 12,6 & 48,7 & 0,58 & 21,0 & 2,7 & 13,0 & 1,7 \\
\hline 26 & 13,3 & 51,5 & 0,43 & 23,7 & 2,7 & 16,8 & 1,9 \\
\hline 27 & 13,9 & 54,3 & 0,65 & 26,5 & 2,7 & 15,7 & 1,6 \\
\hline 28 & 14,5 & 52,5 & 0,44 & 24,7 & 2,7 & 15,6 & 1,7 \\
\hline 29 & 15,1 & 50,7 & 0,60 & 22,9 & 2,7 & 13,3 & 1,6 \\
\hline 30 & 15,7 & 53,4 & 0,63 & 25,6 & 2,7 & 15,1 & 1,6 \\
\hline 31 & 16,3 & 39,9 & 0,47 & 12,2 & 2,7 & 7,55 & 1,7 \\
\hline 32 & 17,0 & 34,7 & 0,41 & 6,92 & 2,7 & 4,58 & 1,8 \\
\hline 33 & 17,6 & 29,6 & 0,35 & & & & \\
\hline 34 & 18,2 & 25,9 & 0,31 & & & & \\
\hline
\end{tabular}


Tabela 10 - Concentrações de ${ }^{210} \mathrm{~Pb}$ total e excesso para o perfil $1 \mathrm{~S}$

\begin{tabular}{|c|c|c|c|c|c|c|c|}
\hline $\begin{array}{l}\text { Profundidade } \\
\text { (cm) }\end{array}$ & $\begin{array}{c}\text { Massa acumulada } \\
(\mathrm{g} \mathrm{cm}-2)\end{array}$ & $\begin{array}{r}{ }^{210} \mathrm{~Pb} \text { total } \\
\left(\mathrm{Bq} \mathrm{kg}^{-1}\right)\end{array}$ & Erro & $\begin{array}{l}{ }^{210} \mathrm{~Pb} \text { exc } \\
\left(\mathrm{Bq} \mathrm{kg}^{-1}\right)\end{array}$ & Erro & $\begin{array}{l}{ }^{210} \mathrm{~Pb} \text { exc } \\
\left(\mathrm{mBq} \mathrm{cm}^{-2}\right)\end{array}$ & Erro \\
\hline 1 & 0,36 & 78,8 & 0,94 & 52,9 & 3,10 & 19,2 & 1,1 \\
\hline 2 & 0,57 & 66,5 & 0,79 & 40,5 & 3,06 & 8,4 & 0,6 \\
\hline 3 & 0,83 & 58,9 & 0,70 & 33,0 & 3,03 & 8,7 & 0,8 \\
\hline 4 & 1,23 & 51,9 & 0,62 & 26,0 & 3,02 & 10,4 & 1,2 \\
\hline 5 & 1,61 & 64,7 & 0,77 & 38,8 & 3,05 & 14,8 & 1,2 \\
\hline 6 & 1,98 & 66,9 & 0,56 & 40,9 & 3,00 & 14,9 & 1,1 \\
\hline 7 & 2,41 & 69,0 & 0,82 & 43,0 & 3,06 & 18,8 & 1,3 \\
\hline 8 & 2,87 & 62,0 & 0,52 & 36,1 & 3,00 & 16,4 & 1,4 \\
\hline 9 & 3,28 & 55,0 & 0,65 & 29,1 & 3,02 & 11,9 & 1,2 \\
\hline 10 & 3,69 & 62,8 & 0,53 & 36,8 & 3,00 & 15,2 & 1,2 \\
\hline 11 & 4,12 & 70,5 & 0,84 & 44,6 & 3,07 & 19,1 & 1,3 \\
\hline 12 & 4,61 & 72,1 & 0,61 & 46,1 & 3,01 & 22,8 & 1,5 \\
\hline 13 & 5,02 & 73,6 & 0,88 & 47,7 & 3,08 & 19,4 & 1,3 \\
\hline 14 & 5,48 & 77,6 & 0,65 & 51,7 & 3,02 & 23,9 & 1,4 \\
\hline 15 & 5,96 & 81,6 & 0,97 & 55,6 & 3,11 & 26,6 & 1,5 \\
\hline 16 & 6,54 & 73,2 & 0,62 & 47,3 & 3,02 & 27,3 & 1,7 \\
\hline 17 & 7,15 & 64,8 & 0,77 & 38,9 & 3,05 & 23,9 & 1,9 \\
\hline 18 & 7,79 & 63,6 & 0,53 & 37,7 & 3,00 & 24,2 & 1,9 \\
\hline 19 & 8,42 & 62,4 & 0,74 & 36,5 & 3,04 & 22,9 & 1,9 \\
\hline 20 & 8,95 & 61,8 & 0,52 & 35,9 & 3,00 & 18,9 & 1,6 \\
\hline 21 & 9,44 & 61,2 & 0,73 & 35,2 & 3,04 & 17,3 & 1,5 \\
\hline 22 & 9,94 & 62,6 & 0,53 & 36,7 & 3,00 & 18,4 & 1,5 \\
\hline 23 & 10,5 & 64,1 & 0,76 & 38,1 & 3,05 & 20,5 & 1,6 \\
\hline 24 & 11,0 & 62,1 & 0,52 & 36,2 & 3,00 & 18,2 & 1,5 \\
\hline 25 & 11,5 & 60,1 & 0,71 & 34,2 & 3,04 & 16,4 & 1,5 \\
\hline 26 & 11,9 & 72,8 & 0,62 & 46,9 & 3,02 & 21,2 & 1,4 \\
\hline 27 & 12,4 & 85,5 & 1,02 & 59,5 & 3,12 & 31,8 & 1,7 \\
\hline 28 & 12,9 & 79,5 & 0,67 & 53,6 & 3,03 & 26,2 & 1,5 \\
\hline 29 & 13,4 & 73,6 & 0,87 & 47,6 & 3,08 & 22,2 & 1,4 \\
\hline 30 & 13,9 & 76,7 & 0,64 & 50,8 & 3,02 & 27,1 & 1,6 \\
\hline 31 & 14,5 & 79,8 & 0,95 & 53,9 & 3,10 & 29,3 & 1,7 \\
\hline 32 & 15,1 & 71,3 & 0,60 & 45,3 & 3,01 & 28,7 & 1,9 \\
\hline 33 & 15,8 & 62,7 & 0,74 & 36,8 & 3,04 & 25,1 & 2,1 \\
\hline 34 & 16,7 & 61,2 & 0,51 & 35,3 & 3,00 & 30,6 & 2,6 \\
\hline 35 & 17,3 & 59,8 & 0,71 & 33,8 & 3,04 & 22,6 & 2,0 \\
\hline 36 & 18,4 & 55,0 & 0,46 & 29,1 & 2,99 & 31,5 & 3,2 \\
\hline 37 & 19,3 & 50,3 & 0,60 & 24,4 & 3,01 & 22,2 & 2,7 \\
\hline 38 & 20,1 & 73,7 & 0,65 & 47,8 & 3,02 & 35,8 & 2,3 \\
\hline 39 & 20,7 & 97,2 & 1,15 & 71,2 & 3,17 & 43,3 & 1,9 \\
\hline 40 & 21,4 & 90,9 & 0,77 & 65,0 & 3,05 & 46,6 & 2,2 \\
\hline 41 & 22,1 & 84,6 & 1,01 & 58,7 & 3,12 & 42,4 & 2,3 \\
\hline 42 & 22,8 & 91,5 & 0,77 & 65,6 & 3,05 & 43,4 & 2,0 \\
\hline 43 & 23,4 & 98,5 & 1,17 & 72,5 & 3,17 & 46,3 & 2,0 \\
\hline 44 & 24,0 & 87,3 & 0,74 & 61,4 & 3,04 & 37,5 & 1,9 \\
\hline 45 & 24,6 & 76,2 & 0,91 & 50,3 & 3,09 & 27,5 & 1,7 \\
\hline 46 & 25,6 & 67,6 & 0,57 & 41,7 & 3,01 & 42,3 & 3,0 \\
\hline 47 & 26,3 & 59,0 & 0,70 & 33,1 & 3,03 & 23,5 & 2,2 \\
\hline 48 & 27,0 & 58,2 & 0,69 & 32,3 & 3,03 & 22,1 & 2,1 \\
\hline 49 & 27,7 & 59,4 & 0,71 & 33,5 & 3,03 & 22,6 & 2,0 \\
\hline 50 & 28,2 & 61,9 & 0,74 & 36,0 & 3,04 & 18,4 & 1,6 \\
\hline 51 & 28,8 & 65,4 & 0,78 & 39,5 & 3,05 & 25,1 & 1,9 \\
\hline
\end{tabular}


Tabela 11 - Concentrações de ${ }^{210} \mathrm{~Pb}$ total e excesso para o perfil $2 \mathrm{~N}$.

\begin{tabular}{|c|c|c|c|c|c|c|c|}
\hline $\begin{array}{l}\text { Profundidade } \\
\text { (cm) }\end{array}$ & $\begin{array}{c}\text { Massa } \\
\text { acumulada } \\
\left(\mathrm{g} \mathrm{cm}^{-2}\right)\end{array}$ & $\begin{array}{c}{ }^{210} \mathrm{~Pb} \text { total } \\
\left(\mathrm{Bq} \mathrm{kg}^{-1}\right)\end{array}$ & Erro & $\begin{array}{c}{ }^{210} \mathrm{~Pb} \operatorname{exc}(\mathrm{Bq} \\
\left.\mathrm{kg}^{-1}\right)\end{array}$ & Erro & $\begin{array}{l}{ }^{210} \mathrm{~Pb} \text { exc } \\
\left(\mathrm{mBq} \mathrm{cm}{ }^{-2}\right)\end{array}$ & Erro \\
\hline 1 & 0,25 & 88,1 & 1,1 & 58,1 & 3,4 & 14,6 & 0,26 \\
\hline 2 & 0,63 & 107 & 1,3 & 77,3 & 3,5 & 29,6 & 0,49 \\
\hline 3 & 1,08 & 132 & 1,6 & 102 & 3,6 & 45,3 & 0,70 \\
\hline 4 & 1,44 & 120 & 1,4 & 90,2 & 3,5 & 32,9 & 0,52 \\
\hline 5 & 1,80 & 116 & 1,4 & 86,0 & 3,5 & 31,0 & 0,50 \\
\hline 6 & 2,18 & 95,1 & 0,82 & 65,1 & 3,3 & 24,2 & 0,30 \\
\hline 7 & 2,60 & 74,3 & 0,88 & 44,3 & 3,3 & 18,8 & 0,37 \\
\hline 8 & 3,00 & 64,3 & 0,55 & 34,3 & 3,3 & 13,8 & 0,22 \\
\hline 9 & 3,42 & 54,3 & 0,65 & 24,3 & 3,3 & 10,2 & 0,27 \\
\hline 10 & 3,82 & 59,7 & 0,50 & 29,7 & 3,3 & 11,6 & 0,20 \\
\hline 11 & 4,24 & 65,2 & 0,77 & 35,2 & 3,3 & 14,9 & 0,33 \\
\hline 12,5 & 4,93 & 63,9 & 0,53 & 33,9 & 3,3 & 23,3 & 0,37 \\
\hline 13 & 5,19 & 62,5 & 0,74 & 32,5 & 3,3 & 8,56 & 0,19 \\
\hline 14 & 5,71 & 58,1 & 0,49 & 28,1 & 3,3 & 14,6 & 0,25 \\
\hline 15 & 6,36 & 53,6 & 0,64 & 23,6 & 3,3 & 15,3 & 0,42 \\
\hline 16 & 6,82 & 98,5 & 0,91 & 68,5 & 3,4 & 31,7 & 0,42 \\
\hline 17 & 7,30 & 143 & 1,7 & 113 & 3,7 & 54,3 & 0,81 \\
\hline 18 & 7,74 & 139 & 1,2 & 109 & 3,4 & 47,3 & 0,51 \\
\hline 19 & 8,05 & 135 & 1,6 & 105 & 3,6 & 32,8 & 0,50 \\
\hline 20 & 8,50 & 130 & 1,1 & 100 & 3,4 & 45,7 & 0,50 \\
\hline 21 & 9,00 & 125 & 1,5 & 95,0 & 3,6 & 46,7 & 0,74 \\
\hline 22 & 9,33 & 122 & 1,0 & 92,2 & 3,4 & 30,5 & 0,34 \\
\hline 23 & 9,62 & 119 & 1,4 & 89,3 & 3,5 & 25,9 & 0,41 \\
\hline 24 & 9,98 & 102 & 0,87 & 72,4 & 3,3 & 26,1 & 0,31 \\
\hline 25 & 10,3 & 85,4 & 1,01 & 55,4 & 3,4 & 18,4 & 0,34 \\
\hline 26 & 10,7 & 78,4 & 0,66 & 48,4 & 3,3 & 18,8 & 0,26 \\
\hline 27 & 11,1 & 71,5 & 0,85 & 41,5 & 3,3 & 15,1 & 0,31 \\
\hline 28 & 11,4 & 65,8 & 0,55 & 35,8 & 3,3 & 13,2 & 0,20 \\
\hline 29 & 11,9 & 60,1 & 0,71 & 30,1 & 3,3 & 12,9 & 0,31 \\
\hline 30 & 12,3 & 71,4 & 0,85 & 41,4 & 3,3 & 19,0 & 0,39 \\
\hline 31 & 12,8 & 58,6 & 0,70 & 28,6 & 3,3 & 14,2 & 0,39 \\
\hline 32 & 13,3 & 56,0 & 0,67 & 26,0 & 3,3 & 12,6 & 0,35 \\
\hline 33 & 13,8 & 55,3 & 0,66 & 25,3 & 3,3 & 13,4 & 0,32 \\
\hline 34 & 14,3 & 62,4 & 0,74 & 32,4 & 3,3 & 16,0 & 0,35 \\
\hline
\end{tabular}


Tabela 12 - Concentrações de ${ }^{210} \mathrm{~Pb}$ total e excesso para o perfil $3 S S$.

\begin{tabular}{|c|c|c|c|c|c|c|c|}
\hline $\begin{array}{l}\text { Profundidade } \\
\text { (cm) }\end{array}$ & $\begin{array}{l}\text { Massa acumulada } \\
\left(\mathrm{g} \mathrm{cm}^{-2}\right)\end{array}$ & $\begin{array}{l}{ }^{210} \mathrm{~Pb} \text { total } \\
\left(\mathrm{Bq} \mathrm{kg}^{-1}\right)\end{array}$ & Erro & $\begin{array}{l}{ }^{210} \mathrm{~Pb} \text { exc } \\
\left(\mathrm{Bq} \mathrm{kg}^{-1}\right)\end{array}$ & Erro & $\begin{array}{l}{ }^{210} \mathrm{~Pb} \text { exc } \\
\left(\mathrm{mBq} \mathrm{cm}^{-2}\right)\end{array}$ & Erro \\
\hline 1 & 0,44 & 79,1 & 0,94 & 52,8 & 2,5 & 23,0 & 1,1 \\
\hline 2 & 0,94 & 86,2 & 1,0 & 59,9 & 2,5 & 29,9 & 1,3 \\
\hline 3 & 1,36 & 95,3 & 1,1 & 69,0 & 2,6 & 28,7 & 1,1 \\
\hline 4 & 1,76 & 105 & 1,2 & 78,5 & 2,6 & 31,7 & 1,1 \\
\hline 5 & 2,22 & 108 & 1,3 & 81,7 & 2,6 & 37,5 & 1,2 \\
\hline 6 & 2,63 & 106 & 0,89 & 79,6 & 2,5 & 32,6 & 1,0 \\
\hline 7 & 3,15 & 104 & 1,2 & 77,5 & 2,6 & 40,8 & 1,4 \\
\hline 8 & 3,62 & 86,7 & 0,74 & 60,5 & 2,4 & 28,2 & 1,1 \\
\hline 9 & 4,00 & 69,7 & 0,83 & 43,5 & 2,4 & 16,3 & 0,92 \\
\hline 10 & 4,41 & 74,6 & 0,63 & 48,4 & 2,4 & 19,9 & 0,98 \\
\hline 11 & 4,81 & 79,5 & 0,95 & 53,3 & 2,5 & 21,4 & 1,0 \\
\hline 12 & 5,22 & 81,8 & 0,69 & 55,6 & 2,4 & 22,9 & 0,99 \\
\hline 13 & 5,93 & 84,1 & 1,0 & 57,9 & 2,5 & 40,9 & 1,8 \\
\hline 14 & 6,39 & 91,8 & 0,77 & 65,6 & 2,4 & 30,2 & 1,1 \\
\hline 15 & 6,84 & 99,5 & 1,2 & 73,3 & 2,6 & 32,9 & 1,2 \\
\hline 16 & 7,21 & 84,2 & 0,72 & 58,0 & 2,4 & 21,7 & 0,90 \\
\hline 17 & 7,66 & 68,9 & 0,82 & 42,7 & 2,4 & 19,1 & 1,1 \\
\hline 18 & 8,12 & 79,4 & 0,67 & 53,2 & 2,4 & 24,6 & 1,1 \\
\hline 19 & 8,55 & 89,9 & 1,1 & 63,6 & 2,5 & 27,3 & 1,1 \\
\hline 20 & 9,03 & 90,7 & 0,76 & 64,5 & 2,4 & 31,1 & 1,2 \\
\hline 21 & 9,43 & 91,5 & 1,1 & 65,3 & 2,5 & 26,2 & 1,0 \\
\hline 22 & 9,84 & 87,3 & 0,73 & 61,1 & 2,4 & 24,7 & 0,98 \\
\hline 23 & 10,3 & 83,2 & 0,99 & 56,9 & 2,5 & 23,9 & 1,1 \\
\hline 24 & 10,7 & 81,8 & 0,69 & 55,6 & 2,4 & 27,2 & 1,2 \\
\hline 25 & 11,1 & 80,5 & 0,96 & 54,2 & 2,5 & 17,3 & 0,80 \\
\hline 26 & 11,5 & 95,8 & 0,82 & 69,6 & 2,4 & 31,8 & 1,1 \\
\hline 27 & 11,9 & 111 & 1,3 & 85,0 & 2,7 & 33,8 & 1,1 \\
\hline 28 & 12,4 & 119 & 1,0 & 92,3 & 2,5 & 44,8 & 1,2 \\
\hline 29 & 12,8 & 126 & 1,5 & 99,6 & 2,7 & 43,5 & 1,2 \\
\hline 30 & 13,3 & 100 & 0,87 & 73,9 & 2,5 & 30,1 & 1,0 \\
\hline 31 & 13,8 & 74,5 & 0,89 & 48,3 & 2,5 & 25,8 & 1,3 \\
\hline 32 & 14,3 & 68,3 & 0,58 & 42,0 & 2,4 & 23,0 & 1,3 \\
\hline 33 & 14,9 & 62,0 & 0,74 & 35,8 & 2,4 & 21,9 & 1,5 \\
\hline 34 & 15,5 & 61,5 & 0,52 & 35,3 & 2,4 & 18,8 & 1,3 \\
\hline 35 & 15,9 & 61,0 & 0,72 & 34,7 & 2,4 & 15,9 & 1,1 \\
\hline 36 & 16,5 & 44,5 & 0,40 & 18,3 & 2,3 & 10,6 & 1,4 \\
\hline 37 & 17,1 & 28,0 & 0,33 & 1,79 & 2,3 & 1,06 & 1,37 \\
\hline 38 & 17,7 & 26,7 & 0,22 & - & & & \\
\hline 39 & 18,3 & 25,4 & 0,30 & - & & & \\
\hline 40 & 18,9 & 25,1 & 0,21 & - & & & \\
\hline 41 & 19,4 & 24,8 & 0,29 & - & & & \\
\hline 42 & 20,1 & 26,0 & 0,22 & - & & & \\
\hline 43 & 20,7 & 27,2 & 0,32 & - & & & \\
\hline 44 & 21,3 & 24,5 & 0,21 & - & & & \\
\hline 45 & 21,9 & 21,8 & 0,26 & - & & & \\
\hline 46 & 22,5 & 23,7 & 0,20 & - & & & \\
\hline 47 & 23,0 & 25,7 & 0,31 & - & & & \\
\hline 48 & 23,6 & 25,9 & 0,22 & - & & & \\
\hline 49 & 24,2 & 26,1 & 0,31 & - & & & \\
\hline 50 & 24,6 & 27,5 & 0,23 & - & & & \\
\hline 51 & 25,1 & 28,8 & 0,34 & - & & & \\
\hline 52 & 25,6 & 26,5 & 0,22 & - & & & \\
\hline 53 & 26,2 & 24,1 & 0,29 & - & & & \\
\hline
\end{tabular}


Tabela 13 - Concentrações de ${ }^{210} \mathrm{~Pb}$ total e excesso para o perfil $3 \mathrm{C}$.

\begin{tabular}{|c|c|c|c|c|c|c|c|}
\hline $\begin{array}{l}\text { Profundidade } \\
\quad(\mathrm{cm})\end{array}$ & $\begin{array}{c}\text { Massa } \\
\text { acumulada } \\
\left(\mathrm{g} \mathrm{cm}^{-2}\right)\end{array}$ & $\begin{array}{c}{ }^{210} \mathrm{~Pb} \text { total } \\
\left(\mathrm{Bq} \mathrm{kg}^{-1}\right)\end{array}$ & Erro & $\begin{array}{l}{ }^{210} \mathrm{~Pb} \mathrm{exc}^{-x} \\
\left(\mathrm{~Bq} \mathrm{~kg}^{-1}\right)\end{array}$ & Erro & $\begin{array}{l}{ }^{210} \mathrm{Pbexc} \\
\left(\mathrm{mBq} \mathrm{cm}{ }^{-2}\right)\end{array}$ & Erro \\
\hline 1 & 0,31 & 80,3 & 0,95 & 58,1 & 3,76 & 18,1 & 1,17 \\
\hline 2 & 0,64 & 76,9 & 0,91 & 54,7 & 3,75 & 18,3 & 1,25 \\
\hline 3 & 1,05 & 71,7 & 0,85 & 49,5 & 3,74 & 20,2 & 1,53 \\
\hline 4 & 1,45 & 82,4 & 0,98 & 60,2 & 3,77 & 24,2 & 1,51 \\
\hline 5 & 1,86 & 95,3 & 1,13 & 73,1 & 3,81 & 29,8 & 1,55 \\
\hline 6 & 2,28 & 91,9 & 0,77 & 69,7 & 3,72 & 29,4 & 1,57 \\
\hline 7 & 2,72 & 88,5 & 1,05 & 66,3 & 3,79 & 29,2 & 1,67 \\
\hline 8 & 3,14 & 94,7 & 0,80 & 72,5 & 3,73 & 30,4 & 1,56 \\
\hline 9 & 3,63 & 101 & 1,20 & 78,7 & 3,83 & 38,4 & 1,87 \\
\hline 10 & 4,27 & 84,5 & 0,72 & 62,3 & 3,71 & 40,0 & 2,38 \\
\hline 11 & 4,93 & 68,1 & 0,81 & 45,9 & 3,73 & 30,3 & 2,47 \\
\hline 12 & 5,64 & 56,0 & 0,48 & 33,8 & 3,67 & 23,8 & 2,59 \\
\hline 13 & 6,32 & 43,8 & 0,52 & 21,6 & 3,68 & 14,7 & 2,49 \\
\hline 14 & 6,95 & 35,2 & 0,30 & 13,0 & 3,65 & 8,26 & 2,32 \\
\hline 15 & 7,61 & 26,6 & 0,32 & 4,34 & 3,65 & 2,86 & 2,41 \\
\hline 16 & 8,25 & 22,9 & 0,19 & & & & \\
\hline 17 & 8,85 & 19,2 & 0,23 & & & & \\
\hline 18 & 9,50 & 18,5 & 0,16 & & & & \\
\hline 19 & 10,1 & 17,8 & 0,21 & & & & \\
\hline 20 & 10,8 & 23,3 & 0,20 & & & & \\
\hline 21 & 11,5 & 28,8 & 0,34 & & & & \\
\hline 22 & 12,2 & 27,1 & 0,23 & & & & \\
\hline 23 & 12,9 & 25,4 & 0,30 & & & & \\
\hline 24 & 13,6 & 24,9 & 0,21 & & & & \\
\hline 25 & 14,4 & 24,5 & 0,29 & & & & \\
\hline 26 & 15,0 & 21,3 & 0,25 & & & & \\
\hline 27 & 15,6 & 21,9 & 0,26 & & & & \\
\hline 28 & 16,1 & 17,9 & 0,21 & & & & \\
\hline 29 & 16,6 & 17,8 & 0,21 & & & & \\
\hline
\end{tabular}


Tabela 14 - Concentrações de ${ }^{210} \mathrm{~Pb}$ total e excesso para o perfil 2SS

\begin{tabular}{|c|c|c|c|c|c|c|c|}
\hline $\begin{array}{l}\text { Profundidade } \\
\text { (cm) }\end{array}$ & $\begin{array}{c}\text { Massa } \\
\text { acumulada } \\
\left(\mathrm{g} \mathrm{cm}^{-2}\right)\end{array}$ & $\begin{array}{c}{ }^{210} \mathrm{~Pb} \text { total } \\
\left(\mathrm{Bq} \mathrm{kg}^{-1}\right)\end{array}$ & Erro & $\begin{array}{c}{ }^{210} \mathrm{~Pb} \text { exc } \\
\left(\mathrm{Bq} \mathrm{kg}^{-1}\right)\end{array}$ & Erro & $\begin{array}{l}{ }^{210} \mathrm{Pbexc}^{-2} \\
(\mathrm{mBq} \mathrm{cm}\end{array}$ & Erro \\
\hline 1 & 0,26 & 85,6 & 1,0 & 63,0 & 3,9 & 16,1 & 0,99 \\
\hline 2 & 0,70 & 82,7 & 0,98 & 60,1 & 3,8 & 26,8 & 1,7 \\
\hline 3 & 1,17 & 82,9 & 0,99 & 60,3 & 3,8 & 28,4 & 1,8 \\
\hline 4 & 1,58 & 94,7 & 1,1 & 72,1 & 3,9 & 29,2 & 1,6 \\
\hline 5 & 1,94 & 89,8 & 1,1 & 67,2 & 3,9 & 24,3 & 1,4 \\
\hline 6 & 2,35 & 88,6 & 0,74 & 66,0 & 3,8 & 27,0 & 1,6 \\
\hline 7 & 2,87 & 87,4 & 1,0 & 64,8 & 3,9 & 33,5 & 2,0 \\
\hline 8 & 3,35 & 82,0 & 0,69 & 59,4 & 3,8 & 28,6 & 1,8 \\
\hline 9 & 3,94 & 76,5 & 0,91 & 53,9 & 3,8 & 32,1 & 2,3 \\
\hline 10 & 4,46 & 91,5 & 0,78 & 68,9 & 3,8 & 35,9 & 2,0 \\
\hline 11 & 5,16 & 107 & 1,3 & 83,9 & 3,9 & 58,2 & 2,7 \\
\hline 12 & 5,81 & 101 & 0,85 & 78,2 & 3,8 & 51,1 & 2,5 \\
\hline 13 & 6,37 & 95,1 & 1,13 & 72,5 & 3,9 & 40,5 & 2,2 \\
\hline 14 & 6,96 & 85,3 & 0,72 & 62,7 & 3,8 & 37,4 & 2,3 \\
\hline 15 & 7,51 & 75,5 & 0,90 & 52,9 & 3,8 & 28,9 & 2,1 \\
\hline 16 & 7,94 & 85,1 & 0,72 & 62,5 & 3,8 & 27,0 & 1,6 \\
\hline 17 & 8,44 & 94,7 & 1,1 & 72,1 & 3,9 & 36,0 & 1,9 \\
\hline 18 & 8,88 & 99,5 & 0,84 & 76,9 & 3,8 & 33,6 & 1,7 \\
\hline 19 & 9,28 & 104 & 1,2 & 81,7 & 3,9 & 32,4 & 1,6 \\
\hline 20 & 9,78 & 110 & 0,93 & 87,6 & 3,8 & 43,9 & 1,9 \\
\hline 21 & 10,2 & 116 & 1,4 & 93,4 & 4,0 & 38,3 & 1,6 \\
\hline 22 & 10,7 & 103 & 0,87 & 80,5 & 3,8 & 40,5 & 1,9 \\
\hline 23 & 11,2 & 90,3 & 1,1 & 67,7 & 3,9 & 35,8 & 2,0 \\
\hline 24 & 11,9 & 69,2 & 0,61 & 46,6 & 3,8 & 30,9 & 2,5 \\
\hline 25 & 12,5 & 48,1 & 0,57 & 25,5 & 3,8 & 17,1 & 2,5 \\
\hline 26 & 13,3 & 38,7 & 0,33 & 16,2 & 3,7 & 12,0 & 2,8 \\
\hline 27 & 14,6 & 29,4 & 0,35 & 6,81 & 3,7 & 8,85 & 4,9 \\
\hline 28 & 15,2 & 26,4 & 0,22 & & & & \\
\hline 29 & 16,1 & 23,3 & 0,28 & & & & \\
\hline 30 & 16,8 & 24,9 & 0,21 & & & & \\
\hline 31 & 17,5 & 26,5 & 0,32 & & & & \\
\hline 32 & 18,2 & 21,3 & 0,19 & & & & \\
\hline 33 & 18,8 & 16,0 & 0,19 & & & & \\
\hline 34 & 19,5 & 18,9 & 0,16 & & & & \\
\hline 35 & 20,1 & 21,7 & 0,26 & & & & \\
\hline 36 & 20,6 & 17,8 & 0,21 & & & & \\
\hline 37 & 21,1 & 21,5 & 0,26 & & & & \\
\hline 38 & 21,6 & 18,8 & 0,22 & & & & \\
\hline 39 & 22,2 & 27,5 & 0,33 & & & & \\
\hline 40 & 23,1 & 25,9 & 0,31 & & & & \\
\hline 42 & 23,9 & 25,8 & 0,31 & & & & \\
\hline
\end{tabular}


Tabela 15 - Concentrações de ${ }^{210} \mathrm{~Pb}$ total e excesso para o perfil 2SS

\begin{tabular}{|c|c|c|c|c|c|c|c|}
\hline $\begin{array}{l}\text { Profundidade } \\
\text { (cm) }\end{array}$ & $\begin{array}{c}\text { Massa } \\
\text { acumulada } \\
\left(\mathrm{g} \mathrm{cm}^{-2}\right)\end{array}$ & $\begin{array}{c}{ }^{210} \mathrm{~Pb} \text { total } \\
\left(\mathrm{Bq} \mathrm{kg}^{-1}\right)\end{array}$ & Erro & $\begin{array}{c}{ }^{210} \mathrm{~Pb} \text { exc } \\
\left(\mathrm{Bq} \mathrm{kg}^{-1}\right)\end{array}$ & Erro & $\begin{array}{l}{ }^{210} \mathrm{Pbexc}^{-2} \\
(\mathrm{mBq} \mathrm{cm})^{-2}\end{array}$ & Erro \\
\hline 1 & 0,50 & 114 & 1,4 & 85,2 & 10 & 42,8 & 5,1 \\
\hline 2 & 0,88 & 94,5 & 1,1 & 65,5 & 10 & 24,6 & 3,8 \\
\hline 3 & 1,26 & 95,9 & 1,1 & 66,9 & 10 & 25,8 & 3,9 \\
\hline 4 & 1,66 & 103 & 1,2 & 74,4 & 10 & 29,4 & 4,0 \\
\hline 5 & 2,06 & 192 & 2,3 & 163 & 10 & 65,5 & 4,2 \\
\hline 6 & 2,48 & 139 & 1,2 & 110 & 10 & 46,6 & 4,3 \\
\hline 7 & 2,76 & 85,1 & 1,0 & 56,0 & 10 & 15,5 & 2,8 \\
\hline 8 & 3,15 & 98,9 & 0,84 & 69,9 & 10 & 27,4 & 4,0 \\
\hline 9 & 3,59 & 113 & 1,3 & 83,7 & 10 & 36,4 & 4,4 \\
\hline 10 & 3,99 & 118 & 1,0 & 89,2 & 10 & 35,6 & 4,1 \\
\hline 11 & 4,42 & 124 & 1,5 & 94,8 & 10 & 41,1 & 4,4 \\
\hline 12 & 4,92 & 126 & 1,1 & 97,2 & 10 & 48,9 & 5,1 \\
\hline 13 & 5,41 & 129 & 1,5 & 99,7 & 10 & 48,1 & 4,9 \\
\hline 14 & 5,81 & 114 & 1,0 & 85,2 & 10 & 34,3 & 4,1 \\
\hline 15 & 6,21 & 100 & 1,2 & 70,7 & 10 & 28,4 & 4,1 \\
\hline 16 & 6,66 & 103 & 0,87 & 74,4 & 10 & 33,1 & 4,5 \\
\hline 17 & 7,11 & 107 & 1,3 & 78,1 & 10 & 35,1 & 4,6 \\
\hline 18 & 7,50 & 102 & 0,85 & 72,5 & 10 & 28,9 & 4,0 \\
\hline 19 & 7,89 & 95,9 & 1,1 & 66,9 & 10 & 25,6 & 3,9 \\
\hline 20 & 8,39 & 85,8 & 0,73 & 56,8 & 10 & 28,6 & 5,1 \\
\hline 21 & 8,74 & 75,7 & 0,90 & 46,7 & 10 & 16,4 & 3,6 \\
\hline 22 & 9,20 & 86,1 & 0,73 & 57,1 & 10 & 26,0 & 4,6 \\
\hline 23 & 9,57 & 96,4 & 1,1 & 67,4 & 10 & 25,0 & 3,8 \\
\hline 24 & 10,1 & 95,2 & 0,80 & 66,1 & 10 & 34,5 & 5,3 \\
\hline 25 & 10,6 & 93,9 & 1,1 & 64,8 & 10 & 31,3 & 4,9 \\
\hline 26 & 10,9 & 93,8 & 0,79 & 64,8 & 10 & 22,8 & 3,6 \\
\hline 27 & 11,3 & 93,8 & 1,1 & 64,7 & 10 & 25,6 & 4,0 \\
\hline 28 & 11,8 & 125 & 1,1 & 95,6 & 10 & 44,0 & 4,7 \\
\hline 29 & 12,2 & 156 & 1,8 & 127 & 10 & 53,2 & 4,3 \\
\hline 30 & 12,6 & 136 & 1,2 & 107 & 10 & 46,3 & 4,4 \\
\hline 31 & 13,0 & 117 & 1,4 & 87,7 & 10 & 36,1 & 4,2 \\
\hline 32 & 13,5 & 117 & 1,0 & 87,6 & 10 & 40,6 & 4,7 \\
\hline 33 & 13,9 & 116 & 1,4 & 87,5 & 10 & 38,1 & 4,4 \\
\hline 34 & 14,4 & 116 & 1,0 & 87,1 & 10 & 43,5 & 5,1 \\
\hline 35 & 15,0 & 116 & 1,4 & 86,7 & 10 & 44,2 & 5,2 \\
\hline 36 & 15,7 & 88,8 & 0,78 & 59,8 & 10 & 47,2 & 8,0 \\
\hline 37 & 16,5 & 62,0 & 0,74 & 33,0 & 10 & 26,3 & 8,1 \\
\hline 38 & 17,3 & 54,0 & 0,46 & 25,0 & 10 & 19,8 & 8,0 \\
\hline 39 & 18,1 & 46,0 & 0,55 & 17,0 & 10 & 13,0 & 7,7 \\
\hline 40 & 19,0 & 37,4 & 0,32 & 8,37 & 10 & 8,00 & 9,7 \\
\hline 41 & 19,8 & 28,8 & 0,34 & & & & \\
\hline 42 & 20,5 & 24,6 & 0,21 & & & & \\
\hline 43 & 21,2 & 20,4 & 0,24 & & & & \\
\hline 44 & 21,7 & 17,6 & 0,15 & & & & \\
\hline 45 & 22,3 & 14,9 & 0,18 & & & & \\
\hline 46 & 22,9 & 28,5 & 0,26 & & & & \\
\hline 47 & 23,4 & 42,0 & 0,50 & & & & \\
\hline 48 & 24,0 & 47,2 & 0,56 & & & & \\
\hline 49 & 24,7 & 37,3 & 0,44 & & & & \\
\hline 50 & 25,4 & 32,9 & 0,39 & & & & \\
\hline 51 & 26,0 & 25,2 & 0,30 & & & & \\
\hline
\end{tabular}


Tabela 16 - Concentrações de ${ }^{210} \mathrm{~Pb}$ total e excesso e taxas de sedimentação para o perfil 2NN.

\begin{tabular}{|c|c|c|c|c|c|c|c|c|c|c|c|}
\hline $\begin{array}{l}\text { Profundidade } \\
\text { (cm) }\end{array}$ & $\begin{array}{c}\text { Massa } \\
\text { acumulada } \\
\left(\mathrm{g} \mathrm{cm}^{-2}\right)\end{array}$ & $\begin{array}{c}{ }^{210} \mathrm{~Pb} \\
\text { total } \\
\left(\mathrm{Bq} \mathrm{kg}^{-1}\right)\end{array}$ & Erro & $\begin{array}{c}{ }^{210} \mathrm{~Pb} \\
\text { exc } \\
\left(\mathrm{Bq} \mathrm{kg}{ }^{-1}\right)\end{array}$ & Erro & $\begin{array}{c}{ }^{210} \text { Pbexc } \\
(\mathrm{mBq} \\
\left.\mathrm{cm}^{-2}\right)\end{array}$ & Erro & Calendario & Erro & $\begin{array}{c}\mathrm{W} \\
(\mathrm{g} \text { ano } \\
\left.\mathrm{cm}^{-2}\right)\end{array}$ & Erro \\
\hline 2 & 0,63 & 93,9 & 1,12 & 72,2 & 8,44 & 26,9 & 3,14 & 2008,6 & 1,1 & 0,20 & 0,001 \\
\hline 3 & 1,05 & 97,8 & 1,16 & 76,1 & 8,45 & 31,5 & 3,50 & 2006,7 & 1,2 & 0,18 & 0,001 \\
\hline 5 & 2,29 & 63,3 & 0,75 & 41,6 & 8,40 & 29,7 & 6,00 & 2001,4 & 1,3 & 0,27 & 0,002 \\
\hline 6 & 2,84 & 67,5 & 0,57 & 45,8 & 8,39 & 25,1 & 4,59 & 1998,6 & 1,3 & 0,23 & 0,001 \\
\hline 7 & 3,54 & 71,7 & 0,85 & 50,1 & 8,41 & 35,0 & 5,89 & 1996,1 & 1,4 & 0,19 & 0,001 \\
\hline 8 & 4,36 & 57,9 & 0,50 & 36,2 & 8,38 & 29,7 & 6,89 & 1992,3 & 1,5 & 0,24 & 0,002 \\
\hline 9 & 5,03 & 44,0 & 0,52 & 22,3 & 8,39 & 14,9 & 5,62 & 1988,6 & 1,5 & 0,34 & 0,004 \\
\hline 13 & 7,50 & 39,8 & 0,47 & 18,2 & 8,38 & 11,3 & 5,24 & 1980,8 & 1,7 & 0,33 & 0,005 \\
\hline 14 & 8,00 & 40,9 & 0,34 & 19,2 & 8,38 & 9,6 & 4,19 & 1978,8 & 1,7 & 0,29 & 0,004 \\
\hline 15 & 8,51 & 41,9 & 0,50 & 20,2 & 8,38 & 10,3 & 4,25 & 1977,0 & 1,8 & 0,26 & 0,004 \\
\hline 16 & 9,07 & 42,2 & 0,35 & 20,5 & 8,38 & 11,5 & 4,70 & 1975,0 & 1,8 & 0,24 & 0,003 \\
\hline 17 & 9,84 & 42,5 & 0,51 & 20,8 & 8,38 & 15,9 & 6,41 & 1972,6 & 1,9 & 0,22 & 0,003 \\
\hline 18 & 10,6 & 40,4 & 0,34 & 18,7 & 8,38 & 13,5 & 6,02 & 1969,0 & 1,9 & 0,22 & 0,003 \\
\hline 19 & 11,1 & 38,3 & 0,46 & 16,6 & 8,38 & 8,92 & 4,49 & 1965,5 & 2,0 & 0,22 & 0,004 \\
\hline 20 & 11,6 & 36,2 & 0,30 & 14,5 & 8,37 & 7,62 & 4,40 & 1963,0 & 2,1 & 0,24 & 0,004 \\
\hline 21 & 12,1 & 34,1 & 0,41 & 12,4 & 8,38 & 6,07 & 4,10 & 1960,7 & 2,1 & 0,26 & 0,006 \\
\hline 22 & 12,7 & 28,6 & 0,24 & - & - & - & - & - & - & - & \\
\hline 29 & 16,0 & 32,5 & 0,39 & 10,8 & 8,38 & 4,26 & 3,30 & 1956,2 & 2,2 & 0,26 & 0,006 \\
\hline 30 & 16,4 & 51,1 & 0,46 & 29,4 & 8,38 & 12,0 & 3,43 & 1954,6 & 2,2 & 0,09 & 0,007 \\
\hline 31 & 16,9 & 69,8 & 0,83 & 48,1 & 8,41 & 24,9 & 4,36 & 1949,7 & 2,5 & 0,05 & 0,008 \\
\hline 32 & 17,8 & 53,4 & 0,47 & 31,7 & 8,38 & 27,5 & 7,26 & 1936,2 & 3,4 & 0,05 & 0,009 \\
\hline 33 & 18,7 & 37,1 & 0,44 & 15,4 & 8,38 & 14,7 & 8,02 & 1908,6 & 6,2 & 0,04 & 0,009 \\
\hline 34 & 19,2 & 33,8 & 0,29 & & & & & & & & \\
\hline 35 & 19,8 & 30,6 & 0,36 & & & & & & & & \\
\hline 36 & 20,2 & 24,4 & 0,21 & & & & & & & & \\
\hline 37 & 21,0 & 18,3 & 0,22 & & & & & & & & \\
\hline 38 & 21,8 & 17,1 & 0,14 & & & & & & & & \\
\hline 39 & 22,7 & 15,9 & 0,19 & & & & & & & & \\
\hline 40 & 23,4 & 15,2 & 0,18 & & & & & & & & \\
\hline 41 & 24,2 & 15,6 & 0,19 & & & & & & & & \\
\hline 42 & 25,1 & 16,3 & 0,19 & & & & & & & & \\
\hline 43 & 26,4 & 14,2 & 0,17 & & & & & & & & \\
\hline
\end{tabular}


Tabela 17 - Concentrações de ${ }^{210} \mathrm{~Pb}$ total e excesso para o perfil $4 \mathrm{C}$.

\begin{tabular}{|c|c|c|c|c|c|c|c|}
\hline $\begin{array}{l}\text { Profundidade } \\
\text { (cm) }\end{array}$ & $\begin{array}{c}\text { Massa } \\
\text { acumulada } \\
\left(\mathrm{g} \mathrm{cm}^{-2}\right)\end{array}$ & $\begin{array}{c}{ }^{210} \mathrm{~Pb} \\
\left(\mathrm{~Bq} \mathrm{~kg}{ }^{-1}\right)\end{array}$ & Erro & $\begin{array}{l}{ }^{210} \mathrm{Pbexc}^{-1} \\
\left(\mathrm{~Bq} \mathrm{~kg}^{-1}\right)\end{array}$ & Erro & $\begin{array}{l}{ }^{210} \mathrm{Pbexc} \\
\left(\mathrm{mBq} \mathrm{cm}{ }^{-2}\right)\end{array}$ & Erro \\
\hline 1 & 0,41 & 98,0 & 1,17 & 67,7 & 3,15 & 27,7 & 1,29 \\
\hline 2 & 0,92 & 65,1 & 0,77 & 34,8 & 3,02 & 17,7 & 2,77 \\
\hline 3 & 1,53 & 58,6 & 0,70 & 28,2 & 3,01 & 17,4 & 4,60 \\
\hline 4 & 2,01 & 74,8 & 0,89 & 44,5 & 3,06 & 21,3 & 6,14 \\
\hline 5 & 2,59 & 67,9 & 0,81 & 37,6 & 3,03 & 21,8 & 7,85 \\
\hline 6 & 3,15 & 54,1 & 0,47 & 23,7 & 2,96 & 13,2 & 9,31 \\
\hline 7 & 3,71 & 40,2 & 0,48 & 9,89 & 2,96 & 5,60 & 11,0 \\
\hline 8 & 4,28 & 41,0 & 0,34 & 10,7 & 2,94 & 6,11 & 12,6 \\
\hline 9 & 4,86 & 41,8 & 0,50 & 11,5 & 2,97 & 6,63 & 14,4 \\
\hline 10 & 5,40 & 36,7 & 0,31 & 6,41 & 2,94 & 3,44 & 15,9 \\
\hline 11 & 5,91 & 31,7 & 0,38 & & & & \\
\hline 12 & 6,49 & 32,0 & 0,27 & & & & \\
\hline 13 & 7,05 & 32,3 & 0,38 & & & & \\
\hline 14 & 7,58 & 30,3 & 0,26 & & & & \\
\hline 15 & 8,09 & 28,4 & 0,34 & & & & \\
\hline 16 & 8,61 & 27,4 & 0,23 & & & & \\
\hline 17 & 9,13 & 26,5 & 0,31 & & & & \\
\hline 18 & 9,63 & 33,9 & 0,29 & & & & \\
\hline 19 & 10,1 & 41,3 & 0,49 & & & & \\
\hline 20 & 10,7 & 35,8 & 0,30 & & & & \\
\hline 21 & 11,1 & 30,2 & 0,36 & & & & \\
\hline 22 & 11,6 & 28,0 & 0,33 & & & & \\
\hline 23 & 12,2 & 26,6 & 0,32 & & & & \\
\hline 24 & 12,7 & 34,9 & 0,41 & & & & \\
\hline 25 & 13,3 & 31,9 & 0,38 & & & & \\
\hline 26 & 14,1 & 30,3 & 0,36 & & & & \\
\hline
\end{tabular}


Tabela 18 - Concentrações de ${ }^{210} \mathrm{~Pb}$ total e excesso e taxas de

sedimentação para o perfil $2 S$

\begin{tabular}{|c|c|c|c|c|c|c|c|c|c|c|c|}
\hline $\begin{array}{l}\text { Profundidade } \\
\quad(\mathrm{cm})\end{array}$ & $\begin{array}{c}\text { Massa } \\
\text { Acumulada } \\
\left(\mathrm{g} \mathrm{cm}^{-2}\right)\end{array}$ & $\begin{array}{c}{ }^{210} \mathrm{~Pb} \text { total } \\
\left(\mathrm{Bq} \mathrm{kg}^{-1}\right)\end{array}$ & Erro & $\begin{array}{l}{ }^{210} \mathrm{Pbexc}^{-1} \\
\left(\mathrm{~Bq} \mathrm{~kg}^{-1}\right)\end{array}$ & Erro & $\begin{array}{l}{ }^{210} \mathrm{Pbexc}^{-2} \\
\left(\mathrm{mBq} \mathrm{cm}{ }^{-2}\right)\end{array}$ & Erro & Calendário & Erro & $\underset{\left(\mathrm{g} \mathrm{cm}_{1}^{-2}\right)}{W}$ ano & Erro \\
\hline 1 & 0,32 & 76,4 & 0,91 & 51,1 & 2,23 & 16,2 & 0,71 & 2010 & 0 & 0,67 & 0,009 \\
\hline 2 & 0,61 & 80,9 & 0,96 & 55,6 & 2,25 & 15,9 & 0,64 & 2009,5 & 0,3 & 0,60 & 0,007 \\
\hline 3 & 0,97 & 81,6 & 0,97 & 56,3 & 2,26 & 20,3 & 0,81 & 2009,0 & 0,4 & 0,59 & 0,007 \\
\hline 4 & 1,38 & 105 & 1,25 & 79,9 & 2,39 & 33,4 & 1,00 & 2008,4 & 0,4 & 0,41 & 0,004 \\
\hline 5 & 1,88 & 88,3 & 1,05 & 63,0 & 2,29 & 31,2 & 1,14 & 2007,4 & 0,4 & 0,50 & 0,006 \\
\hline 6 & 2,30 & 84,6 & 0,71 & 59,3 & 2,16 & 25,0 & 0,91 & 2006,4 & 0,4 & 0,51 & 0,006 \\
\hline 7 & 2,78 & 80,9 & 0,96 & 55,6 & 2,25 & 26,4 & 1,07 & 2005,5 & 0,4 & 0,53 & 0,007 \\
\hline 8 & 3,20 & 83,7 & 0,70 & 58,4 & 2,16 & 24,5 & 0,90 & 2004,6 & 0,4 & 0,49 & 0,006 \\
\hline 9 & 3,63 & 86,5 & 1,03 & 61,2 & 2,28 & 26,6 & 0,99 & 2003,8 & 0,4 & 0,46 & 0,005 \\
\hline 10 & 4,06 & 76,6 & 0,65 & 51,3 & 2,14 & 22,2 & 0,93 & 2002,8 & 0,4 & 0,53 & 0,007 \\
\hline 11 & 4,52 & 66,6 & 0,79 & 41,3 & 2,19 & 18,8 & 1,00 & 2002,0 & 0,4 & 0,64 & 0,010 \\
\hline 12 & 4,98 & 64,3 & 0,54 & 39,0 & 2,11 & 17,9 & 0,97 & 2001,3 & 0,4 & 0,66 & 0,011 \\
\hline 13 & 5,46 & 62,0 & 0,74 & 36,7 & 2,17 & 17,7 & 1,05 & 2000,6 & 0,4 & 0,69 & 0,012 \\
\hline 14 & 5,95 & 63,7 & 0,54 & 38,4 & 2,11 & 18,9 & 1,04 & 1999,9 & 0,4 & 0,65 & 0,011 \\
\hline 15 & 6,44 & 65,4 & 0,78 & 40,1 & 2,18 & 19,6 & 1,07 & 1999,1 & 0,4 & 0,60 & 0,010 \\
\hline 16 & 6,88 & 60,5 & 0,51 & 35,2 & 2,10 & 15,5 & 0,93 & 1998,3 & 0,4 & 0,67 & 0,012 \\
\hline 17 & 7,47 & 55,6 & 0,66 & 30,3 & 2,14 & 17,7 & 1,25 & 1997,6 & 0,4 & 0,76 & 0,016 \\
\hline 18 & 7,97 & 61,9 & 0,52 & 36,6 & 2,10 & 18,6 & 1,07 & 1996,8 & 0,4 & 0,62 & 0,011 \\
\hline 19 & 8,44 & 68,2 & 0,81 & 42,9 & 2,19 & 20,2 & 1,03 & 1996,0 & 0,4 & 0,51 & 0,008 \\
\hline 20 & 8,97 & 61,4 & 0,52 & 36,0 & 2,10 & 18,9 & 1,10 & 1995,1 & 0,4 & 0,59 & 0,011 \\
\hline 21 & 9,56 & 54,5 & 0,65 & 29,1 & 2,14 & 17,3 & 1,27 & 1994,2 & 0,4 & 0,71 & 0,016 \\
\hline 22 & 10,2 & 69,4 & 0,60 & 44,0 & 2,12 & 26,2 & 1,26 & 1993,3 & 0,4 & 0,46 & 0,007 \\
\hline 23 & 10,6 & 84,3 & 1,00 & 58,9 & 2,27 & 27,9 & 1,08 & 1992,0 & 0,4 & 0,33 & 0,004 \\
\hline 24 & 11,1 & 82,4 & 0,69 & 57,1 & 2,15 & 28,8 & 1,09 & 1990,5 & 0,4 & 0,32 & 0,004 \\
\hline 25 & 11,6 & 80,5 & 0,96 & 55,2 & 2,25 & 26,1 & 1,07 & 1988,9 & 0,5 & 0,32 & 0,004 \\
\hline 26 & 12,1 & 104 & 0,89 & 78,6 & 2,23 & 38,2 & 1,08 & 1987,4 & 0,5 & 0,21 & 0,002 \\
\hline 27 & 12,6 & 127 & 1,51 & 102,0 & 2,54 & 55,8 & 1,39 & 1985,0 & 0,5 & 0,15 & 0,001 \\
\hline 28 & 13,1 & 113 & 0,96 & 88,2 & 2,25 & 42,5 & 1,09 & 1981,3 & 0,5 & 0,16 & 0,001 \\
\hline 29 & 13,6 & 99,7 & 1,18 & 74,4 & 2,36 & 38,1 & 1,21 & 1978,0 & 0,6 & 0,17 & 0,002 \\
\hline 30 & 14,1 & 103 & 0,86 & 77,2 & 2,21 & 37,2 & 1,06 & 1974,9 & 0,6 & 0,15 & 0,001 \\
\hline 31 & 14,7 & 105 & 1,25 & 80,1 & 2,39 & 47,4 & 1,41 & 1971,4 & 0,6 & 0,13 & 0,001 \\
\hline 32 & 15,2 & 86,3 & 0,74 & 61,0 & 2,17 & 29,4 & 1,04 & 1966,4 & 0,7 & 0,14 & 0,002 \\
\hline 33 & 15,8 & 67,1 & 0,80 & 41,8 & 2,19 & 26,8 & 1,41 & 1962,9 & 0,8 & 0,19 & 0,003 \\
\hline 34 & 16,4 & 62,2 & 0,52 & 36,9 & 2,10 & 22,2 & 1,27 & 1959,3 & 0,8 & 0,19 & 0,004 \\
\hline 35 & 17,1 & 57,3 & 0,68 & 32,0 & 2,15 & 20,1 & 1,35 & 1955,9 & 0,9 & 0,20 & 0,004 \\
\hline 36 & 17,4 & 52,0 & 0,44 & 26,6 & 2,08 & 7,8 & 0,61 & 1952,6 & 1,0 & 0,21 & 0,005 \\
\hline 37 & 18,0 & 46,6 & 0,55 & 21,3 & 2,11 & 13,1 & 1,30 & 1951,2 & 1,0 & 0,26 & 0,008 \\
\hline 38 & 18,7 & 53,5 & 0,45 & 28,1 & 2,09 & 19,8 & 1,47 & 1948,7 & 1,0 & 0,18 & 0,004 \\
\hline 39 & 19,4 & 60,3 & 0,72 & 35,0 & 2,16 & 23,9 & 1,48 & 1944,5 & 1,1 & 0,13 & 0,003 \\
\hline 40 & 20,1 & 58,5 & 0,49 & 33,1 & 2,10 & 23,9 & 1,51 & 1938,5 & 1,3 & 0,11 & 0,002 \\
\hline 41 & 20,8 & 56,6 & 0,67 & 31,3 & 2,15 & 22,0 & 1,51 & 1931,3 & 1,5 & 0,09 & 0,002 \\
\hline 42 & 21,6 & 49,0 & 0,42 & 23,7 & 2,08 & 19,5 & 1,71 & 1922,7 & 1,9 & 0,09 & 0,003 \\
\hline 43 & 22,4 & 41,5 & 0,49 & 16,2 & 2,10 & 12,6 & 1,63 & 1912,6 & 2,3 & 0,10 & 0,004 \\
\hline 44 & 23,1 & 39,8 & 0,34 & 14,5 & 2,07 & 10,4 & 1,48 & 1903,8 & 2,7 & 0,09 & 0,004 \\
\hline 45 & 23,9 & 38,2 & 0,45 & 12,9 & 2,09 & 10,7 & 1,74 & 1894,1 & 3,3 & 0,07 & 0,004 \\
\hline 46 & 24,8 & 37,0 & 0,31 & 11,6 & 2,06 & 9,94 & 1,76 & 1879,6 & 4,3 & 0,05 & 0,003 \\
\hline 47 & 25,7 & 35,7 & 0,42 & 10,4 & 2,08 & 8,89 & 1,77 & 1855,5 & 6,4 & 0,03 & 0,002 \\
\hline 48 & 26,6 & 27,9 & 0,33 & - & & - & - & - & & - & - \\
\hline 49 & 27,4 & 24,8 & 0,29 & - & & - & - & - & & - & - \\
\hline 50 & 28,2 & 25,6 & 0,30 & - & & - & - & - & & - & - \\
\hline 51 & 29,2 & 23,0 & 0,27 & - & & - & - & - & & - & - \\
\hline
\end{tabular}


Tabela 19 - Concentrações de ${ }^{210} \mathrm{~Pb}$ total e excesso e taxas de sedimentação para o perfil $2 \mathrm{C}$

\begin{tabular}{|c|c|c|c|c|c|c|c|c|c|c|c|}
\hline $\begin{array}{l}\text { Profundidade } \\
\quad(\mathrm{cm})\end{array}$ & $\begin{array}{l}\text { Massa } \\
\text { acumulada } \\
\left(\mathrm{g} \mathrm{cm}^{-2}\right)\end{array}$ & $\begin{array}{c}{ }^{210} \mathrm{~Pb} \text { total } \\
\left(\mathrm{Bq} \mathrm{kg}^{-1}\right)\end{array}$ & Erro & $\begin{array}{c}{ }^{210} \mathrm{~Pb} \text { exc } \\
\left(\mathrm{Bq} \mathrm{kg}^{-1}\right)\end{array}$ & Erro & $\begin{array}{c}{ }^{210} \mathrm{~Pb} \text { exc } \\
\left(\mathrm{mBq} \mathrm{cm}{ }^{-2}\right)\end{array}$ & Erro & Calendário & Erro & $\begin{array}{c}\mathrm{W} \\
\left(\mathrm{g} \mathrm{cm}_{1}^{-2} \text { ano }\right. \\
1\end{array}$ & erro \\
\hline 1 & 0,17 & 68,5 & 0,81 & 41,0 & 3,1 & 7,1 & 4,4 & 2010 & 0 & 0,40 & 0,013 \\
\hline 2 & 0,45 & 73,9 & 0,88 & 46,3 & 3,2 & 12,9 & 4,4 & 2009,6 & 0,85 & 0,35 & 0,013 \\
\hline 3 & 0,77 & 74,2 & 0,88 & 46,6 & 3,2 & 15,0 & 4,4 & 2008,8 & 0,86 & 0,34 & 0,014 \\
\hline 4 & 1,10 & 69,4 & 0,82 & 41,8 & 3,1 & 13,9 & 4,4 & 2007,8 & 0,86 & 0,37 & 0,014 \\
\hline 5 & 1,50 & 69,9 & 0,83 & 42,4 & 3,1 & 16,8 & 4,4 & 2006,9 & 0,86 & 0,35 & 0,013 \\
\hline 6 & 1,91 & 77,1 & 0,65 & 49,5 & 3,1 & 20,1 & 4,3 & 2005,8 & 0,9 & 0,29 & 0,015 \\
\hline 7 & 2,30 & 84,2 & 1,00 & 56,6 & 3,2 & 22,5 & 4,4 & 2004,3 & 0,9 & 0,24 & 0,026 \\
\hline 8 & 2,75 & 89,2 & 0,75 & 61,6 & 3,1 & 27,6 & 4,4 & 2002,7 & 0,9 & 0,21 & 0,022 \\
\hline 9 & 3,29 & 94,1 & 1,12 & 66,6 & 3,2 & 36,2 & 4,4 & 2000,5 & 0,9 & 0,18 & 0,011 \\
\hline 10 & 3,75 & 101,5 & 0,85 & 73,9 & 3,2 & 33,8 & 4,4 & 1997,4 & 1,0 & 0,15 & 0,006 \\
\hline 11 & 4,30 & 108,8 & 1,29 & 81,2 & 3,3 & 44,9 & 4,5 & 1994,3 & 1,0 & 0,12 & 0,004 \\
\hline 12 & 4,79 & 103,1 & 0,87 & 75,6 & 3,2 & 36,8 & 4,4 & 1989,5 & 1,1 & 0,12 & 0,003 \\
\hline 13 & 5,27 & 97,5 & 1,16 & 69,9 & 3,2 & 33,2 & 4,4 & 1985,0 & 1,2 & 0,11 & 0,004 \\
\hline 14 & 5,69 & 82,3 & 0,70 & 54,7 & 3,1 & 23,4 & 4,3 & 1980,3 & 1,3 & 0,12 & 0,003 \\
\hline 15 & 6,09 & 67,1 & 0,80 & 39,5 & 3,1 & 15,6 & 4,4 & 1976,5 & 1,3 & 0,15 & 0,005 \\
\hline 16 & 6,56 & 62,5 & 0,53 & 34,9 & 3,1 & 16,6 & 4,3 & 1973,7 & 1,4 & 0,15 & 0,005 \\
\hline 17 & 7,08 & 57,9 & 0,69 & 30,3 & 3,1 & 15,9 & 4,3 & 1970,4 & 1,5 & 0,16 & 0,005 \\
\hline 18 & 7,56 & 55,4 & 0,47 & 27,8 & 3,1 & 13,1 & 4,3 & 1967,0 & 1,6 & 0,16 & 0,005 \\
\hline 19 & 8,02 & 52,9 & 0,63 & 25,3 & 3,1 & 11,7 & 4,3 & 1963,8 & 1,6 & 0,16 & 0,006 \\
\hline 20 & 8,48 & 59,3 & 0,50 & 31,8 & 3,1 & 14,8 & 4,3 & 1960,7 & 1,7 & 0,11 & 0,004 \\
\hline 21 & 8,92 & 65,8 & 0,78 & 38,2 & 3,1 & 16,8 & 4,4 & 1956,2 & 1,8 & 0,08 & 0,005 \\
\hline 22 & 9,42 & 62,5 & 0,52 & 35,0 & 3,1 & 17,5 & 4,3 & 1950,2 & 2,0 & 0,07 & 0,004 \\
\hline 23 & 10,0 & 59,3 & 0,70 & 31,7 & 3,1 & 18,3 & 4,3 & 1942,6 & 2,3 & 0,06 & 0,003 \\
\hline 24 & 10,6 & 52,5 & 0,44 & 25,0 & 3,1 & 15,0 & 4,3 & 1932,0 & 2,9 & 0,06 & 0,003 \\
\hline 25 & 11,3 & 45,8 & 0,54 & 18,2 & 3,1 & 12,6 & 4,3 & 1919,6 & 3,8 & 0,05 & 0,002 \\
\hline 26 & 11,9 & 40,3 & 0,34 & 12,8 & 3,1 & 8,28 & 4,3 & 1903,5 & 5,4 & 0,05 & 0,002 \\
\hline 27 & 12,8 & 34,9 & 0,41 & 7,33 & 3,1 & 6,21 & 4,3 & 1885,6 & 7,7 & 0,05 & 0,002 \\
\hline 28 & 13,8 & 32,4 & 0,38 & 4,81 & 3,10 & 4,81 & 4,30 & 1858,93 & 12 & 0,03 & 0,002 \\
\hline 29 & 14,7 & 28,3 & 0,34 & - & - & - & - & - & - & - & - \\
\hline 30 & 15,8 & 23,5 & 0,28 & - & - & - & - & - & - & - & - \\
\hline 31 & 16,9 & 27,6 & 0,33 & - & - & - & - & - & - & - & - \\
\hline 32 & 18,0 & 30,8 & 0,37 & - & - & - & - & - & - & - & - \\
\hline
\end{tabular}


Tabela 20 - Concentrações de ${ }^{210} \mathrm{~Pb}$ total e excesso e taxas de sedimentação para o perfil $4 \mathrm{~S}$.

\begin{tabular}{|c|c|c|c|c|c|c|c|c|c|c|c|}
\hline $\begin{array}{l}\text { Profundidade } \\
\text { (cm) }\end{array}$ & $\begin{array}{c}\text { Massa } \\
\text { acumulada } \\
\left(\mathrm{g} \mathrm{cm}^{-2}\right)\end{array}$ & $\begin{array}{c}210 \mathrm{~Pb} \\
\text { total }(\mathrm{Bq} \\
\left.\mathrm{kg}^{-1}\right)\end{array}$ & Erro & $\begin{array}{c}210 \mathrm{~Pb} \\
\operatorname{exc}(\mathrm{Bq} \mathrm{kg}- \\
1)\end{array}$ & Erro & $\begin{array}{l}210 \mathrm{Pbexc} \\
\left(\mathrm{mBq} \mathrm{cm}^{-}\right.\end{array}$ & Erro & Calendario & erro & $\begin{array}{c}\mathrm{W}\left(\mathrm{g} \mathrm{cm}^{-2}\right. \\
\left.\mathrm{ano}^{-1}\right)\end{array}$ & erro \\
\hline 1 & 0,35 & 83,0 & 0,99 & 56,6 & 0,99 & 20,0 & 0,35 & 2010 & 0 & 0,92 & 0,032 \\
\hline 2 & 0,88 & 91,9 & 1,1 & 63,6 & 1,1 & 33,7 & 0,58 & 2009,61 & 0,1 & 0,81 & 0,028 \\
\hline 3 & 1,42 & 85,2 & 1,0 & 56,9 & 1,0 & 30,8 & 0,55 & 2008,95 & 0,1 & 0,88 & 0,032 \\
\hline 4 & 2,07 & 76,5 & 0,91 & 48,2 & 0,91 & 31,3 & 0,59 & 2008,32 & 0,1 & 1,02 & 0,039 \\
\hline 5 & 2,74 & 105 & 1,2 & 76,7 & 1,2 & 51,1 & 0,83 & 2007,68 & 0,1 & 0,63 & 0,021 \\
\hline 6 & 3,51 & 93,3 & 0,79 & 65,0 & 0,79 & 50,2 & 0,61 & 2006,60 & 0,1 & 0,72 & 0,018 \\
\hline 7 & 4,35 & 81,7 & 0,97 & 53,3 & 0,97 & 44,5 & 0,81 & 2005,51 & 0,1 & 0,84 & 0,031 \\
\hline 8 & 5,06 & 89,5 & 0,76 & 61,2 & 0,76 & 43,8 & 0,54 & 2004,50 & 0,1 & 0,71 & 0,018 \\
\hline 9 & 5,77 & 97,4 & 1,2 & 69,1 & 1,2 & 48,8 & 0,82 & 2003,48 & 0,1 & 0,61 & 0,021 \\
\hline 11 & 7,16 & 96,1 & 0,81 & 67,7 & 0,81 & 94,3 & 1,1 & 2002,31 & 0,1 & 0,60 & 0,015 \\
\hline 12 & 8,02 & 94,8 & 1,1 & 66,4 & 1,1 & 57,0 & 0,97 & 1999,91 & 0,1 & 0,57 & 0,020 \\
\hline 13 & 8,89 & 93,0 & 0,78 & 64,7 & 0,78 & 56,4 & 0,68 & 1998,37 & 0,1 & 0,56 & 0,014 \\
\hline 14 & 9,68 & 91,3 & 1,1 & 63,0 & 1,1 & 49,7 & 0,86 & 1996,76 & 0,1 & 0,54 & 0,019 \\
\hline 15 & 10,4 & 107 & 0,91 & 78,6 & 0,91 & 60,5 & 0,70 & 1995,28 & 0,1 & 0,42 & 0,010 \\
\hline 16 & 11,2 & 122 & 1,5 & 94,2 & 1,5 & 70,3 & 1,1 & 1993,38 & 0,1 & 0,33 & 0,010 \\
\hline 17 & 12,1 & 113 & 0,95 & 84,3 & 0,95 & 73,7 & 0,83 & 1991,02 & 0,1 & 0,34 & 0,008 \\
\hline 18 & 12,8 & 103 & 1,2 & 74,4 & 1,2 & 56,0 & 0,92 & 1988,34 & 0,1 & 0,35 & 0,006 \\
\hline 19 & 13,6 & 106 & 0,90 & 78,1 & 0,90 & 58,4 & 0,67 & 1986,15 & 0,1 & 0,32 & 0,008 \\
\hline 20 & 14,3 & 110 & 1,3 & 81,9 & 1,3 & 59,7 & 0,96 & 1983,69 & 0,1 & 0,28 & 0,005 \\
\hline 21 & 15,1 & 107 & 0,90 & 78,6 & 0,90 & 64,7 & 0,74 & 1980,96 & 0,1 & 0,27 & 0,007 \\
\hline 22 & 15,9 & 104 & 1,2 & 75,3 & 1,2 & 61,0 & 1,0 & 1977,72 & 0,1 & 0,25 & 0,009 \\
\hline 23 & 16,7 & 94,3 & 0,80 & 65,9 & 0,80 & 51,6 & 0,62 & 1974,33 & 0,1 & 0,26 & 0,008 \\
\hline 24 & 17,6 & 84,9 & 1,0 & 56,5 & 1,0 & 48,2 & 0,86 & 1971,16 & 0,1 & 0,27 & 0,005 \\
\hline 25 & 18,5 & 82,6 & 0,69 & 54,2 & 0,69 & 48,1 & 0,62 & 1967,87 & 0,1 & 0,26 & 0,009 \\
\hline 26 & 19,3 & 80,2 & 0,95 & 51,9 & 0,95 & 42,0 & 0,77 & 1964,23 & 0,1 & 0,24 & 0,005 \\
\hline 27 & 20,1 & 83,9 & 0,71 & 55,6 & 0,71 & 45,5 & 0,58 & 1960,66 & 0,1 & 0,20 & 0,007 \\
\hline 28 & 20,9 & 87,6 & 1,0 & 59,2 & 1,0 & 47,7 & 0,84 & 1956,30 & 0,1 & 0,16 & 0,007 \\
\hline 29 & 21,7 & 81,3 & 0,69 & 52,9 & 0,69 & 41,9 & 0,54 & 1950,98 & 0,1 & 0,16 & 0,008 \\
\hline 30 & 22,6 & 75,0 & 0,89 & 46,6 & 0,89 & 42,2 & 0,81 & 1945,44 & 0,1 & 0,15 & 0,009 \\
\hline 31 & 23,5 & 74,5 & 0,89 & 46,2 & 0,89 & 40,0 & 0,77 & 1938,71 & 0,1 & 0,12 & 0,008 \\
\hline 32 & 24,5 & 66,8 & 0,79 & 38,5 & 0,79 & 40,3 & 0,83 & 1930,67 & 0,2 & 0,11 & 0,008 \\
\hline 33 & 25,6 & 64,9 & 0,77 & 36,6 & 0,77 & 39,1 & 0,82 & 1919,82 & 0,2 & 0,09 & 0,006 \\
\hline 34 & 26,7 & 50,4 & 0,60 & 22,1 & 0,60 & 25,0 & 0,68 & 1903,96 & 0,2 & 0,06 & 0,008 \\
\hline 35 & 28,0 & 47,1 & 0,56 & $\begin{array}{l}18,7 \\
6,15 \\
2,20 \\
1,11 \\
0,22 \\
0,05\end{array}$ & 0,56 & $\begin{array}{l}25,1 \\
7,38 \\
2,42 \\
1,11 \\
0,20 \\
0,05\end{array}$ & 0,75 & 1887,13 & 0,3 & 0,06 & 0,007 \\
\hline
\end{tabular}


Tabela 21 - Determinação de elementos no perfil 2S. Valores em mg $\mathrm{kg}^{-1} \mathrm{e}\left({ }^{*}\right)$ valores em $\mathrm{g} \mathrm{kg}^{-1}$.

\begin{tabular}{|c|c|c|c|c|c|c|c|c|c|c|c|c|c|c|c|c|}
\hline M.A. & Li & $e$ & B & $a^{*}$ & $\mathbf{g}^{\star}$ & $\mathrm{Al}^{\star}$ & * & $c$ & * & V & $\mathrm{Cr}$ & ${ }^{*}$ & * & 0 & $\mathrm{Ni}$ & $u$ \\
\hline 0,32 & 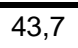 & $\overline{0}$ & 3 & & 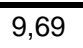 & 10 & 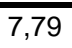 & 3 & 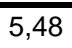 & 1 & 2 & & 37,4 & 1 & 3 & 5 \\
\hline & & & & & & & & & & & & & & & & 0,6 \\
\hline 97 & & & & & & 46 & & & & & & & & & & 4,8 \\
\hline 1,38 & 0,5 & 66 & 65,1 & & 16 & 14 & 84 & & & & & & & & & 3,9 \\
\hline 1,88 & 0 & & & & & & & & & & & & & & & 1,1 \\
\hline 2,30 & 4 & & & & 36 & & & & & & & & & & & 8,1 \\
\hline 2,78 & 46,2 & 84 & 59,0 & - & 63 & 144 & 3,76 & & ,34 & & & & & & 6,4 & 0,1 \\
\hline 3,20 & & & & & & & & & & & & & & & & 1,4 \\
\hline 3,63 &, 7 & 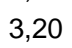 & & & & & & & & & & & & & & 9 \\
\hline 4,06 & & 02 & & & & 12 & ,33 & & & & & & & & & 9,7 \\
\hline 452 & & & & & & & & & & & & & & & & 1,2 \\
\hline 4,98 & & 54 & & & & & 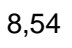 & & & & & & & & & 7,8 \\
\hline 5,46 & 46,3 & 59 & 38,8 & & & 13 & & & & & & & & & & 9,3 \\
\hline & & & & & & & & & & & & & & & & 9,0 \\
\hline 6,44 & & 1 & & & & & & & & & & & & & & 0,9 \\
\hline 6,88 & & 36 & & & & & & & & & & & & & & 5,6 \\
\hline & & & & & & & & & & & & & & & & 7,1 \\
\hline & & & & & & & & & & & & & & & & 2,8 \\
\hline 8 & & & & & & & & & & & & & & & & 4,1 \\
\hline & & & & & & & & & & & & & & & & 2,7 \\
\hline & & & & & & & & & & & & & & & & 0,4 \\
\hline & & & & & & & & & & & & & & & & 7,3 \\
\hline & & & & & & & & & & & & & & & & 7,9 \\
\hline & & & & & & & & & & & & & & & & 5,5 \\
\hline & & & & & & & & & & & & & & & & 2,6 \\
\hline & & & & & & & & & & & & & & & & 8,9 \\
\hline & & & & & & & & & & & & & & & & 8,0 \\
\hline & & & & & & & & & & & & & & & & 6,6 \\
\hline 13 & & & 44,2 & & & & & & & & & & & & & 7,0 \\
\hline & & & - & & & & & & & & & & & & & 7,4 \\
\hline & & & - & & & & & & & & & & & & & 4,4 \\
\hline & & & - & & & & & & & & & & & & & 3,4 \\
\hline & & & & & & & & & & & & & & & & 0,1 \\
\hline & & & & & & & & & & & & & & & & 8,8 \\
\hline 17, & 0 & 2 & 59,1 & & & & & & & & & & & & & 9,1 \\
\hline & & & & & & & & & & & & & & & & 2,7 \\
\hline & & & & & & & & & & & & & & & & 3,1 \\
\hline 18 & & 2 & & & & & & & & & & & & & & 9,8 \\
\hline & & & & & & & & & & & & & & & &, 2 \\
\hline & & & & & & & & & & & & & & & & 5,1 \\
\hline 20,79 & & & & & & & & & & & & & & & & 8,6 \\
\hline & & & 45,0 & & & & & & & & & & & & & 7,7 \\
\hline & & & - & & & & & & & & & & & & & 0,5 \\
\hline & & 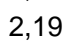 & 44,6 & & & & & & & & & & & & & 7,3 \\
\hline & & & . & & & & & & & & & & & & & 0,8 \\
\hline & & & 0,6 & & & & & & & & & & & & & 28,0 \\
\hline & & 09 & . & & & & & & & & & & & & 33,6 & 29,2 \\
\hline & & & 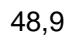 & & & & & & & & & & & & 30,7 & 25,7 \\
\hline 27,43 & 37, & , & 50,1 & & & & & & & & & & & & & 5,4 \\
\hline 28,23 & 44,6 & 2,01 & - & 12 & & 88 & 16 & & & 88 & & & 45,9 & & 33,3 & 25,8 \\
\hline 29,20 & 45,5 & 1,74 & 2,6 & 15 & 10,6 & 95 & 15 & 12,7 & 5,76 & 91 & 77,7 & 0,70 & 44,4 & 13,0 & 33,2 & 27,2 \\
\hline
\end{tabular}




\begin{tabular}{|c|c|c|c|c|c|c|c|c|c|c|c|c|c|c|c|c|c|}
\hline M.A. & $n$ & $\mathbf{a}$ & e & s & e & b & Sr & $\mathbf{Y}$ & lb & 10 & ig & d & b & Cs & $\mathrm{Ba}$ & a & $\mathrm{Ce}$ \\
\hline 32 & & & & & 8 & 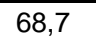 & 148 & 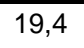 & 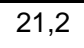 & & 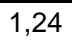 & & 4 & 1 & 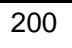 & 5 & 11 \\
\hline & & & & & & & & & & & & & & & & & 21 \\
\hline . & & & & & & & & & & & & & & & 9 & & 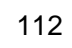 \\
\hline 1,38 & 26 & 4,5 & ,7 & 3,2 &, 73 & 7,6 & 200 & 9,5 & 3,6 & & & & & & 17 & & 03 \\
\hline & & & & & & & & & & & & & & & & & 11 \\
\hline 2,30 & & & & & 15 & & & 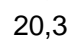 & 0 & & & & & & 7 & & 15 \\
\hline 2,78 & 26 & 6,1 & ,9 & 8,3 &, 50 & 83,2 & & 20,7 & 22,8 & & ,42 & & ,25 & & 31 & 6,8 & 18 \\
\hline & & & & & & & & & & & & & & & & & 14 \\
\hline 3,63 & 23 & 6 & & & 69 & & & 0 & & & & & & & & & 5 \\
\hline 4,06 & 124 & 3,8 & . & & ,28 & 24,0 & & 13,3 & & & & & & & 99 & & 74 \\
\hline 4,52 & & & & & & & & & & & & & & & & & 8 \\
\hline 4,98 & & & & & . & & & ${ }^{\circ}$ & & & & & & & & & 6 \\
\hline 5,46 & 97 & 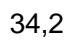 & & & 46 & 94 & & 16,9 & 24,4 & & & & & & & & 97 \\
\hline & & & & & & & & & & & & & & & & & 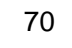 \\
\hline 6 & & & & & & & & 22 & & & & & & & & & 16 \\
\hline & & & & & & & & 21. & & & & & & & & & 18 \\
\hline & & & & & & & & & & & & & & & & & \\
\hline & & & & & & & & & & & & & & & & & 25 \\
\hline & & & & & & & & 21 & & & & & & & & & 22 \\
\hline & & & & & & & & & & & & & & & & & 76 \\
\hline & & & & & & & & & & & & & & & & & 1 \\
\hline & & & & & & & & & & & & & & & & & 6 \\
\hline & & & & & & & & & & & & & & & & & 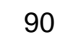 \\
\hline & & & & & & & & & & & & & & & & & 01 \\
\hline & & & & & 4,37 & & & 18 & & & & & & & & & 4 \\
\hline & & & & & & & & & & & & & & & & & 7 \\
\hline & & & & & & & & & & & & & & & & & 7 \\
\hline & & & & & & & & & & & & & & & & & \\
\hline & & & & & & & & & & & & & & & & & \\
\hline & & & & & & & & & & & & & & & & & \\
\hline & & & & & & & & & & & & & & & & & \\
\hline & & & & & & & & & & & & & & & & & ,2 \\
\hline & & & & & & & & & & & & & & & & & \\
\hline & & & & & & & & & & & & & & & & & \\
\hline 17 & 10 & & & & & & & 1 & & & & & & & & & 7,5 \\
\hline & & & & & & & & & & & & & & & & & ,9 \\
\hline & & & & & & & & & & & & & & & & & \\
\hline 18,6 & 10 & 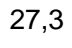 & & & 4,0 & & & 1 & 2 & & & & & & & & 8,2 \\
\hline & & & & & & & & & & & & & & & & & \\
\hline & & & & & & & & & & & & & & & & & \\
\hline 20 & 104 & 26, & & & & & & & & & & & & & & & 78,9 \\
\hline & & & & & & & & & & & & & & & & & 3,4 \\
\hline & & & & & & & & & & & & & & & & & \\
\hline & 98 & 4,1 & & & & & & & & & & & & & & & 55,6 \\
\hline & & & & & & & & 16 & & & & & & & & &, 5 \\
\hline & & & & & & & & & & & & & & & & & \\
\hline & & 5,6 & & & & & & & & & & & & & & & 74,0 \\
\hline & & & & & & & & 14 & & & & & & & & ,5 & 2,6 \\
\hline & & & 4, & & & & & 9 , & & & & & & & & & 6,0 \\
\hline 28,23 & 98,2 & 24,1 & 4,5 & 12,8 & 4,08 & 100,4 & & 14,2 & & & 0,62 & & & 4,13 & 437 & 34,9 & 69,4 \\
\hline 29,20 & 88,7 & 23,6 & 4,7 & 16,0 & 7,98 & 95,7 & 810 & 15,7 & 20,85 & 1,14 & 0,96 & 0,26 & 0,15 & 4,01 & 419 & 41,0 & 79,1 \\
\hline
\end{tabular}




\begin{tabular}{|c|c|c|c|c|c|c|c|c|c|c|c|c|c|c|c|c|c|}
\hline M.A. & $r$ & d & $\mathrm{m}$ & $u$ & id & $\mathrm{Tb}$ & Dy & lo & ir & $\mathrm{m}$ & b & Lu & W & b & $\mathbf{B i}$ & $\mathrm{hh}$ & U \\
\hline & & & & & & & & & & & & & & & & & \\
\hline 0,61 & 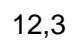 & & & & 46 & & & & & & & & & & & & \\
\hline 0 & & & & & & & & & & & & & & & & & \\
\hline 1,38 & 10,8 & 8,2 & 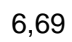 & & & & & & & & & & & & & , 8 & 11 \\
\hline 1,88 & 1,6 & 1,5 & & 64 & 80 &, 89 & 4,67 & & 2,45 & & & & & & & 7,4 & 3,03 \\
\hline 230 & & & & & & & & & & & & & & & & & \\
\hline 2,78 & 12,5 & 5,1 & & & & & ,73 & & & & & & & & & 3,8 & 3,35 \\
\hline 3,20 & 12,3 & 4,8 & 51 & 1,73 & 87 & (2) & 4,68 & & 2,45 & & &, 31 & & & & & 3,23 \\
\hline 363 & & & & & & & & & & & & & & & & & 2,46 \\
\hline 4,06 & 8,28 & 1,1 & & 1,30 & 84 & & 3,90 & & 02 & & & & & 6 & & ,7 & 2,57 \\
\hline 4,52 & 8,95 & & & & & & & & & & & & & & & & \\
\hline 4,98 & & & & & & & & & & & & & & & & & 2,49 \\
\hline 5,46 & 9,80 & 5,4 & 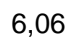 & & & & & & & & & & & & & & 2,68 \\
\hline 5,95 & 7 & ,5 & & & & & 3,90 & & & & & & & & & & 2,04 \\
\hline 6,44 & & & & & & & & & & & & & & & & & 3,23 \\
\hline 6,88 & 1 & & & & & & & & & & & & & & & & 3,27 \\
\hline 7,47 & 1 & & & & & & & & & & & & & & & & \\
\hline 79 & & & & & & & & & & & & & & & & & 3,22 \\
\hline 844 & & & & & & & & & & & & & & & & & \\
\hline 8,97 & 8 & & & & & & & & & & & & & & & & \\
\hline 9,56 & & 5 & & & & & & & & & & & & & & & 35 \\
\hline & & & & & & & & & & & & & & & & & \\
\hline & & & & & & & & & & & & & & & & & \\
\hline 1 & 1 & & & & & & & & & & & & & & & & \\
\hline & 9,9 & & & & & & & & & & & & & & & & \\
\hline 12 & & & & & & & & & & & & & & & & & \\
\hline 12,65 & 1 & b & & & & & & & & & & & & & & & 2,76 \\
\hline & & & & & & & & & & & & & & & & & \\
\hline & & & & & & & & & & & & & & & & & \\
\hline 14 & 10 &, 9 & & & & & & & & & & & & & & & 2,59 \\
\hline & & & & & & & & & & & & & & & & & \\
\hline & & & & & & & & & & & & & & & & & \\
\hline 15,8 & 9,3 & ,2 & & & & & & & & & & & & & & & 2,95 \\
\hline & & & & & & & & & & & & & & & & & \\
\hline & & & & & & & & & & & & & & & & & \\
\hline 17, & 87 & 4 & & 1 & 5,64 & & 0 & & & & & & & & & & 2,50 \\
\hline & & & & & & & & & & & & & & & & & \\
\hline & & & & & & & & & & & & & & & & & \\
\hline & & 4,0 & & & & & & & & & & & & & & & \\
\hline & & & & & & & & & & & & & & & & & \\
\hline & & & & & & & & & & & & & & & & & \\
\hline 21,61 & 5,6 & 21,2 & & 1 , & 3,97 & & 2 & & 2 & & & & &, 5 & & & 2,90 \\
\hline 223 & & & & & & & & & & & & & & & & & 2 \\
\hline & 6,23 & ט, & & & & & & & & & & & & & & & 2,81 \\
\hline 23,94 & 8,87 & 32,5 & & & & & 3,2 & & 1,77 & & & & & 26,4 & 14 & 12,8 & 2,90 \\
\hline 248 & 8 & 4 & & & 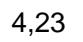 & & & & & & & & & & & & 2,78 \\
\hline & & 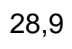 & & & & & & & & & & & & & & & 3,19 \\
\hline 26,58 & 7,7 & 28,2 & & & & & & & & & & & & & & 11,5 & 3,28 \\
\hline & 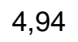 & 0 & & & 0 & 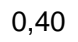 & 2 & & & 0 & & 0 & & 8 & 0,16 & 92 & 3,03 \\
\hline 28,23 & 7,55 & 27,7 & 4,8 & 1,32 & 4,76 & 0,58 & 3,04 & & ו & & & & & 23,1 & & 10,8 & 2,75 \\
\hline 29,20 & 8,73 & 31,3 & 5,64 & 1,38 & 5,37 & 0,68 & 3,50 & 0,61 & 1,81 & 0,25 & 1,63 & 0,25 & 1,22 & 24,6 & 0,21 & 12,7 & 3,32 \\
\hline
\end{tabular}


Tabela 22 - Determinação de elementos no perfil 2C. Valores em mg $\mathrm{kg}^{-1} \mathrm{e}\left(^{*}\right)$ valores em $\mathrm{g} \mathrm{kg}^{-1}$

\begin{tabular}{|c|c|c|c|c|c|c|c|c|c|c|c|c|c|c|c|c|c|}
\hline M.A. & Li & e & B & $a^{*}$ & $a^{*}$ & * & ${ }^{*}$ & $\mathrm{Ca}^{*}$ & Sc & & V & $\mathrm{Cr}$ & $\mathrm{Mn}^{*}$ & $\mathrm{Fe}^{*}$ & ;o & $\mathrm{Ni}$ & $\mathrm{Cu}$ \\
\hline 0 & & 2,45 & & & & & & & & & 129 & & & & & & \\
\hline 0,45 & 46,3 & 69 & 42,7 & 5,9 & 31 & & 14 & 0 & क,3 & 31 & 114 & 1,2 & 96 & 54 & 2,9 & 3 & 3,2 \\
\hline 0,77 & 452 & 79 & 587 & 3 & 8,34 & 157 & 8,81 & 4 & 5,7 & 8 & 123 &, 5 & 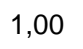 & 59 &, 9 & 6,7 & 6,3 \\
\hline 1,1 & , & 64 & 6 & 0,0 & 7,56 & & 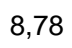 & . & 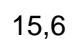 & & . & 72,9 & & & 3 & 4 & 6,8 \\
\hline 1,00 & T & $2,0 \Omega$ & 44,0 & 25,5 & $r$ & & & & & & $1<6$ & 01,0 & & & & & 3 \\
\hline 1,91 & 48,8 & 2,28 & 67,4 & 28,0 & 8,2 & & & & 7 & & 111 & 72,8 & & 58 & 6 & 6 &, 7 \\
\hline 2,30 & 51 & 1,99 & 72,4 & 27,2 & 76 & 1 & 2 & 31,0 & 15,2 & 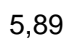 & 121 & 3,6 & 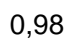 & 60 & 3 & 0 &, 6 \\
\hline 2,75 & 198 & 20 & 546 & 5,5 & 8,31 & 152 & 10,8 & 4 & 14 & 5,91 & 1 & 9 & 100 & 56 & 0 & 6 & 32,0 \\
\hline 3,2 & (ד, ד, & 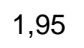 & ו,דט & $2, L$ & (1) & וסו & 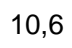 & Jo, & $12, U$ & $3,4 \mathrm{~J}$ & 10 & 71,2 & & & & 29,5 & 27,9 \\
\hline 3,75 & 51, & 2,26 & 67 & 22,5 & 8,61 & 12 & 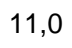 & 63 & 12,0 & 5,36 & 107 & 4 & 0,98 & 50 & 9 & 8 & 26,8 \\
\hline 4,30 & 60,0 & 2,53 & 57,4 & 18,9 & 8,78 & 14 & 1 & 63,1 & 14,1 & 5,6 & 120 & 77,1 & 1, & 59 & ,7 & 1 & 31,7 \\
\hline 4,79 & 50 , & 239 & 57 & 23 & 80 & 1 & 9,23 & 56,4 & 1 & 5,35 & 0 & 3 & & & 122 & & 4 \\
\hline 5,27 & 5 & 2,19 & 6 & 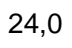 & 7,70 & & & & 12 & & & 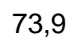 & & & 127 & & 6 \\
\hline 5,6 & 54,3 & 2,82 & 5 & 2 & 8,32 & & 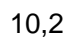 & 4 & $r$ & 5,46 & 1 & 3 & (1,05 & 60 & 14,0 & 35,0 & 3,6 \\
\hline 6,09 & 52,1 & 3,22 & 62,0 & 27,0 & 7,96 & 18 & ,59 & 18 & 15,5 & $5, \varsigma$ & 117 & 79,0 & I, & 63 & 4 & 36,1 & 36,4 \\
\hline 6,56 & 50,9 & 2,75 & 61,9 & 24,6 & 7,69 & 16 & 9,21 & 17,2 & 15,3 & 6,47 & 123 & 79,4 & 1, & 68 & 14,3 & 35,6 & 38,3 \\
\hline 7,08 & 38 & 1,9 & 5,2 & 20,4 & 5,67 & 11 & 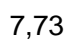 & 80 & 15,8 & 6 & 126 & 75,6 & 0 & $c^{2}$ & 4 & 35,4 & 40,7 \\
\hline 7,5 & 52 & 2,29 & 56,0 & 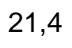 & 6,84 & - & 0,95 & 1 & 17,0 & 6,53 & 135 & 89,1 & & 6 & & & 0 \\
\hline 8,02 & 46,3 & 2,35 & 48,3 & 21,6 & 5,9 & 18 & ,77 & 8,9 & 15,5 & 5,7 & 128 & 87,4 & 0,6 & 4 & 3,1 & 0,7 & 39,1 \\
\hline 8,48 & 53,3 & 2,31 & 59,7 & 23,3 & 6,80 & 170 & 8,33 & 10,9 & 15,6 & 5,85 & 127 & 85,0 & 0,8 & 64 & 13,1 & 39,9 & 41,2 \\
\hline 8,92 & 53,3 & 2,88 & 57,9 & 24,4 & . & 17 & 865 & 14 & 14 & 5,5 & 139 & 86,3 & 0 & 66 & 9 & 30 & 39,2 \\
\hline 9,42 & 5 & إن & r & $c<, v$ & 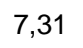 & . & 010 & 1 & 1 & 6,16 & 1 & 78,4 & & 62 & & & 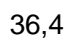 \\
\hline 10,00 & 7 & r & 48,5 & 1 & 0 & 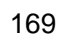 & 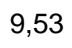 & 1 & o & 7,08 & 1 & 76,1 & & & & 31,5 & ,4 \\
\hline 10,60 & 53,7 & 2,48 & 2,9 & 14,7 & 7,73 & 170 & 10,7 & 32,0 & 14,7 & 7,19 & 120 & 81,1 & 1,00 & 3 & 14,4 & 33,3 & 34,5 \\
\hline 11,29 & 51,1 & 3,16 & 62,7 & 13,7 & 8,27 & 153 & 11,9 & 31,3 & 13,0 & 6,15 & 108 & 84,3 & 0,99 & 57 & 14,3 & 35,9 & 31,7 \\
\hline 11,9 & 46,1 & 1,96 & 65,2 & 13,2 & 6,28 & 13 & 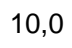 & 18,8 & 12 & 16 & 139 & 80,0 & 1 , & 1 & 13,7 & 200 & 38,1 \\
\hline 12,7 & c & דم0 & 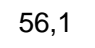 & 12,8 & مอ? & 10 & 0 & 32,3 & 13,0 & 150 & 123 & 76,5 & & $c 5$ & 4,0 & 0 & 35,8 \\
\hline 13,79 & 40,1 & 2,41 & 10,3 & 10,8 & 7,87 & 1 & 13 & 23,9 & 12,6 & 17,7 & 115 & 68,0 & 1,5 & 68 & 13,4 & 25,3 & 33,1 \\
\hline 14,73 & 43,8 & 2,34 & 54,3 & 11,6 & 7,61 & 111 & 1 & 22,9 & 11,5 & 17,8 & 124 & 76,4 & 1,17 & 5 & 14,6 & 27,6 & 31,3 \\
\hline 15,78 & 46 & 2,76 & & 11 & (3) & 1 & ) & 22,2 & 12,1 & 15 & 103 & 72,8 & 1,16 & 9 & 2 & ,2 & 9,2 \\
\hline 16,89 & 46,3 & 205 & 33,9 & 12,3 & م० & 127 & 16,2 & 23,8 & 11,9 & 15,6 & 122 & 78,7 & 10 & 63 & 15,4 & 29,0 & 34,8 \\
\hline 18,0 & 47,5 & 2,95 & 55,9 & 8,4 & 7,47 & 117 & 17,1 & 23,2 & 11,1 & 17,8 & 121 & 79,0 & 1,23 & 68 & 14,0 & 28,7 & 29,7 \\
\hline
\end{tabular}




\begin{tabular}{|c|c|c|c|c|c|c|c|c|c|c|c|c|c|c|c|c|c|}
\hline M.A. & Zn & a & e & $\mathbf{s}$ & e & b & $\mathrm{Sr}$ & $\mathbf{Y}$ & b & 10 & $\mathrm{Ag}$ & d & $\mathrm{Sb}$ & is & $\mathrm{Ba}$ & $a$ & e \\
\hline 0,17 & 107 & 0,2 & 35 & 98 & 6.54 & 33 & 146 & 20,3 & 5 & 55 & 34 & 17 & 25 & ,79 & 201 & 52,0 & 13 \\
\hline 0 & 98 & 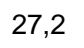 & 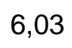 & 16,2 & 3,88 & 63,7 & 141 & 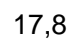 & 17,9 & 2 & 5 & 0,31 & 25 & 9 & 0 & 5 & 10 \\
\hline וז, & . & -6 & 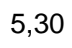 & . & 4,37 & 66,8 & r & 10,0 & 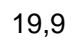 & 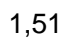 & 0 & 23 & 4 & 8 & 9 & & 5 \\
\hline 1,10 & 政11 & 2 & , & & & & 117 & 2 & & 5 & & & 7 & & 0 & & 21 \\
\hline 1,50 & 111 & 31,2 & 5,56 & 1 & 3,01 & 68,3 & 129 & 20,0 & $\angle U, \angle$ & 1,44 & 40 & 0,17 & 22 &, 53 & 26 & 9 & 16 \\
\hline 1,91 & 97 & 26,5 & 5,23 & 19,8 & $<\mathrm{LD}$ & 55,8 & 208 & 17,3 & 18,4 & 1,23 & 63 & 0,36 & ,24 & ,03 & 240 & 0 & 106 \\
\hline 2,30 & 107 & 29,8 & 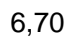 & 20 , & 5,19 & 60,9 & 212 & 18,2 & 7 &, 53 & 5 & 37 & 24 & 5 & 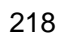 & 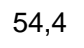 & 12 \\
\hline 2,75 & 100 & 26,4 & 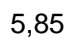 & , & $<\mathrm{LD}$ & , & 331 & 18,6 & 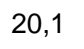 & 1,29 & 6 &,, 00 & 0,20 &, 01 & 20 & & 08 \\
\hline 3,29 & 9 & 25,5 & 00 & 18 & 4,00 & 0 & 36 & 17,0 & 18,0 & 24 & 4 & 0,29 & 25 & 0 & 288 & 0 & 11 \\
\hline 3,75 & 99 & 26,1 & 4,91 & 21,8 & $<\mathrm{LD}$ & 65,5 & 479 & 16,0 & 18,4 & 1,33 & 0,58 & 0,19 & 0,28 & 3,07 & 276 &, 9 & 00 \\
\hline 4,30 & 101 & 28,6 & 5,54 & 24,6 & 7,01 & 7 & 491 & 17,7 & 4 & 1 & 8 & 33 & 3 & 3 & n & 48,4 & 6 \\
\hline $4,7 \subseteq$ & 9 & 25 & 4,38 & 21 & 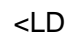 & 56,9 & 4 & 16,2 & & 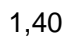 & 3 & & 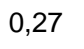 & & & & 8 \\
\hline 5,27 & דטו & 2,0 & 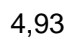 & (10, & $<\mathrm{LD}$ & 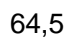 & 322 & 19,3 & 20,0 & 1,40 & 00 & 0,70 & 0,24 & ד & 26 & T) & 123 \\
\hline 5,69 & 110 & 29,3 & 5,92 & 17,1 & $<\mathrm{LD}$ & 0 & 36 & 19 , & 19,0 & 1,57 & 8 & J,39 & 4 & 0 & 202 & 57,0 & 22 \\
\hline 6,09 & 115 & 31,9 & 6,01 & 12,7 & $<\mathrm{LD}$ & 65,7 & 165 & 21,3 & 20,4 & 1,63 & 0,38 & 0,56 & 0,23 & 3,62 & 210 & 56,9 & 135 \\
\hline 6,56 & 120 & 31,4 & 01 & 14,2 & $<\mathrm{LD}$ & 64 & 13 & 21,9 & 20,3 & 1,65 & 0,60 & 0,41 & 0,21 & 3,34 & 219 & 7 & 143 \\
\hline 7,08 & $11 \varepsilon$ & 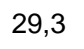 & 6,34 & 4 & 6,07 & 57,7 & 1 & ${ }^{\circ}$ & & 1,49 & & 0,48 & 0,17 & & & & 8 \\
\hline 7,5 & 1 & 33,4 & 6,35 & 12,6 & 3,33 & 63,9 & 1 & 21,6 & 19,7 & $1,4 c$ & 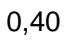 & 0,52 & 0,18 & 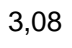 & 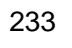 & 58,9 & 27 \\
\hline 8,02 & 108 & 31,4 & 6,04 & 11,9 & 4,15 & 56,0 & 97 & 20,0 & 27,2 & 1,50 & ,49 & 0,52 & 0,20 & 2,82 & 228 & 56,3 & 21 \\
\hline 8,48 & 114 & 30,6 & 5,68 & 14,3 & 3,71 & 56,1 & 98 & 19,0 & 19,5 & 1,65 & 0,42 & 0,48 & 0,23 & 2,92 & 226 & 59,9 & 126 \\
\hline 8,92 & 114 & 30,4 & 5,94 & 15, & 3,62 & 61,0 & 126 & 20,0 & 19,5 & 1,66 & 0,39 & 0,50 & 0,23 & 3,23 & 213 & 5 & 122 \\
\hline 9,42 & 111 & 30,5 & , & 14 & $<\mathrm{LL}$ & $50 ?$ & 13 & 18 & 19 & , & 5 & 0,4 & 0,25 & 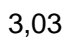 & 232 & & 17 \\
\hline 10,0 & 108 & o & 5 & 1 & 2, & 65,8 & 17 & 1 & 22,3 & 1,53 & & 0 & 1 & & 0 & & 20 \\
\hline 10,60 & 107 & 29,3 & 5,92 & 15,0 & $<\mathrm{LD}$ & 73 & 21 & 19,5 & 22,2 & 1,38 & 9 & 0,35 & ,21 & 3,76 & 269 & 0 & 50 \\
\hline 11,29 & 109 & 27,8 & 5,15 & 15,2 & $<\mathrm{LD}$ & 79,5 & 221 & 18,8 & 21,4 & 1,46 & 0,50 & 0,25 & 0,20 & 4,14 & 295 & 53,4 & 112 \\
\hline 11,94 & 114 & 23,5 & 6,73 & 13,4 & 2,29 & 53,9 & 165 & 24,0 & 32,3 & 1,44 & 0 & 0,61 & 0,20 & 2,77 & 240 & 2 & 84 \\
\hline 12,79 & 107 & م & 100 & 101 & 2,72 & 700 & 232 & 19,5 & 200 & 1,16 & 1,33 & 0,40 & 0,15 & 3,56 & 312 & 49,5 & Pa \\
\hline 13,79 & 103 & 20,1 & 5,25 & 10,6 & $<L D$ & 70,8 & 225 & 20,0 & 37,5 & 0,96 & 1,02 & 0,26 & 0,11 & 2,95 & 359 & 52,1 & 106 \\
\hline 14,73 & 110 & 22,3 & 5,11 & 9,8 & 2,44 & 72,8 & 194 & 16,1 & 38,3 & 1,04 & 1,08 & 0,32 & 0,11 & 3,45 & 358 & 44,3 & 9 \\
\hline 15,78 & 105 & 21,0 & 4,83 & 9 & $<L$ & 78,6 & 197 & 18,5 & 36,4 & 0,95 & 1,21 & 0,39 & 0,09 & 3,77 & 345 & 46,9 & 7 \\
\hline 16,89 & 112 & 23,2 & 4,44 & 10,3 & 2,58 & 86,0 & 219 & 16,8 & 42,4 & 1,04 & 0,74 & 0,17 & 0,11 & 4,00 & 404 & 40,8 & 6 \\
\hline 18,0 & 121 & 22,7 &, 92 & 10,3 & 2,74 & 34,5 & 208 & 16,0 & 34,5 & 1,12 & ,31 & 0,33 & 0,10 & 3,49 & 381 & 35,90 & 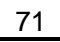 \\
\hline
\end{tabular}




\begin{tabular}{|c|c|c|c|c|c|c|c|c|c|c|c|c|c|c|c|c|c|}
\hline A. & & & & & d & & & 10 & & & & 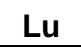 & W & & $3 \mathbf{i}$ & h & $\mathbf{U}$ \\
\hline & & & & & & & & & & & & & & & & & \\
\hline & & & & & & & & & & & & & & & & & \\
\hline & & & & & & & & & & & & & & & & & \\
\hline & & & & & & & & & & & & & & & & & \\
\hline & & & & & & & & & & & & & & & & & \\
\hline & & & & & & & & & & & & & & & & & \\
\hline & & & & & & & & & & & & & & & & & \\
\hline & & & & & & & & & & & & & & & & & \\
\hline 3,29 & & & & & & & & & & & & & & & & & \\
\hline & & & & & & & & & & & & & & & & & \\
\hline & & & & & & & & & & & & & & & & & \\
\hline & & & & & & & & & & & & & & & & & \\
\hline 5 . & & 5,2 & & & & & & & & & & & & & & & \\
\hline 5 & 10 & & & & & & & & & & & & & & & & \\
\hline & & & & & & & & & & & & & & & & & \\
\hline & & & & & & & & & & & & & & & & & \\
\hline & & & & & & & & & & & & & & & & & \\
\hline$\theta_{0}$ & & & & & & & & & & & & & & & & & \\
\hline 8,0 & 0 & & & & & & & & & & & & & & & & \\
\hline & & & & & & & & & & & & & & & & & \\
\hline & & & & & & & & & & & & & & & & & \\
\hline 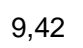 & & 8,4 & & & 7,0 & & & & & ק? & & 26 & 6 & & & & 30 \\
\hline & 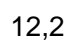 & 7 & & & 7,04 & & & & & 0,30 & & & & & & & \\
\hline & & & & & & & & & & & & & & & & & \\
\hline & & & & & & & & & & & & & & & & & \\
\hline & & & & & & & & & & & & & & & & & \\
\hline & & & & & & & & & & & & & & & & & \\
\hline 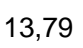 & 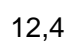 & 140 & 7 & 100 & 7,20 & & 4,23 & 0 & 221 & 0,32 & & 0,33 & 1,07 & 23,7 & & 16,6 & \\
\hline & & & & & & & & & & & & & & & & & \\
\hline & & 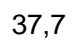 & & & 0,6 & & $T$, & & & 0,32 & & & & & & & \\
\hline 16,89 & (2) & 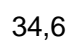 & & & 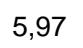 & & 3,80 & 0,6 & & 0,29 & & 0 & & & & 13,1 & \\
\hline 180 & 31 &, 5 & 0 & 16 & 12 & 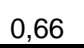 & 27 & 0,66 & ספ 1 & 0,26 & 89 & 0,27 & 1,38 & 7,6 & 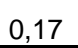 & 13,0 & 5,49 \\
\hline
\end{tabular}


Tabela 23 - Fator de enriquecimento e Igeo do perfil 2S

Fator de enriquecimento/Al

Igeo

\begin{tabular}{|c|c|c|c|c|c|c|c|c|c|c|c|c|c|c|c|c|c|c|c|c|}
\hline Ita & & $r$ & & 0 & i & $\mathbf{u}$ & n & d & b & & g & ir & $n$ & 0 & li & $\underline{\mathbf{u}}$ & n & d & b & br \\
\hline & & & & & & & & & & & & & & & & & & & & -2 \\
\hline & & & & & & & & & & & & & & & & & & & & -2 \\
\hline & & & & & & & & & & & 0.6 & & & 0,4 & & & 2 & & & 2 \\
\hline & & & & & & & & & & & & & & & & & & & & \\
\hline & & & & & & & & & & & & & & & & & & & & . \\
\hline & & & & & & & & & & & & & & & & & & & & -1 \\
\hline & & & & & & & & & ,9 & & 7 & 3 & & 4 & & & 0,2 & & & -2 \\
\hline 2 & & & & & & & & & & ,2 & & & & & & & & & & -1 \\
\hline & & & & & & & & & & & & & & & & & & & & ( \\
\hline & & & & & & & & & & & & & & & & & & & & -3 \\
\hline & & & & & & & & & ,9 & & 8 & $-0,3$ & & 4 & & & 3 & & 12 & -2 \\
\hline $2 C$ & & & & & & & & & & & & 0.2 & & & & & 0,3 & & & -2 \\
\hline & & & & & & & & & 8 & & 8 & & & & & & $-0,2$ & & & -2 \\
\hline & & & & & & & & & & & & & & & & & & & & -2 \\
\hline & & & & & & & & & & & $-0,8$ & & & & & & & & & -2 \\
\hline & & & & & & & 0 & & & & & & & & & & & & & -2 \\
\hline & & & & & & & & & 8 & & 9 & & & $-C$ & & & 3 & & & -2, \\
\hline & & & & & & & 7 & & 8 & & $-0,9$ & & & & & & & & & -2 \\
\hline & & & & & & & & & & & & & & & & & & & & -2 \\
\hline & & & & & & & & & & & & & & & & & & & & -2 \\
\hline & & & & & & & & & 0 & & 0 & & & -0 & & & 2 & & & -2, \\
\hline & & & & & & & & & 1 & 0,3 & 1 & , J & 1 & $-0,4$ & & & 0,3 & & & -2, \\
\hline & & & & & & & & & & & & & & & & & & & & \\
\hline & & & & & & & & & & & & & & & & & & & & -2 \\
\hline & & & & & & & & & ,8 & & -0 & & & & & & & & & -1 \\
\hline & & & & & & 0 & 8 & & ,9 & & $-0,7$ & J,3 & 0,3 & $-0,3$ & & & ,3 & 2 & & -1, \\
\hline & & & & & & & & & & & & & & & & & & & & -1, \\
\hline & & & & & & & & & & & & & & & & & & & & -1 \\
\hline & & & & & & & & & 0,8 & & 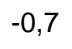 & & & & & & & & & -0 \\
\hline & & & & & & & 9 & & 9 & & $-0,6$ & -( & ,2 & $-0,5$ & & & & 4 & & $-0,8$ \\
\hline & & & & & & & & & & & & & & & & & & & & -0 \\
\hline & & & & & & & & & & & & & & & & & & & & -0 \\
\hline & & & & & & & & & & & $-0,4$ & & & & & & & & & -0 \\
\hline & & & & & & 9 & ,9 & 0,9 & 1,0 & 0 & $-0,4$ & $-0,6$ & 1 & $-0,6$ & & & 0,5 & $-0,5$ & & -0, \\
\hline & & & & & & & & & & & $-0,2$ & & & & & & & & & 0 \\
\hline & & & & & & & & & & & & & & & & & & & & -0 \\
\hline & & & & & & & & & & & & & & & & & & & & -0 \\
\hline & & & & & 0,8 & & 0,8 & & 1,0 & & $-0,3$ & 4 & 1 & 5 & & & $-0,5$ & & & $-0,5$ \\
\hline & & & & & & & & & 0,9 & & $-0,3$ & & 2 & 6 & & & & & & 0 \\
\hline & & & & & & & & & & & -0 & & & & & & & & & $-U$, \\
\hline & & & & & & & & & & & -0 & & & & & & & & & . \\
\hline & & & & & & & & & 1,2 & & . & & & & & & & & & $-1,6$ \\
\hline & & & & & & & & & & & -0 & & & & & & & & & $-1,3$ \\
\hline & & & & & & & & & 1, & & -1 & & -0 & $-0,6$ & & & & & & -1 \\
\hline & & & & & & & & & & & -0 & & & $-0,4$ & & & & & & $-0,8$ \\
\hline & & & & & & 1,1 & 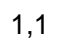 & & 1, & & 00 & & & & & & & & & $-1,0$ \\
\hline 0,0 & & & & . & . & 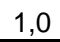 & 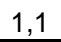 & 0,6 & . & &, & 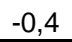 & 0,0 & 0,0 & & & , & 0,0 & & 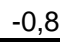 \\
\hline
\end{tabular}


Tabela 24 - Fator de enriquecimento e Igeo do perfil 2C.

FE

Igeo

\begin{tabular}{|c|c|c|c|c|c|c|c|c|c|c|c|c|c|c|c|c|c|c|c|c|}
\hline M.A & I & & & Co & i & u & $\mathrm{n}$ & d & $\mathbf{P b}$ & & $\mathbf{g}$ & $\mathrm{Gr}$ & $n$ & Co & Vi & u & ?n & d & b & $r$ \\
\hline & & & & & & & & & & & & & & & & & & ,4 & ,2 & \\
\hline 0,4 & & & & & & & 0 & 8 & 0,9 & 6 & 5 & & 9 & 8 & 4 & & 8 & ,6 &, 4 & \\
\hline 0 & & & & & & 0,9 & 0 & 0,6 & & $c$ & - & - & 8 & 6 & 2 & 4 & 7 & ,0 & $-0,3$ & \\
\hline 1, & 0,7 & & & & 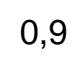 & 0 & 0,8 & 0,5 & 0 & 0,4 & & - & 0 & - & 3 & & $-0,6$ & 1 & $-0,3$ & \\
\hline 1,5 & & & & & & 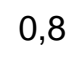 & 0,7 & 4 & 9 & 4 & & $-0,5$ & $-1,0$ & $-0,8$ & $-0,3$ & $-0,4$ & $-0,6$ & ,4 & $-0,3$ & \\
\hline 1, & 9 & 8 & & 0 & 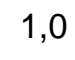 & 0,8 & 0,7 & 1,0 & 1,0 & 0,8 & & -( & ,8 & $-0,7$ & $-0,3$ & & $-0,8$ & $-0,3$ & $-0,4$ & -( \\
\hline 2 , & 0,7 & 0 & 0 & & 0 & 0,9 & 0,7 & 0,9 & 0,9 & 0,8 & $-0,6$ & -( & $-0,9$ & $-0,7$ & $-0,2$ & 4 & $-0,7$ & $-0,3$ & $-0,3$ & \\
\hline 2 & 0,8 & & & & 1,0 & 3 & 0,7 & 0,9 & 0 & 1,3 & $-0,5$ & -( & 8 & $-0,7$ & $-0,3$ & - & - &, 4 & $-0,5$ & \\
\hline , & 0,8 & 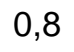 & 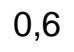 & 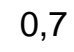 & 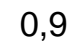 & 0 & 0 & 0,8 & 1 & 1,5 & 7 & $-c$ & 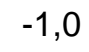 & 9 & $-0,5$ & $-0,8$ & . & 6 & - & \\
\hline 3,8 & 0,9 & & & 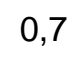 & & 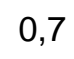 & $c$ & 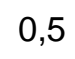 & ) & 9 & 5 & - & 9 & 9 & 4 & $-0,8$ & 8 & 3 & - & \\
\hline 4,3 & 0,9 & 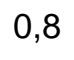 & 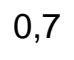 & 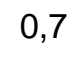 & 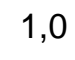 & 0 & 0 & 0 & 1 & 2 & 5 & -( & 8 & $-0,8$ & $-0,4$ & - & $-0,7$ & $-0,5$ & $-0,3$ & \\
\hline 4,8 & 0,9 & c & 0 & 0 & 1 & 0,9 & 0,7 & 1,0 & 1 & 1,9 & $-0,6$ & $-C$ & $-0,7$ & $-0,8$ & $-0,4$ & -( & $-0,8$ & $-0,4$ & $-0,3$ & \\
\hline 5, & 0 & & & & & & 0,7 & 1,2 & 1,0 & 1,2 & $-0,6$ & $-0,6$ & - & $-0,8$ & $-0,4$ & $-0,6$ & $-0,7$ & 0,0 & $-0,2$ & \\
\hline 5,7 & 0 & $c$ & & 0,7 & 0 & 0,8 & 0,7 & 0,9 & 0,9 & 1,3 & & $-c$ & & $-0,6$ & $-0,3$ & $-0,5$ & $-0,6$ & $-0,2$ & $-0,2$ & \\
\hline$b$, & 0,6 & & & 4 & 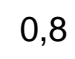 & $c$ & 0 & 1 & c & 0,5 & 6 & -( & 8 & 7 & 2 & $-0,4$ & - & 0,3 & $-0,2$ & \\
\hline 6,6 & 0,7 & 0,7 & 0,6 & $0, r$ & 0,9 & 0,9 & 0,8 & 0,5 & 1,0 & 0,0 & $-0,6$ & $-0,5$ & $-0,8$ & $-0,6$ & $-0,2$ & $-0,3$ & $-0,5$ & $-0,2$ & $-0,1$ & \\
\hline 7, & 0 & 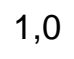 & 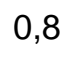 & 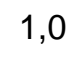 & 1,3 & 1,3 & 1,1 & 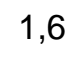 & 1,2 & 0 & $-1,1$ & - & $-0,9$ & . & - & - & 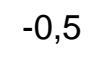 & 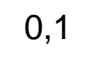 & 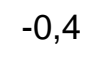 & \\
\hline 7, & 0 & 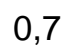 & & s & & 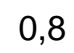 & $c$ & 1 & $c$ & 0 & 8 & $-c$ & 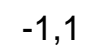 & $-c$ & 0 & $-0,2$ & -( & , & -0 & \\
\hline 8, & 0 & 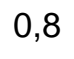 & & 0 & 1,0 & 0,8 & 0,7 & 1,2 & 0,8 & 0,3 & $-1,0$ & $-0,4$ & . & -07 & $-0,1$ & $-0,3$ & $-0,6$ & 0,2 & $-0,3$ & - \\
\hline 8,5 & 0,6 & 0,8 & 0 & 0, & 1,0 & 0,9 & 0,7 & 1,1 & 0,9 & 0,3 & $-0,8$ & $-0,4$ & $-1,2$ & $-0,7$ & $-0,1$ & $-0,2$ & $-0,6$ & 0,1 & $-0,2$ & \\
\hline 8,9 & 0,6 & 0,8 & 0 & 0,6 & 0,9 & 0,9 & 0,7 & 1,1 & 1,0 & 0,4 & $-0,7$ & $-0,4$ & $-0,9$ & $-0,8$ & $-0,1$ & $-0,3$ & $-0,6$ & 0,1 & $-0,1$ & \\
\hline 9, & 0 & 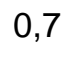 & & 0 & 1 & $c$ & 0 & 1 & 0 & 0 & $\left.\right|^{-c}$ & -( & -( & $-c$ & -0 & -( & $-c$ & 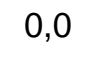 & & \\
\hline 10,0 & 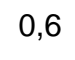 & 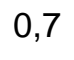 & & 0,6 & 0,8 & 0,0 & 0 & 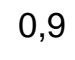 & 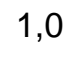 & 0 & -1 & - & -( & 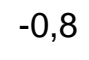 & $-c$ & -( & - & 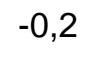 & - & - \\
\hline 10,6 & 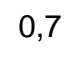 & 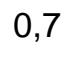 & 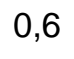 & 0,7 & 0,8 & 0,8 & 0 & 0 & 0 & $c$ & $-0,6$ & $-c$ & . & , & 3 & - & . & 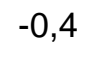 & ( & . \\
\hline 11,3 & 0,8 & 0 & 0 & 0 & 1 & 0 & 0 & 0 & 1,0 & 0,8 & $-0,5$ & $-0,4$ & $-0,9$ & $-0,6$ & $-0,2$ & $-0,6$ & $-0,6$ & $-0,9$ & $-0,2$ & - \\
\hline 1 & 0,7 & 1,0 & 1 & 0,9 & 1,0 & 1 & 0 & 1,8 & 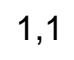 & 0,7 & 9 & $-0,5$ & $-0,5$ & $-0,7$ & $-0,5$ & $-0,3$ & $-0,6$ & 0,4 & $-0,3$ & - \\
\hline 12,8 & 0,9 & 0,9 & & 0 & 0 & 1 & 0 & 1 & 0 & 1,0 & $\left.\right|^{-c}$ & $-c$ & $-0,4$ & $-0,6$ & $-0,6$ & $-0,4$ & $-0,7$ & $-0,2$ & $-0,6$ & - \\
\hline 13,8 & 0 & 0,9 & 1 & 1,0 & 1,0 & 1,1 & 1,0 & 0,9 & 1,0 & 1,2 & $-0,6$ & $-0,8$ & $-0,2$ & $-0,7$ & $-0,7$ & $-0,5$ & $-0,7$ & $-0,8$ & $-0,7$ & $-0,4$ \\
\hline
\end{tabular}


Tabela 25 - Fluxo de incorporação de elementos no ponto 2C.Valores de Massa Acumulada em $\mathrm{g} \mathrm{cm}^{-2}$ e fluxos em $\mathrm{g} \mathrm{cm}^{-2} \mathrm{ano}^{-1}$

\begin{tabular}{|c|c|c|c|c|c|c|c|c|c|c|c|c|c|}
\hline M.A. & g & Al & $\mathrm{Ti}$ & $r$ & n & e & & & & n & Sr & Cd & Pb \\
\hline & & & & & & & & & & & & & \\
\hline & & & & & & & & & & & & & \\
\hline & & & 1871 & & & & & & & & & & \\
\hline & & & & 6 & & & & & & & & & \\
\hline 1 & & 3 & & $L_{1}$ & 319 & & & & & & & & \\
\hline 1,91 & $r$ & . & 1635 & 21,3 & 305 & & 3,99 & & 928 & 28,3 & 9 & & 8,85 \\
\hline 2 , & & $?$ & & 20 & 2 & & 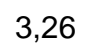 & & & & & & \\
\hline 2,75 & 3 & 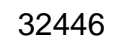 & 1263 & 15,8 & 215 & & 2,78 & & 685 & 21,3 & 8 & 0,076 & 598 \\
\hline 3,2 & & 4 & & 13 & 16 & & & & & & & & \\
\hline 3,75 & 3 & 2228 & (TL & 1 & 148 & & 100 & & & & & & \\
\hline 4 & ; & 18015 & 701 & & 1 & 7306 & & & & & & & 391 \\
\hline & & & 019 & & 131 & & & & & & & & \\
\hline- & & 16486 & 682 & & & & & & & & & & \\
\hline & & & & & 12 & & & & & & & & \\
\hline & & & & & & & & & & & & & \\
\hline 6,5 & 1176 & (7) & & & 15 & & & & & & 20,8 & & \\
\hline 7 & & 18694 & 1068 & & & & & & & & & & \\
\hline , & .0 & 3 & 10 & & 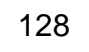 & & & & & & & & \\
\hline & & & & 13 & 10 & & & & & & 15 & & \\
\hline & & & & & & & & & & & & & \\
\hline 8,9 & 582 & & & & 79 & & 1,05 & 3,17 & 0. & 9,23 & 10 & & 2 , \\
\hline & & & & & & & & & & & & & \\
\hline $10, c$ & 442 & 10787 & 453 & 10 & 61 & דת & 10 & 201 & 0 & 60 & 11 & 0 & 2,24 \\
\hline & 451 & & & & & & & & & & $1<, 0$ & & \\
\hline 11,2 & 451 & & & & & & & & & & 12,1 & & \\
\hline & 296 & & & & & & & & & & & & \\
\hline 16 & 309 & & 743 & 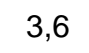 & 03 & & 0,00 & & , & & & 018 & $1, L 1$ \\
\hline & & & & & & & & & & & r & & \\
\hline
\end{tabular}


Tabela 26 - Fluxo de incorporação de elementos no ponto 2S.Valores de Massa Acumulada em $\mathrm{g} \mathrm{cm}^{-2}$ e fluxos em $\mathrm{\mu g} \mathrm{cm}^{-2}$ ano-1 $^{-1}$

\begin{tabular}{|c|c|c|c|c|c|c|c|c|c|c|c|c|c|}
\hline Calendário & Mg & Al & $\mathrm{Ti}$ & $\mathrm{Cr}$ & $\mathbf{M n}$ & $\mathrm{Fe}$ & Co & $\mathbf{N i}$ & $\mathrm{Cu}$ & $\mathrm{Zn}$ & $\mathrm{Sr}$ & Cd & $\mathrm{Pb}$ \\
\hline 2010 & 6456 & 89082 & 3648 & 58 & 760 & 44869 & 8,7 & 22 & 24 & 73 & 99 & 0,185 & 25 \\
\hline 2009,5 & 5706 & & 3667 & 55 & 793 & 44326 & 9,2 & 22 & 25 & 76 & 97 & 0,246 & 22 \\
\hline 2009,0 & 5547 & 85596 & 3889 & 54 & 765 & 45409 & 8,9 & 22 & 26 & 74 & 106 & 0,191 & 21 \\
\hline 2008,4 & 3716 & 58725 & 2523 & 37 & 534 & 30275 & 6,2 & 15 & 18 & 51 & 81 & 0,147 & 14 \\
\hline 2007,4 & 4434 & 69083 & 2917 & 42 & 584 & 36108 & 7,1 & 17 & 20 & 62 & 110 & 0,190 & 17 \\
\hline 2006,4 & 4540 & 71256 & 3055 & 43 & 614 & 37807 & 7,6 & 19 & 20 & 60 & 142 & 0,190 & 17 \\
\hline 2005,5 & 4595 & 76800 & 3375 & 50 & 642 & 40026 & 7,7 & 19 & 21 & 67 & 108 & 0,220 & 20 \\
\hline 2004,6 & 4311 & & 3161 & 44 & 592 & 36215 & 7,2 & 18 & 20 & 61 & 126 & 0,200 & 17 \\
\hline 2003,8 & 3070 & 55564 & 2974 & 39 & 500 & 32828 & 6,8 & 16 & 19 & 56 & 46 & 0,182 & 17 \\
\hline 2002,8 & 3479 & 63935 & 3411 & 47 & 563 & 38653 & 7,7 & 19 & 21 & 66 & 54 & 0,224 & 19 \\
\hline 2002,0 & 5128 & 83524 & 4353 & 58 & 726 & 48915 & 9,6 & 23 & 26 & 75 & 119 & 0,212 & 22 \\
\hline 2001,3 & 5058 & 82850 & 4275 & 58 & 751 & 50421 & 9,9 & 24 & 25 & 77 & 104 & 0,240 & 23 \\
\hline 2000,6 & 5643 & 92858 & 4616 & 61 & 862 & 52238 & 11 & 26 & 27 & 88 & 99 & 0,251 & 23 \\
\hline 1999,9 & 4663 & 74453 & 4266 & 58 & 768 & 40389 & 11 & 26 & 25 & 80 & 93 & 0,224 & 22 \\
\hline 1999,1 & 5006 & 82003 & 4041 & 56 & 755 & 46502 & 9,5 & 24 & 25 & 79 & 132 & 0,194 & 21 \\
\hline 1998,3 & 6112 & 97210 & 4711 & 66 & 835 & 53341 & 12 & 28 & 31 & 87 & 147 & 0,250 & 24 \\
\hline 1997,6 & 5991 & 102640 & 4975 & 70 & 863 & 56810 & 12 & 28 & 28 & 89 & 156 & 0,230 & 24 \\
\hline 1996,8 & 4542 & 93351 & 4179 & 60 & 783 & 49130 & 10,0 & 25 & 26 & 74 & 84 & 0,210 & 22 \\
\hline 1996,0 & 4050 & 74906 & 3412 & 49 & 711 & 40873 & 8,5 & 20 & 23 & 65 & 74 & 0,147 & 19 \\
\hline 1995,1 & 4139 & 71671 & 4072 & 60 & 713 & 46664 & 10 & 25 & 25 & 76 & 76 & 0,228 & 22 \\
\hline 1994,2 & 5072 & 79922 & 5115 & 66 & 747 & 49719 & 11 & 26 & 29 & 92 & 136 & 0,356 & 24 \\
\hline 1993,3 & 3038 & 43962 & 2817 & 38 & 449 & 27659 & 7,0 & 16 & 17 & 55 & 94 & 0,173 & 15 \\
\hline 1992,0 & 2602 & 39881 & 2167 & 34 & 408 & 26167 & 5,4 & 14 & 16 & 46 & 54 & 0,093 & 11 \\
\hline 1990,5 & 2790 & 40745 & 2114 & 30 & 446 & 25745 & 5,6 & 13 & 15 & 43 & 69 & 0,112 & 11 \\
\hline 1988,9 & 2823 & 43003 & 2078 & 32 & 416 & 25943 & 5,5 & 14 & 14 & 40 & 95 & 0,110 & 11 \\
\hline 1987,4 & 1867 & 26497 & 1462 & 20 & 275 & 15396 & 3,4 & 8,4 & 8,3 & 25 & 84 & 0,066 & 6,9 \\
\hline 1985,0 & 1369 & 18802 & 922 & 13 & 180 & 10793 & 2,2 & 5,6 & 5,8 & 17 & 69 & 0,033 & 4,9 \\
\hline 1981,3 & 1490 & 19525 & 923 & 14 & 197 & 11653 & 2,4 & 6,0 & 5,8 & 18 & 77 & 0,034 & 5,1 \\
\hline 1978,0 & 1512 & 19082 & 849 & 14 & 181 & 10975 & 2,2 & 5,4 & 4,6 & 17 & 91 & 0,037 & 4,7 \\
\hline 1974,9 & 1404 & 16669 & 846 & 13 & 177 & 9953 & 2,1 & 5,1 & 5,5 & 16 & 83 & 0,038 & 4,6 \\
\hline 1971,4 & 1357 & 14322 & 669 & 11 & 143 & 8983 & 1,9 & 4,9 & 4,4 & 16 & 80 & 0,027 & 3,8 \\
\hline 1966,4 & 1412 & 15349 & 820 & 12 & 158 & 9325 & 2,1 & 4,8 & 4,8 & 16 & 98 & 0,035 & 4,2 \\
\hline 1962,9 & 2061 & 19569 & 1073 & 15 & 188 & 10971 & 2,6 & 6,2 & 5,6 & 20 & 146 & 0,045 & 5,4 \\
\hline 1959,3 & 2102 & 19519 & 1060 & 14 & 200 & 11209 & 2,5 & 6,1 & 5,5 & 19 & 135 & 0,046 & 5,4 \\
\hline 1955,9 & 2512 & 22969 & 1149 & 17 & 227 & 13374 & 2,8 & 6,9 & 5,7 & 21 & 150 & 0,042 & 5,7 \\
\hline 1952,6 & 2002 & 22609 & 1165 & 19 & 235 & 13321 & 3,3 & 7,3 & 7,0 & 24 & 119 & 0,056 & 6,6 \\
\hline 1951,2 & 3181 & 30541 & 1445 & 22 & 262 & 16348 & 3,6 & 8,5 & 7,2 & 26 & 189 & 0,055 & 7,5 \\
\hline 1948,7 & 2037 & 19382 & 1008 & 15 & 175 & 11286 & 2,5 & 6,0 & 5,3 & 19 & 124 & 0,049 & 5,4 \\
\hline 1944,5 & 1436 & 14466 & 657 & 10 & 112 & 7344 & 1,6 & 4,0 & 3,2 & 12 & 82 & 0,027 & 3,7 \\
\hline 1938,5 & 1151 & 11859 & 710 & 9,7 & 97 & 6000 & 1,7 & 4,0 & 3,9 & 12 & 74 & 0,021 & 3,2 \\
\hline 1931,3 & 901 & 9150 & 553 & 7,4 & 75 & 4726 & 1,3 & 3,0 & 2,7 & 9,7 & 55 & 0,022 & 2,5 \\
\hline 1922,7 & 637 & 6794 & 549 & 6,8 & 62 & 4234 & 1,3 & 3,0 & 2,6 & 9,6 & 30 & 0,024 & 2,4 \\
\hline 1912,6 & 905 & 9633 & 612 & 8,2 & 75 & 4924 & 1,5 & 3,5 & 3,1 & 11,2 & 40 & 0,029 & 2,9 \\
\hline 1903,8 & 531 & 6598 & 493 & 6,5 & 56 & 3969 & 1,1 & 2,6 & 2,3 & 8,4 & 25 & 0,024 & 2,2 \\
\hline 1894,1 & 718 & 7122 & 408 & 5,9 & 56 & 3627 & 1,0 & 2,5 & 2,2 & 8,1 & 38 & 0,016 & 1,9 \\
\hline 1879,6 & 410 & 4338 & 301 & 3,8 & 36 & 2386 & 0,73 & 1,6 & 1,4 & 5,3 & 25 & 0,013 & 1,3 \\
\hline 1855,5 & 243 & 2437 & 156 & 2,2 & 20 & 1292 & 0,36 & 0,89 & 0,78 & 3,0 & 14 & 0,005 & 0,73 \\
\hline
\end{tabular}

